


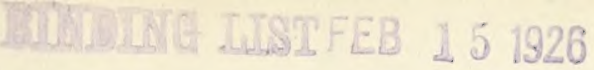

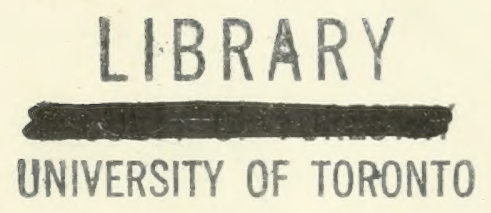





\section{Die \\ Stadtwaldungen von Zürich.}

Von

\section{Ulrich Meister,}

Stadtforstmeister in Zürich.

Mit 22 Lichtdrucktafeln und 12 Textbildern.

Zweite, erweiterte Auflage.

…

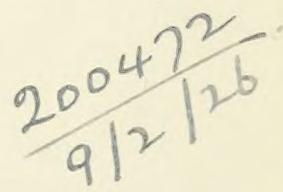

Zürich

Druckerei der Neuen Zürcher Zeitung

1903. 


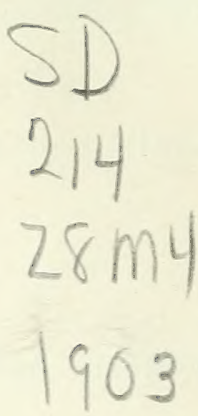




\section{Vorrede zur ersten Auflage}

1883.

Die Aufstellung eines neuen Wirtschaftsplanes der Stadtwaldungen von Zürich gab mir Veranlassung über den gewöhnlichen Rahmen der Ertragsregulierungsarbeiten hinaus in das Wesen des zu behandelnden Objektes einzudringen. Die Arbeit gewann insbesondere durch das Studium der historischen Entwicklung der Wirtschaft, wie durch die genaue Ermittlung der Zuwachsverhältnisse und der dieselben bedingenden Faktoren den Charakter der forstlichen Monographie über ein bisher unaufgeschlossenes, nicht wenig interessantes Gebiet. Kann durch die gewünschte Verbreitung ihres Inhaltes zur Hebung der Forstwirtschaft im allgemeinen wie zum weiteren Ausbau der Forstwissenschaft ein auch nur kleiner Beitrag geleistet werden, so ist damit mein Zweck vollständig erreicht. -

Ich erlaube mir auch diesen Anlass zu benützen, um den Herren, welche mich bei meiner Arbeit unterstützt haben, meinen verbindlichsten Dank auszusprechen.

Ganz besonders Herrn Prof. G. von Wyss für seine wirksame Beteiligung bei der Klarlegung der historischen Verhältnisse, Herrn Prof. Schulze am chemischen Institute der landwirtschaft- 
lichen Abteilung des eidgenössischen Polytechnikums für die Durchführung der Bodenanalysen, Herrn Mösch, Direktor der naturhistorischen Sammlungen am eidgenössischen Polytechnikum für die wertvollen Aufschlüsse über die geognostischen Verhältnisse des Sihltales und endlich Herrn Privatdozent Jäggi, Konservator des botanischen Gartens in Zürich, für die pflanzengeographischen Angaben über den in Behandlung fallenden Terrainabschnitt.

Ebenso erwähne ich dankbarst der fleissigen Mitarbeit der Forstpraktikanten Arthur Jakson, Max Siber und G. Reinacher von Zürich.

Forsthaus Sihlwald, im April 1882. 


\section{Vorrede zur zweiten Auflage}

1903.

Die nach Ablauf von zwanzig Jahren neuerdings an die Leitung des Betriebes der Stadtwaldungen Zürich herantretende Hauptrevision des Wirtschaftsplanes 1880 liess es angezeigt erscheinen, diese Arbeit ähnlich wie die frühere zu benützen, um ein vollständiges Bild des vorher nur kurz skizzierten Betriebes zu geben. Das inzwischen gesammeite forststatische und forststatistische Material gestattet die Zuwachs- und Nutzungsverhältnisse des Waldes in einer den wissenschaftlichen Anforderungen der Gegenwart entsprechenderen Art zu analysieren und $\mathrm{zu}$ verwerten. Auch das eigenartige Transportwesen wie der Verarbeitungsbetrieb des Sihlwaldes mussten, dem Wunsche der vielen Sihlwaldbesucher entsprechend, in einer neuen Auflage detailliertere Berücksichtigung finden.

So erscheint denn die Monographie in wesentlich verändertem Gewande als ein Dokument der wirtschaftlichen und wissenschaftlichen Entwicklung des stadtzürcherischen Forstbetriebes zu Anfang des zwanzigsten Jahrhunderts. Sie überliefert der Zukunft nicht nur das Bild der Vergangenheit, sondern auch der Gegenwart des von der Stadt Zürich seit einem Jahrtausend mit besonderer Vorliebe gepflegten Sihlwaldes. 
Wir verdanken bei diesem Anlass ganz besonders die wertvolle Unterstützung, die uns bei der Lösung dieser Aufgabe von Herrn Flury, Adjunkt der eidgenössischen Zentralanstalt für das forstliche Versuchswesen, und von dem Forstassistenten Herm Tuchschmid zuteil wurde. Für die verdienstliche Bearbeitung des botanischen Teiles unter wissenschaftlicher Verwertung des Sihlwaldherbariums sprechen wir Herrn Dr. phil. Emil Schoch und Herrn stud. phil. Thellung unsern wärmsten Dank aus.

Zürich, im September 1903.

U. Meister. 


\title{
Inhaltsverzeichnis.
}

\author{
I. Inare inut Givisse \\ II. Der Boden ........ i;

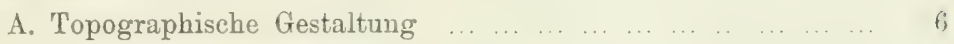

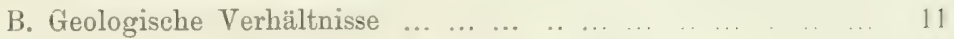 \\ 1. Die obere Süsswăsser-Molasse $\quad \ldots \begin{array}{lllllllll} & \ldots & \ldots & \ldots & \ldots & \ldots & \ldots & \ldots & 11\end{array}$ \\ 2. Die Ueberreste der Glacialperiode $\ldots \begin{array}{lllllllll} & \ldots & \ldots & \ldots & \ldots & \ldots & \ldots & & 1\end{array}$

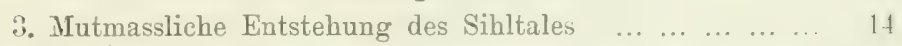 \\ C. Physikalische und chemische Zusammensetzung des Bodeus 1n

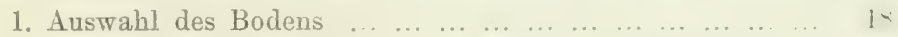 \\ 2. Ermittlung des mechanischen Mischungsverhältnisses ... 1V \\ 3. Chemische Zusammensetzung der Feinerde ... . . . . . .

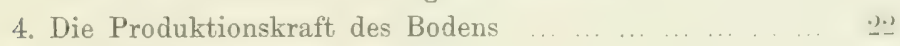

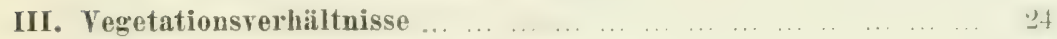

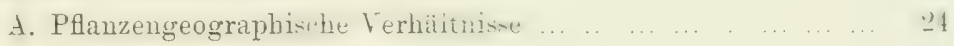

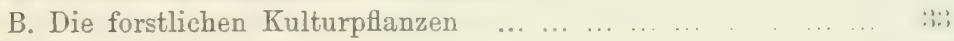

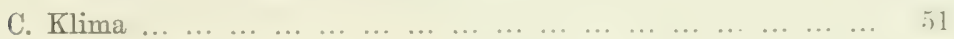

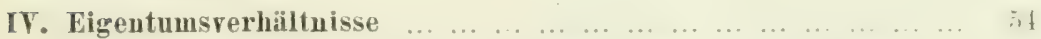

A. Entwicklung der Eigentumsverhältnisse von $85: 3-1224 \ldots$. . . it

B. Eigentumsverhältnisse vom Anfang des 16. bis zum Schluss

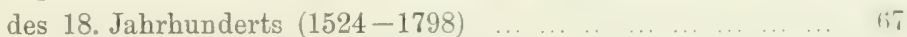

1. Der Sihlwald und die Albishölzer

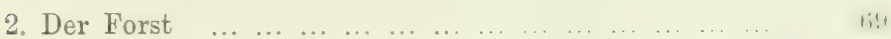

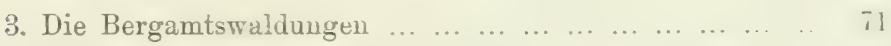

C. Entwicklung der Eigentumsverhältnisse von 1798-1880 i::

1. Uebergang des heutigen Waldbesitzes an die Stadtbürger$\begin{array}{llllllllllllllll}\text { gemeinde } & . . & \ldots & \ldots & \ldots & \ldots & \ldots & \ldots & \ldots & \ldots & \ldots & \ldots & \ldots & \ldots & \ldots & \cdots\end{array}$

2. Die Veränderungen des Arealbestandes von 1798-1900 i

3. Die Entledigung des Eigentums von Ansprüehen Dritter -11

4. Die Verwendung der Erträge d. städtischen Waldeigentums

V. Bisherige Bewirtschaftung und gegenwätiger Zustand ... in

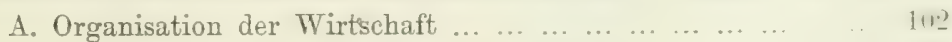

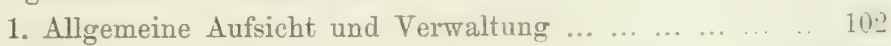

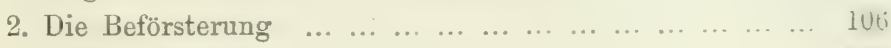

3. Die gegenwärtige Organisation des Betriebes $\ldots \ldots \ldots$.... 109

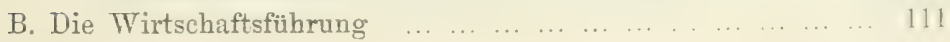




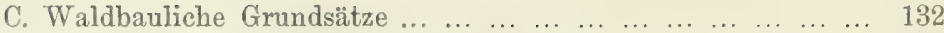

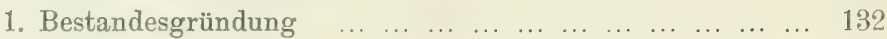

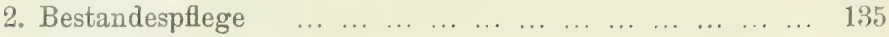

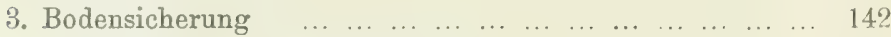

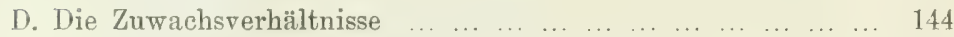

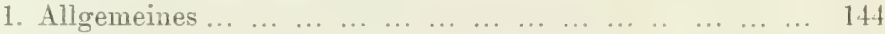

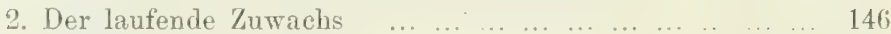

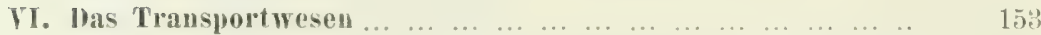

A. Die an das Transportwesen zu stellenden Anforderungen ... 15\%

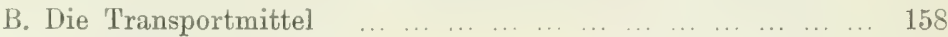

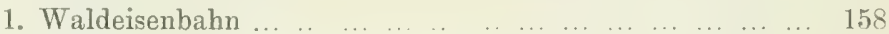

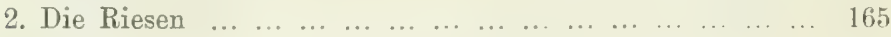

3. Uebrige Hülfsmittel für den Holztransport $\ldots \ldots \ldots \ldots$

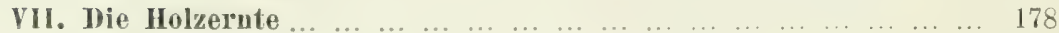

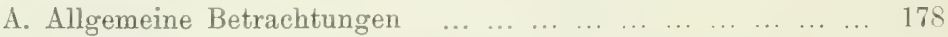

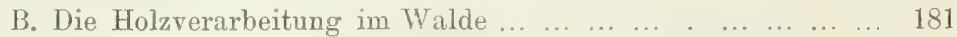

(\% Die der Verwertung vorangehende weitere Verarbeitung ... 189

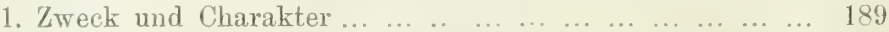

2. Die verschiedenen Abteilungen des Verarbeitungsbetriebes 190

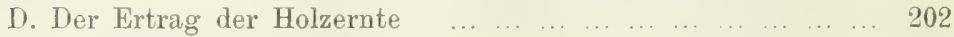

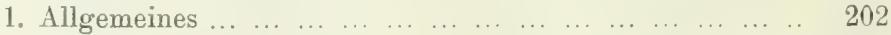

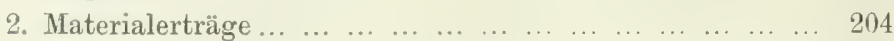

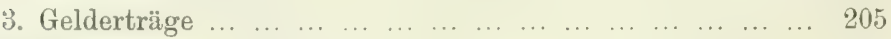

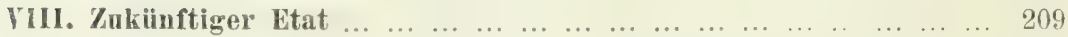

A. Grundsätzliche Auffassung der Etatsbildung $\quad \ldots \quad \ldots \quad \ldots \quad \ldots \quad \ldots \quad 209$

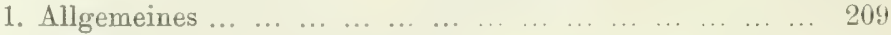

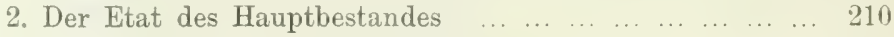

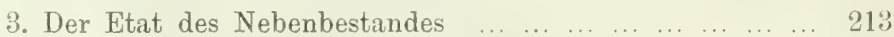

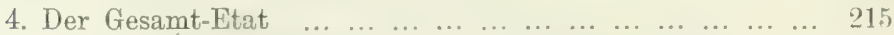

B. Die Anwendung der rorstehenden Grundsätze auf die kon-

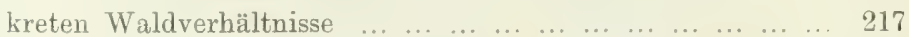

1. Die Ausscheidung in Betriebsklassen und Abteilungen 217

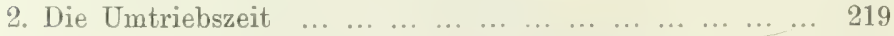

3. Die Berechnung des Etats nach der beigefügten Ertragstafel 222

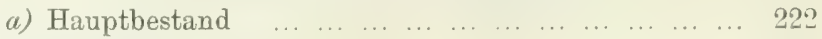

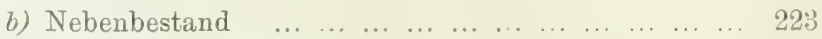

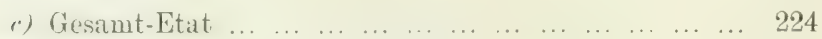

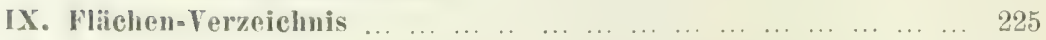

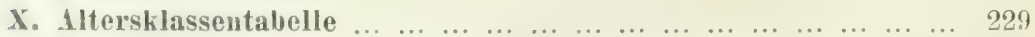

XI. Ertragstafel für die Buche im sihlwald, Hauptbestand ... ... 235

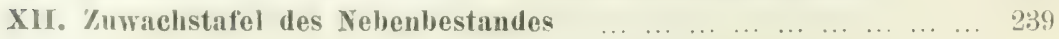




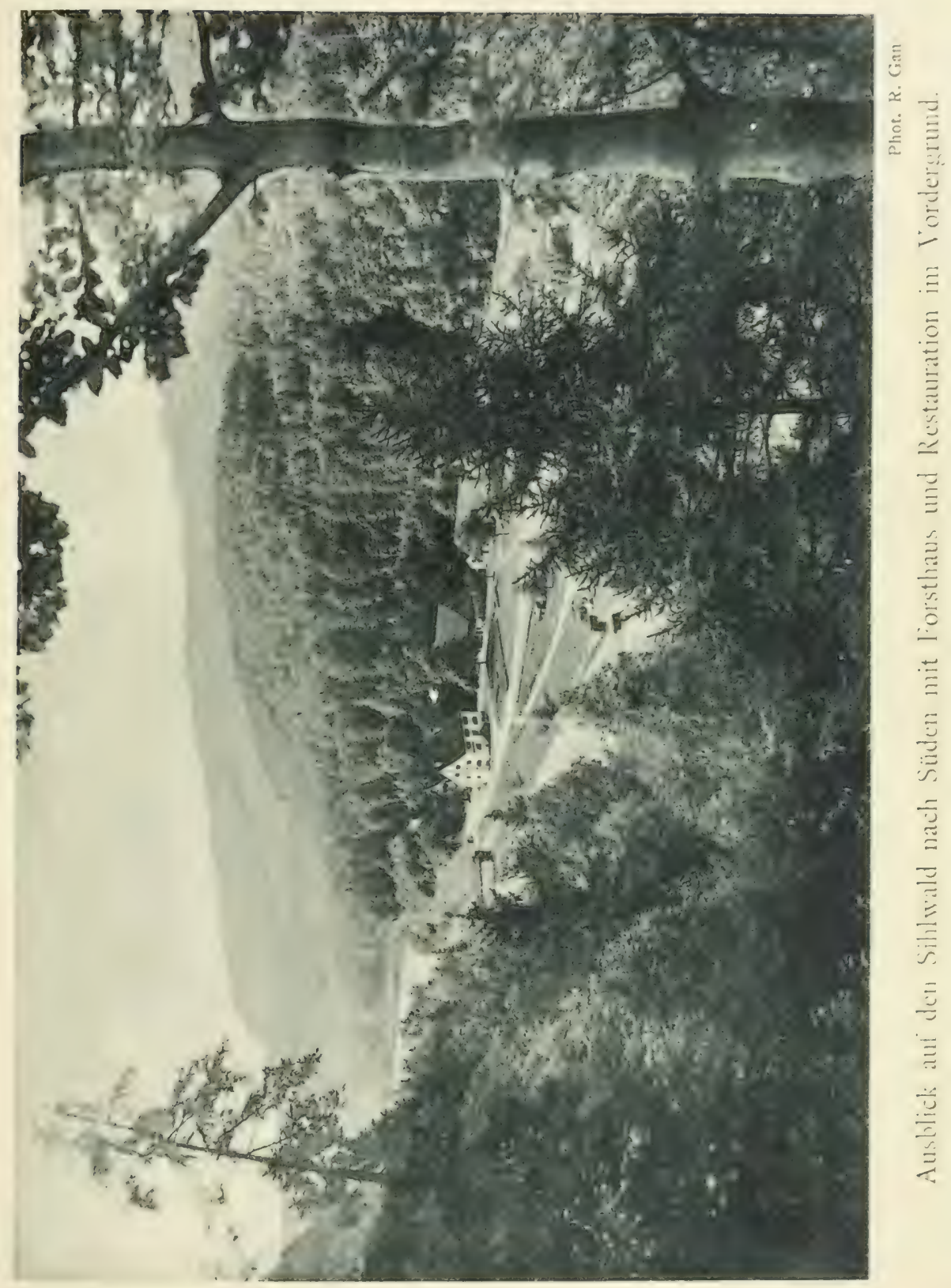





\section{I. \\ Lage und Grösse.}

Die Waldungen der Stadtgemeinde Zürich liegen nur zu einem kleinen Bestandteil, mit 460 ha, in der Gemarkung des eigenen Gemeinwesens, im Tal der Limmat; weitaus der grösste Teil derselben liegt ausserhalb des Stadtbannes Zürich, im Tal der Sihl, 1-3 Stunden von Zürich entfernt. Auch mit Bezug auf die Eigentumsverhältnisse ist ein einheitliches Besitztum zurzeit noch nicht zu konstatieren. Die politische Gemeinde Zürich ist im Besitz verschiedener, innerhalb ihrer Gemarkmug liegender Waldbezirke, sowie von Teilrechten vorhandener Korporationswaldungen. I laneben finden sich seit dem Jahre 1893 die Waldungen der Bürgergemeinde, die sich ihrerseits wieder ausscheiden in die eigentlichen bürgerlichen Waldungen und in eine zweite, als Stiftungsgut ausgeschiedene Kategorie, in den ursprünglichen Stadtwald von Zürich. Administrativ bilden diese verschiedenen Kategorien insofern ein Ganzes, als sie einheitlich, wenn auch mit gesonderter Rechnungsführung, der städtischen Forstverwaltung, bezw. dem Vorstand des Finanzwesens unterstellt sind.

Für die vorstehenden Darlegungen fallen im wesentlichen nur die Waldungen des Stiftungsgutes in Betracht, indem die übrigen zwei Kategorien zufolge ihrer zurzeit noch nicht klar herausgestalteten Bewirtschaftung und der noch weiter fortdauernden Aeufnung derselben als in einem Uebergangsstadium befindlich, für eine definitive Regulierung ihrer Verhältnisse sich vorerst noch nicht eignen.

Die Waldungen des städtischen Stiftungsgutes umfassen ein Areal von 1152,8 ha, wovon der Forstbezirk Adlisberg mit 107,8 ha an dem rechten Limmatufer auf dem Zürichberg, im Stadtkreise selbst liegt, während der übrige Teil mit 1044,8 ha im Tal der Sihl in der Gemarkung der Gemeinden Langnau, Oberrieden, Horgen, 
Hirzel und Hausen gelegen ist. Mit Ausnahme des Wildpark-Komplexes Langenberg, der nur ein Areal von 45 ha umfasst, bildet der übrige Teil der Sihltalwaldungen ein zusammenhängendes Ganzes. ein Teilstück des Sihltales, in einer Längenausdehnung von $13 \mathrm{~km}$. Der Umstand, dass mit Ausnahme des Gebietes der öffentlichen Talstrasse und der zwei Eisenbahnlinien: Thalwil-Zug und der Sihltalbahn. nur städtisches Besitztum in diesem Teilstück vorhanden ist, gibt demselben den Charakter einer in sich abgeschlossenen «Domäne». Derselbe tritt zufolge der topographischen Gestaltung des Terrains, der örtlichen Abgeschiedenheit, wie der historischen Entwicklung und der Besiedlungsverhältnisse noch in besonders eigenartiger Weise zutage. ${ }^{1}$ ) Auch im Forstbetriebe selbst hat die Abgeschiedenheit des Sihltalwald-Komplexes dazu geführt, der forstlichen Wirtschaftspolitik eine andere Bahn anzuweisen, als diejenige. in welcher sich im grossen und allgemeinen die forstliche Behandlung der meisten Kommunal-Waldungen bewegt. Der Forstbetrieb der Sihltalwaldungen findet in seiner unmittelbaren Nähe kein ausreichendes Absatzgebiet für seine Rohprodukte, es mangelt die nötige Käuferschaft für den Konsum der alljährlich zum Hiebe gelangenden Holzmassen. Allerdings hat sich im Verlauf der zwei letzten Dezennien die Zugïnglichkeit der Sihltalwaldungen in hohem Grade verbessert. Im Jahre 1880 ermangelten dieselben noch öffentlicher Strassen und Brücken; 1885 wurde dann endlich nach siebenjährigem liriege mit den Gemeinden Horgen und Langnau die Sihlwaldstrasse als öffentliche Strasse. die als solche vom Staate unterhalten wird, erklärt. An Stelle der früheren stegartigen Sihlübergänge finden sich heute zwei fahrbare Brücken, wovon diejenige beim Forsthaus von seiven der Stadt im Jahre 1883, diejenige im obern Sihlwald von seiten der Gemeinde Horgen, im Jahre 1902 erstellt wurde. Dank der zu Anfang der neunziger Jahre gebauten Sihltalbahn und der den obern , Sihlwald durchquerenden Bahnlinie Thalwil-Zug ist sodann eine nicht bloss für den Personenverkehr, sondern speziell auch für den Holztransport äusserst bequeme Verbindung mit Zürich und dem Zürichsee vorhanden, wodurch es möglich ist, die Walderzeugnisse in verarbeiteter Form einem grössern Marktgebiete zugänglich zu machen. Der die Sihltalwaldungen durchziehende Sihlfluss dient nicht mehr wie früher

1) Siehe nebenstehende Tafeln I und II, sowie III und IV mit dem in Jahre 1738 erbauten Forsthaus und der eigentlichen Sihlwald-Kolonie. 


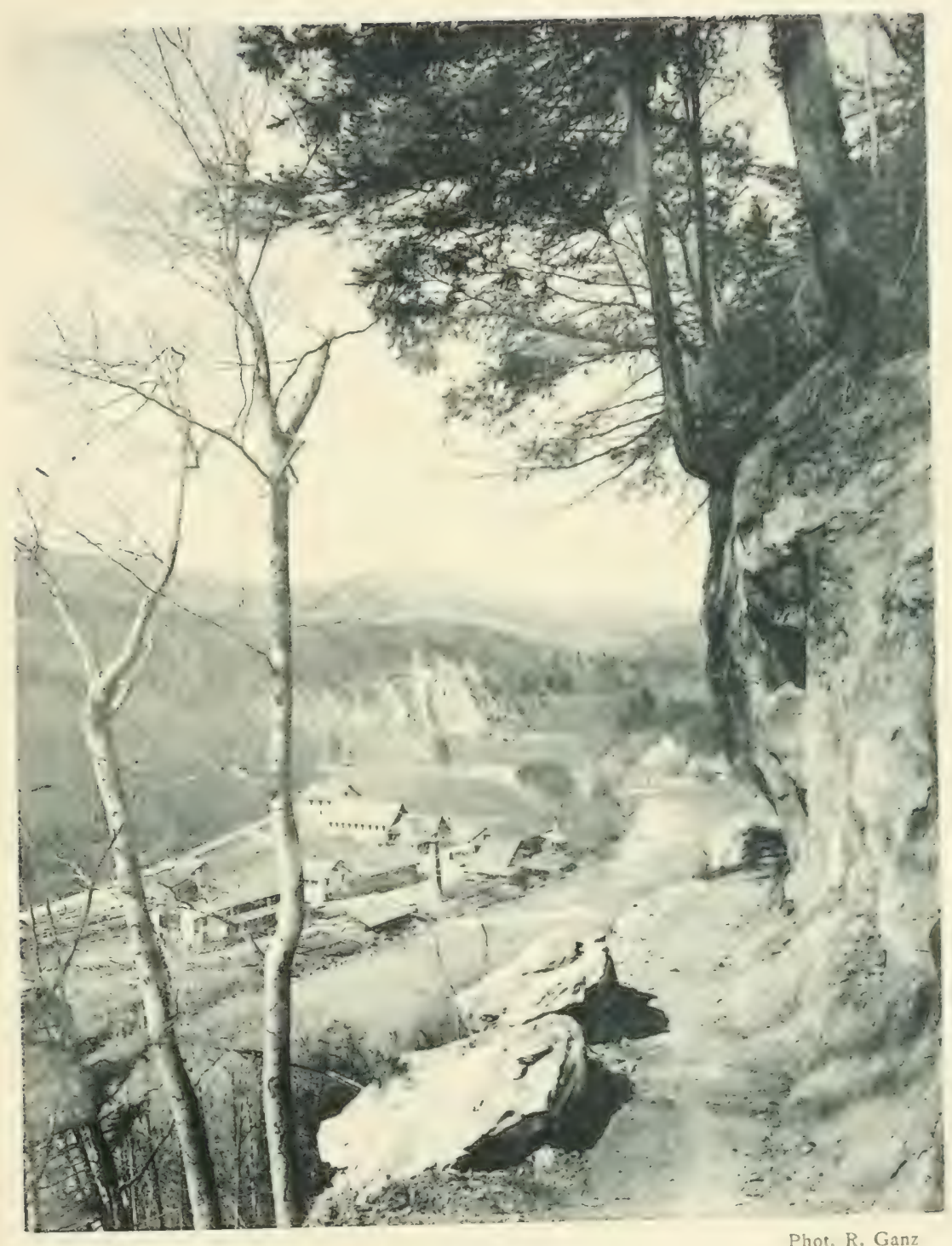

Ausblick auf das Sihlwaldgebiet nach Norden mit dem IVerkplatz in Vordergrund. 

Uebersichtsplan der Stadtwaldungen.

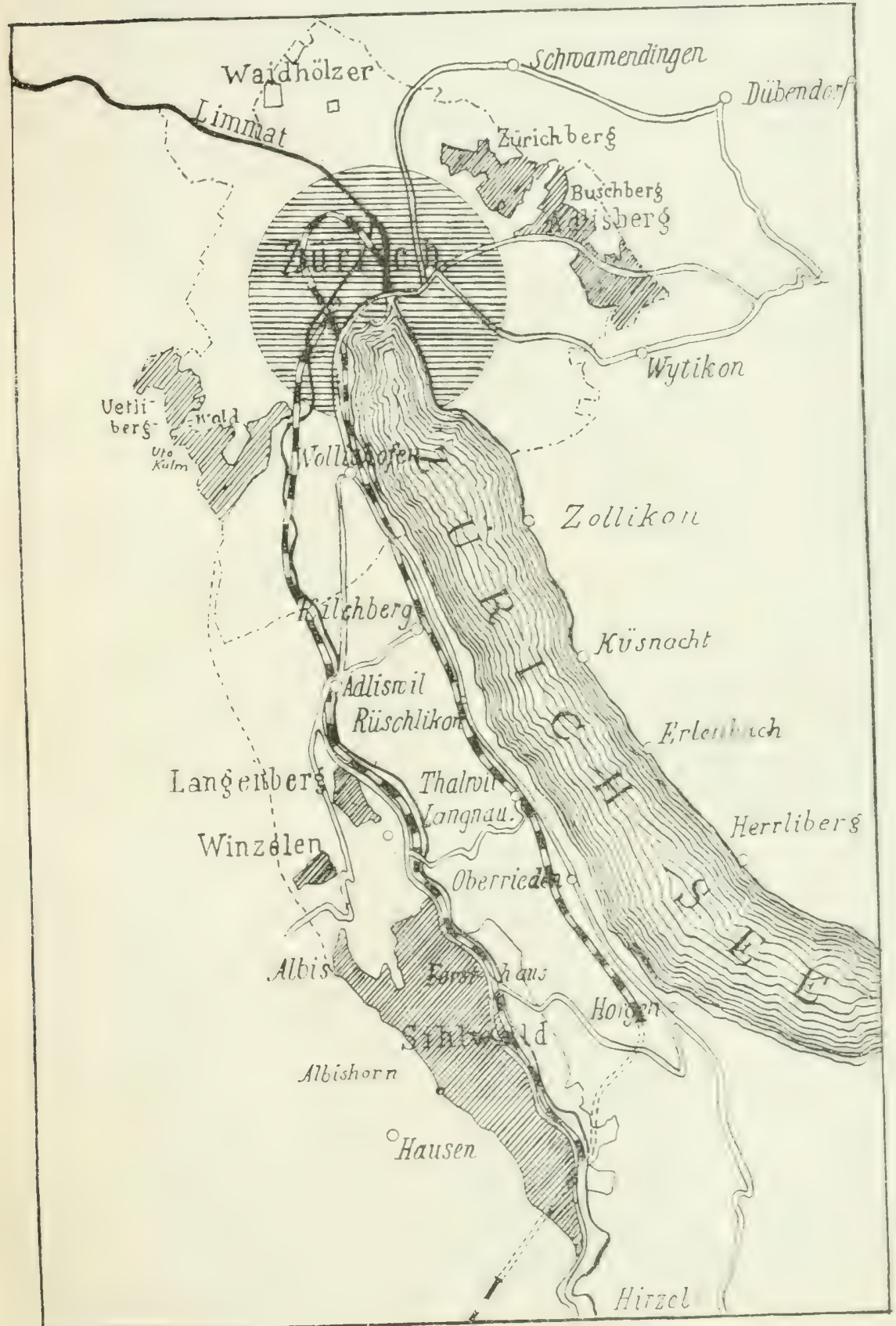

Masstab $=1: 125000$. 
der Flösserei, sondern ausschliesslich motorischer Terwendung, so im Sihlwaldgebiet zum Betrieb des dortigen Holzverarbeitungsgeschäftes. War er früher durch seine häufigen starken Anschwellungen dem angrenzenden Gelände gefährlich, so ist es der im letzten Dezennium rom Kanton Ziurich systematisch durchgreführten Flusskorrektion gelungen, auch bei grössern Hochwassern Uferanbrüche oder Ueberschwemmungen fernzuhalten.

Die Stadtwaldungen von Zürich wurden in den Jahren 1874 bis 1878 polygonometrisch vermessen. Das diesbezugliche Vermessungsoperat hat den Charakter der Katasteraufnahme. Die polygonometrische Originalaufnahme wurde im Massstab 1:2000 kartiert und sodann ein Uebersichtsplan im Massstab 1:5000 angefertigt und lithographisch vervielfältigt; die Kosten von Vermessung und Kartierung beliefen sich auf die Summe von 25.000 Fr. Der Aufnahme und Darstellung des 'T'errains wurde in weitgehendem Masse durch die Wahl von Horizontalkurven mit zwei Meter Aequidistanz Rechnung getragen. Durch die Versteinung und Verpfählung einer grössern Anzahl von polygonometrischen Fixpunkten, die sich im Uebersichtsplan eingetragen finden, ist die möglichste Erleichterung der Orientierung geboten.

Frühere Vermessungswerke der Stadtwaldungen haben dieser neuen Aufnahme gegenüber nur historischen Wert. immerhin bieten sie auch dem Forstbetrieb der Gegenwart wertvolle Anhaltspunkte, indem seit Anfang des neunzehnten Jahrhunderts die jährlichen Holzschläge in dieselben eingezeichnet wurden. Die erste bekannte Vermessung der Sihltalwaldungen datiert vom Jahre 1680. Es findet sich aber von uem bezüglichen Grundriss nur eine im Jahre 174:3 durch den Ingenieur Albcrtimi angefertigte Kopie in den Händen der Forstverwaltung. Ueber den Fraumünster-Forst ist eine erste Aufnahme bekannt und vorhanden vom Jahr 1728. In den Jahren 1793 - 1796 wurde der Sihlwald ein zweitesmal vermessen und kartiert von dem durch seine topographischen Arbeiten hervorragend bekannten Schanzenherr Fehr. Die betreffenden Pläne sind Messtischaufnahmen im Massstab 1:2400.

Die sämtlichen Waldungen des Stiftungsgutes sind mit behauenen Marksteinen umgrenzt, und auch die Abteilungen in gleicher Weise ausgeschieden. Die erste Ausmarkung und Markenbeschreibung datiert aus dem Jahre 1491.

Die Waldungen der politischen Gemeinde Zürich umfassen ein Areal von 199,36 ha. Hievon liegt der grössere 'Teil ebenfalls 


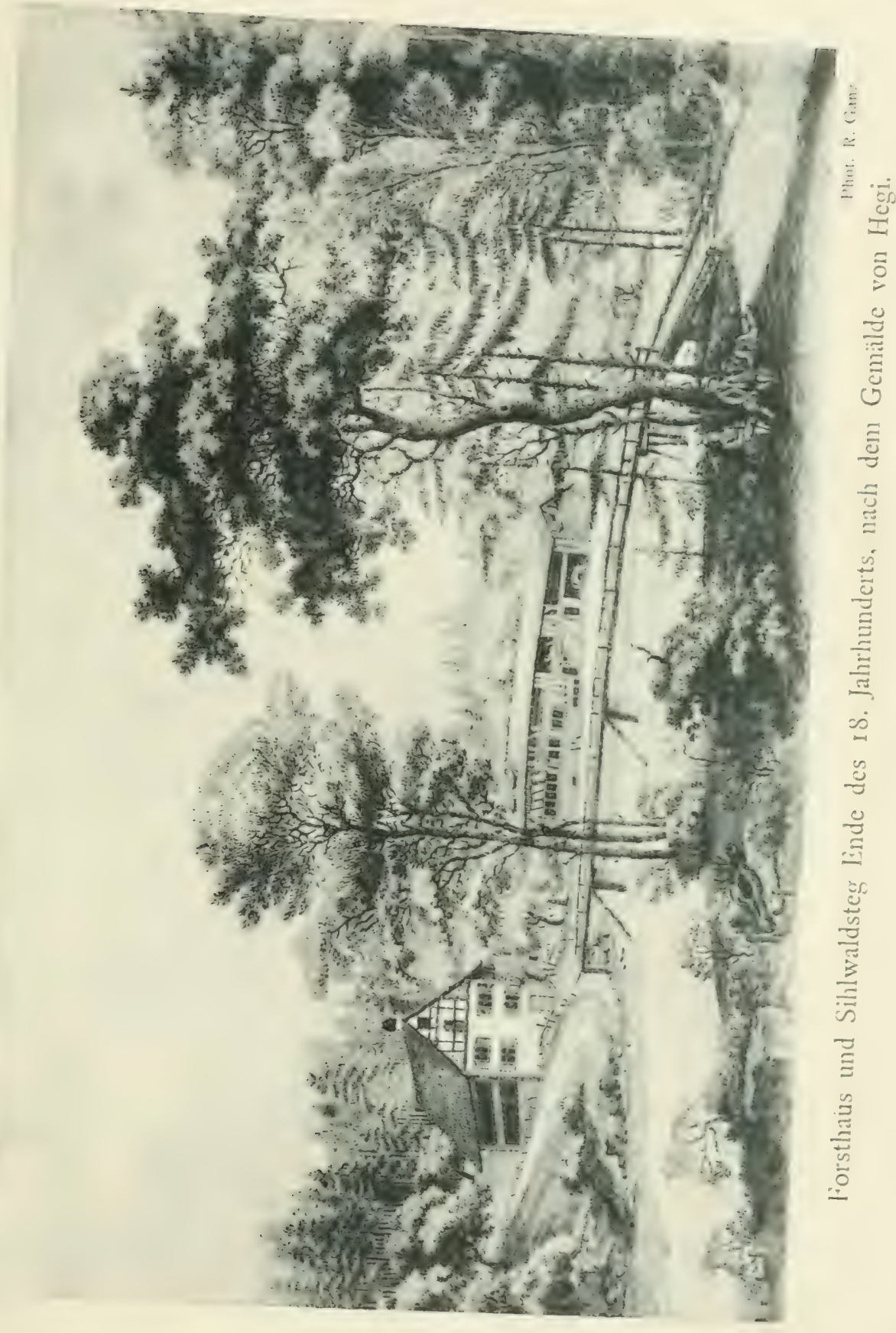





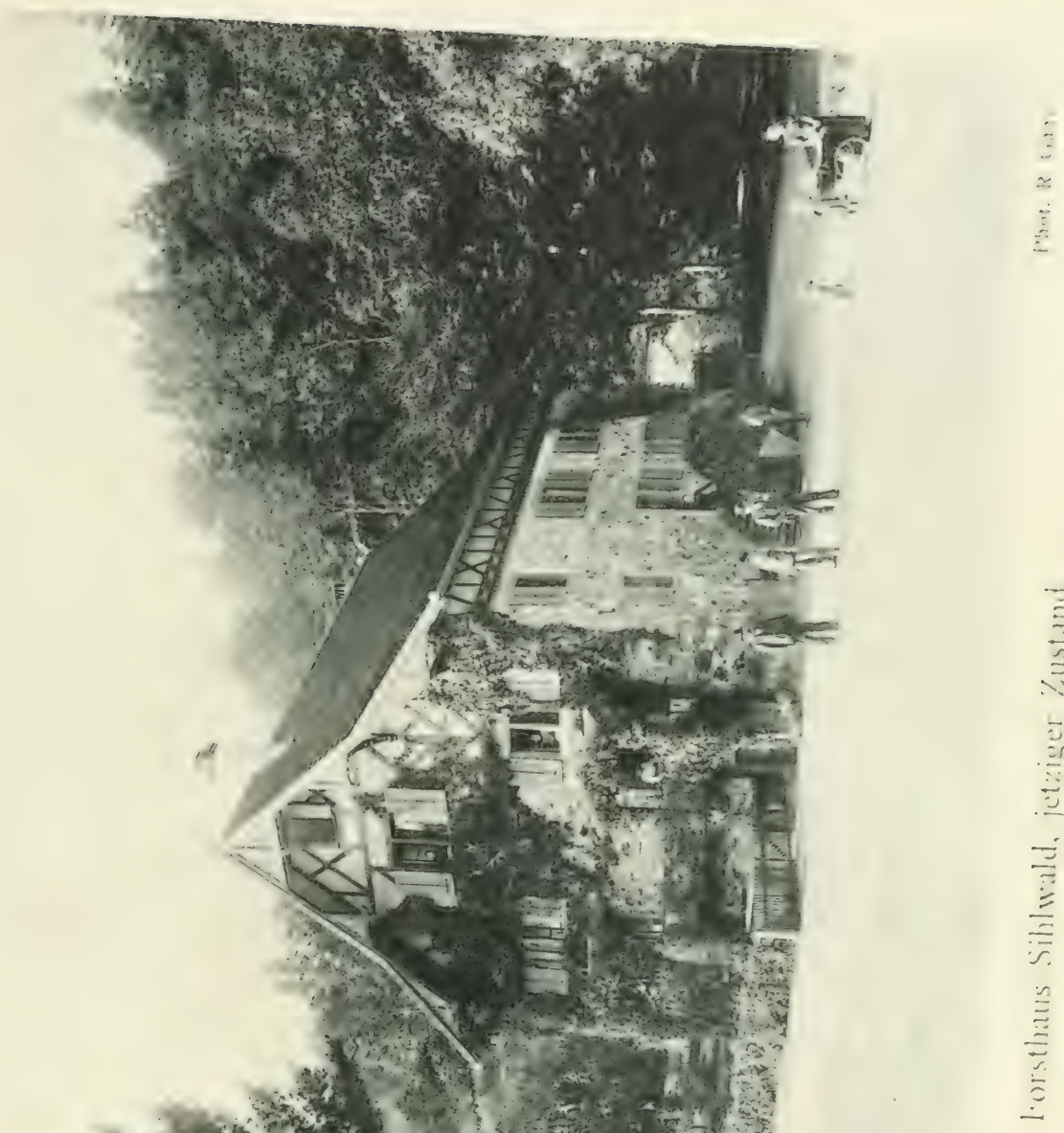



am Albishang im untern Sihltal; es ist dies die ehemalige Gemeinde- und Korporationswaldung Wiedikon mit 176.94 ha., welche angrenzend an das Waffenplatz- und Schiessplatzareal bis an den Kamm des Uetliberges reicht. Andere kleinere Parzellen liegen auf dem rechten Limmatufer.

Die Bürgergemeindewaldungen mit 172,33 ha liegen am rechten Limmatufer auf dem Rücken des Zürichberges. Wie die Waldungen der politischen Gemeinde, befinden sie sich ebenfalls innerhalb der Gemarkung der Stadt. 


\section{II. \\ Der Boden.}

\section{A. Topographische Gestaltung.}

Die Gestaltung der Bodenoberfläche der Stadtwaldungen von Zürich trägt den Charakter der schweizerischen Vorberge und des Mittellandes. Vertikale Terrainerhebungen von 460 bis $900 \mathrm{~m}$ ü. M. in Form länglicher, durchschnittlich breitrückiger Höhenzüge ; in den Abzweigungen niederer Stufe, senkrecht zur Talachse auslaufende Vorsprünge, mit breiten, ziemlich ebenen Terrassen, diese -elhst durch Wasserläufe zweiter und dritter Ordnung stark erodiert - in diesen Formen gliedern sich die meisten Terrainabschnitte.

Aehnlich verhält es sich auch mit der allgemeinen Exposition. Der Grundcharakter derselben ist entsprechend der konstanten Richtung der Höhenzüge von West nach Ost, entweder südwestlich oder nordöstlich. Diejenige des wesentlichsten Waldteiles, des Sihlwaldes, muss gerade ihres nordöstlichen Charakters halber, als eine für Waldwirtschaft sehr günstige bezeichnet werden.

Der Zïrichberg als einzelner Bestandteil der rechtsufrigen Talbegleitung des Zürichsees und der Limmat, gehört der Allmannkette an, die hier infolge allseitiger Erosion einen mamelonartigen Charakter angenommen hat und sich in Form ausgesprochener Einzellügel pråsentiert. Die tiefste Partie, das Plateau des Katzenschwanzes und der Looren liegt auf der Stufe von $630 \mathrm{~m}$ ü. M., indes der weitaus grösste Teil, die Hügelkuppe, sich in einer Höhenlage von $680-700 \mathrm{~m}$ ü. M. befindet.

Die Sihltalwaldungen bilden ein vollständiges, von Südost nach Nordwest streichendes Talstück. Die linksufrige, höhere Talwand wird gebildet aus dem nordöstlichen Hang der Albiskette, die im Sihltal beim Sihlzopf ihren östlichen Ausläufer hat und das Tal der Sihl bis unterhalb Zürich begleitet, in einer Höhe von 800 bis 918 m ü. M. Der ganze Albiskamm ist, soweit er die Stadtwaldung begrenzt, reich an aussichtsvollen Punkten auf den Kiurichsee 


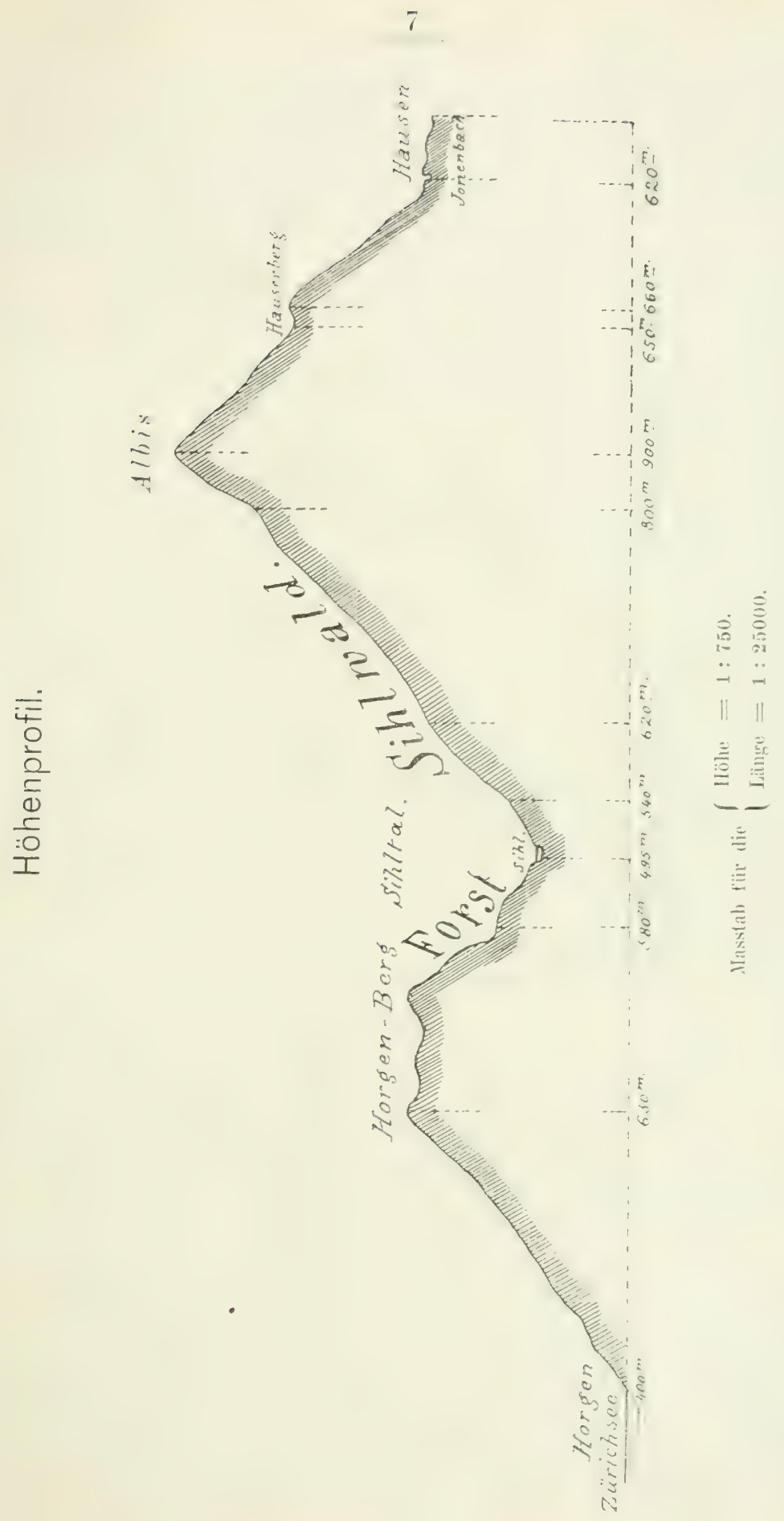


und die innere Schweiz, es gelten speziell die Albishochwacht $880 \mathrm{~m}$ ü. M. und das Albishorn $915 \mathrm{~m}$ ü. M. als ebenbürtige Rivalen der mit Recht hochgeschätzten Fernsicht vom Uetliberg. Der rechtsseitige Talhang hesteht aus der südwestlichen Abdachung des Horgerberges, der als linksufriger Höhenzug des Zürichsees, See und Sihltal trennt und eine Höhe von $630 \mathrm{~m}$ erreicht. Die Stadtwaldung reicht indessen nicht überall auf diese Höhe.

Die Talsohle selbst liegt zwischen 532 und $466 \mathrm{~m}$ ü. M., so dass die Differenz zwischen den höchsten und tiefsten Partien der Sihltalwaldungen $449 \mathrm{~m}$ beträgt. Wie bei den meisten Erosionstälern der Molasse, so ist auch im Tal der Sihl die eigentliche Sohle von nur geringer Ausdehnung, nirgends über $500 \mathrm{~m}$ breit; sie ist sogar, mit Ausnahme einiger weniger Stellen, wie beim oberen Sihlwaldsteg, beim Forsthaus Sihlwald und bei LangnauGontenbach fast ganz vom Fluss in Beschlag genommen.

Das Sihltal trågt, entsprechend seinem Ursprunge, einen gewissen gleichartigen, durch das nebenstehende Profil in seinen allgemeinen Umrissen ausgedrückten Charakter. Die unterste, der Talsohle zunächst folgende jüngste Erosionsstufe zeigt beidseitig verhältnismåssig steile Neigungsverhältnisse. Dann folgt links und rechts ein vom Sihlzopf über die Tableten, über den Eichbach bis auf den Langenberg hinunter reichendes, auf der Höhe von 550 bis $510 \mathrm{~m}$ ü. M. sich hinziehendes, 300-400 m breites Plateau, ein früheres Talbecken. Von diesem aus weist das Terrain sodann eine erneut stärkere Neigung von $15^{\circ}$ bis auf die Höhe von $650 \mathrm{~m}$, auf der das breiteste und fruchtbarste Plateau des Sihlwaldes liegt. Diesem Plateau folgt abermals eine steilere Partie, die auf der Höhe von $760 \mathrm{~m}$ in eine meist noch gut erhaltene Seiten-Moräne übergeht, deren äusserer, dem Albis zugekehrter 'Teil, im mittleren und unteren Sihltal, eine kleine Hochebene bildet, über der in steilem Aufstieg die Bürglenwand mit 36-42 ${ }^{\circ}$ Neigung, die letzte Stufe des Albishanges bildet.

Nicht weniger als 22 Wasserläufe, die Seitenarme miteingerechnet, durchbrechen auf der linksufrigen, zirka $13 \mathrm{~km}$ langen Strecke die 'Talwand, so dass die Bodengestaltung trotz ihres scheinbaren Zusammenhanges im grossen, im Detail eine stark unterbrochene ist und als eine für den Betrieb wie für die Kommunikation ziemlich ungünstige bezeichnet werden muss. Diese Wasserläufe bewirken inshesondere in regenreichen Jahrgängen ein rapides Vorwärtsschreiten der Eiosion. Die Bäche vertiefen sich, die 
Einhänge zeigen Abrutschungen und der unproduktive Boden vermehrt sich in zunehmendem Masse. Die in den letzten dahren vorgenommenen Bachverbauungen mit hölzernen und steinernen Bachsperren zeigen, in welcher Weise dem Fortschreiten der Erosion mit Erfolg entgegengewirkt werden kann.

Die Neigungswinkel des Bodens, auf dem die städtischen Waldungen stehen, zeigen die allergrössten Variationen. Ebenes 'Terrain gehört zu den Seltenheiten. Neigungswinkel von 5-11 ${ }^{0}$ gehören $\mathrm{zu}$ den am häufigsten vorkommenden, solche von $11-25^{\circ}$ sind indessen noch sehr zahlreich vorhanden; bis $36^{\circ}$ bleibt der Boden geschlossen bewaldet. Ueber $36^{\circ}$ wird die Bestockung lückig, einzelne Bodenpartien schälen sich meist infolge Einwirkung der Nässe vom felsigen Untergrund $a b$, die Baumwelt hält sich nur noch auf wenigen Stellen und bei $42^{\circ}$ gehört das Vorhandensein von Bäumen geradezu zu den Seltenheiten. Solch steile Partien finden sich indes nur in der obersten und untersten Stufe des Sihlwaldhanges und an einzelnen Bacheinhängen, so unten bei den Wüstenfelsen, beim Hebeisen und oben an der Bürglen.

Einen Faktor eigentümlicher und zugleich schwer wiegender Art bildet für die Stadtwaldungen von Zürich das Vorhandensein des $36 \mathrm{~m}$ breiten Sihlflusses. Dieses hier in dem letzten Dritteil seines Laufes sich durch das Tal ziehende Gewässer hat vollständig den Charakter des Bergwassers. Es ist nicht schiffbar und im Sihlwaldgebiet nur auf zwei Brücken überschreitbar. Wenn droben in seinem grossen Anfangsgebiete im Tal der Biber, der Alp und der eigentlichen Sihl, am Fusse des Mythen, die Regengüsse auf das wenig bewaldete Gebiet in nicht grösserer Menge als im Sihlwald fallen, schwillt der an und für sich kleine, hellgrüne Fluss rasch zum gelbflutenden Strome an. Oft 1,60 bis 1,80 m über den gewöhnlichen Wasserstand hinaustretend, war er ehedem talabwärts für die vorhandenen Brücken und niederen Uferstellen ein wildzerstörender Geselle. Solche hohe Wasserstände sind inshe-sondere zu notieren aus den Jahren 1708, 1864, 1875 und 1877. Seit Durchführung der Flusskorrektion scheint diese Gefahr beseitigt zu sein.

Die Sihl gehört zu den wenigen Flüssen der Vorberge, die im Winter vollständig zufrieren und infolgedessen gewöhnlich im Dezember und im Februar durch Eisgang beträchtlichen Sehaden anrichten. So im strengen Winter des Jahres 1829/30 und im Winter 1879/80. Im letzteren staute sich der Eisgang unmittelbar vor dem oberen Sihlwaldsteg in gletscherartiger Weise an; die 
Sihl suchte sich auf dem linken Ufer ein neues Bett und liess die gewaltigen Eismassen bis im Monat März liegen, wo alsdann ein trockener warmer Föhn die gefürchtete Masse unschädlich talabwärts führte.

Die Sihl gehört nebst dem Rhein, der Thur, der Töss und der Limmat zu den Gewåssern I. Klasse, die als solche von Staats wegen korrigiert und in einen regelmässigen Lauf gebracht werden. Seit dem Jahre 1885 wird an dieser Aufgabe, und zwar in rationeller und von grossem Erfolg begleiteter Art gearbeitet. Durch die Einführung eines gleichförmigen Querprofiles von $36 \mathrm{~m}$ Breite wird die angestrebte Sohlenausgleichung und damit zugleich ein durchschnittliches Gefäll von $7 \%$ orreicht, die Herstellung des ideellen Normalprofiles vollzieht sich durch eine konstante Fortschiebung der Geschiebsmassen. Uferanbrüche finden dank der soliden Uferversicherung durch Rohsteimmanerwerk nicht mehr statt.

Vom 13. Jahrhundert an bis zum Jahr 1864 wurde die Sihl in nutzbringender Weise zum Holztransport in Form der WildenF'lösserei verwendet. Sie eignete sich diesfalls in ganz vorzüglicher Weise. da sie durchschnittlich ein starkes Gefäll hat und ehemals für das Auffangen des Senk- und Wildholzes mit Schiffen befahren werden konnte. Veränderte Betriebseinrichtungen, die flussabwärts stetig sich mehrenden Fabrikwehre, sowie eine anderweitige vorteilhaftere Verwendung des Ausladeplatzes in Zürich gaben indes Veranlassung, diese Transportmethode aufzugeben.

Die Wasserkraft der Sihl ist innerhalb des Gebietes der städtischen Waldungen, d. h. soweit diese die Sihl beidseitig begrenzen, bis zur Stunde nur durch das Sägewerk der Forstverwaltung ausgenutzt. Die weitere Ausnutzung des noch disponibeln Gefälls von $44 \mathrm{~m}$ dürfte dereinst Veranlassung werden, auch in das stille Waldtal hinein jene Regungen von Handel und Gewerbe zu bringen, denen sich die Landwirtschaft dann anschliesst, um belebte Dörfer und fruchtbare Wiesen und Felder an die Stelle des in unverdrossener Ruhe aufstrebenden Waldes zu setzen. Zurzeit wird das Projekt, die Sihl oberhalb Einsiedeln zu stauen und in Form eines 1160 ha grossen, $96.372,000 \mathrm{~m}^{3}$ fassenden Sees und Ueberleitung desselben in den Zürichsee 63,000 HP für elektrische Kraftübertragung zu gewinnen, in ernstliche Erwägung gezogen. Das Sihlbecken würde bei Ausführung dieses Werkes nur noch von den Zuflüssen $\mathrm{Al}_{\mathrm{p}}$, und Biber und vom Wildwasser benützt. 


\section{B. Geologische Verhältnisse.}

\section{Die obere Süsswasser-Molasse}

ist das älteste anstehende Gebirge des Sihltales und des Adlisbergs. Sie ruht auf dem marinen Muschelsandsteine, welcher bei «Bäch» in den steil gehobenen Bänken der Werkstein-Brüche zutage tritt.

Sie besteht hauptsächlich aus grauen Mergelsandsteinbänken, die im allgemeinen wegen ihres schwachen Kalkgehaltes von geringer Festigkeit und daher für bauliche Zwecke nicht verwendbar sind. Die lose Beschaffenheit begünstigt auch die Verwitterung in hohem Grade, sodass sich an den steileren Bergwänden zahlreiche Abrutschungen und regetationslose Stellen bilden. Diese Ërscheinungen treten am auffallendsten da zutage, wo vorherrschend mergelige und bituminöse, schiefrige Einlagerungen vorkommen, wie an der Faletsche und unter dem Albisgrat. Der höchste Grad der Verwitterung aber stellt sich da ein, wo die braunen, gelblichen und grünlichblauen Lebermergel einige Entwicklung erreicht haben. Der das Zement in den Sandsteinen bildende, mit Säuren aufbrausende Mergel, wird durch die atmosphärischen Einwirkungen rasch zerstört, und der feinkörnige aus Quarz und Feldspat bestehende Sand wird infolgedessen vom Regen fortgeschwemmt und an flacheren stellen abgelagert. Hier schreitet dann die Verwitterung noch weiter fort, indem sich der Feldspat zu plastischem Ton (Lehm) verwandelt.

In der oberen Süsswasser-Molasse kommen zuweilen auch noch Braunkohlenlager und mit diesen bituminöse Kalkmergel-Bänke vol. Dahin gehört die Pechkohle von Käpfnach, deren südliche Verbreitung bis in das Sihlbett im Steinkratten in unser Gebiet hinüberragt.

Häufiger als die Kohlenlager erscheinen lockere, oder auch festverkittete Nagelfluhbänke. oft ron grosser Mächtigkeit. of abe-1 ron nur geringer Ausdehnung. Solche Nester kennen wir im Sandstein etwa $12 \mathrm{~m}$ unter dem Schnabelpass $760-780 \mathrm{~m}$ ï. M. und im Fussweg am Howen. Die Nagelfluh erreicht hier $5 \mathrm{~m}$ Dicke. Weiter östlich am steilen Abhang des Albis trifft man noch zuweilen Nagelfluhtrümmer, deren Anstehendes unter Schutt und Humus verborgen liegt, so in den Schnabelguitern.

Schiefrige Mergel erscheinen in der oberen Süsswasser-Molasse auch ohne Begleitung von Kohlen und mit ihnen untergeordnete 
Bänke ron Kalk, jedoch nur in den obersten Höhenlagen, so zwischen dem Gütsch und der Bürglen.

Im Sihlwaldgebiete tritt die Molasse zunächst westlich von der Säge bei den Risleten-Felsen direkt zutage, in Form horizontal relagerter Sandstein-IIergelbänke, die hier eine steile. nackte. immerwährend abbröckelnde Felswand bilden. Ferner sind sie im Einschnitte des Thomannbaches, an der Talwand bis hoch hinauf, zwischen Vorder-Risleten und Teufels-Buche blossgelegt. An der rechten Sihlseite bildet die Molasse das Flussufer von der Rüitimatt bis zur Forsthausbrücke in ununterbrochener Folge, in einer abgedeckten Wand von $15 \mathrm{~m}$ Höhe. Weiter östlich tritt sie mehr sporadisch auf, meist in geringer Ausdehnung unter der Schuttdecke: so bei den Wüsten Felsen, beim Schueppenloch, in der stengelen und im Steinkratten, woselbst in Flussbette die erwähnte Kohle ausgeht.

An der linken Talseite tritt die Molasse noch nördlich unter dem Häuliboden, teils in den Wassergräben und teils an den steileren Halden zutage. Im Sihlzopf drängt ein im Talgrunde vorspringendes Molasseriff die Sihl auf kurze Erstreckung aus ihrer allgemeinen Richtung; sie scheint hier überhaupt in grösserer Masse im Talgrunde unter einer nur geringen Schuttdecke anzustehen, sowie sie demn auch of was höher noch mehrmals entblösst liegt. Ferner treffen wir sie im Wallenbrunnen, im Roten Meer und noch in grösserem Zusammenhang an steilen Absturz unter dem Grat zwischen GütschBürglenstutz und dem Riesenhügel, welch' letzterer aus vorherrschend mergeligen Molassegesteinen besteht, woher denn auch der sumpfige Charakter de: Umgebung rührt.

Weiter westlich lässt sich die Molasse unter dem SchnabelEinschnitt bis gegen die Hochwacht verfolgen, immerfort auf den höchsten Stellen des Rückens von einer Decke glacialen Schuttes iiberlagert. Gegen den Albissattel sehen wir nur noch östlich vom Albisbrïnneli Molasse auftreten. während das Plateau und die Gehänge von mächtigen Massen glacialen Schuttes überdeckt sind.

\section{Die Ueberreste der Glacialperiode.}

Auf den plateauähnlichen, sanften Abhängen des Sihlwaldes findet sich eine mehr oder weniger mächtige Bodenablagerung, die aus vorherrschend sandigem, bei Einwirkung von Säuren schwach aufbrausendem und mager anzufühlendem Ton, mit Nestern von 
Sand und verschiedenartigen Geschieben besteht. - Es ist dies ein letzter Rest der Glacialperiode.

Dieser Boden hat die Eigenschaft, das Wasser in grösseren Quantitäten aufzunehmen und zurückzuhalten. Er bildet mit den

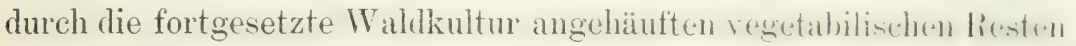
eine vorzügliche Dammerde. Es erscheint dieser Boden teils in Verbindung mit Gletscherschutt, teils auch ohne diesen als umittelbare. Decke der Molasse. Seine Entstehung verdankt der Lehm dem verwitterten Molasse-Feldspat und seine weniger plastische Figenachaff dem Molasse-Quarzsand. Indem noch die kalkreichen und schlammi-

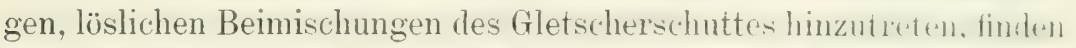
sich alle Bedingungen zur Bildung des fruchtharsten Bodens vereinigt.

Die Verbreitung dieses Bodens findet sich im Sihlwald hauptsächlich auf den plateauartigen sanftigen Abhängen und zwar zwischen folgenden Höhengrenzen:

Meter ii. M.

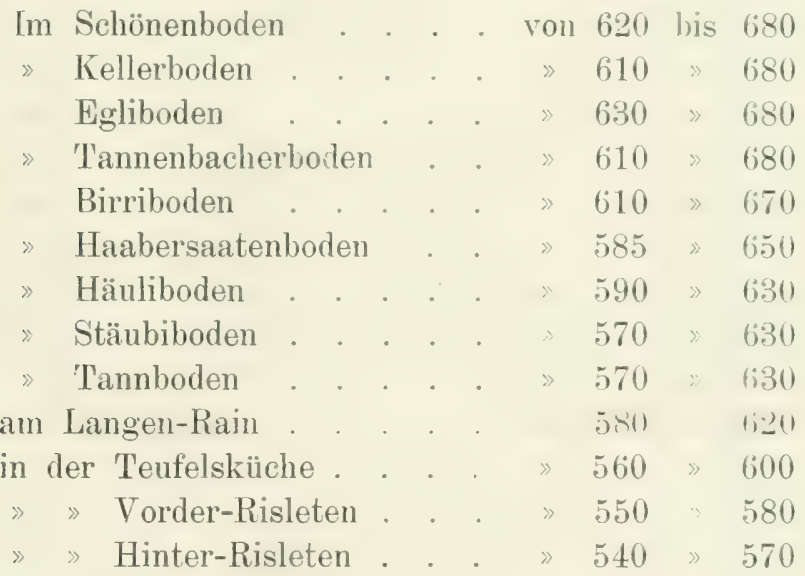

Es muss als charakteristische Erscheinung hervorgehoben werden, dass diese in ihrer Bodenbeschatfenheit analogen plateanartigen Hånge sowohl in der senkrechten Richtung zur 'Talachse, als in ihrer Längsrichtung einen einheitlichen Neigungswinkel haben und zwar $3^{0}$ nach der einen und $1^{0}$ nach der anderen Seite. Es ergibt sich dieses auch aus ihren respektiven Höhenlagen.

In den Gräben und Bachschluchten, welche diese Plateaux zahlreich durchlaufen, ist meist der feinere Sand fortgeschwemmt. dagegen sind die gröberen Geschiebe liegen geblieben.

Innerhalb dieser ganzen Stufe können wir daher unterscheiden Boden aus echten Moränen und Gletscherboden. 
Von Morïnen in wallartiger Form, mit groben Blöcken zwischen ungeschichtetem Schutt, finden sich vier. Die erste erstreckt sich iuber das Tobel, eine zweite zwischen dem Tannboden und Weissen Stem, die dritte im Stäubiboden und die vierte am Wyden-Rain, alle in $560 \mathrm{~m}$ Horizont.

Soweit der Gletscherboden über die obenerwähnten Plateaux verbreitet ist, besteht er aus grusartigem scharfkantigem Schutt, mit Lehm und Dammerde gemischt. Sein allgemeiner Charakter trägt grosse Aehnlichkeit mit dem Naterial echter Moränen, hier wie dort besteht er aus kleineren und grösseren, scharfkantigen bis sandigen Gesteinsbrocken, zwischen welchen zuweilen einzelne bedeutendere, bald scharf-, bald stumpfkantige Sernfgesteine liegen. Der Gletscherboden ist aber nicht mehr in Form eigentlicher Wälle massiert, er hat vielmehr den Charakter einer leichten Decke, die ohne bestimmte Regelmässigkeit die Abhänge und den Rücken des Albiszuges überzieht.

Die vorkommenden Gesteine sind vorherrschend schwarzer Jurakalk und grauer bis schwärzlicher Kalk und Kieselkalk der Kreidezeit. Auch eocäne Sandsteine finden sich zahlreich; seltener dagegen die weissen und gelben, im Kerne granen Dolomite. Viele dieser Kalksteinbrocken sind geritzt, wie das Material in den Moränen.

Auf diesem Schutte liegen auch vereinzelte Blöcke (Fündlinge) alpiner Gesteine, die ehemals ohne Zweifel vom gleichen Schutte, wie er jetzt die Unterlage bildet, umhüllt waren; so besonders beim Schweikhof, auf dem Rücken des Albis bis zum Bruderalbis, wo sich zahlreiche sernfgesteine (inchiefer und Konglomerate) hefinden.

Krystallinischen Gesteinen (Gneis und Granite) des Bündnerlandes begegnet man nördlich vom Albisgrat nicht, dagegen kommen beim Schweikhof, an der sïdlichen und östlichen Abdachung Granite des Rieusstales (Gotthard) vor.

Das Gletscherbodenmaterial der Sihltalwaldungen sowohl am linken, als am rechten Eingang des Sihltales stammt aus den Glarner-, St. Galler- und Schwyzer-Alpen.

\section{Mutmassliche Entstehung des Sihltales.}

Der Albis und der Horgerberg standen offenbar in einer früheren Zeit in unmittelbarerem Zusammenhange als heute. Wahrscheinlich formierten vor der Talbildung der Nordhang des Albis 
und derjenige des Horgerberges eine ununterbrochene Abdachung bis an den Zürichsee.

In der älteren Diluvialzeit mochte das heutige Sihltal bereits eine weniger steile Unterbrechung des Abhanges, vielleicht eine Art Terrasse vorgestellt haben, welche allmählich durch die vom Albis herabfliessenden Quellen ausgewaschen wurde. Das so entstandene Rinnsal wurde alsdann rückwärts, durch die Einmündung frischer, höher gelegener Quellen verlängert, bis es schliesslich die bei Schindellegi nach dem Zürichsee abfliessende Sihl aufnahm.

Man darf daher annehmen, dass das Sihltal auf diese Weise schon vor der Gletscherzeit eịne dem jetzigen Tal ähnliche Gestalt angenommen hatte; dagegen ist ganz sicher die Verbreiterung des Tales erst durch den Gletscher geschehen, während dann das schluchtartige Ausfurchen des heutigen Sihlbettes in die Periode nach der Gletscherzeit fällt.

Als die Gletscher vom Wallenseetal, vom Linthtal und dem hintern Sihltal zu einem Mantel vereinigt unsere Gegend bedeckten. lag nicht nur das Sihltal unter der starren, langsam sich westwärts bewegenden Eismasse begraben, sondern es mag auch der Albis und der Uetliberg hoch vom Eis überragt worden sein, so dass der lagernde Gletscher eine Dicke von mindestens $400 \mathrm{~m}$ erreichen mochte. Ueber dem Albisgrate stand der Gletscher in Verbindung mit dem Reuss- und Muottatal-Gletscher; diesen Schluss erlauben die auf jenem Rücken mit Sernifiten vorkommenden Gotthardgranite. Im nördlichen Teil des Kantons waren diese Gletscher mit dem Rheintal-Gletscher verbunden.

Die langsam vorwärtsschleichende starre Masse musste einen enormen Druck auf ihre Unterlage ausüben und in ihrer Bewegung alles, was nicht durch grössere Festigkeit Widerstand zu leisten vermochte, zermalmen. Nur auf diesem Wege kann man sich die Entstehung der breiten, mit Lehm bedeckten Terrassen im Sihlwald erklären. (Auffassung von Direktor Mösch am eidg. Polytechnikum †.) Eine andere Auffassung dokumentiert Alexander Wettstein in seiner Geologie von Zïrich und Umgebung (Zürich, Verlag von J. Wurster \& Cie., 1885). Seine eingehenden geologischen und orographischen Studien führen zum Schlusse, dass das Sillital erst in der letzten Periode der Eiszeit entstanden sein kann. Der ursprüngliche Lauf der Sihl zog sich von Sihlbrugg nach Baar und dem Zugersee; die Molasseterrasse vom Albiskamm bis zum Zürichsee setzte sich ununterbrochen fort. 
Bei der mächtigen Ausdehnung der Gletscher wurde der Sihl der Ausgang gegen Baar durch den stark vordringenden Reussgletscher versperrt. auf der östlichen Seite bildete der Linthgletscher einen undurchbrechbaren Damm. sodass sich über Sihlbrugg ein Gletschersee bildete, der sich seinen Abfluss längs des Linthgletschers in der Molasse der Zimmerbergterrasse suchte. Mit Hülfe der Gletscherbäche des Linthgletschers war die Erosion der weichen Molasse eine leichte Sache.

Beim Zurückgehen des Gletschers war die Erosion bei Sihlbrugg schon so weit fortgeschritten, dass die Sihl ihren ursprünglichen Lauf nach Westen nicht mehr einnehmen konnte, indem ihr früheres Bett bedeutend höher lag als das jetzige.

Die Annahme, dass das Sihltal vor der Gletscherzeit ein engeres, aber weniger tiefes Tal gewesen sei, erhält eine wesentliche Stütze in dem Vorhandensein des unter dem Klemmeriboden gegen Nord weit vorspringenden Molassefels, um welchen herum die Sihl jetzt einen fast rechtwinkligen Lauf zu nehmen gezwungen ist. Denn, untersuchen wir hier im Hinblick auf das genannte Hindernis die Lagerungsweise der Molasse, so sehen wir, dass die Schichten beider Talseiten mit einander auf das genaueste korrespondieren. Daraus können wir schliessen, dass sie vor der Talbildung miteinander im Zusammenhang gestanden haben mussten. Die Annahme einer bereits vorhandenen eigentlichen Erdspalte muss auch deswegen ganz ausser Betracht fallen, weil im Flussbette die Schichten durchsetzen; sodann ist die Richtung einer Spalte stets eine gerade, oder mindestens weniger gekrümmte, als der Lauf der Sihl. Das unter dcu erwähnten Klemmeriboden vorspringende Molasseriff lag aber auch während der Zeit, da der Gletscher das Tal bedeckte, noch unter der Sohle des Tales, denn es ist wohl anzunehmen, dass die gewaltigen Wassermassen, die dem Gletscher entströmten, dieses Hindernis nicht umgangen, sondern weggeräumt hätten, wenn diese Aufgabe nicht etwa dem Gletscher selbst zugefallen wäre. Der Gletscher bewegte sich wenigstens in der Sohle auf möglichst geradem Wege durch das Tal abwärts und ebnete dessen Boden zu einer breiten Mulde. Die seitlichen Reste dieser Mulde aber sind jetzt noch vorhanden, es sind dies die erwähnten Lehmterrassen, deren Fläche vom Schönenboden bis Hinter-Risleten (von $610-540 \mathrm{~m}$ ) die einstige Sohle des Gletschers bezeichnet.

Verfolgt man das Tal abwärts, über Langnau hinaus, so bildet der Langenberg als unterstes Stück Sihlwald eine mächtige 
Talsperre von Molassesandstein, neben welcher dié Sihl nördlich sich ihr enges schluchtartiges Bett eingesägt hat. Beim Forsthaus im Langenberg, welches auf Molasse steht, ist der Fels vom dariiber hinweggegangenen Gletscher geschliffen. Hier teilte sich das Eis im Anfang seines Vordringens wahrscheinlich in einen nördlichen und einen südlichen Arm, später beim Anwachsen des Gletschers räumte derselbe das Hindernis bis auf den heutigen Rest hinweg. Diese Talsperre besitzt annähernd die nämliche Höhe, wie die genannten Terrassen, welche die ursprüngliche Gletschermulde bezeichnen.

Nachdem sodann der Gletscher auf dem Rückzuge war, sågte das Wasser mit Hülfe des vorhandenen Schuttes in das Molassegestein eine Rinne, die von jenen Zeiten bis auf die heutige Stunde an Tiefe und Breite zunahm.

Beim Vorrücken feilte und säuberte der Gletscher den Boden. während beim Riickgang desselhen das mineralisch. Material liegen blieb, welches der Gletscher aus den Alpen mit sich führte. Die Fündlinge, der Schutt und Lehm, die End- und Seitenmoränen sind als Zeugen des einst vorhandenen Gletschers bis auf die heutige Zeit geblieben.

Ob das Vorrücken des Gletschers in zwei weit auseinander liegenden Perioden geschah, zwischen welchen das Land wieder eine Vegetationsdecke gewonnen hatte, ist aus dem in unserem Lande vorhandenen Gletschermateriale nicht ersichtlich, indem die Gesteine beider Epochen sich voneinander nicht unterscheiden. Ebensowenig lässt sich sicher bestimmen, welcher von beiden Gletschern am weitesten sich in das Land hinaus erstreckte.

Aus den, stellenweise rein gewaschenen, glattpolierten Geröllsteinablagerungen, wie sie auf der Uetlibergkuppe, auf der Baldern, am Schnabel und auf dem Albis erscheinen. lässt sich eine stärkere lokale Wirkung des dem zurïckziehenden Gletscher entströinenden Wassers erkennen.

Die westlichste unserer vier Moränen macht durch ihre wallartige Form den Eindruck einer Seitenmoräne, während die übrigen drei sich leichter durch die Annahme zeitweiligen Vorrückens und Aufstauens des Materials des auf dem Rückzug begrift'men filetscher: erklären. Dagegen scheinen die Wälle, welche von Hirzel bis gegen Zürich, zwischen dem See- und Sihltal die Wasserscheide bilden, echte Seitenmorånen darzustellen. 


\section{Physikalische und chemische Zusammen- setzung des Bodens.}

Die an und für sich durchaus günstigen Vegetationsverhältnisse zeigen in quantitativer Richtung so erhebliche Differenzen, dass es von Interesse sein musste. innerhalb der hiedurch sich bildenden Bonitätsklassen durch Vornahme einer mechanischen und chemischen Analyse die Ursachen zu ermitteln, auf denen die Ertragsähigkeit und due Differenzen derselben innerhalb der einzelnen Bodenkategorien beruhen mögen. Durch das verdankenswerte Entgegenkommen und die Arbeiten der chemischen Abteilung des forst- und landwirtschaftlichen Institutes des Eidgen. Politechnikums in Zürich, $\left.{ }^{1}\right)$ sind wir in die Lage versetzt, die wichtigsten Ergebnisse der bezüglichen Untersuchungen zusammenstellen zu können. Wenn auch diese höchst interessanten Resultate nicht derart ausgefallen sind, dass sie messbare Anhaltspunkte für Feststellung typischer Boden-Bonitätsgruppen parallel den Bestandes-Bonitätsgruppen zu liefern vermögen, so sind dieselben immerhin wichtig genug und es darf keineswegs als Widerspruch bezeichnet werden, wenn die Differenzen in den AnalysenErgebnissen verhältnismässig kleiner sind, als die Differenzen des Zuwachses oder der Massenproduktion der zugehörenden Böden.

Der Gang der Untersuchung war folgender:

\section{Auswahl des Bodens.}

Aus jeder der für die Aufstellung der Ertragstafeln adoptierten vier Bonitäts-Klassen wurde aus je einer Probefläche ein Bodenzylinder von $50 \mathrm{~cm}$ Tiefe ausgehoben, nachdem vorher die unverwesten organischen Substanzen, d. h. die sog. Laub- und Moosschicht entfernt worden war.

\section{Ermittlung des mechanischen Mischungsverhältnisses.}

Abgewogene Quantitäten wurden in Wasser aufgeweicht, sodann noch eine Zeit lang mit Wasser gekocht, hierauf auf das engmaschige Sieb eines Knop'schen Bodensiebnetzes gebracht und

1) Unter der Leitung des Herrn Prof. Dr. E. Schultze. 
nun so lange mit Wasser ausgewaschen, als das letztere noch getrübt ablief. In solcher Weise wurde die Feinerde, welche durch das Sieb hindurchging, von den auf dem Sieb zurückbleibenden gröberen Bodenteilen getrennt. Die gröberen Bodenteile wurden sodann vermittelst des genannten Siebnetzes in füf verschiedene Korngrössen, nämlich grober Kies, feiner Kies, sehr feiner Kies, grober Sand und feiner Sand zerlegt. Die Ergebnisse waren folgende:

In 1000 Teilen lufttrockenen Bodens waren enthalten:

\begin{tabular}{lrrrr} 
& \multicolumn{4}{c}{ Bonitäten } \\
& \multicolumn{1}{c}{ I } & II & \multicolumn{1}{c}{ III } & \multicolumn{1}{c}{ IV } \\
1. Grober Kies & 18,75 & 10,50 & 19,01 & 8,21 \\
2. Feiner Kies & 7,50 & 11,21 & 9,35 & 12,00 \\
3. Sehr feiner Kies & 12,50 & 18,93 & 15,28 & 25,78 \\
4. Grober Sand & 13,75 & 43,92 & 50,42 & 65,62 \\
5. Feiner Sand & 7,50 & 38,66 & 52,93 & 46,63 \\
6. Feinerde & 940,00 & 877,48 & 862,01 & 841,76
\end{tabular}

Die durch das feinste Sieb hindurchgegangene Feinerde wurde durch Absetzenlassen aus der vom Sieb abgelaufenen Flüssigkeit resp. durch Eindämpfen des letzteren ohne Verlust gewonnen und für weitere Bestimmungen verwendet. Zunächst wurden abgewogene Proben derselben durch Schlemmen in einem Kuhn'schen Schlemmzylinder in den tonigen oder leicht abschlemmbaren 'T'eil, und in den Schlemmrückstand, d. i. den sandigen Teil zerlegt. Es ergaben sich hiebei folgende Zahlen:

100 Teile der lufttrockenen Feinerde enthalten:

\begin{tabular}{lcccc} 
& \multicolumn{4}{c}{ Bonitäten } \\
& I & II & III & IV \\
Toniger T'eil & 74,52 & 65,83 & 69,30 & 65,50 \\
Sandiger T'eil & 25,48 & 34,17 & 30,70 & 34,50
\end{tabular}

Der grosse Feinerdegehalt entspricht demgemäss gleichzeitig einem grossen Gehalt des Bodens an mechanisch stark zerteilter Tonerde und diese Zerteilung äussert sich als solche durch eine stärkere Produktionskraft oder höhere Bonität. Der Feinerdegehalt als solcher wäre mithin an und für sich als Massstab für die Bodengiite selbst zu taxieren. ${ }^{1}$ )

1) Vergl. Die Bedeutung der Standortsanalysen zur Feststellung der Bestandesbonität. Forstwissenschaftliches Centralblatt 1881. 3. 


\section{Chemische Zusammensetzung der Feinerde.}

Zunächst wurden die in kalter Salzsäure löslichen Quantitäten von Kalk, Magnesia. Kali und Phosphorsäure bestimmt. 1)ie Bestimmungen wurden in der Weise ausgeführt, dass abgewogene Quantitäten der Feinerde 48 stunden lang unter wiederholtem Umschütteln mit kalter Salzsäure in Berührung gelassen wurden. Die so entstandenen Auszüge wurden darauf durch Filtration vom ungelösten Rückstande getrennt: abgemessene Anteile derselben dienten für die einzelnen Bestimmungen. Die erhaltenen Resultate sind folgende:

Auf 100 Teile lufttrockener Feinerde waren in Lösung übergegangen:

$\begin{array}{lcccc} & \text { I } & \text { II } & \text { III } & \text { IV } \\ \text { Kalk } & 5,190 & 0,274 & 0,655 & 0,406 \\ \text { Magnesia } & 0,920 & 0,427 & 0,287 & 0,600 \\ \text { Kali } & 0,050 & 0,047 & 0,052 & 0,045 \\ \text { Phosphorsäure } & 0,098 & 0,075 & 0,040 & 0,050\end{array}$

Eine weitere Untersuchung der Feinerde erstreckte sich auf den Glühverlust, welcher als solcher Weiser sein muss für die vorhandene organische Substanz und das chemisch gebundene Wasser.

Im ferneren erstreckte sich die Untersuchung auf den eigentlichen Humusgehalt. Dieser letztere wurde dadurch ermittelt, dass der in organischer Form vorhandene Kohlenstoff bestimmt und aus der Menge desselben der Humusgehalt berechnet wurde, unter der Annahme, dass der Humus $58 \%$ Kohlenstoff enthält. Die Ergebnisse sind wie folgt:

Bonitäten

$\begin{array}{lcccc} & \text { I } & \text { II } & \text { III } & \text { IV } \\ \text { Glühverlust } & - & 4,80 & 6,40 & - \\ \text { Humusgehalt } & 1,73 & 1,60 & 1,55 & 1,34 \\ \text { Stickstoffgehalt } & - & 0,10 & 0,10 & -\end{array}$

Fasst man die Ergebnisse der chemischen Analyse in ihrer Totalität zusammen, so zeigen einzig der Magnesia-. Phosphorsäureund Humusgehalt der verschiedenen Bonitätsklassen eine gewisse Proportionalität zur Bestandesbonität. Die Differenzen sind allerdings nur durch kleine Bruchteile ansgedriickt. und es hedarf offenbar noch weiterer Untersuchungen, um bestimnte Schlussfolgerungen darauf basieren zu dürfen. Immerhin ist der Satz, den Dr. C. Ebermayer in seiner chemischen Statistik des Waldbaues ${ }^{1}$ ) aufstellt,

$\left.{ }^{1}\right)$ Die gesamte Lehre'der Waldstreu von Dr. Carl Ebermayer; Bedeutung der Aschenbestandteile für die Fruchtbarkeit des Waldbodens. Abschn. 6, p. 103. 
dass die Fruchtbarkeit bedingt sei vorab durch den Phosphorsäuregehalt, entschieden hier ebenfalls zutreffend. Vergleichen wir die darin erwähnte Bodenanalyse von Schütz mit der unsrigen, so ergibt:

$\begin{array}{cc}\text { Kiefernboden } & \text { Sihlwaldhoden } \\ \text { von Sehiitz } & \text { von Sehulze }\end{array}$

$\begin{array}{rlll}\text { I. Bonität } \% & 0,0501 & 0,098 \text { Phosphorsäure } \\ \text { II. Bonität \% } & 0,0569 & 0,075 & \text { \# } \\ \text { III. Bonität } \% & 0,0388 & 0,040 & \text { \% } \\ \text { IV. Bonität } \% & 0,0299 & 0,050\end{array}$

Keiner der übrigen Bestandteile ist seinem Gehalt nach der Bonität derart kongruent wie die Phosphorsäure. Es mag deshalb gestattet sein aus der Analogie der Ergebnisse zweier so unabhängiger Untersuchungen etwelche positive Schlus folgerungen äher die eigentlichen Ursachen der Bestandesgüte herauszulesen und sie in Zusammenhang zu bringen mit dem weiteren Ergebnis umfassender Untersuchungen, welche Dr. Ebermayer über den Mineratstoffbedarf der Waldbäume, als das Resultat der gegenwärtigen Forschungen auf diesem Gebiete in seinem neuesten Werke über die naturgesetzlichen Grundlagen des Wald- und Ackerbaues ${ }^{1}$ ) in Form weniger Sätze, denen wir unsere Beobachtungen gegenüberstellen, ausspricht :

«1. Esche, Ahorn und Ulme stellen unter allen Waldbäumen die grössten Anforderungen an Kali und Phosphorsäure, dagegen ist der Kalkbedarf nur ein mittlerer.»-

Daraus erklärt sich das ungewöhnlich verbreitete und zugleich günstige Vorkommen dieser Holzarten im Sihlwald. Der starke Gehalt an Magnesia darf als eine das Wirken des Kali unterstützende Beigabe betrachtet werden.

«2. Die Buche nähert sich bezüglich ihrer Ansprüche an Kali und Phosphorsäure den Eichen. ist aber genügsamer als diese; sie verlangt vor allem weniger Kalk.

Für den Sihlivald tritt auch hier eine Uebereinstimmung mit diesem Satze insofern zutage, als Esche und Ahorn vorab auf verwittertem glacialem Schutte prädominieren, während auf dem lehmreichen Tonboden des Plateaus mit seinem grossen Kieselsäuregehalt die Buche im Vorsprung bleiben muss.

$\left.{ }^{1}\right)$ Dr. Ehermayer, Physiologische Chemie der Pflanzen, I. Bd.; der Mineralstoftbedarf der Waldbäume pag. 574. 
«3. Der Gehalt des Bodens an Kali, Magnesia und Phosphorsäure macht sich besonders im jugendlichen Alter fühlbar und es sind die gleichen Stoffe vorab für die Samenbildung von Bedeutung.»-

Für den Sihlwald lässt sich diese Schlussfolgerung daraus herleiten, dass die natürliche Verjüngung der Buche eine ungerwöhnlich leichte, und die Entricklung der jungen Buchenbestände eine ausnahmsweise günstige ist. -

\section{Die Produktionskraft des Bodens.}

Der Boden der Stadtwaldungen darf im allgemeinen als ein sehr guter, der Holzproduktion durchaus zusagender bezeichnet werden. Wo nicht mechanische Störungen die Bodenoberfläche, sei es durch Schlipfe. Abrutschungen oder Ueherwerfungen. gewaltsam verändern, und wo nicht Hand in Hand damit Stauungen des Wasserabflusses und demzufolge Vernässungen entstehen, gedeiht der Wald vortrefflich. Da jene Vorkommnisse zu den Ausnahmen zählen, so kommen dank der Jahrhunderte hindurch andauernden pflegsamen Behandlung der Waldung sogenannte Blössen nur spärlich vor. In den oberen Höhenlagen des Sihltales, im Sihlwald, in der Winzelen und teilweise im Forst finden sich freilich heute noch Partien zerstörten oder veränderten Bodens; so namentlich in den Abteilungen $3,6,10,16$ und 17 des Sihlwaldes, teils am Ursprung, teils längs der vorhandenen Bachläufe. Leider sind die Wasseransammlungen, welche sich am Fusse der Bürglenlıalden, Abteilung 10, fast konstant bemerkbar machen und als die Ursache dieser Verwüstungen anzusehen sind, sehr schwer zu verhindern oder zu zerteilen. Man hat es seinerzeit mit der Drainage versucht, allein wie leicht erklärlich ohne Erfolg. Die in den letzten Jahren angelegten Entwässerungsgraben haben bessere Wirkung gezeigt; es trat aber dabei auch eine neue Schattenseite an den Tag, indem die Talfahrt des Wassers in langen, geraden, offenen Läufen zur Bildung tiefer Bachbette und damit zum Entstehen never seitlicher Abrutschungen Veranlassung gibt.

Soweit bis jetzt gleichzeitig mit den Verbauungen von unten entgegengearbeitet werden komnte. ist es allerdings gelungen. diesem neuen Zerstörungsgang Einhalt zu gebieten.

Die um die alten und nenen Bachläufe herum hefindlichen Mööser in Abteilung $3,6,7,10,19$ und 20 des Sihlwaldes eignen sich wenig 
zur Aufforstung, es ist daher durch die Jahrhunderte hindurch nur ein successives Hineindrängen des Waldes in dieselben, nicht aber eine direkte, künstliche Bestockung d. h. Aufforstung angestrebt worden. - So ist es auch im Forst, wo die noch vorhandenen Riedter teilweise erhebliche Streue-Erträge liefern. Im Adlisberg treten analoge Verhältnisse auf dem südöstlichen Teil zutage, wenn auch nicht in sehr ausgedehntem Masse.

Wenn man den vorhandenen Boden in diejenigen Standortsbonitäten einrangiert, welche bei Aufstellung der Lrfahrungstafeln massgebend waren, so fallen vom eigentlich produktiven Waldboden:

$18 \%$ in die I. Bonität.
$37 \%$ II.
$28 \% » \geqslant$ III. $\%$
$17 \%$ IV.

Daraus folgt, dass $83 \%$ des gesamten Areals durchaus günstige Bodenverhältnisse aufzuweisen haben. Der übrige Teil mit $17 \%$ ist immerhin so beschaffen, dass er unter anderen Verhältnissen unbedenklich in die Kategorie des für Holzproduktion noch ganz gut geeigneten Bodens einrangiert werden dürfte. Der eigentlich unproduktive Boden, exclusive Wege, Strassen, Gewässer, ist in der Flächentabelle bereits mit 15,8 ha ausgeschieden; er schliesst die sämtlichen Rutsch- und Feldpartien in sich, deren Wiederanbau für eine längere Zeit unmöglich sein wird. 


\section{III. \\ Vegetationsverhältnisse.}

\section{A. Pflanzeng'eographische Verhältnisse.}

Nach Oswald Heer kann die Flora des Kantons Zürich als aus drei verschiedenen Gruppen bestehend dargestellt werden. Es muss unterschieden werden:

1. eine Flora der Ebene

2. eine Flora des Gebirgslandes und der Alpen

3. eine Flora, welche die durch die Menschen eingeschleppten und eingeführten Pflanzen enthält.

Die Flora der Stadtwaldungen Zürichs und speziell diejenige der Sihltalwaldungen gehört ihrer ganzen Natur nach wesentlich in die zweite Kategorie; zwar nicht in dem Sinne, dass man im Sihltal einer reinen Alpenflora begegnen würde, denn zahlreiche Ebenenpflanzen mischen sich unter die Kinder der luftigen Höhen. Anderseits aber sind manche Alpenpflanzen den Bächen und Gletschern ins Tal gefolgt und bilden hier im Tieflande eine kleine Kolonie, welche alljährlich von den heruntergeschwemmten Alpenbewohnern einen neuen Zuwachs erhält, wodurch die Aussterbenden ersetzt werden.

Um die gegenwärtige Zusammenstellung einer Flora zu ver' stehen, muss die florengeschichtliche Entwicklung derselben, ihr allmählicher Aufbau aus einzelnen Elementen, in Betracht gezogen werden. Als Ausgangspunkt nehmen wir die Flora der Tertiärzeit an, die sich, wie allgemein angenommen wird, bereits damals in eine Gebirgsflora und eine Flora der Ebene gegliedert haben muss. Der ersteren gehörten viele unserer farbenprächtigsten Alpenblumen, die Gentianen, Primeln, Alpenrosen etc. an. Die Ebenenflora dagegen hestand fast durrhweg ans Pflanzen, die jetzt in Mitteleuropat wildwachsend völlig verschwunden sind. Nur in fossilem Zustande, 
als Versteinerungen haben sich diese Zeugen eines tropischen Klimas in unserer Gegend erhalten. Ihre nächsten lebenden Verwandten, verschiedene Palmen, Kampferbam, Feigenhaum, Platane. Tulpenbaum etc. finden sich in den subtropischen Regionen Ostasiens und Nordamerikas. Die Gründe des Aussterbens der 'T'ertiärpflanzen sind in der darauf folgenden Erdepoche, der Glacialzeit, zu suchen, durch die ein vollständiger Wechsel des Klimas bedingt wurde. Beträchtliches Sinken der Temperatur verbunden mit reichlichen, anhaltenden Niederschlägen führte zu einer enormen Ausdehnung der Hochgebirgsgletscher, die nun mit ihrem hunderte von Metern mächtigen Eismantel das schweizerische Mittelland, mithin auch die höchsten Punkte unseres Gebietes bedeckten. Unter den Einflüssen dieses ewigen Winters erstarb die Vegetation. Die Ebenenpflanzen der Tertiärzeit verschwanden, da die für ihre Existenz notwendige grosse Wärme sich auch nach der Eiszeit nicht wieder einstellte, für immer aus unserem Gebiet. Anders die Gebirgspflanzen; sie liessen sich vom Gletscher in die Ebene hinab vorschieben; dort siedelten sie sich in gleicher Vergesellschaftung an, wie heute $1000 \mathrm{~m}$ höher. Am Ende der Eiszeit folgte die Alpenflora den wieder zurücktretenden Gletschern ins Gebirge, da und dort an geeigneten Stellen versprengte Liolonien zurücklassend. Auch unser Gebiet zeigt am Albis Beispiele für solche tertiär-alpine Abkömmlinge. Ihr Vorkommen hier, ganz isoliert von ihren Geschwistern in den Alpen, die heute unmöglich mehr an diese vorgeschobenen Stellen gelangen könnten, lässt sich nur durch die Annahme eines einstmals unter veränderten klimatischen Verhältnissen in den Torbergen weitausgedehnten und später zerstückelten Verbreitungsgebietes erklären. Von diesen «Glacialrelikten» sind diejenigen Alpenpflanzen wohl zu unterscheiden, die nur der Sihl entlang, in der Tiefe des Tales, auf Kiesbänken, Cferböschungen etc. sich vorfinden; sie wurden durch die Sihl aus den höheren Regionen des Kantons Schwyz herabgeschwemmt und haben sich erst in relativ junger Zeit vorübergehend oder bleibend hier angesiedelt. Weitaus der grösste Teil des von den Gletschern verlassenen Gebietes wurde von zwei neuen Florenelementen besiedelt und zwar dem auf die Eiszeit folgenden Steppenklima entsprechend zuerst vom xerothermischen (d. h. trocken-warmen) Florenelement. Die hieher gehörenden Pflanzen sind aus verschiedenen, während der Eiszeit unvergletschert gebliebenen Gebieten bei uns eingewandert, teils aus dem Mittelmeergebiet, teils aus den Steppen am Schwarzen 
Meere; für andere wieder ist die Heimat im Süden Afrikas zu suchen. Noch später, wohl infolge erneuter Klimaschwankungen im Sinne einer Abkühlung und Vermehrung der Niederschläge, kam es zur Einwanderung der Wald- und Wiesenpflanzen, des silvestren Florenelementes, das von unvergletschert gebliebenen Teilen Nordasiens und Nordamerikas seinen Ausgang genommen hat. Wie einst die Steppenflora gegenüber der Alpenflora, nahm jetzt die Wald- und Wiesenflora von den ihr zusagenden Standorten Besitz und überliess der Steppenflora nur die sonnigsten und trockensten Stellen zum Wohnsitz. Das Gebiet des Sihlwaldes, durch reichliche Niederschläge und viel Schatten ausgezeichnet, wurde fast ganz von der silvestren Flora in Beschlag genommen. Noch haben wir eines letzten Florenelementes zu gedenken, das seine Existenz der Tätigkeit der Menschen verdankt, der Ruderaloder Schuttflora mit den Bewohnern der Brachstellen, Schuttplätze u. S. w. Im Sihltal sind diese nevesten Bürger unserer Flora namentlich längs der Eisenbahn eingewandert. Zu eben diesem jüngsten Elemente zählen auch die hin und wieder auftretenden Gartenflüchtlinge (verwilderte Zier- und Nutzpflanzen).

Eine dem Sihlwaldgebiet allein angehörende Pflanzenspezies gibt es nicht, weil, wie aben gesagt, sämtliche Florenelemente erst nach der Gletscherzeit unsere Gegend besiedelten und ihre Entstehungszentren grösstenteils weit abliegen.

Immerhin weist der Sihlwald eine Pflanzenart auf, die, soviel bis heute bekannt ist, im Kanton Zürich hier ihren einzigen Standort hat, nämlich Valeriana excelsa. Eine andere Art, Daphne laureola. kommt ausser am Altis nur noch an der Lägern vor.

Unsere Sihlwaldflora gruppiert sich mit Rücksicht auf die Florengeschichte folgendermassen: ${ }^{1}$ )

\section{Alpenpflanzen.}

A. Ueberreste der einstigen Glacialvegetation: Pinus montana, Orchis globosa? (nach einer alten Angabe, am Albis). Alnus viridis, Trollius europaeus (Hochwacht), Saxifraga aizoides (Bürglenstock), Rosa alpina, Circaea alpina (Albis? nach einer

1) Nomenklatur und Anordnung der im folgenden aufgezählten Pflanzen nach Schinz und Keller. Flora der Schweiz (1900). Von den meisten Arten finden sich Belege in dem nit grosser Sorgfalt und Genauigkeit angelegten Sihlwald-Herbarium Kd. Forster, a. Lehrer in Rüschlikon. 
alten Angabe), Linaria alpina, Pinguicula alpina, Campanula pusilla, Homogyne alpina (Hochwacht), Arnica montana (Albis).

$\mathrm{Zu}$ den Glacialrelikten dürfen wohl auch folgende alpine Moose gerechnet werden: Dicranum fulvum, 'Trichostomum rubellum, Rhacomitrium heterostichum, Grimmia ovata, Bartramia bederi, Eurhynchium crassinervium, Scapania albicans.

B. Herabgeschwemmte Alpenpflanzen, die sich längs der Sihl angesiedelt haben: Gypsophila repens, Ranunculus alpestris, Ranunculus montanus, Aconitum Napellus, Arabis alpina, Teucrium montanum, Linaria alpina, Campanula pusilla, Carduus personata.

\section{Postglacial eingewanderte Berg- und Ehenempflanzen.'}

A. Xerothermisches Florenelement (im Sihlwald nur schwach vertreten).

1. Mediterranes Element: Ophrys muscifera, Ophrys arachnites (fuciflora), Evonymus latifolius $\left(\mathrm{A}^{2}\right)$, Daphne laureola $\left(\mathrm{S}^{2}\right)$, Asperula cynanchica.

2. Pontisches Element. Festuca amethystina (auf dem Albis und an dessen Abhängen, eine schon von Joh. Scheuchzer aufgefundene und beschriebene Art [Agrostographia, 1715, pag. 276], die aber von allen spätern Zürcher Pflanzensammlern verkannt und erst im Sommer 1880 von dem verstorbenen Botaniker Jäggi wieder aufgefunden und sichergestellt wurde), Peucedanum Cervaria (A).

3. Altafrikanisches Element: Tamus communis, Polygala chamaebuxus, Ilex aquifolium, Impatiens noli me tangere, Erica carnea.

B. Silvestres Florenelement (hieher gehört die grosse Mehrzahl der Sihlwaldpflanzen).

\section{Lichenes (Flechten):}

Baeomyces roseus, Sphyridium byssoides, Collema furvum, Peltigera canina, P. horizontalis, P. aphthosa, Solorina saccata, Parmelia saxatilis, P. physodes, P. terebrata, P. tiliacea, P. caperata, P. olivacea, P. perlata, Evernia prunastri, E. furfuracea.

1) Da die Zugehörigkeit der Flechten und Moose zu den verschiedenen Florenelementen noch nicht genügend erforscht ist, führen wir sämtliche nicht alpinen Arten unter dem silvestren Florenelement auf.

$\left.{ }^{2}\right)$ Abkürzungen: $(\mathrm{A})=$ Albis, $(\mathrm{S})=$ Sihlwald. 
Usnea barbata, Cladonia coccifera, C. cornucopioides, C. fimbriata, C. pyxidata, C. rangiferina (Renntierflechte), C. furcata, Stereocaulon tomentosum, Xanthoria parietina, Physcia ciliaris, Ph. stellaris, Endocarpon miniatum.

\section{Hepaticae (Lebermoose):}

Ricciaceae: Riccia glauca.

Marchantiaceae: Marchantia polymorpha, Chomiocarpon quadratus (Preissia commutata).

Jungermanniaceae: Metzgeria furcata, M. furcata var. prolifera, M. pubescens, Pellia epiphylla, Jungermannia trichophylla, J. bicuspidata, J. quinquedentata, J. Mülleri, Plagiochila asplenoides, P. interrupta, Lophocolea bidendata, L. heterophylla, Chiloscyphus polyanthus, Calypogeia trichomanes, Lepidosia reptans, Mastigophora trilobata, M. deflexa, Trichocoela tomentella, Stephanina (Radula) complanata, Bellincinia (Madotheca) platyphylla, B. laevigata, Frullania Tamarisci, F. dilatata, Eulejeunia serpyllifolia, Scapania aequiloba.

Musci frondosi (Laubmoose):

Sphagnaceae: Sphagnum acutifolium, S. squarrosum, S. cymbifolium.

Phascaceae: Phascum cuspidatum.

Bruchiaceae: Pleuridium subulatum.

Weisiaceae: Dichodontium pellucidum, Weisia viridula, Dicranoweisia crispula.

Dicranaceae: Dictanella heteromalla, D. varia, D. rufescens, Dicranum undulatum, D. palustre, D. scoparium, D. longifolium, D. viride, D. montanum, Dicranodontium longirostre. Leucobryaceae: Leucobryum glaucum.

Fissidentaceae: Fissidens adiantoides, F. taxifolius, F. decipiens, F. pusillus.

Seligeriaceae: Seligeria recurvata.

Ditrichaceae: Ceratodon purpureus, Distichum capillaceum.

Pottiacene: Pterigoneurum filiforme, Eucladium verticillatum, Pottia truncata, Trichostomum rubellum, Barbula ruralis, B. subulata, B. tortuosa, B. unguiculata, B. recurvifolia, B. rigidula, B. inclinata, B. muralis, B. paludosa.

Grimmiaceae: Cinclidotus fontinaloides, Grimmia Hartmannii, G. pulvinata, G. apocarpa, Rhacomitrium canescens, Hedwigia 
ciliata, Orthotrichum straminosum, 0 . speciosum, O. affine, O. anomalum, O. cupulatum, Ulota Ludwigii, U. Bruchii, U. crispa, U. crispula.

Funariaceae: F. hygrometrica, Phycomitrum pyriforme, P.eurystoma, P. patens.

Bryaceae: Bryum roseum, B. pallens, B. pseudo-triquetrum, B. capillare, B. argenteum, B. badium, B. caespiticium, B. pallescens, Webera albicans, W. cruda, W. nutans, Mnium stellare, M. serratum, M. undulatum, M. insigne, M. cuspidatum, M. rostratum, M. punctatum, Philonotis calcarea, Bartramia Halleri, Gymnocybe palustris, Aulacomnium palustre.

Polytrichaceae: Polytrichum strictum, P. juniperinum, P. piliferum, P. commune, P. formosum, P. gracile, Pogonatum urnigerum, P. aloides, P. nanum, Atrichum undulatum, Georgia pellucida.

Buxbaumiaceae: Diphyscium foliosum.

Fontinalaceae: Fontinalis antipyretica.

Leskeaceae: Leskea nervosa, Pseudoleskea catenulata, Thuidium abietinum, Th. recognitum, Th. tamariscinum, Anomodon viticulosus, A. attenuatus, A. longifolius, A. apiculatus.

Neckeraceae: Neckera complanata, N. crispa, N. pennata.

Hypnaceae: Patygyrium repens, Climacium dendroides, Antitrichia curtipendula, Leucodon sciuroides, Homslothecium sericeum, Homalia trichomanoides, Pylaisia polyantha, Eurhynchium striatum, E. rusciforme, E. murale, E. praelongum, E. piliferum, E. velutinoides, E. striatulum, E. depressum, E. Vaucheri, Plagiothecium denticulatum, P. silvaticum, Amblystegium riparium, A. irriguum, A. serpens, A. confervoides, A. subtile, Camptothecium nitens, C. lutescens, Brachythecium rivulare, B. glareosum, B. populeum, B. rutabulum, B. velutinum, B. salebrosum, Hypnum palustre, H. purum, H. Schreberi, H. cuspidatum, H. giganteum, H. crista castrensis,

- H. molluscum, H. cupressiforme, H. cupressiforme var. filiforme, $\mathrm{H}$. incurvatum, $\mathrm{H}$. rugosum, $\mathrm{H}$. commutatum, $\mathrm{H}$. intermedium, H. Wilsonii, H. aduncum, H. scorpioides, H. lycopodioides, H. fluitans, H. uncinatum, H. squarrosum, H. stellatum, H. chrysophyllum, H. filicinum, Hylocomium brevirostrum, H. splendens, H. loreum, H. triquetrum, Isothecium myurum, Thamnium alopecurum, Cylindrothecium concinnum, Orthothecium intricatum, 0 . rufescens. 
Pteridophyten:

Polypodiaceae: Athyrium filix femina, Cystopteris fragilis, Aspidium dryopteris, A. phegopteris, A. Robertianum, A. montanum, A. thelypteris, A. filix mas, A. spinulosum, A. lobatum, Blechnum spicant, Asplenum trichomanes, A. viride, A. ruta muraria, Pteridium aquilinum, Polypodium vulgare.

Equisetaceae: Equisetum silvaticum, E. maximum (Telmateja),

E. arvense, E. palustre, E. Heleocharis (limosum), E. variegatum (an der Sihl), E. hiemale.

Lycopodiaceae: Lycopodium clavatum.

\section{Siphonogamen (Phanerogamen) :}

Gramina: Milium effusum, Calamagrostis varia, Holcus mollis (A), Deschampsia caespitosa, Avena pratensis (A), Danthonia decumbens (A), Cynosurus cristatus, Sesleria caerulea, Glyceria plicata, Festuca silvatica, F. ovina var. duriuscula, und var. glauca, Bromus asper var. ramosus, Nardus stricta (A), Lolium perenne var. tenue, Elymus europaeus (S), Brachypodium silvaticum, Agropyrum caninum.

Cyperaceae: Eriophorum latifolium, Trichophorum (Eriophorum) alpinum, Blysmus (Scirpus) compressus, Scirpus silvaticus, Schoenus ferrugineus, Carex paniculata, C. remota, C. leporina, C. tomentosa, C. ornithopoda, C. alba, C. flava, C. flava $X$ Hornschuchiana (C. fulva), C. pilulifera, C. humilis, C. pendula, C. silvatica.

Araceae: Arum maculatum.

Juncaceae: Juncus obtusiflorus, J. Leersii (conglomeratus), Luzula campestris, L. silvatica, L. nemorosa.

Liliaceae: Tofieldia calyculata, Anthericus ramosus, Allium ursinum, Lilium martagon, Najanthemum (Smilacina) bifolium, Paris quadrifolia, Convallaria majalis, Polygonatum officinale, P. multiflorum, P. verticillatum.

Amaryllidaceae: Leucojum vernum.

Orchidaceae: Orchis militaris, O. mascula, O. incarnata, O. ustulata, O. purpurea, Gymnadenia odoratissima, G. conopea, Platanthera bifolia, P. chlorantha, Epipactis rubiginosa, Cephalanthera rubra, C. ensifolia (xiphophyllum), C. grandifiora (pallens), Spiranthes aestivalis, Neottia nidus avis, Goodyera repens, Herminium monorchis (A und S). 
Salicaceae: Salix caprea, S. grandifolia, S. triandra var. discolor, Ulmaceae: Ulmus montana.

[S. incana, S. repens.

Santalaceae: Thesium tenuifolium, Th. pratense.

Aristolochiaceae: Asarum europaeum (S).

Polygonaceae: Polygonum bistorta, Rumex sanguineus (nemorosus).

Caryophyllaceae: Silene nutans, Melandrium rubrum (diurnum), Dianthus superbus, Moehringia trinervia, Stellaria graminea.

Ranunculaceae: Helleborus viridis (S), Anemone hepatica, Actaea spicata, Aquilegia vulgaris var. atrata, Aconitum lycoctonum, Ranunculus aconitifolius, R. lanuginosus (S), R. silvaticus (nemorosus) (S), Thalictrum aquilegifolium.

Cruciferae: Cardamine silvatica, C. amara, Dentaria digitata (S), Arabis hirsuta.

Droseraceae: Drosera rotundifolia.

Saxifragaceae: Saxifraga mutata, Chrysosplenium alternifolium. Rosaceae: Sorbus aucuparia, S. aria, S. aria $X$ aucuparia (S. hybrida), vielleicht nur verwildert, Aruncus silvester (Spiraea aruncus), Potentilla erecta, Geum rivale, Alchimilla pratensis (vulgaris), Agrimonia eupatoria, Sanguisorba officinalis, Rubus suberectus, Prunus padus.

Leguminosae. Trifolium medium, T. ochroleucum, T. montanum, T. agrarium, Anthyllis vulneraria, Lotus uliginosus, Astragalus glycyphyllus, Vicia dumetorum, Lathyrus vernus, L. montanus.

Geraniaceae: Geranium pyrenaicum, G. sanguineum, G. silvaticum. Polygalaceae: Polygala vulgare subsp. comosum, P. amarellum. Euphorbiaceae: Mercurialis perennis, Euphorbia dulcis, E. verrucosa.

Hypericaceae. Hypericum humifusum, H. montanum, H. hirsutum, H. quadrangulum, H. Desetangsii.

Cistaceae: Helianthemum vulgare.

Violaceae: Viola mirabilis, V. alba, V. silvestris, V. Riviniana. Thymelaeaceae. Daphne mezereum.

Oenotheraceae: Epilobium hirsutum, E. palustre, E. montanum, Circaea lutetiana.

Araliaceae: Hedera helix.

Umbelliferae: Sanicula europaea, Chaerophyllum hirsutum, var. Cicutaria, Bupleurum longifolium, Pimpinella saxifraga, Silaus selinoides (pratensis), Laserpitium latifolium. 
Pirolaceae: Pirola secunda, P. rotundifolia, P. chlorantha. P. minor, Monotropa hirsuta (Hypopitys).

Ericaceae: Vaccinium Vitis idaea, Calluna vulgaris.

Primulaceae: Primula farinosa, Lysimachia nemorum.

Gentianaceae: Blackstonia (Chlora) perfoliata, Erythraea Centaurium, Gentiana verna, G. cruciata, G. ciliata, G. Wettsteinii (germanica), G. asclepiadea, G. pneumonanthe.

Asclepiadaceae: Vincetoxicum officinale.

Apocynacece: Vinca minor.

Borraginaceae: Myosotis palustris.

Labiatae: Teucrium scorodonia, Brunella grandiflora, Melittis melissophyllum, Stachys alpina (A), Stachys (Betonica) officinalis, Salvia glutinosa (S), Origanum vulgare, Thymus Serpyllum.

Solanaceae: Atropa belladonna.

Scrophulariaceae: Scrophularia nodosa, Veronica latifolia (urticifolia), V. montana (S), Alectorolophus angustifolius (A), A. minor. var. vittulatus, Pedicularis palustris.

Utriculariaceae: Pinguicula vulgaris.

Rubiaceae: Asperula odorata, Galium verum, G. uliginosum, G. boreale, G. rotundifolium (A), G. asperum (silvestre).

Caprifoliaceae: Sambucus racemosa, S. ebulus, Lonicera alpigena. L. nigra, L. periclymenum.

Valerianaceae: Valeriana officinalis, V. excelsa (sambucifolia) (S), einziger Standort im Kanton Zürich; V. dioica, V. tripteris (S).

Dipsaceae: Knautia silvatica.

Campanulaceae: Whyteuma orbiculare, Campanula patula.

Compositae: Bellidiastrum Michelii, Gnaphalium silvaticum, Inula salicina, I. vulgaris (Conyza squarrosa), Buphthalmum salicifolium, Chrysanthemum leucanthemum, Petasites albus, Senecio silvaticus, S. erucifolius, S. aquaticus, Carlina vulgaris, C. acaulis (A), Carduus defloratus, Cirsium bulbosum, C. acaule, Lactuca muralis, Centaurea montana, C. scabiosa, Leontodon hispidus, Scorzonera humilis (A), Taraxacum paludosum, Crepis praemorsa, C. paludosa, Prenanthes purpurea, Hieracium florentinum, H. vulgatum, H. boreale.

C. Ruderalpflanzen und Gartenflüchtlinge: Poa compressa, Allium carinatum, Narcissus poëticus, N. pseudonarcissus, (verwilderte Zierpflanzen) Rumex acetosella, Papaver Lecoquii, 
Thlaspi arvense, Erucastrum Pollichii (Bahnkörper der Sihltalbahn), Barbarea vulgaris (Sihlbett), Alyssum calycinum (Bahnkörper), Melilotus alba, M. altissima, Trifolium procumbens, T. hybridum (Bahnkörper), Coronilla varia, Geranium molle, Malva moschata, M. silvestris, Echium vulgare, Solanum nigrum, Erigeron (Stenactis) annuus, Crepis (Barkhausia) taraxacifolia.

\section{B. Die forstlichen Kulturpflanzen.}

Die dem nordschweizerischen Molasse-Hügelland angehörenden Laub- und Nadelholzarten bilden den Hauptbestand der Waldung. Alnus viridis und Pinus montana sind die beiden einzigen auffallenden Erscheinungen der lokalen Baumwelt. Viel charakteristischer ist dagegen die Verteilung der Arten mit Bezug auf den Standort und ihre vertikale Erhebung über Meer. In dieser Beziehung präsentieren sich das linke und das rechte Sihlufer als zwei ganz verschiedene pflanzengeographische Komplexe. Das rechte Sihlufer ist in ausgesprochenstem Masse von den Nadelhölzern beherrscht; nur in der untersten, dem Flussbette zunächst liegenden Zone suchen die Laubhölzer Terrain zu gewinnen. Das viel ausgedehntere linksufrige sihlyebiet dagegen ist mit Lauhiölzern ïherdeckt und enthält nur wenige Prozente von Nadelhölzern. Diese auffallende Verschiedenheit der Ptlanzendecke in zwei so nahe aneinander gelegenen Gebieten gewinnt noch an Interesse durch den Umstand, dass ein Zurïckgehen um drei bis vier Jahrhunderte den Nachweis liefert, dass diese grosse Verschiedenheit früher nicht bestanden hat. Zufolge einer Reihe von Daten aus dem 13. und 14. Jahrhundert hatte dazumal auch der linksufrige Teil des Sihlwaldes vorwiegend mit Nadelholz bestanden. Es muss sich daher ein Wandlungsprozess der Arten vollzogen haben, der sich in neuerer Zeit dank den starken Durchforstungen und Vorhieben zu Gunsten des Nadelholzes zu wiederholen scheint.

Als im Jahr 1280 ein grosser Teil von Zürich ein Raub der Flammen geworden war und die Stadt neu aufgebaut werden musste, lieferte der Sihlwald das nötige Bauholz. Die forstpolizeilichen Bestimmungen des Richtebriefes von 1304 beziehen sich wesentlich 
nur auf die Bauholznutzung. Noch Anno 1554, fast drei Jahrhunderte später, verfügt der Rat, «dass die Scheiter aus dem Sihlwald und den nächstgelegenen Hölzern, die meistens tannen sind, den gemeinen Armen zu 1 क 5 fo ausgeteilt werden». Nachher scheint ein Umwandlungsprozess stattgefunden zu haben. Wir besitzen von 1630 an bis auf den heutigen Tag ein vollständiges Wirtschaftsbuch, das sowohl die in Form der Hauptnutzungen, als der Zwischennutzungen bezogenen Erträge nach Laub- und Nadelholz angibt. Durch diese Aufzeichnungen wird der unanfechthare Beweis geliefert, dass der Sihlwald sich allmählich aus einem vorherrschenden Nadelwald in einen Laubwald umgewandelt hat.

Die in Prozenten des Gesamtmaterialertrages ausgedrückten Verhältniszahlen weisen von Dezennium zu Dezennium auf eine stetige Zunahme der Laubholzmassen und Hand in Hand damit auf eine Abnahme der Nadelholzerträge hin, so dass, wenn man auch dem Wirken des Zufalles bei den Schlagergebnissen eine wesentliche Rolle zuschreiben wollte, das Walten eines Naturgesetzes infolge der Stetigkeit der Erscheinung dennoch angenommen werden muss.

Die nachstehenden Zahlenreihen dürften am deutlichsten für diese Behauptung sprechen.

$$
\text { Hiebergebnisse von } 1630-1890 \text {. }
$$

\begin{tabular}{lcc|ccr} 
Zeitperioden: & $\begin{array}{c}\text { Laub- Nadel- } \\
\text { holz: }\end{array}$ & Zeitperioden: & \multicolumn{2}{c}{$\begin{array}{c}\text { Laub- Nadel- } \\
\text { holz: }\end{array}$} \\
& $\%$ & $\%$ & & & \\
1 & & & \\
$1631-1640$ & 45 & 55 & $1761-1770$ & 72 & 28 \\
$1641-1650$ & 39 & 61 & $1771-1780$ & 75 & 25 \\
$1651-1660$ & 40 & 60 & $1781-1790$ & 84 & 16 \\
$1661-1670$ & 43 & 57 & $1791-1800$ & 86 & 14 \\
$1671-1680$ & 46 & 54 & $1801-1810$ & 91 & 9 \\
$1681-1690$ & 49 & 51 & $1811-1820$ & 93 & 7 \\
$1691-1700$ & 51 & 49 & $1821-1830$ & 88 & 12 \\
$1701-1710$ & 58 & 42 & $1831-1840$ & 88 & 12 \\
$1711-1720$ & 57 & 43 & $1841-1850$ & 82 & 18 \\
$1721-1730$ & 56 & 44 & $1851-1860$ & 83 & 17 \\
$1731-1740$ & 60 & 40 & $1861-1870$ & 84 & 16 \\
$1741-1750$ & 68 & 32 & $1871-1880$ & 86 & 14 \\
$1751-1760$ & 70 & 30 & $1881-1900$ & 71 & 29
\end{tabular}

Die Ursachen, welche diesen Wechsel herbeiführten, mögen verschiedenartige sein. Die Bodenverhältnisse des linken und rechten. Sihlufers sind an und für sich wenig von einander verschieden und 
ebenso ist ausdrücklich zu konstatieren, dass der künstliche Holzanbau weder auf dem Wege der Saat noch der Anpflanzung in irgend einer Weise zu dieser Metamorphose des Waldbildes Veranlassung gegeben haben kann. Die natiuliche Verjiingung hat, so lange der Sihlwald besteht und bis zur heutigen Stunde die Wiederaufforstung der Schläge in fast ausschliesslicher Weise bewerkstelligt. Die wenigen Bestandesergånzungen, die jeweilen vorgenommen wurden. übten offenbar nur einen unbedeutenden Einfluss auf das Mischungsverhältnis aus, so dass von einer Einwirkung ihrerseits nicht gesprochen werden kann. Wir befinden uns hier also vor einer natürlichen Umwandlung der Bodenbestockung, die nicht bloss im vollen Gegensatz steht zu der in Nord-und Mitteldeutschland sich vollziehenden Verdrängung der Buche durch die Fichte, sondern die an und für sich als eine eigenartige physiologische Erscheinung der Waldkultur bezeichnet werden muss. ${ }^{1}$ )

In erster Linie ist die Metamorphose des Sihlwaldes wohl zunächst dem Nutzungszweck zuzuschreiben, den die Stadt Zürich als vielhundertjährige Eigentümerin ihrer Domäne beilegte. Die von ihr an den Wald und an die Wirtschaft gestellten Anforderungen gingen hauptsächlich dahin, Brennholz zu lieferm, und da lag es nahe, vorab der Buchennqchzucht alle Aufmerksamkeit zu schenken. Der auf dem linken Ufer der Sihl liegende Forst hat sich innerhalb eines historisch nachweisbaren Wirtschafts\%eitraumes von fünf Jahrhunderten unverändert den Habitus des Nadelholzwaldes zu erhalten gewusst. Von diesem Forst wissen wir aber, dass seine Nutzniesser, die Besitzer der 12 Hofstetten gemåss ihrem Bedürfnis, vom Walde vorab: Zaunholz für die Weide, Holz für ihre Rebpfähle und Bauholz für ihre Häuser verlangten, also auf Nadelhölzer hindrången mussten. Nur der Nadelholzwald konnte ihnen dieses Material liefern; jede andere Betriebsart, die diesem Zwecke nicht diente, wurde daher missachtet und infolgedessen auch unterdrïckt. Wie zu Anfang des 18. Jahrhunderts mit der künstlichen Bestandesnachbesserung. speziell mit der Saat hegonnen wurde, warf man sich, wie nachweisbar ist, auch nur auf die Nadelhölzer. Und so blieb der Forst, was er von jeher war, ein Nadelwald. Anders aber gestalteten sich die Dinge im Sihlwald. Nachdem der Bauholzbedarf der durch ihre Umwallung fest einge-

1) Siehe von Berg: Das Verdrängen des Laubwaldes im nördlichen Deutschland. Kettner: Beschreibung des Murg- und Ostales. G. Heyer: Das Verhalten der Waldbäume. 
grenzten Stadt gegen die Mitte des 15. Jahrhunderts gedeckt war und der Bau steinerner Wohnhåuser mehr gebråuchlich wurde, trat das Bremholzbedürfnis mehr und mehr in den Vordergrund und dieses wuchs von Jahrzelint zu Jahrzehnt mit der Wohlhabenheit und Ausdehnung des zürcherischen Gemeinwesens. Da reichte denn der Sihlwald bald nicht mehr aus, diesen Brennholzbedarf zu decken. Von 1577 an salı sich der Rat alljährlich veranlasst, bedeutende Brennholzankäufe in dem Kanton Schwyz zu machen. Das war der Anfang des sogenannten Blütschen-Holzhandels, der bis zum Jahre 1826 dauerte. Es liegt daher sehr nahe, anzunehmen, dass sich die Wirtschaft in der gleichen Zeit mit aller Macht auf die Brennholzerziehung werfen musste, nicht bloss durch quantitative, sondern auch durch qualitative Vermehrung des Zuwachses. Dieses letztere Ziel war vornehmlich durch die Begïnstigung der Laubhölzer zu erreichen. Die nachweisbar von der Mitte des 16. Jahrhunderts an eingelegten Durchforstungen, die natiurliche Verjüngung an und für sich, die für den Nadelwald zu niedrige, für den Laubholzwald unter vorhandenen Standortsverhältnissen genügende Umtriebszeit von 80-100 Jahren - alle diese Momente trugen das ihrige dazu bei, die Buche auf Kosten der Tanne zu begünstigen und ihr schliesslich die Oberherrschaft zu sichern.

Als einen weiteren Erklärungsgrund für das allmähliche Ueberhandnehmen der Laubhölzer, vorab der Buche, müssen wir sodann die stetig sich verbessernde Bestandespflege und ihre Rückvirkung auf die Bodenbeschaffenheit bezeichnen. Noch heute treffen wir an denjenigen Stellen des linksufrigen Sihlhanges, wo fortdauernde Abrutschungen, oder Ueberstürzungen des Terrains, schlechte Wirtschaft etc., der Holzproduktion eine von Humus entblösste Ernährungsschicht überliefern, vorwiegend nur die genügsamen Nadelhölzer, speziell die Fichte und die Kiefer. Den ganzen Albishang entlang bis zum Gebirgsstock des Uto tritt diese gleiche Erscheinung zutage. Die Nadelhölztr zeigen sich immer da prädominierend, wo der Boden auf irgend eine Art decastiert ist und wo "v infolgedessen den anspruchsvolleren Laubhölzern nicht mehrgenügt. Der gepflegte Gemeinde-oder Korporationswald ist fast ausnahmslos Buchenwald, der stark parzellierte, wirtschaftlich leichtsinnig behandelte Privatwald dagegen wurde vom Nadelholz in Beschlag genommen. Im gepflegten Buchen- oder Laubholzhochwald bildet sich rasch eine starke Laubdecke. welche besonders dem Ankeimen des leichten Nadelholzsamens ungünstig ist; der Nadelholzkeimling kann nicht 

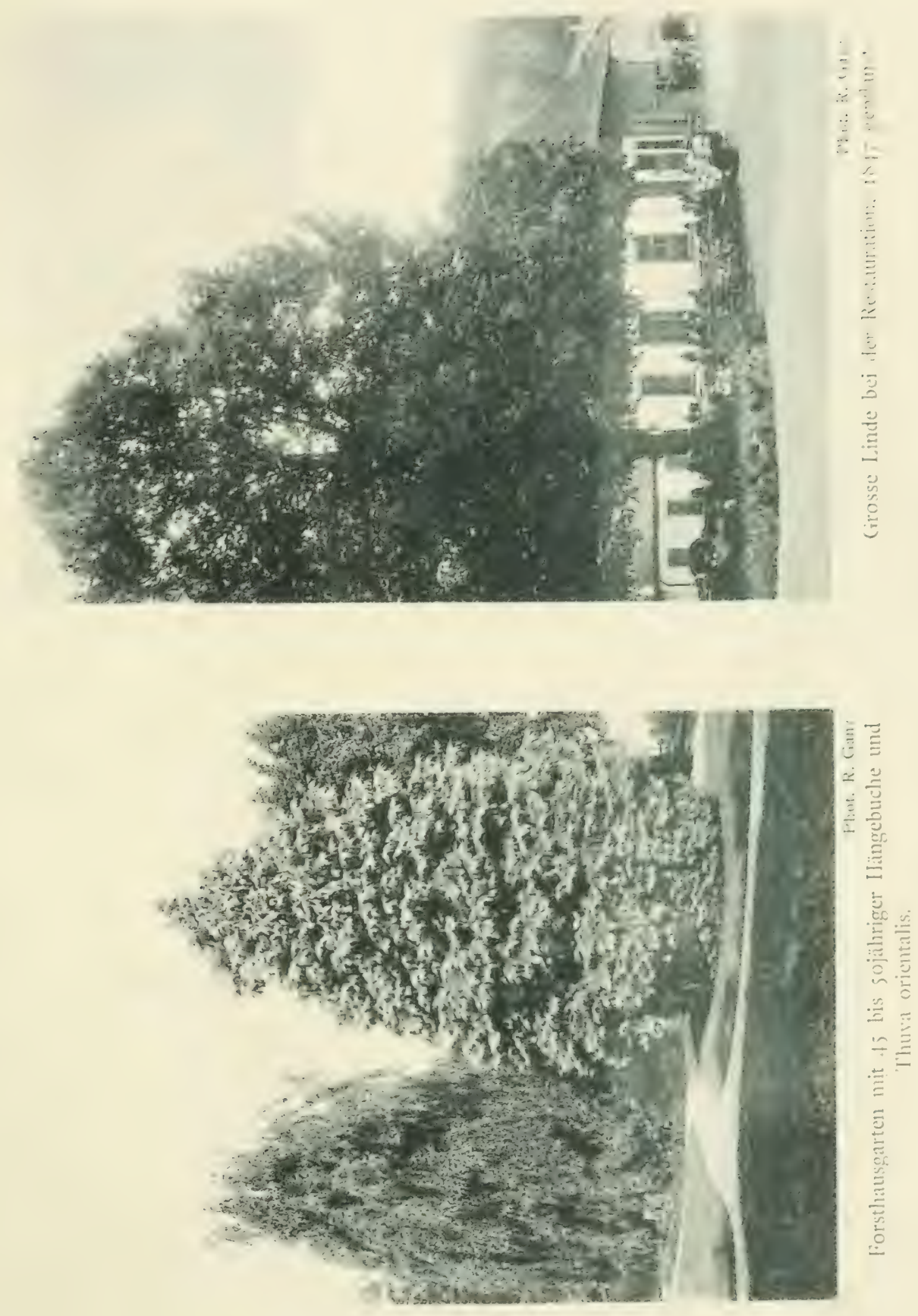

hinreichend Wurzel fassen, um sich auf die Dauer behaupten zu können. während bei dem kräftigeren Laubholzkeimling diese Hindernisse viel weniger ins Gewicht fallen und daher eher zur Begünstigung der Buche auf Kosten der Nadelhölzer beitragen. Wir beobachten noch heute in unsern gemischten Laub- und Nadelholzwaldungen diese gleiche Erschwerung des Aufkommens der Nadelhölzer und zwar macht sich diese Tatsache in eben dem Masse bemerkbar, als die Verjüngung der Buche sich in dieser Gegend so ausserordentlich leicht vollzieht.

In allen diesen Momenten glauben wir wenigstens Anhaltspunkte, wenn auch nicht die vollständige Erklärung für die konstatierte Metamorphose des Sihlwaldes gefunden zu haben.

Was nun den speziellen Charakter der beiden so verschiedenartig aussehenden Waldbilder, Sihlwald und Forst, anbetrifft, so haben wir, mit dem Laubwald beginnend, zu konstatieren, dass die Buche, Fagus silvatica, die Hauptbestandesbildnerin ist; ihr finden sich beigesellt: die Esche, Fraxinus excelsior; der Bergahorn, Acer pseudoplatanus, und der Spitzahorn, Acer platanoides; die Ulme, Ulmus montana, die Hainbuche, Carpinus betulus, und die Schwarzerle, Alnus glutinosa.

Der Kirschbaum, Prunus cerasus, die in unserem Molassegebiet sonst so vielfach auftretende Birke, Aspe und Sahlweide finden sich sehr spärlich im Sihlwald, höchstens in den Bestandesjungwüchsen. Die anlässlich der Ermittlung der Zuwachstafeln von 1880 eingelegten Probeflächen ergaben: $80 \%$ Buchen, 9,5\% Ahorn, $8 \%$ Eschen, 2,5\% Ulmen, so dass das quantitative Vorkommen der einzelnen Holzarten sich im allgemeinen in der obenangeführten Reihenfolge ausdrückt. An einzelnen Orten tritt die Esche in reinen Beständen auf.

Die Fürsorge für die Erhaltung der je länger je mehr vom Holzmarkte verlangten Eschen und Ahorne ist im Sihlwald seit Jahrhunderten vorhanden. Zufolge einem Ratsbeschluss von Anno 1567 wird verfügt: "Dass im Silwald keine Reifstangen mehr und nie das Spiesholz gehauen werden soll. Nachdem M. G. H. berichtet, dass mit Abhauung des Spiesholzes und der Reifstangen im Silwald gar ein Unmass gebraucht, und so fürderhin nit mit anderer Ordnung darin gefahren oder das Spies- und Reifstangenhauen eintweder darin ganz abgestellt, dass es dem Wald mittlerweilen nit erleidenlich seyn würde, haben sie sich zur Fürkommung dessen entsehlossen und wellent: Dieweil der Silwald ja weltanher 
allein auf Gem. Stadt und Bürgerschaft gedienet und gewartet, so solle es ferner bey demselben bleiben und hiefür allein Spiesholz als ein Ehafte und Nutz gemeiner Bürger- und Landschaft und gar keine Reifstangen mehr von Jemandem darin gehauen werden; und dass, so man hiefür Hölzer zu Spiessen notdürftig, dasselbig allein in dem Hau so man des nächsten oder das nachgehende Jahr hauen will und sonst im Wald gar nienen gehauen noch genohmen werden und dass ein Silherr selbst oder seine Diener im Silwald einem jeden Zeugherrn, der mit den Knechten in Wald gan, soll zeigen, wie breit der nächst oder der Hau aufs ander Jahr gan soll, und dann der Zeugherr mit den Knechten verschaffen, dass das Spiessholz allein so im nächsten oder andern Hau gefunden wird und sonst gar nüt gehauen, auch nützlich aufgemacht, und dem Wald so weit möglich geschont werde.» 11. Okt. C. S. (36, pag. 5).

Zufolge der in den letzten zwei Dezennien eingeführten Begünstigung der gemischten Bestände hat sich das Mischungsverhältnis zu Ungunsten der Buche und zu Gunsten von Ahorn und Esche wie der Nadelhölzer wesentlich verändert und verbessert.

Die vertikale Höhenerhebung fördert in dem Vorkommen der einen oder andern der genannten Holzarten im allgemeinen keine merkbaren Unterschiede zutage. Wir begegnen dem gleichen Mischungsverhältnisse in der oberen Region von $850-900 \mathrm{~m}$, wie in der unteren von $500-550 \mathrm{~m}$, ja es zeigt sich gegenteilig ein fast stärkeres Auftreten der Esche in den oberen Regionen, als in den unteren.

Der Charakter and die Entwicklung der einzelnen Gattung und Art innerhalb des allgemeinen Bestandesbildes macht sich in mehrfach eigenartiger Weise geltend. Was zunächst die Buche, den Hauptrepräsentanten des Sihlwaldes betrifft, so ist dieselbe in die Kategorie der Gebirgsbuche, im Gegensatz zur Küsten- oder Inselbuche, einzureihen. Schlank und hoch gewachsen, entwickelt sie auf dem langen, glatten, astreinen Stamme eine verhältnismässig sehr kleine Krone. Das Reisigprozent unserer 90jährigen Laubholzbestände ist daher bloss $7,5 \%$ bei der $I$. und $11,2 \%$ bei der IV. Bonität. Die Baumformzahl schwankt bei 90 Jahren zwischen 0,551 und 0,631. Die Baumhöhen bewegen sich innerhalb 35-28 m. Ein Kürzerwerden der Buche mit zunehmender Erhebung über Meer lässt sich am Gebirgsstocke des Albis nicht in deutlich wahrnehmbarer Art konstatieren, da die 'Terrainpartien der obersten 
Bergstufe mehrteils so abnormaler Art sind, dass die veränderten Wachstumserscheinungen dieser Lagen, eher diesem Umstande als der Einwirkung der vertikalen Erhebung über Meer zugeschrieben werden müssen. Die Samenfähigkeit tritt im feuchteren Sihlwaldgebiet verhältnismässig spät ein; früher dagegen auf dem trockeneren Standort des Adlisbergs, wo sie sich schon mit 55-60 Jahren bemerkbar macht, während sie im Sihlwald erst mit 65-70 Jahren eintritt.

Vollmasten zeigen sich selten, häufiger dagegen Sprengmasten, durch welche die Verjüngung sehr leicht zu bewerkstelligen ist. Das Gesamtauftreten der Buche ist ein ausgesprochen üppiges. Die Natur scheint ihr im Sihlwald nach den verschiedensten Richtungen hin alle diejenigen Hülfsmittel zu bieten, welche sie zu einer durch die günstigsten Zuwachsverhältnisse sich ausdrückenden Existenz bedarf. Forscht man nach den Ursachen, welche einem derartigen Auftreten zugrunde liegen, so müssen diese einerseits in der Bodenbeschaffenheit, anderseits in der Exposition des Terrains und endlich im Lokalklima gesucht werden.

Die chemische Bodenbeschaffenheit ${ }^{1}$ ) bietet allerdings nicht in dem Masse Anhaltspunkte für die Lösung der vorliegenden Frage, wie man es hätte erwarten dürfen. Entgegen der vielfach verbreiteten und auch von Dr. Moriz Willkomm ${ }^{2}$ ) aufrecht erhaltenen Anschauung, als sei das Auftreten der Buche wesentlich bedingt durch das quantitative Vorkommen des Kalkes, ist es hier vielmehr der Gehalt an Magnesia und an Phosphorsäure, der uns in auffallend starkem Masse entgegentritt. und daher in einem engeren Zusanmenhange mit dem Buchenwachstum zu stehen scheint. Ebermayer ${ }^{3}$ ) fand für den Phosphorsäuregehalt des Buchenstammholzes im Durchschnitt von der Wurzel bis zur Krone das Verhältnis von 0,53 auf 1000; unsere Sihlwalderde hat zwischen $0,40-0,75$ oder durchschnittlich 0,63 .

Da der Phosphorsäuregehalt des landwirtschaftlichen Kulturbodens für dessen Güte von bestimmendem Einfluss ist, darf die identische Schlussfolgerung wohl auch mit Bezug auf die Walderde und speziell auf den eigentlichen Buchenboden gezogen werden.

\footnotetext{
1) Siehe p. 20 und 21.

2) Dr. Moriz Willkomm: Forstliche Flora von Deutschland und Oesterreich.

3) Dr. Ebermayer: Die gesimte Lehre der Waldstren 1). 110-111.
} 
Das mechanische Mengungsverhältnis des Sihlwaldbodens charakterisiert sich durch den überraschend grossen Feinerdegehalt. Unzweifelhaft steht dieser Umstand mit der Prosperität der Buche im engsten Zusammenhang. Welche Ursachen dagegen ảen Wachstums-Abweichungen innerhalb der vier für die Taxation aufgestellten Bonitäten zugrunde liegen, ist schwer zu entziffern. Der sandige Lehm des Untergrundes und Obergrundes zeigt überall eine sich wenig voneinander unterscheidende, lose Beschaffenheit. Je mehr er sich nach oben dem eigentlichen Wurzelraum nähert, desto aufgeschlossener erweist er sich. Je stärker die Beimengung glacialen Schuttes, desto reichhaltiger ist alsdann die Bestandesmischung. In eben dem Masse, als diese abnimmt, treten die Ahorne, Esche und Ulme aus der Bestandesmischung zurück und die Buche bleibt alleinige Bestandesbildnerin. Es tritt diese Erscheinung namentlich überall an den der Sihl zugekehrten Ausläufen des mittleren Sihlwaldplateaus zutage. Bemerkenswert ist, dass die grösste Zuwachsziffer keineswegs mit der stärksten Humusschicht zusammenfällt, sie scheint vielmehr von der Mächtigkeit und Beschaffenheit des Untergrundes im ganzen abhängig zu sein.

Wenn es demnach schwer hält, die der Prosperität der Sihlwaldbuche zugrunde liegenden Faktoren ausschliesslich aus der Bodenbeschaffenheit abzuleiten, so ist dieses nicht weniger mit dem Faktor Exposition der Fall. Wäre der vielfach aufgestellte Satz: dass die Buche vornehmlich die südüstlichen Lagen aufsuche. richtig. so miisste im sihltal eine nicht geringe Zahl örtlicher Abweichungen von dieser Exposition, ein weniger frohwüchsiges Vorkommen der Buchen aufweisen, als es tatsächlich der Fall ist. Oestliche Lagen gelten im allgemeinen als die der Buche am meisten zusagenden und es ist auch die allgemeine Exposition des Sihlwaldes allerdings zum grösseren Teil eine östliche-südöstliche. Allein der jenseitige westliche Hang des Albisberges, der mit dem sogenannten Hauserwald überdeckt ist, zeigt ein nicht minder kräftiges Gedeihen des Buchenhochwaldes, als der östliche-siidöstliche Sihlwaldhamg. End wenn Kerner nachweist, dass an den südöstlichen Hängen vermöge der Einwirkung der Insolation durchschnittlich eine höhere Bodentemperatur konstatiert werden könne, welche ihrerseits mit dem Gedeihen der Buche im innigsten Zusammenhang stehe, so kann eine ähnliche Schlussfolgerung mit Bezug auf die Art und Weise des Auftretens der Buche in den Stadtwaldungen von Zürich nicht abgeleitet werden. Mehr als das geographische, macht wohl 
das örtliche Klima, vorab dessen Niederschlagsmenge, seinen Einfluss auf die vorhandene Flora der Laubhölzer, speziell der Buche geltend. Es liegt die Möglichkeit vor, zwei bis drei Stunden auseinanderliegende Komplexe mit ganz veränderter geographischer Lage, mit Bezug auf ihre Niederschlagsmengen zu vergleichen: den Adlisberg-Komplex einerseits, den Sihlwald und den Hauserberg anderseits. Indem das Vorkommen der Buche an diesen zwei Orten ein total verschiedenes ist, kann diese Erscheinung weder der Bodenbeschaffenheit, noch der Exposition zugeschrieben werden. Dagegen zeigt sich zwischen diesen beiden Gruppen eine sehr erhebliche Differenz der Niederschlagsmengen und zwar in dem Sinne, dass die Komplexe am Albis, welche günstigere Zuwachsverhältnisse der Buche zeigen, eine grössere Regenmenge, der Adlisberg mit seinem weniger günstigen Auftreten der Buche, eine erheblich niederere Niederschlagsquote aufweist, so dass eine unleugbare Kongruenz der beiderseitigen Differenzen zutage tritt.

Wir lassen hier die während vier Jahren gesammelten Notierungen für die Sommermonate und sodann die Regentabelle des Sihlwaldes $1877-1900$ folgen:

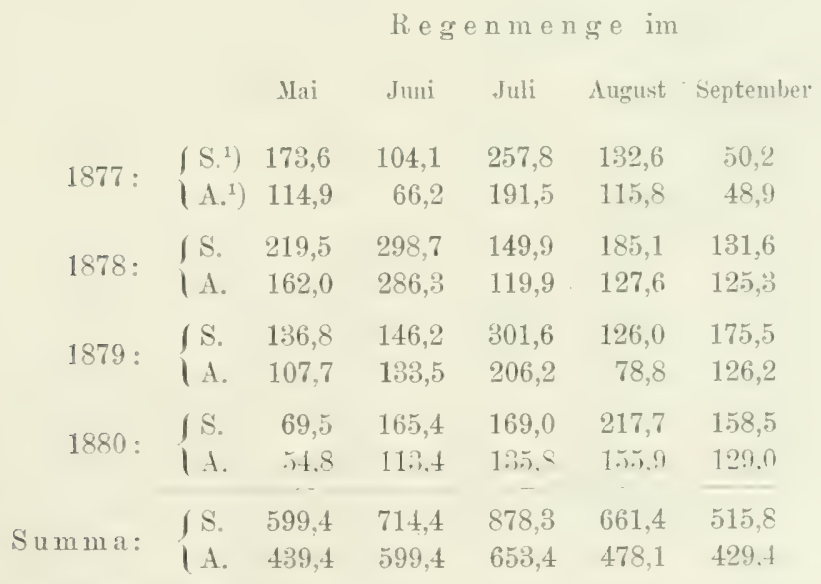

Durchschnittl. Differenz zurischen

Sihlwald und Adlisberg: $\left.\quad 40,0 \quad 29,0 \quad 56,2 \quad 45,8 \quad 21,6^{2}\right)$

1) $\mathrm{S}=$ Sihlwald, $\mathrm{A}=$ Adlisberg.

2) Die vergleichenden Notierungen wurden nicht weiter fortgresetzt. 
Regen-Tabelle für den Sihlwald.

\begin{tabular}{|c|c|c|c|c|c|c|c|c|c|c|c|c|c|c|c|}
\hline Jahr & 竎 & 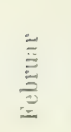 & $\stackrel{E}{E}$ & 焉 & 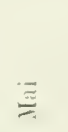 & 主 & 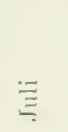 & 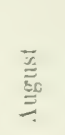 & 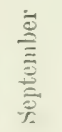 & 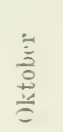 & 䓂 & 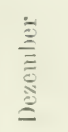 & $\begin{array}{c}\mathrm{Reg} \\
\text { mence }\end{array}$ & $\begin{array}{l}\text { tal } \\
\text { e } 11- \\
\text { tage }\end{array}$ & 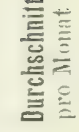 \\
\hline & $\mathrm{mm}$ & $\mathrm{mm}$ & $\mathrm{mm}$ & $\mathrm{mm}$ & $\mathrm{mm}$ & $\mathrm{mm}$ & $\mathrm{mm}$ & $\mathrm{mm}$ & $\mathrm{mm}$ & $\mathrm{mm}$ & $\mathrm{mm}$ & $\mathrm{mm}$ & $\mathrm{mm}$ & Zahl & \\
\hline 877 & 54 & 138 & 122 & 220 & 174 & 104 & 258 & 133 & 50 & 86 & 109 & 131 & 1579 & 175 & \\
\hline 878 & 115 & 49 & 124 & 164 & 219 & 299 & 150 & 185 & 132 & 94 & 73 & 130 & 1734 & 184 & \\
\hline 879 & 5. & 182 & 46 & 154 & 137 & 146 & 302 & 126 & 175 & 98 & 140 & 45 & 1604 & 158 & \\
\hline 880 & 24 & 50 & 29 & 221 & 70 & 165 & 169 & 218 & 159 & 247 & 44 & 137 & 1533 & 144 & \\
\hline 881 & 42 & 70 & 110 & 157 & 95 & 175 & 63 & 304 & 311 & 133 & 23 & 32 & 1515 & 160 & \\
\hline 882 & 35 & 39 & 53 & 122 & 146 & 348 & 213 & 188 & 301 & 181 & 249 & 157 & 2032 & 183 & \\
\hline 883 & 57 & 62 & 60 & 109 & 190 & 235 & 302 & 106 & 156 & 161 & 154 & 87 & 1679 & 171 & \\
\hline 884 & 46 & 102 & 29 & 63 & 126 & 227 & 216 & 194 & 97 & 57 & 40 & 116 & 1313 & 145 & \\
\hline 88.5 & 11 & 110 & 108 & 81 & 254 & 92 & 124 & 82 & 197 & 253 & 108 & 127 & 1547 & 159 & \\
\hline 886 & 53 & 51 & 73 & 118 & 79 & 209 & $2 \mathrm{i} 1$ & 261 & 110 & 92 & 93 & 144 & 1494 & 144 & \\
\hline 887 & 8 & 9 & 107 & 92 & 134 & 54 & 245 & 117 & 152 & 49 & 37 & 121 & 1125 & 136 & \\
\hline 1888 & 29 & 56 & 112 & 139 & 45 & 175 & 246 & 185 & 223 & 104 & 85 & 18 & 1417 & 151 & \\
\hline 1889 & 20 & 114 & 55 & 75 & 94 & 174 & 166 & 150 & 133 & 158 & 76 & 32 & 1247 & 151 & \\
\hline 1890 & 49 & - & 41 & 102 & 153 & 188 & 166 & 334 & 66 & 156 & 81 & 7 & 1343 & 131 & 12 \\
\hline 1891 & 31 & 8 & 95 & 105 & 134 & 138 & 314 & 232 & 158 & 91 & 123 & 160 & 1589 & 143 & \\
\hline 1892 & 70 & 112 & 28 & 80 & 50 & 185 & 275 & 147 & 262 & 221 & 82 & 40 & 1552 & 143 & 30 \\
\hline 1893 & 62 & 72 & 33 & - & 143 & 133 & 127 & 33 & 101 & 90 & 107 & 30 & 931 & 122 & \\
\hline 1894 & 30 & 73 & 40 & 63 & 127 & 90 & 211 & 136 & 125 & 85 & 34 & 69 & 1083 & 144 & 0 \\
\hline 1895 & 71 & 27 & 110 & 90 & 108 & 135 & 59 & 145 & 18 & 116 & 94 & 162 & 1135 & 125 & \\
\hline 1896 & 14 & 51 & 187 & 179 & 125 & 147 & 125 & 142 & 207 & 138 & 51 & 49 & 1415 & 144 & 117 \\
\hline 1897 & 22 & 165 & 87 & 111 & 133 & 124 & 128 & 248 & 297 & 21 & 14 & 39 & 1389 & 116 & 115 \\
\hline 1898 & 12 & 176 & 67 & 122 & 190 & 204 & 107 & 101 & 33 & 120 & 102 & 54 & 1288 & 149 & 108 \\
\hline 1899 & 123 & 35 & 10 & 166 & 105 & 51 & 88 & 81 & 138 & 85 & 21 & 78 & 981 & 129 & \\
\hline 1900 & 155 & 117 & 79 & 81 & 138 & 108 & 203 & 130 & 46 & 75 & 63 & 71 & 1269 & 155 & 105 \\
\hline
\end{tabular}

De Candolle stellt in seiner Géographie botanique pag. 177, 237 den Satz auf, dass das Vorkommen und die geographische Verbreitung der Buche im höchsten Grade abhängig sei von der Anzahl Regentage und der gefallenen Regenmenge. Auch Moriz Willkomm findet in seiner forstlichen Flora von Deutschland und Oesterreich diese Erscheinung zutreffend. Es könnte nun auf den ersten Blick gesucht erscheinen, die Wachstumsdifferenzen der Buche bei so geringer geographischer Differenz der örtlichen Lage, wie es hier der Fall ist, mit diesen Erscheinungen im grossen in Verbindung bringen zu wollen. Allein es dürfte doch das sich hier bietende Zusammentreffen von Ursache und Wirkung mehr denn ein blosser Zufall sein, und alle Veranlassung bieten, die angeführten meteoro- 
logischen Einwirkungen auf die Buche als ursächliche Bedingung der Art und Weise des Vorkommens dieser Holzart aufzufassen.

Als eine ungelöste Frage konstatieren wir im Anschluss an die Betrachtungen über die Buche das Vorkommen zweier Varietäten dieser Spezies: der sogenannten Steinbuche und der Schwarzbuche. Erstere charakterisiert sich äusserlich durch ihre länglich zerrissene Rinde, in der 'Textur des Holzes durch das Fehlen des Spiegels, d. h. der diesfälligen Markstrahlen und durch eine viel grössere Elastizität. Die Schwarzbuche kennzeichnet sich durch die gan\% glatte, aber durchweg intensiv schwarz gefärbte Rinde und durch die dem Exterieur der Haimbuche verwandte Gliederung der Gitfässhündel in striemenartige Wülste, so dass der Stamm nirgends die regelmässige glatte Form der gewöhnlichen Buche zeigt. Auch hier ist das Holz zäher, als bei der normalen Buche, gilt jedoch als brüchiger denn dasjenige der Steinbuche.

Von den Ahornarten zeigt Acer pseudoplatanus das verbreitetste Auftreten, obschon auch Acer platanoides in relativ ungewöhnlich starkem Masse auftritt. Mit den Eschen und Ulmen liebt der Ahorn vorzugsweise humusreiche Mulden und einen mit Trümmergestein stark vermengten Boden, unterscheidet sich aber in seinem Auftreten von diesen beiden Arten, sowie von demjenigen der Buche dadurch, dass sein Höhenzuwachs mit demjenigen der Buche, Esche und Ulme nicht Schritt zu halten vermag. Mit dem Alter von $50-60-70$ Jahren macht sich das Absterben einer stetig zunehmenden Individuenzahl infolge mangelnder Lichteinwirkung hemerkbar. Ahorne mit Stärkeverhältnissen, welche denjenigen der genannten Holzarten entsprechen, kommen daher nicht vor, und Durchmesser von über $40 \mathrm{~cm}$ bei Brusthöhe gehören zu den äussersten Seltenheiten. Sollten vielleirht hier Fenchtigkeitsgrad und Nieder:chlagsmenge eine entgegengesetzte Wirkung ausüben als bei der Buche?

Das Auftreten des Bergahorns ist ein viel verbreiteteres, als das des zierlichen Spitzahorns; insbesondere macht sich bei dieser letzteren Art mit der zunehmenden vertikalen Erhebung eine rasche Abnahme bemerkbar. Die Anforderungen an die Luft- und Lichteinwirkung sind grösser, die schattenertragenden Eigenschaften geringer als bei dem Bergahorn. Der stärkere Höhenwuchs der Buche und ihre daraus entspringende Verdämmung der übrigen Holzarten, speziell der Ahorne, macht sich deshalb auch bei dem Spitzahorn noch in wahrnehmbarerer Weise geltend. Die unbedingte Unempfindlichkeit der beiden Ahornarten gegen die Spätfröste mildert an 
und für sich die prädominierende Tendenz der Buche. Die gegen den Frost äusserst empfindlichen Buchen und Eschen bleiben infolge der häufigen Frostschädigungen, die in den tieferen Lagen eintreten, etwas zurück und lassen den Ahornarten, speziell dem Spitzahorn, dadurch einen Vorsprung, der trotz dem später schnelleren Wachsturn der Buche nicht mehr nachgeholt wird. Aus dieser Erscheinung erklärt sich wohl auch das überwiegende Auftreten des Spitzahorns in den tieferen Lagen.

Die Ulme ist stellenweise, insbesondere in feuchten, humosen Mulden zahlreich vertreten. Sie ist weniger lichtfordernd als die Esche und Ahorne und hält im Höhenwachstum eher mit der Buche Schritt. Wo sie daher in einem ihr konvenierenden Standort in die späteren Bestandesalter forterhalten wird, erwächst sie zu einem äusserst stattlichen Baume, dessen Maximal-Durchmesserstärken grösser sind, als die der Ahorne, ohne dass hiebei die Höhe der Buchen und Eschen erreicht würde. Charakteristisch für die Art ist die Erscheinung, dass auch hier mitten in den Laubholzjungwüchsen des Sihlwaldes der sperrige Wuchs der Ulmen, der die Verdämmung der anderen Holzarten in so hohem Masse bedingt, in gleicher Weise zutage tritt, wie in den Nadelholzwaldungen. Die Laubwaldungen des Adlisberges enthalten weit weniger Ulmen als die des Sihltales, während das Mischungsverhältnis der Ahorne an beiden Orten ein sehr starkes ist. Unzweifelhaft verlangt die Ulme eine bedeutende Luft- und Bodenfeuchtigkeit: denn sie ist am stärksten vertreten, wo man diesen beiden Faktoren in ausgesprochener Weise begegnet.

Die Esche ist in sümtlichen Stadtwald-Komplexen, sogar im Nadelholzbestand des Forstes stark vertreten. Die qualitativ und quantitativ günstige Art und Weise dieses Auftretens, speziell in den Sihlwaldungen ist eine vielleicht selten vorkommende. Wo der Boden irgend hinreichende Frische zeigt, ist die Esche in den Jungwüchsen, in den schattigen Mulden wie in den offenen Halden, in den Lagen zunächst der Sihl wie am oberen Albisrücken, nahezu prädominierend, und die Wirtschaft hat bei den Durchforstungen andauernde Obsorge zu verwenden, dass ein allen Anforderungen entsprechendes Mischungsverhältnis aller Laubhölzer erzielt werden kann. Eine nicht geringe Zahl von Lokalkomplexen nennt sich gemäss der Jahrhunderte hindurch erhaltenen Bestockung mit Eschen, so der Eschentobelbach, das Spiessenhauertobel, wo im 13. bis 16. Jahrhundert die Schäfte für die Hauptwaffe des schweizerischen 
Fussvolkes gehauen wurden. Die Esche hält mit der Buche im Höhenwachstum vollständig Schritt, und erreicht ihr grösstes Maximum nur wenig frïher als die Buche. Nach den allerdings noch nicht hinlänglich genau belegten Erhebungen fällt dasselbe in das 65. Jahr. Von da an leidet sie dann von der Verdåmmung durch die Buche, und mit dem Momente, wo der Lichteinfluss ein behinderter zu werden beginnt, wo die Beastung sich nicht mehr entwickeln kann, tritt ein rasches Abnehmen des Stärkezuwachses ein. Es dürfte fortdauernden Untersuchungen gelingen, diese Rückwirkungen von relativer Bestanddichtigkeit und Bestandeshöhe auf den Stärkezuwachs gesetzmässig zu statuieren und dadurch den wirtschaftlichen Grundsatz abzuleiten, 1) dass der Torhieb in den Sihltallaubholabeständen mit dem Momente zu beginnen habe, wo das Maximum des Höhezuwachses der Esche erreicht ist, und 2) dass Eschen, Ahorne und Ulmen im allgemeinen in die Kategorie der Vorhiebhölะer fallen sollten.

Als eine eigenartige Erscheinung der Stadtwaldungen von Zürich ist zu konstatieren, dass einer der geschätztesten Repräsentanten des Laubholzwaldes, die Eiche, nur sehr spärlich in den hiesigen Bestandesmischungen vertreten ist. Wir begegnen allerdings überall, sowohl im Sihltal als auf dem Adlisber'g, einzelnen Vertretern dieser Holzart und zwar ganz unabhångig von dem Einflusse verschiedener vertikaler Höhenlagen oder Expositionen. Die Eiche lindet sich noch auf dem Albiskamm bei $900 \mathrm{~m}$, wenn auch etwas kürzer wie unten in der Sihlniederung bei $480 \mathrm{~m}$ und zwar meist in Form von Quercus pedunculata. Der lockere, mineralisch kräftige Lehm mit seiner grossen Bodenfrische scheint ihr zu behagen, dagegen mag die starke Einmischung mit Buche und deren kräftiges Gedeihen, ihrer Verbreitung auf die Dauer unbedingte Hindernisse in den Weg legen. Dass diese Erscheinung sich nicht erst in neueren Zeiten, sondern bereits auch in früheren Jahrhunderten geltend machte, geht teilweise aus Aufzeichnungen hervor, teilweise wird dieselbe auch illustriert durch die auffällige Tatsache, dass das zur Zeit noch in der Limmat stehende, im Jahr 1396/991') erbaute Rathaus in Zürich auf Buchenpfähle, die nur dem Sihlwald entnommen sein konnten, gestellt wurde. Es kann doch wohl nur dem Mangel an Eichenholz zuzuschreiben sein, dass das weniger

1) Vergl. das alte Zürich von Sal. Vögelin, Heft 4, p. 172, und G.v. Wyss, eine Züricher Chronik aus den 15. Jahrhundert p. 19. 
dauerhafte Buchenholz hier, im Gegensatz zum Eichenholz, Verwendung gefunden hat!

Im Jahre 1792 wurde an irgend einer, leider nicht genannten Stelle des Sihlwaldes, eine grössere Einpflanzung von Eichen ausgeführt; aber schon heute ist es unmöglich, Spuren hievon in irgend einer Altersklasse zu finden.

Offenbar lässt sich diese ganze Erscheinung auf nichts anderes, als auf das prädominierende Auftreten der Buche zurückführen. Die lichtfordernde Eiche wird von der Buche im Wachstum überholt und es gelingt infolgedessen nur einzelnen wenigen Individuen in dem Kampf ums Dasein die Oberhand zu behaupten, wenn nicht äussere Einwirkungen die rasche Entwicklung der Buche beeinträchtigen. Dies ist der Fall in den unteren Terrassen des Sihlwaldes, welche häufigen Spätfrostschaden aufweisen: hier bleibt dann die empfindliche Buche zurück, und die Eiche, der Ahorn, die Hainbuche und die Ulme, welche weniger vom Froste leiden, benutzen alsdann dieses Vorkommnis, um ihrer Schwester den Rang abzulaufen. Nicht minder ungünstig mag sich für lie Eiche anch der kurze Verjüngungszeitraum der Samenschläge und die dunkle Haltung der Buchenlichtschläge erweisen.

Im Adlisberg, wo das Gedeihen der Buche ein weniger üppiges, die Belaubung in der Regel eine weniger dichte ist, tritt die Eiche quantitativ und qualitativ viel bedeutsamer auf.

Die Hainbuche ist noch spärlicher vertreten in den Stadtwaldungen als die Eiche; zudem ist das Vorkommen dieser Holzart auf wenige Komplexe lokalisiert. Sie ist nur zu treffen in den untern Lagen des Sihitales und zwar meist auf Schuttkegeln früherer Bäche und gleichzeitig da, wo Spätfröste die rasch aufwachsenden Buchen und Eschen etwas zurückbehalten in dem Verdämmungsprozess, der sich vollzieht und fortsetzt, sobald die Buche wieder ungehindert ihrem gewöhnlichen Entwicklungsgang folgen kann. In der Höhe von $700 \mathrm{~m}$. wo sich die Hainbuche im Adlisberg noch aufhält, findet sich dieselbe im Sihltal nicht mehr.

Massholder, Linde, Birke, Schwarz-, Weisserle, Sahlweide, Aspe und der wilde Kirschbaum finden sich in verhältnismässig äusserst untergeordnetem Mengeverhältnisse vor. I lie Jahrhunderte hindurch andauernde Bestandespflege der. Sihltalwaldungen mit ihren konsequent durchgeführten säuberungen und Reinisungshieben in den jungen Beständen, der fortwährend gegen alles, was nicht Buche, Esche oder Ahorne hiess geführte Kampf. gestatteten den sogenamnten Weich- 
hölzern nicht, das Terrain dauernd in Beschlag zu nehmen und nur da, wo infolge zu entfernter oder unzugänglicher Lage die Bestandespflege weniger intensiv ausgefülnrt wurde, ist ihr Vorkommen zu konstatieren. Wo hingegen Ankäufe von Privatwaldungen gemacht worden sind, findet sich meistens ein buntes Konglomerat aller Holzarten, in welchem die obengenannten Arten nicht unwesentlich vertreten sind. So in den Abteilungen 3 und 4 des Adlisberges, in den angekauften Risletenhölzern und den Gütern des rechten Sihlufers, Stengeln, Tableten und Steinmatt.

Die in den zwei letzten Dezennien eingeschlagene Wirtschaftsführung der städtischen Waldungen hat sich von dem exklusiven Verhalten gegenüber den sogenannten Weichbölzern emanzipiert. Mit der Tendenz, den Reinertrag der Waldungen durch eine intensive Sortimentswirtschaft zu heben, ist die Erziehung wertvoller Birken-, Aspen-, Kirschbaum- etc. Sortimente nicht bloss vereinbar, sondern im Gegenteil angezeigt. Speziell der Kirschbaum crwächst im Sihltal zu schönen langschäftigen. der Nutzholzverwertun: (Wöhelschreinerei) sehr günstigen Exemplaren.

Die Nadelhölzer, welche in ihrer örtlichen Verbreitung ein verschiedenartiges Verhalten an den Tag legen, sind in erster Linie durch die Fichte repräsentiert. Diese Holzart tritt speziell auf den Moränerücken und in den reinen Nadelholzbeständen des rechten Sihlufers in äusserst langschäftiger, vollholziger Form nuf und zeigt hier grosse Tendenz zum Ausharren in dichtem Bestandesschluss. Ihr Holz ist dabei äusserst feinjährig, für Schnittwaren von vorzüglicher Qualität und daher sehr gesucht. Die Fichten des linken Sihlufers, welche inmitten des Buchenhochwaldes aufwachsen, erreichen als Einzelindividuen wohl äusserst starke Dimensionen. zeigen indessen hiebei kleinere Formzahlen, einen weniger geraden Wuchs und eine gröbere Textur des Holzes, als die der rechtsufrigen Bestände. Nur in den oberen Lagen des linksufrigen Sihltales, in den Sihlwaldbeständen der Höhen zwischen 800 und $900 \mathrm{~m}$ der Abteilungen $\mathrm{Nr}, 2,3$ und 19 nähert sich das Auftreten der Fichte wieder mehr demjenigen der rechtsufrigen Bestände und zwar charakterisiert es sich durch vermehrte Tendenz zur geschlossenen Bestandesbildung und zu reinschäftigerem Wuchs. Die Fichte nimmt hier vollständig den Habitus der Bergregion an, in eben dem Masse als die. Ueberreste glacialen Schuttes dem Boden selbst verwandte Eigenschaften verleihen. Die Anlage neuer Fichtenbestände, sei es durch Saat oder Pflanzung, begegnet sowohl im lufteuchten Sihltal. 
wie auf dem trockenen Albisberg wenig Schwierigkeiten. Mit Ausnahme der Spätfröste erleiden die jungen Aufwüchse wenig Angriffe, so dass die auf dem Wege des künstlichen Holzanbaues angesiedelten Fichten ein durchaus günstiges Gedeihen auch für die $\mathrm{Zu}-$ kunft versprechen, sofern sie nicht erste Anpflanzungen auf Wiesboden sind, wo sie im 40. - 50. Jahr meistens von Rotfäule (Trametes radiciperda) befallen werden.

Die natürliche Verjüngung der Fichte wird einerseits durch die häufigen Samenjahre erleichtert. ander'seits durch das rasche Nachdrången des Laubholzes erschwert. Wo der Boden für letztere weniger günstig ist, macht. sich sofort ein stärkerer Fichtenanflug bemerkbar.

Die Weisstame tritt eher zahlreicher und in Begleit von nicht weniger günstigen Wachstumserscheinungen auf als die Fichte. Sie verhält sich mit Bezug auf ihre Ansprüche an Lage und Boden ähnlich wie diese, wenn sie auch im allgemeinen mehr die frischeren und feuchten Bodenpartien für sich in Beschlag nimmt. Auffallend bleibt. dass sie, obschon schattenertragender und in der Jugend schattenfordernder als die Fichte, gegenüher dem prädominierenden Einflusse der Buche sich dennoch keineswegs widerstandsfähiger erweist als erstere. So finden sich z. B. in der schönsten, langschäftigsten und geschlossensten Buchenpartie des Sihlwaldes in Abteilung 8, Birriboden, unter den dort vorhandenen Nadelhölzern nur sehr wenige Weisstannen, wohl aber vorwiegend Fichten; umgekehrt tritt dann im Adlisberg die Tanne in den Vordergrund.

Die Föhre, Pinus silvestris, ist im eigentlichen Forst wohl ein von jeher angesiedelt Bar Bau, dem durch den seit bald zwei Jahrhunderten erfolgten künstlichen Anbau vermehrte Verbreitung und vermehrte Bedeutung gegeben wurde. Auch in den jüngeren Beständen der Risleten und des Adlisberges hat sie anlässlich der Aufforstung angekaufter Hofgüter starke Verbreitung gefunden. Im eigentlichen Sihlwald fehlt sie dagegen fast ganz, und wo sie noch erscheint, zeigt sie im Gegensatz zur Lärche, die inmitten der reinen Buchenbestinde eine ausserordentlich günstige Entwicklung aufweist, keineswegs ein frohwüchsiges frisches Gedeihen. Offenbar unterliegt die Kiefer, ähnlich wie die Eiche in der Mitbewerbung um Licht und Boden der rasch aufstrebenden Buche.

Die reinen Föhrenbestände, welche in den letzten zwei Dezennien angelegt worden sind, haben in bedeutendem Masse durch Schneedruck gelitten und gestatten bis zur Stunde nicht das 
günstige Urteil über ihre zukünftige Entwicklung, wie die jungen Fichtenpflanzungen.

Die Lärche ist keine autochthone Baumart des Sihlwaldes: sie wurde in der Mitte des 18. Jahrhunderts durch Saat und Pflanzung daselbst heimisch gemacht. Zirka im Jahre 1737 soll die erste Lärchen- und Föhrensaat gemacht worden sein, denn nach einer Bestandesbeschreibung vom Jahre 1797 fanden sich in einer Abteilung des Forstes bereits «20-60jährige Föhren und Lärchen und Tannen». Bestimmter nachweisbar ist indessen eine Lärchensaat von 1771. Die Lärche gedeiht sowohl auf dem rechten, wie auf dem linken Sihlufer in befriedigender Weise, sobald sie in Untermischung mit anderen Hölzern, speziell mit Buchen gebracht ist. In reinen Beständen zeigt sie dagegen das gleiche iible Verhalten wie anderwärts und zwar gleichmåssig in der Höhe von $480 \mathrm{~m}$ wie bei $850 \mathrm{~m}$. Ihr Wachstumsgang ist am günstigsten in den Beständen mit südlicher und südöstlicher Exposition. Sie überragt hier an Höhenwachstum dauernd alle anderen Holzarten. Dagegen steht sie im Dickenwachstum hinter der Kiefer und der Weisstanne zurück. Das Holz der im Sihltal gewachsenen, im Alter von 90-100 Jahren geschlagenen Lärchen, ist demjenigen der Lärchen des Bündnerlandes nicht gleichwertig. Auffällig ist das geringe Samenproduktionsvermögen der Lärche und die damit verbundene schwierige natürliche Verjüngung dieser Holzart.

In den vierziger Jahren wurden nicht unerhebliche Aufforstungen von Pinus austriaca gemacht. Bis zur Stunde zeigt diese Holzart kein anderes, geschweige denn ein günstigeres Verhalten als die gewöhnliche Pinus silvestris. Eingepflanzte Pinus strobus, zur Zeit im Alter von 40-50 Jahren stehend, scheinen sich im allgemeinen in dem geschlossenen dichten Schluss unserer Nadelholzbestände nicht ganz wohl zu befinden. Es verlangt diese Holzart offenbar eine grössere Lichteinwirkung.

Weitere Versuche mit dem Einbau exotischer Holzarten wurden in den Stadtwaldungen grundsätzlich nicht vorgenommen. Ohne geradezu absoluter Gegner der diesen Einbau begünstigenden Richtung zu sein, halten wir dafür, dass in emer ausgesprochenen Zuchtwahl der in unseren Standorten heimischen Holzcurten grössere Erfolge für die Steigerung der Rentabilität unserer Waldungen zu erzielen wären.

Vereinzelt, wenn auch eher auf dem Aussterbeetat stehend, tritt die Eibe, Taxus baccata, auf; auffallenderweise nicht in den 
starken. langschäftigen Exemplaren, wie im unteren Teil des Sihltales, und überall stark verdämmend wirkend.

Des Vorkommens der Pinus montana ist bereits Erwähnung getan. Es ist dasselbe indessen mehr als eine botanische, denn als rein forstlich wichtige Erscheinung zu würdigen, indem sich keineswegs irgend eine forstliche Massregel auf dieses Vorkommen gründet oder zurückführen lässt. Die Bergfichte schmückt die steilen Abbrüche der Molassefelsen und Mergelbänder und trägt dadurch in bescheidenem Masse zu etwelcher Befestigung des Bodens bei.

Aus der Klasse der Forstunkräuter sind vornehmlich drei Repräsentanten zu erwähnen, die stellenweise dem Forstbetriebe ernstliche Schwierigkeiten bereiten: Epilobium angustifolium, das hochaufschiessende Herbstweidenröschen, sodann Rubus fruticosus, die strauchartig wuchernde Brombeere, und endlich Clematis vitalba, die wilde Waldrebe (Niele), die in den Jungwüchsen vielfach waldzerstörend auftritt. Die beiden erstern machen sich wesentlich an lückigen, vernässten Stellen, wo der Bestandesschluss vor der Verjüngung lange durch Schneedruck, Windfall etc. unterbrochen war, hemerkbar und hereiten der künstlichen Bestandesnachbesserung wie der natürlichen Verjüngung vielerlei Schwierigkeiten. Im übrigen aher sorgt die rasche Entwicklung des natülichen Holzaufschlages bei richtiger Bestandesverjüngung von selbst dafür, dass der Waldbestand das Terrain siegreich $\mathrm{zu}$ behaupten weiss und die Forstunkräuter in den Hintergrund treten.

Am liebsten deckt sich der Boden der Buchenwaldungen mit dicht üppigem Aufwuchs des wilden Knoblauches, Allium ursinum und als Nachwirkung des früheren Vorherrschens der Nadelhölzer bildet heute noch der Saurklee, Oxalis acetosella, den Schmuck des Sihlwaldes. Die der Verjüngung anderwärts so sehr in den Weg tretende Heidelbeere, Vaccinium myrtillus, ist nur auf einzelnen geringeren Partien des Forstes und Sihlwaldes in etwas stärkerer Zahl vorhanden. 


\section{Klima.}

Das Klima, welches in Verbindung mit Lage und Boden 'Veranlassung zu dem erwähnten günstigen Stand der Vegetationsverhältnisse in den Stadtwaldungen von Zürich gibt, darf im allgemeinen als ein mildes, und soweit es speziell die Sihltalwaldungen betrifft, als ein feuchtes bezeichnet werden. Die dem Zürichsee parallele Richtung des Sihltales, verbunden mit dem Umstand, dass dieses Längstal eine offene Abzweigung für die grosse Föhnrichtung aus dem Reusstal bildet, sichert dieser Windströmung als der vorherrschenden, einen grossen und zugleich günstigen Einfluss auf die Vegetationsverhältnisse der Sihltalwaldungen zu. Zudem bildet der linksufrige Seerücken einen bedeutsamen Schutz gegen die rauhen, trockenen Nordostwinde. So kommt es denn, dass der Winter des Sihltales weder streng noch rauh ist. Es fallen wohl mitunter grössere Schneemassen als in Zürich und berwirken als solche beträchtlichen Schaden, wie z. B. Anno 1858; allein der Frühling erscheint doch ziemlich früh und die mittlere Temperatur ist im Vergleich zu anderen Lagen eher eine günstigere, was fortgesetzte phänologische Aufzeichnungen dartun werden.

Wie anlässlich des Auftretens der Buche bereits erwähnt wurde, ist die Anzahl der Regentage im Sihltale eine verhältnismässig sehr grosse und eine grössere als im Adlisberg. Mag man nun diese Erscheinung als Rückäusserung des grossen Waldareals oder als den Ausfluss der konstant auftretenden Luftströnung sï̈west nach Nordost, welche in der Richtung Pilatus-Hörnli das Sihltal quer durchschneidet, zurückführen, soviel steht fest, sie erweist sich für die Holzproduktion sehr günstig und hilft wesentlich mit dazu, in Verbindung mit den günstigen Borlenverhältnissen einer geordneten Forstwirtschaft reichen Erfolg zu sichern. Hagelschaden ist nur in den obersten Lagen des Albishanges hie und da zu konstatieren, während er dagegen in der unteren Talsohle zu den grössten Seltenheiten gehört.

Grosse verheerende Wolkenbrüche gehören ebenfalls zu den selteneren Erscheinungen. Thre schädliche Wirkung wird zudem durch die intensive Bewaldung gemildert.

Kältegrade, welche für einzelne Holzarten zu empfindlich waren, sind bis zur Stunde nicht nachweisbar, da selbst im strengen Winter 1879/80 weder Buchen noch Ahorne gelitten haben und 
aus dieser Zeit nur mit Bezug auf die Esche ein Reissen oberhalb des Wurzelstockes zu konstatieren ist. Der grossen Disposition einzelner Partien der Talsohle und des ersten Plateaus für Spätfröste ist bereits Erwähnung getan.

Weitaus die gefährlichste aller atmosphärischen Einwirkungen speziell der Sihltalwaldungen ist diejenige des Schneedruckes und zwar speziell der in das Spätjahr und den Vorwinter fallenden Schneeniederschläge. Zufolge der hohen Bergwand des Albis und der Höhenlage des Sihltales überhaupt macht sich im Spätjahr stärker als anderswo ein Sinken der Temperatur bei grossem Feuchtigkeitsgehalt der Luft fühlbar. Sobald diese Temperatur bis auf $4^{\circ} \mathrm{C}$. über den Gefrierpunkt sinkt, erfolgen die Niederschläge in Form von Schnee.

Der verhängnisvollste meteorologische Akt dieser Art war der Schneefall vom 28. September 1885. An diesem Tage brauste jener unheilvolle, von Nordwest nach Südost sich ziehende Schneesturm daher, der durch seine furchtbare Wirkung über 100 Hektaren schönster Buchenwaldbestände absolut zerstörte und im ganzen übrigen Wald Schädigungen hervorrief, welche die bisher so geregelte Wirtschaft sistierten und den durch eine Jahrhunderte hindurch dauernde sorgfältige Pflege erreichten Normalstand des Sihlwaldes mit einem Schlage zertrümmerten.

Die meteorologische Station beim Forsthaus Sihlwald notierte am 28. September, vorm. $10^{1} / 4 \mathrm{Uhr}$, bei $+3{ }^{0} \mathrm{C}$. heftiges Schneegestöber. Es dauerte bis gegen abends $8 \mathrm{Uhr}$ fort und löste sich nachher in Regen auf, der bei einer Schichthöhe von 30 und mehr en Schnee für sich eine Niederscillagsmenge von $58 \mathrm{~mm}$ lieferte und bis früh morgens 7 Uhr am 29. eine Gesamtniederschlagsmenge von $70,8 \mathrm{~mm}$ ergab. Das rasche Sinken der Temperatur bewirkte ein Anhaften des Schnees an den Blättern, so dass sich eine stetig wachsende Last auf den Kronen ablagerte. Im obern Sihlwald, wo leider keine meteorologische Kontrollstation zur Konstatierung der gefallenen Schneemassen zur Verfügung stand, war dieselbe dem angerichteten Schaden zufolge unzweifelhaft noch grösser als im untern Sihlwald. Ein warmer, neue Feuchtigkeit zuführender Luftstrom von Südost musste die Schneedichtigkeit rermehrt hahen. Während die Wirkung der Schneelast im untern Sihwald sich auf das Knicken und Umbiegen einzelner Bäume und Horste an besonders exponierten südöstlichen Halden, wie z. B. auf dem Hang oberhalb der Säge bis zum Weissenstein beschränkte, manifestierte sie sich auf dem in 
der Richtung Südost exponierten Plateau der Abteilung 3, 4, 5 und 6 des obern Waldes, in der Breite eines Streifens von 300 bis $400 \mathrm{~m}$ und auf eine Länge von $1 \frac{1}{2} \mathrm{~km}$, als eigentliche Waldzerstörung. Je üppiger der Bestand und die Belaubung, je kräftiger die einzelnen Bäume und ihre Kronen waren, um so mehr Anhaltspunkte fand die ungewohnte Last, die sich in Form eines zusammenhängenden Schneedaches auf der grossen Kronenfläche ablagerte. Was fest wurzelte, brach, was schwach war, bog sich; wo die Bodenverhältnisse das Eindringen der Wurzeln weniger begünstigten, stïrzte der beschwerte Baum, andere im Fallen mit sich reissend. Durchforstete und nichtdurchforstete Partien wurden in gleicher Weise verheert. Eine Ausnahme machten nur die leider zu spärlich vertretenen Nadelhölzer. So begann dann am 28. September, nachmittags $4 \mathrm{Uhr}$, ein die ganze Nacht hindurch dauerndes Zerstörungswerk, wie es nicht bloss der Sihlwald noch nie erlebt hat, sondern auch die Amnalen der Forstgeschichte äherhaupt in analoger Weise niemals konstatieren können. Der vom Stadtforstamt unterm 12. Oktober vorläufig erstattete Bericht schätzte ein Schneebruchmaterialquantum von 16,000 Festmeter; aber die nachher vorgenommene genauere Aufarbeitung, die mit dem Jahre 1888 zu Ende ging, beziffert dasselben, mit Einschluss der noch erfolgten nachträglichen Schädigungen, auf ein Quantum von 44,790 Festmeter. 


\section{IV. \\ Eigentumsverhältnisse.}

\section{A. Entwicklung der Eigentumsverhältnisse von $853-1524$.}

Es mag zu den selteneren Erscheinungen gehören, dass der ganze Waldbesitz eines Gemeindewesens in seiner Totalität ausserhalb des Friedkreises der betreffenden Gemeinde liegt, wie das bei Zürich der Fall ist. Der Schlüssel zu dieser Tatsache liegt in der yeschichtlichen Entwicklung der zugehurigen Eigentumsrechte. Diese selbst führt uns hinauf bis ins 9. Jahrhundert, in die Zeit, da die königliche Pfalz auf dem Lindenhof Mittelpunkt des königlichen Castrums Zürich war, da die Fraumünsterabtei zu ihrer nachherigen Bedeutung emporstieg, und neben Kloster und Königshof ausserhalb des Castrums eine Anzahl freier Alamannen die Markgenossenschaft am Zürichberge bildeten. Ein volles Jahrtausend ist an der Entwicklung dieser Eigentumsverhältnisse vorübergegangen und es liegt in der Natur der Dinge, dass damit der eigentliche Ursprung der Eigentumsrechte sich allmählich mit einem sagenhaften Schleier umwoben hat, den zu lüften und auf den Grund der Dinge zu gehen es umsomehr der Mühe lohnen mag, als die Zahl der zu Gebote stehenden Urkunden nur eine sehr beschränkte ist. Der Ausgangspunkt für die grösste Abteilung des städtischen Waldeigentums liegt in der Schenkungs-Urkunde der Fraumünsterabtei Zürich.

Am 21. Juli 853 schenkte der Enkel Karls des Grossen, König Ludwig der Deutsche, von Regensburg aus seiner Tochter Hildegard, als der ersten Aebtissin des Nonnenklosters in dem vicus Zïrich «seinen Hof Zürich» nebst allem. Zubehör, worunter insbesondere das Ländchen Uri und «unser Forst, Albis genannt,» inbegriffen waren. 
"In super etiam forestem nrm Albis nomine et quic quid in eisdem locis nri iuris atque possessionis Jure proprietatis est, et ad nrm opus Instanti tempore pertinere videtur totum et integrum ad monasterium nrm tradimus quod situm est in eodem uico turegum ubi sets felix. Et sceta regula marty resxpi corpore quiescunt»

so lautete die bezügliche Stelle der Stiftungsurkunde ${ }^{1}$ ).

Nun kennen wir allerdings einen Wald, «Albis» genannt, heutzutage nicht mehr. Der dunkle Kronenschmuck, der den Hang des Albisbergzuges bis hinunter ins Tal der Sihl und an deren linkes Ufer, zusammenhängend überdeckt, heisst Sihlwald. Aufsteigend vom rechten Sihlufer. über die Moränenhügel hinüher. und hinunter bis an das linksufrige Seegestade und an die Dörfer Thalwil und Oberrieden erstreckt sich dagegen der zusammenhängende Waldkomplex Forst. Der von König Ludwig geschenkte Wald «Albis» hat sich also unter diesem Schenkungsnamen nicht erhalten. Vorhanden ist nur der Berg Albis.

"Albis» hiess in früheren Zeiten bis ins 14. Jahrhundert hinein der ganze Gebirgszug, der von Urdorf an bis zur Sihlbrücke bei Hirzel hinaufreicht und das Tal der Reppisch vom Zürichsee trennt. In dem Vertrage vom Jahre 1309, den die österreichischen Herzoge mit der Stadt Zürich geschlossen hatten, heisst es, dass das «Tal von Dietikon uff zwischen Albis und dem Wasser bis $n$ Wediswile» - nicht für militärische Zwecke benutzt werden dürfe). Es wird also sogar noch zu dieser Zeit der aus einem Tal und einem Bergrücken bestehende Terrainabschnitt als Ganzes aufgefasst. Heute verstehen wir unter Albis nur den zwischen dem Sihl- und Reppischtale liegenden Bergzug rom Albissattel bis zur sihlbrïicke bei Hirzel. Den Wald Albis als solchen kennt niemand auf dem Albis-Gebirgsrücken.

Aus dem Umstande, dass der Name Albis dem eigentlichen Zentrum des Gebirgszuges und zugleich seiner höchsten Partie geblieben ist, dürften wir aber doch zunächst die Berechtigung schöpfen, den «Forestum nostrum Albis nomine» in die Gegend zu verlegen, in der heute der Name Albis fortbesteht und wo zugleich Sihlwald und Forst sich als einen grossen, zusammenhängenden, einzig durch den Sihlfluss unterbrochenen Waldkomplex präsentieren.

1) Bluntschli, Staats- und Rechtsgeschichte, Beil. p. 487 und G. v. Wyss, Geschichte der Fraumünsterabtei.

) Tschudy Chronik I. 248. 
Welchen Umfang hatte nun dieser Albisforst? IVar er ein streng nm-renzter. genau ausgeschielener Terrainabschnitt, umfasste er nur den heutigen Frorst oder die Totalität von Sihlwald und Forst?

Vom Jahre 853 bis zum Jahre 1263 mangelt es neben der Stiftungsurkunde an irgend einem anderen urkundlichen Hinweis über den Albisforst. Erst im Jahre 1263, zu der Zeit da in dem langjährigen Streite zwischen den Freiherren jungen Herrn Berchtold und Walter, Gebrüder von Schnabelburg der Schiedsspruch gefällt wurde «um eine Vogtei über den Forst der da lit bi Sile»,1) tritt uns der Wald «Forst» wieder vor Augen. Die fünf Schiedsrichter berichten in ihrem zu Tellwile an dem Stade den 18. Januar 1263 aufgesetzten Spruche: «dass die Aebtissin die Bauern der Jungherren von Schnabelburg, welche auf den drei Huben sitzen, bei all den Rechten und Gewohnheiten, die sie bisher an dem Forste hatten, bleiben lassen soll, ganz unter den gleichen Bedingungen, unter welchen diese Bauern auf die Huben kamen.»

Der Ort der Ausübung dieser drei Hubgerechtigkeiten ist offenbar entscheidend für die Lage und die Ausdehnung des "Forstes der da lit bei Sile».2)

Wo befanden sich also die drei Huben, auf der Sihlwald- oder auf der Forstseite? Die Antwort muss dahin lauten, dass diese 3 Huben nirgends wo anders als im Forst $\mathrm{zu}$ finden sind.

In den Offnungen derer von Oberrieden, in welchen die Nutzungsverhältnisse des Fraumünsterforstes geordnet sind, ist immer von drei Häuen die Rede, von demjenigen von Ludretikon, von einem zweiten in Thalwil und einem dritten für Oberrieden und Moorschwand. Diesen Häzen entsprach offenbar die Zahl der Huben; erst belief sie sich nur auf drei Huben, nachher stieg sie infolge der Zerlegung der Huben in Schupposen auf 12 Schupposen, später sogar auf 16. Die Vermehrung der 'Teilrechte war aber nur eine solche, die Bezug hatte auf das Mass der Ansprïche innert den drei einzelnen Häuen; das Nutzungsobjekt veränderte sich nicht. So fielen auf den Ludretiker-Han 4, auf den Thalwiler-Hau 4 und auf den Oberrieder-Hau 8 Gerechtigkeiten ${ }^{3}$ ).

1) Prof. G. v. Wyss, Geschichte d. Fraumünsterabtei, Beil. Nr. 186, p. 186, 169.

“) Siehe pag. 57 ron Obigem.

3) Verschieden von diesen 12 Schupposen des Forstes sind die 12 Hofstetten zu 'T'alwile, die dem Kloster Muri gehörten, denen der Wald Bamnegg als Gut von Muri übergeben wurde laut Offnung über die Rechte von Muri in Talwile und Oberrieden. Grimm: Weissth. I. 56. Nach dieser Oftinung hatte Muri ausser diesen Hofstetten :3 Güter: 1. gen. Seehof; 2. die Bannegg; 3̈. das Gut auf dem Albis. 
Die Huber hatten ihr Fastnachtshuhn als Lehnzins an das Stift zu entrichten, wie dies z. B. aus einem Kaufbrief vom 4. Mai 1432 ersichtlich ist. wo es heisst:

«ein Fastnachtshuhn jährlichen Zinses der Abtei Zürich soll Herdegen Vogel zu Tellwyl wegen der dem Bertschi Hanss zu Oberrieden den 4. Mai abverkauften, seiner fälligen Ehehofstatt, so eine der XII ist, die Rechtung und Freiheit im Forst hat.

Und in der Hofwigtrechnung vom Jahr 1474 heisst es :

«Und wellich der Gütter hat so der Hofwigtgenoss sind, so nemint jährlich söllich Hofwigt im Forst oder nit nichzit destominder sellend sy myner Frowen Gnad und Jhrem Gotzhus Jhr Zins holz jährlich geben und usrichten.»

Es bildete sich diesen Sätzen gemäss aus den Rechten und Gewolınheiten der Bauern, die auf den drei Huben sassen, ein stets weiter gehendes Nutzungsrecht an den Wald, dem gegenüber das Recht des Grundherrn mehr und mehr in den Hintergrund trat. Das Objekt der Nutzniessung dagegen blieb trotz der Vermehrung der Nutzniesser das gleiche; es ist dies repräsentiert durch die drei Hüue des Forstes. Das Nutzungsrecht beschränkte sich auf diese und ging niemals auf den Sihlwald über; es macht sich von allen diesen Erscheinungen im sog. Sihlwald auch nicht die leiseste Spur geltend. Keine Urkunde, weder der I. noch der II. Richtebrief, noch die Protokolle des Zürcher Stadtbuches aus dem 14. Jahrhundert weisen auf Lehensverhältnisse hin, wie wir sie im Forst treffen. Weder Anrechte von Hofstetten, noch von Hofwigtgenossen, weder Weiderecht noch Baurecht einzelner werden geltend gemacht. Es darf daher mit Sicherheit angenommen werden, dass der Sihlwald im Jahr 1263 bereits ohne jegliche Gemeinschaft mit dem Fraumünsterstift ist, und dass die Schenkung des «Forestum Albis nomine» damals jedenfalls nur noch fortbestanden hat für einen Teil des ursprïnglichen Gesamtohjektes, welches vom Albiskamm bis zum See reichte, wenn nicht ïberhaupt von Anfang an bloss der eigentliche Forstteil verschenlt worden ist.

Für diese letzte Auffassung spricht nun die etymologische Bedeutung des Wortes: Forst. - Forst bedeutete im 9. - 13. Jahrhundert eine in ein besonderes Rechtsverhältnis eingetretene Waldung; ein vom Kaiser oder König gebannter, der allgemeinen Benutzung entzogener, besonders gehegter oder befriedeter Wald. 
Silvam in forestum convertere ${ }^{1}$ ) - bedeutet den der allgemeinen Benutzung unterstellten Wald in den Forst umwandeln. Die Forste erscheinen daher als Gegensatz zu den gemeinschaftlich besessenen Waldungen und die karolingischen Urkunden unterscheiden stets silva et forestis. ${ }^{2}$ ) Wir haben in der ganzen Umgebung des Sihlwaldes und Forstes, im Kanton Zürich überhaupt, keinen zweiten Wald, der wie dieser dem Fraumünster geschenkte Wald: Forst heisst. Ziehen wir ferner in Betracht die Art und Weise. wie die dem Fraumünsterstifte im Schiedsspruch vom Jahre 1263 zuerkannten Rechte dargelegt sind «dass die Aeptissin diesen Forst sol han mit Bann und Getwings», - so wären in diesen, die Bannforste charakterisierenden Worten weitere Hinweise dafür enthalten, dass das dem Fraumünster im Jahr 853 geschenkte Objekt «Forestum Albis nomine» als solches wahrscheinlich nur den nachmaligen Fraumiunsterforst umfasste und dass der Silhlwald in der Schenkung gar nicht inbegriffen war, jedenfalls aber bei den später erfolgenden Bestätigungen der Schenkung durch die nachherigen Könige wieder zuhanden des Reiches, d.h. des Reichshofes zurïckgezogen wurde.

Die Frage, wie der Sihlwald an die Stadt Zürich gelangt sei, ist somit aus der Schenkungsurkunde nicht ersichtlich und daher noch weiterer Untersuchung zu unterbreiten. Zur Stunde gilt noch die hierauf bezügliche Darstellung Johs. v. Müllers, der sie seinerseits den Áitteilungen des Chronisten Legidius Tschudy entnahm. als die richtige. Nach dieser wäre der Sihlwald der Stadt Zürich anlässlich der Zerstörung der Achnabelburg von den österreichischen Herzogen, d. h. von der Königin Agnes für freundliche Beihülfe geschenkt worden. Fine nähere Prüfung der tatsächlichen Verhältnisse führt indessen dazu. diese Auffassung als eine nicht korrekte bezeichnen zu müssen. Es mag uns gestattet sein, den Beweis hiefür zu leisten, wie folgt:

"In Zürich bestand zur Zeit der Stiftung der Fraumünsterabtei neben dem an die Abtei geschenkten, ihre Grundlage bildenden Hofe, curtis 'l'uregum, im 8. bis 12. Jahrhundert auch der königliche, resp. der herzoglich alamannische Hof (curtis senioratus), dessen Mittelpunkt die Pfalz auf dem Lindenhofe bildete. Zu ihm gehörten die königlichen Burgmänner, Diener und Hörigen, die Fiskalinen und Grundstücke innert oder ausserhalb des Ortes bildeten seinen Bestand. Besass nun der König, resp. das Reich am Gebirgs-

1) Du Cange, 1. c. 607. s. Bernhardt, Geschichte des Waldeigentums I. pag. 25.

$\left.{ }^{2}\right)$ Silva et foreste nostra. Urkunde Karls des Grossen. Waitz IV. 110. Not. 2. 
zuge des Albis umfangreiche Waldungen, so ist mehr als wahrscheinlich, dass neben dem an die Abtei geschenkten, auch dem königlichen Reichshofe in Zürich Teile jener Waldmgen zugewiesen waren und wahrscheinlich eine längere Zeit auch verblieben.»1)

Wir glauben zu dieser Deutung der Eigentumsverhältnisse unterstützende Nomente einmal in der ganz mabhängigen Nutzungsart des Forstes nachgewiesen zu haben, dann aber namentlich in dem Umstande zu finden, dass anderwärts in der gleichen Zeitperiode analoge Verhältnisse konstatiert sind. Wir zitieren Nürnberg ${ }^{2}$ ), Weissenburg ${ }^{3}$ ) und Hagenau ${ }^{4}$ ), wo Königshöfe und daneben königliche Forste lagen, wo Schenkungen an nebenanliegende Klöster stattgefunden hatten und den eigentlichen Pfalzen demnoch Besit\%tum zur Befriedigung der Bedürfnisse ihrer Insassen geblieben ist.

"Ueber diese Waldungen des Reichshofes, wie über den Reichshof selber verfügte der König, resp. sein Stellvertreter - hier von 920-1080 die jeweiligen Herzoge von Alamannien oder Schwaben und von 1097-1218 die Herzoge von Zähringen - die an Kaisers Statt über Zürich gesetzt, den kaiserlichen Schirm über die beiden Stifte übten, und die Reichsvogtei und Kirchenvogtei im ganzen Umfange der Reichsvogtei, resp. der Güter des Stiftes besassen. Unter den Königen und den Herzogen verwalteten die Grafen von Lenzburg-Baden seit 972 das ihnen als erbliches Recht zukommende Amt der Vogtei.»

Durch das Erlöschen der Zähringer 1218 und infolge der damit eintretenden Zersplitterung der Reichsvogtei Zürich ${ }^{5}$ ) biluten sich nunmehr für Zürich, für die umliegenden und die weiteren zur Reichsvogtei gehörig gewesenen Gebiete ganz neue Verhältnisse der Gerichtsbarkeit aus. Aus dem früheren Ganzen entstanden eine Menge getrennter Bezirke. Vom linken Ufer des Sees und der Limmat kam die hohe Gerichtsbarkeit zwischen dem Albis und dem See in die Hand der Freien von Schnabelburg, aber nur soweit es die Güter der zürcherischen Gotteshäuser betrifft.

Es hängt nun von der Auffassung der im Begriff der hohen Gerichtsbarkeit eingeschlossenen Befugnis ab, ob wir für die Stellung:

1) Wir folgen in der Darstellung dieses Momentes wesentlich den uns ron den HH. Prof, G.v. Wyss und Dr. H. Zeller-Werdmieller gütigst gemachten Angaben.

2) Beschreibung des Nürnberger Reichswaldes v. Leyer 1858.

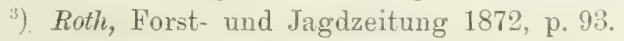

4) Schöpflin, Alsatia Illustrata Germ. 1761.

5) Siehe Friedrich $v$. Wyss, Beiträge in der Zeitschrift für schweiz. Recht. Bid. 17. 1872. 
des Sihlwaldes zur Stadt Zürich Ende des 13. und Anfang des 14. Jahrhunderts eine Abklärung herbeiführen können oder nicht.

Nach Bluntschli (Staats- und Rechtsgeschichte des Kantons Zïrich) ${ }^{1}$ ) umfassen die Begriffe Reichsvogtei und nachher die der hohen Gerichtsbarkeit identisch:

1. Den Bezug der Reichssteuer.

2. Die Anführung im Kriege.

3. Den Blutbann.

An einem anderen Orte ${ }^{2}$ ) wird auch noch angeführt die Oberaufsicht, d.h. das Hoheitsrecht ïber das dem Reichshof seit Anfang zustehende Grundeigentum, namentlich auch über die Waldungen, welche den königlichen Pfalzen zur Befriedigung ihres Jagdvergnügens wie des Holzbedürfnisses ihrer Insassen angewiesen sein mussten. Allerdings übten nun über Zürich, die Stadt und ihve Zubhörden, königliche Vögte die Vogtei aus: über das zwischen dem See und dem Albis gelegene Klosterland dagegen die Freiherren von Eschenbach und Schnabelburg.

So gut indessen eine Teilung der gesamten Reichsvogtei möglich war, ebensowohl konnte eine Ausscheidung der Objekte derselben in dem Sinne stattfinden, dass der Reichsvogt den Blutbann und die Gerichtsbarkeit erhielt, die Nutzungsrechte anf die Guiter und auf den unenthehrlichen Wald dagegen (samt dem Aufsichtsrecht) unzertrennlich dem Reichshof und dessen Insassen, d. h. der mittlerweile herausgebildeten Gemeinde Ziirich belassen wurden. ${ }^{3}$ )

Dem entsprechend muss angenommen werden, dass die hohe Gerichtsbarkeit des Reichsvogtes diejenige über den Sihlwald mit eingeschlossen habe, dass die Nutzung dagegen der. Stadt Ziirich verblieb. Die Analogie zeitgenössischer. Terhältnisse in Deutschland, der Streit und Schiedsspruch zwischen den Schnabelburgern und dem Fraumünsteramt ron 1263 sind freilich die einzigen festen Anhaltspunkte für diese Auffassung, aber sie dürften sich in Ermanglung urkundlicher Belege als ausreichend erweisen.

Ueberall, wo wir die karolingischen Hofgüter als Pertinenzen der zustehenden Pfalzen vom 9. Jahrhundert antreffen, ist der Reichsvogt zugleich Verwalter des Reiches desselben Namens. ${ }^{4}$ ) Wie wir

1) Siehe Absehnitt II. 6. \$\$ 5, 142-143 und pag. 210-211.

2) Siehe Bluntschli, Geschichte der Republik Zürich, Kapitel 5.

") Siehe historische und kritische Beiträge zu der Historie der eidgen. Geschichte des Regimentes der Stadt Zürich. pag. 64, 65 und 72.

I) Siehe Bluntschli, (ieschichte der Republik Zürich, Kapitel 5, pag. 62. 
die sogenannten Forsten als der Jagd halber der allgemeinen Nutzung entzogene Eigentumsanteile der Könige bezeichneten, waren umgekehrt die nicht in diese Kategorie fallenden Reichswaldungen derart administriert, dass die Kaiser und Könige für sich und ihre Stellvertreter den Wildbann vorbehielten, während die Holz- etc. Nutzungen den Hofinsassen verblieben. So war's im Hagenauer-, und so war's im Nürnberger Reichswald.

Die geringe Wertung des Holzes, die hohe Würdigung der Jagd umgekehrt, führte dazu, dass die Rechtsanschauung, wonach dem Grundherrn vorab Luft-, Wasser- und Tierfang in Wald und Weide gehörten, auch den Reichsvögten oder den Inhabern der hohen Gerichtsbarkeit auf dem zu einer ehemaligen Reichsvogtei gehörenden Grund und Boden, sehr genehm war und dass diese jene Rechte als vom Reiche zu Lehen an sie übergetragen, gerne ausübten. Wenn wir diese Darlegung als die wahrscheinliche ansehen, dann wird uns auch der langjährige Streit, den die Jungherren von Schnabelburg mit der Aebtissin führten, klar. Es handelte sich hier darum, zu entscheiden, ob den Schnabelburgern an dem Forste der Abtei noch aus der Reichsvogtei entspringende, nutzbringende Rechte zuständen, ob das Recht zu «Twingen» und zu «hegen» dem Lehensherrn (der Aebtissin), oder aber den Schirmherren, d. h. den Schnabelburgern gehöre oder nicht. Es war ihnen ja alles Land zwischen Albis und dem See, es war ihnen Horgen, es war ihnen auch der Sihlforst mit der hohen Gerichtsbarkeit zugetan und auch die Gerichtsbarkeit über die ausserhalb des Furstes, auf ihren Ehehofstatten wohnenden Bauern wurde ihnen ausdrücklich zuerkannt. nicht aber das Hoheits- oder Jagdrecht über den Forst, so gerne sie solches für sich beansprucht hätten.

Wohl hierin allein findet sich der Grund zu der Auffassung der Chronisten Aegidius Tschudy und Stumpf, welche von Anspruchsrechten der Schnabelburger auf den Sihlwald und von Uebertragung derselben an die Stadt sprechen, obschon nachweisbar Rat und Bürger schon lange vorker ïber die Nutzung des Sihlwaldes verfügt haben! Der Forst dem Stift und den über dessen Besitzungen die Reichsvogtei ausübenden Schnabelburgern, der Sihlwald dem Reichsvogt Zürichs und dem Reichshof bezw. der Gemeinde Zürich, das war wohl das Eigentumsverhältnis vom 13. Jahrhundert an.

Der Nachweis zu diesem letzteren Verhältnis liegt in gewissen Bestimmungen des Richtebriefes der Bürger von Ziirich. In der ersten Rezension dieses interessanten Aktenstückes. welche in die 
zweite Hälfte des 13. Jahrhunderts verlegt wird, und wohl auch ihrer forstlichen Bestimmungen wegen in die Zeit vor dem durch Wakerbold 1280 gestifteten Brande zu verlegen ist, heisst es: ${ }^{1}$ ) "vom Silholze. Wir der Rat von Zürich und die Burger sind gemeinlich übereinkommen, was Holzes die Sile nieder trait, das soll man geben ein hundert umb XII pfenningen und nit türer» u. s. f.

So wenig juristische und administrative Details allerdings in dieser kurzen Notiz vorhanden sein mögen, bedeutungsvoll ist sie dadurch, dass sie herauslesen lässt, dass Rat und Bürger der Stadt Ziurich zu dieser Zeit bereits über das Sihlholz verfügt haben, und nicht etwa der Reichsvogt. Dieser Beweis wird noch vervollständigt durch den II. Richtebrief, dessen Rezension nachweisbar in das Jahr 1304 fällt. $\left.^{2}\right)$ Hier finden sich nun folgende charakteristische Sätze:

«54. Das nieman Holz das im geben wirt us dem Silwalde verkoufe als der mitte der vertigunge lone.

55. Das man nieman Zimber us dem Silwalde geben soll, wan der für für buwen will.

56. Dem Zimber us dem Silwalde gegeben wirt das der es zehand howen und usvertigon sol.»

Aus diesen Bestimmungen geht wohl des unzweideutigsten hervor, dass die Stadt Zürich sich Anno 1304 im vollen unverkïmmerten Nutzniessungsrecht über den Sihlwald befunden hat, ja dass, weil man bereits gezwungen war, Missbräuchen gegenüber einer allzu ausgedehnten Benutzung steuern zu müssen, dieses Nutzungsrecht wohl schon sehr lange vorher ausgeübt worden sein musste! Der Missbrauch ist erst eine Folge des Gebrauches.

Für uns unterliegt es aber auch keinem Zweifel, dass diese Benutzung sich auf den ganzen Sihlwald und nicht bloss auf einen Teil desselben erstreckte. Schon die Bestimmung des I. Richtebriefes: "so was Holzes di Sil niedertrait», lässt den Gedanken, dass nur ein Teil des Sihlwaldholzes der stadt, ein anderer Teil den Freiherren von Schnabelburg gehört habe, als nicht wahrscheinlich erscheinen. Die ganze T'errainkonfiguration weist alles Holz, das an den Hängen des Sihlwaldes geschlagen wird, talwärts, der Sihl zu. Diese selbst hätte für den Fall von zweierlei Besitzern auch zweierlei Holz in den Floss aufnehmen müssen. Dass dem jemals so ge-

1) Helvet. Biblioth. II. 1735, pag. 53 .

") Archiv für schweiz. Geschichte, V. Bd., pag. 228. Der Richtebrief der Bürger von Zürich. Mitgeteilt von Fr. Ott. 
schehen sei, dafuir sind bis jetzt keine Anhaltspunkte beigebracht worden und der II. Richtebrief der Stadt, der die wirtschaftlichen Verhältnisse in streng polizeilichem Sinne ordnet, hätte nicht ormangelt, Bestimmungen hierüber aufzunehmen. Gewiss hätte es bei einer solchen Ausnutzung überhaupt an Veranlassung zu Streit nicht gefehlt, wenn zweierlei Holz, Schnabelburger- und Stadtzürcherholz die Sihl hinuntergeflösst worden wäre. Und so wenig es je den Schnabelburgern an Veranlassung mangelte, den viel älteren Rechten der Aebtissin gegeniiber ebenfalls Anspuruchsechte auf den Forst geltend zu machen, so wenig hätten sie wohl gezaudert, Ansprüche gegenüber der Stadt zu erheben mit Bezug auf das Holz des Sihlwaldes.

Der Hof der Schnabelburger lag auf der Einsattlung zwischen der Albishochwacht und dem sogenannten Bürglenstutz. Seine Umgrenzung oder sein Umfang lässt sich annähernd ermitteln aus folgenden Nachweisen. Die erste Harchenbeschreibung über den Sihlwald, welche vom Jahre 1491 datiert, sagt:

«und gadt der wald von dem nider Albis uber der egg (Kamm) der Höhe nach. Am Heuscherberg hin biss an dem Hoff, den man nännt Schnabelburg. Und dann an dem Hoff Schnabelburg gegen der Sihl hin dem Hag und dem Bach nider bis an die Rissenten (heutige Risleten)».

Nach der Offnung von Rengg gehörte der Hol Rengg», dessen Güter sich noch heute gegen das Plateau der Schnabelweiden hinauf erstrecken, im 14. Jahrhundert der Probstei Zürich. d. h. dem Grossmünster («von den Rechten so die Probstei Zürich hat in dem Hof zu Rengg» ${ }^{1}$ ). Wir hätten damit eine östliche, südliche und nördliche Begrenzung des Schnabelburger Hofes.

Im Jahre 1563 kaufte die Stadt Zürich 11 Jucharten Wald und Wiesen im sogenannten Kolben, die an den Schnabelberg grenzen. Und in den Jahren 1825 und 1826 erwirbt die Stadt von verschiedenen Besitzern 130 Jucharten Acker- und Wiesland und Holz, sämtlich auf dem Schnabelberg gelegen. Fasst man diese Ankäufe mit den. anfangs der siebziger Jahre des letzten Jahrhunderts noch erworbenen Gütern auf dem Albisplateau zusammen, so mag der derart als «Schnabelhof zuiter . sich beschreihende Komplex zirka 100 Hektaren umfassen; das ist wohl genug Land für die Existenz einer beschränkten Kriegsfeste, wie sie der Natur der

$\left.{ }^{1}\right)$ Siehe Fr. von Wyss, Zeitschrift für schweiz. Recht. pag. 62. 
Terrainverhältnisse nach zu schliessen sich hier vorgefunden haben konnte. Die Hauptburg und das Gut der Schnabelburger mochte ja immerhin Eschenbach oder Maschwanden sein.

Es war im Jahre 1308. da nahm Walter von Eschenbach auf Schnabelburg an der Ermordung König Albrechts teil. Die hinterlassenen Kinder des Erschlagenen, die Herzoge Leopold und Friedrich und die Königin Agnes übten in bekannter. Weise Blutrache an den Mördern: sie schickten sich an deren Burgen und Festen zu zerstören; sie zerstörten die Stammburg Eschibach, die Burgen zu Rüssegg und Maschwanden und wandten sich dann auch an die Schnabelburg. Um die Eroberung der Burg mit aller Sicherheit durchzuführen, schlossen die Herzoge von Oesterreich am 1. August 1309 einen Vertrag mit der Stadt Zürich, wornach sie sich insbesondere die Verpflegung und eine neutrale Haltung Zürichs sicherten. umgekehrt aber als Gegenleistung zugestanden, dass sie das ganze Tal von Dietikon aufwärts zwischen dem Albis und dem See bis nach Wädenswil nicht mit dem Heere betreten wollten und dass den Bürgern überhaupt kein Schaden zugefügt werden solle.

Man einigte sich zu gegenseitiger Geiselschaft und zu 200 Mark Silber für den Fall, als österreichischerseits der Vertrag verletzt würde. Nun berichtet Aegidius Tschudy ${ }^{1}$ ) in seiner Chronik: dass die Königin Agnes, die ein "geschwind und listig Wyb war» den ganzen Sihlwald his hinauf über Horgen den Zürchern ror Abschlus: des Vertrages geschenkt habe, um sie für denselben überhaupt günstig zu stimmen. - Diese Auffassung muss schon deswegen Bedenken erregen, da wir bereits im I. und II. Richtebrief die Stadt Zürich im Besitze des Sihlwaldes getroffen haben, sie wird aber noch viel zweifelhafter durch die, nach der Eroberung der Schnabelhurg stattgehabten nachweisharen Vorgänge. Der Chronist Stumpf schreibt: $\left.{ }^{2}\right)$

«Zürich beklaget sich, etwas Schadens, so jnen in der Belagerung des schlosses Schnabelburg durch ab- und zuryten der herzogischen zugefügt. So ward die Sach zu Diessenhofen durch glyche Zusätz und ein Obmann mit Recht ausgesprochen am Mittwoch vor Thome 1309. Die Fürsten geben den Zürchern 200 M. silbers uff Zil und 'Tag.» und darauf fährt er fort:

1) Chronik von Aeg. T'schudy I. 248.

2) Siehe Stumpf, Gemeiner löbl. Eidgenossenschaft, Beschreibung 1584. Buch VI. Kapitel XVIII. 
«In diesem Krieg und jahr haben die Oesterreicher der statt Zürich geschenkt einen grossen Teil des Sihlwald. Ist zu achten, dass sie solichs geben haben an die Bezahlung des oberkannten 'Abtrags.»

Aegidius 'Tschudy führt uns den Spruchbrief von Diessenhofen ${ }^{1}$ ) mit der gleich hochgestrilten Entschädigungssumme von 200 Wark an. Jeder der beiden Chronisten stützt sich auf eine einzige Urkunde, auf den Spruchbrief von Diessenhofen. Dieser Spruchbrief erklärt die Herzoge von Oesterreich als zahlungspflichtig für 200 Mark Silber und ordnet die Zahlungstermine in einer Art und Weise, dass anzunehmen ist, es sei die Bezahlung möglich geworden und auch erfolgt.

Die Schenkung und der zugehörige Brief wäre nach Tschudy durch die Königin Agnes erfolgt. Die Zahlung der Zno Mark geschah durch die Herzoge. Tschudy lässt nun den Silklwald und das Sihlfeld vor, Stumpf nach dem Vertrag vom 1. August 1309, resp. dem Schiedsspruch von Diessenhofen, del eine schenkweise, der andere pfandweis an die Stadt Zürich iibergehen; Stumpf spricht zudem nur von einem Teil des Sihlwaldes. Beide Auffassungen sind in keiner Weise von irgend einer Urkunde bestätigt. Eine Sichtung ist daher notwendig. Ziehen wir nun in Betracht:

1. dass zufolge den Bestimmungen des I. und II. Richtebriefes die Stadt Zürich den Sihlwald tatsächlich lange vor 1308 benutzt hat:

2. dass eine bloss teilweise Benutzung des Sihlwaldes der Verhältnisse halber mehr als unwahrscheinlich ist;

3. dass die Domäne Schnabelburg nachweisbar bis in dieses Jahrhundert hinein fortbestanden hat und erst in dieser neueren Zeit von der Stadt Zürich käuflich erworben wurde:

4. dass die Schnabelburger als Reichsvögte in diesem Gebiet kaum jemals mehr als die hohe Gerichtsbarkeit inkl. den Wildbann besessen haben konnten,

so scheint uns die Schlussfolgerung richtig zu sein:

dass von einer Verschenkung des Sihlwaldes durch die österreichischen Herzoge nicht die Rede sein kann, sondern nur noch von einer Uebertragung der hohen Gerichtsbarkeit über dieses Gebiet an die Stadt Zürich, nachdem die letzten Reichsvögte, welche dieselbe ausgeübt hatten, die Freiherren

1) Siehe Aeg. Tschudy pag. 251. 
von Schnabelburg, anlässlich der Blutrache beseitigt worden waren.

Damit wäre dann allerdings die durch Johs. v. Müller verbreitete Auffassung als eine unkorrekte aufzugeben - und wir hätten begründetere Veranlassung anzunehmen:

Der Sihlwald war vom 9.-14. Jahrhundert dem Reichshof zugehörig und wurde von diesem benutzt. Die Reichsvögte waren die hiefür gegebenen Verwalter. Nach dem Aussterben der Zähringer und mit der Zersplitterung der Reichsvogtei führte die Entwicklung der Verhältnisse dazu, dass die aus dem Reichshofe sich heraus entwickelnde, mehr und mehr erstarkende Gemeinde im Genuss der Fortbenutzung des Sihlwaldes verblieb, während die hohe Gerichtsbarkeit, Bann und Jagd, bei den Reichsvögten über die Stadt Zürich verblieb und von diesen im Sinne der Zeit ausgeübt wurden, bis die Ereignisse des Jahres 1309 dazu führten, dass die Stadt sich auch dieses letzte Ueberbleibsel der frïheren Herrschaftsrechte aneignen konnte. -

Vom Jahre 1309 an blieb die Stadt Zïrich in unbeschrünkter Weise Herrin des Sihlwaldes. Weder König noch Kaiser, noch irgend ein Lehensherr macht von da ab Ansprüche auf den Sihlwald geltend. Die Aebtissin wartete ihres Forstes, in ihrer Machtsphäre beengt durch die kräftiger und kräftiger werdende Stadtgemeinde. in dem Genusse ihres Eigentums am Forst mehr und mehr beschränkt. durch die Nutzniessungen, welche sich die drei Huben allmählich anzueignen wussten, so dass dem Grundeigentümer nicht mehr blieb als das bescheidene Dispositionsrecht, die Gerichtsbarkeit und ein geringer Lehenszins.

Die Verhältnisse der Benutzung der Markgenossenschaft am Zürich- und Adlisberge beurkunden im 14. Jahrhundert einen nicht minder energischen Umschwung.

Die Erstellung der städtischen Befestigung trennte die in der Stadt wohnenden Bürger von den verburgerten Freien am Zürichberge. Die Benutzung an Wald und Weide dauerte aber für beide gemeinschaftlich fort. Ausserhalb des Festungsringes entstanden die Wachten Hottingen und Fluntern; sie waren mitnutzungsberechtigt an der Allmend und aus der Stadt waren es die Bürger des Oberdorfes. Ratserkenntnis aus dieser Periode M. 1. 65. P.4.6.

«Man schribet allen Räten, daz der Rat mit geschworn eiden hat erwarn um die Allmeinde Offendorf vssin, daz 
man in dem Dritten iare so dazvelt in brache lit, der Burger vê triben sol vf die weide - und daz jeglich Rat, der danne sitzet - die burger scherme uf der Allmeinde.» u. s. f.

Der Rat benutzt die Hölzer des Adlisberges und Zürichberges wesentlich für Bauten und gibt das noch disponible Bremnholz sowohl an Bürger in der Stadt, als an solche, welche in den Wachten wohnen und sich hiefür bewerben, zu ermässigten, alljährlich hiefür festgesetzten Preisen ab.

So blieben die Verhältnisse bis zum Jahre 1540, da die neue Bergamtsordnung die mittlerweile sich mehrenden Ligentums- und Nutzungsansprüche an Wald und Weide der ausserhalb der Stadt wohnenden Berechtigten in bestimmter Weise normierte.

\section{B. Die Eigentumsverhältnisse}

vom Anfang des 16. bis zum Schluss des 18. Jahrhunderts (1524-1798).

An dem regen Entwicklungsgange, durch den das geistige und materielle Leben Zürichs im 16. Jahrhundert sich auszeichnet. nimmt derjenige 'T'eil, der auf die Waldwirtschaft Bezug hat, nicht die unbedeutendste Stellung ein. In forstorganisatorischer, wie in rein wirtschaftlicher Beziehung tritt eine vermehrte Fürsorge des Rates für den Wald zutage. Der Wert der Waldprodukte wird höher geachtet, deshalb ihre Verteilung weniger blosser Willkiir und Begünstigung überlassen. Der Rat sorgt sogar noch im weiteren für jährliche Zufuhr gekauften Holzes aus dem Kanton Schwyz und dem St. Galler Oberland. Es beginnt der sogenannte «Blütschenoder Oberländer Holzhandel», der bis zum Jahre 1826 fortdauerte und dem die Absicht zugrunde lag, jedermann in der Stadt den Bezug billigen Holzes zu ermöglichen. Aber mehr noch als durch all diese Bestrebungen manifestiert sich die gesteigerte Wertung des Waldes und der Waldwirtschaft in den umfassenden Ankäufen und Arrondierungen, welche in diese Periode fallen. Es ergibt sich der Beweis hiefür am besten aus der chronologischen Darlegung der Arealveränderungen bis zum Ende des 18. Jahrhunderts und zwar am deutlichsten, wenn die einzelnen Hauptdistrikte speziell ins Auge gefasst werden. 


\section{Der Sihlwald und die Albishölzer.}

Der noch in Jahre 1492 an den jetzigen Thomannbach stossende Silhwald konnte sich weder nach seiner südöstlichen Seite in der Richtung gegen den Schweikhof. noch gegen den Berggrat am Allis hin vergrössern. Seine Ausdehnung war gegeben in der Richtung nach Nordwest gegen Langnau und Adliswil. - Im Jahre 1506 machte die Stadt den Anfang mit der Erweiterung nach dieser Richtung hin. Sie kaufte den heutigen Langenberg.

1515 erwirbt sie unmittelbar daran angrenzend die jetzige Winzelen, dazumal «Winzischwend» genannt.

1537 erfolgen die ersten Ankäufe für den nachmaligen Schweizertobel-Komplex, der nach drei Jahrhunderten anlässlich der Servitutsablösung an die Gemeinden Langnau und Adliswil abgetreten wurde.

1538 Ankauf der Risleten, d. h. des jetzigen Kolbenholzes.

1553 wird der Langenberg wieder um 11 Jucharten und

1557 nochmals um 15 Jucharten vergrössert.

1558 Ankauf der Ragnau.

1564 Ankauf von 11 Jucharten rom Schnabelburgerhof.

1589 Vergrösserung der Winzelen.

Das 17. Jahrhundert zeigt nun bereits weniger 'Tendenz nach einer Waldvermehrung. Entsprechend der auch in der Organisation sich bemerkbar machenden konservativen Strömung werden wenig Arealveränderungen vorgenommen. Erst gegen Ablauf des Jahrhunderts tritt vermehrtes Leben zutage.

1680 wird der erste Grundriss vom Sihlwald und den Albishölzern aufgenommen.

1697 wird der erste Wirtschaftsplan aufgestellt.

1698 wird die "Schleipfende Fliieh" bei der Ragnau angekauft.

1695 wird die Winzelen abermals vergrössert und

1697 wird die Winzelen und der Langenberg auf den Bestand gebracht, auf dem sich die beiden Komplexe bis zum Jahre 1798 befanden.

Auffallenderweise lässt nun das ganze 18. Jahrhundert das Areal der Sihlamtswaldungen unverändert; mit dem Jahre 1798 ist daher sein Bestand zufolge der vom Schanzenherr Fehr vorgenommenen Vermessung: $\quad$ Sihlwald $=682,00$ ha

$\left.\begin{array}{c}\text { Winzelen, Langenberg } \\ \text { und Schweizertobel }\end{array}\right\}=81,40$ ha $\}=763,40$ ha 


\section{Der Forst.}

Die wichtigste Metamorphose in den Wald- und Eigentumsverhältnissen der Stadt Zürich führte die Säkularisation der Fraumünsterabtei herbei. Am Liebfrauentag des Jahres 1524 cedierte Anna v. Zimmermann, die letzte der Aebtissinnen des einst so mächtigen Stiftes, schenkungsweise alle Güter des Klosters der Stadt Zürich, und damit auch den Forst, den König Ludwig im Jahre 853 der Abtei geschenkt hatte. Seinem Umfange nach zwar wenig verändert, war der solcher Art geschenkte Wald keineswegs mehr jenes freie Eigentum, wie wir dasselbe in seiner Eigenschaft als Forestum nostrum Albis nomine kennen lernten. Die Anrechte der Bauern auf den Drei Huben, von denen der Schiedsspruch des Jahres 1263 redet, hatten sich teils durch Käufe von den Grafen von Kyburg, welche demnach einen Anteil vom Forst besessen haben müssen, teils durch Begünsiigung der Aebtissin auf dem Wege der Teilung, Vererbung etc. auf 15 Anteile, die sich innerhalb der ehemaligen drei Häuen verteilten, ausgedehnt. Dazu kamen 15 Fal- oder Fadtannen-Gerechtigkeiten, die je alle drei Jahre iliren Hau hatten, und endlich 561 Hofwigtburden, letztere entstanden aus einer Retribution des Zinshoizes, das die Lehensleute des Klosters ab sämtlichen Gütern dem Stifte alljährlich zu hringen hatten. Soviel Burdinen als einer an die Schifflände Ziïrich zu liefern hatte, durfte er umgekehrt auch für sich aus dem Forst beanspruchen. Das «Kloster» und nachher das "Ampt» erhielt aus dem Forst jährlich nur soviel, als gewisse Brennholz- und Bauholzbedürfnisse für ihre Minimalbefriedigung beanspruchten. So war denn allerdings das Eigentumsrecht in bedentendem Umfang reduziert und die Ansprüche der Nutzniesser waren nicht geringer als der Nutzen, der dem Grundherrn zuteil wurde.

Die Eigentumsübertragung an die Stadt bot indessen willkommenen Anlass, Ordnung in die Verwaltung hineinzubringen. Die alten Offnungen und Rodel wurden ernevert und bereits im . Jahre 15:4 eine neue Verordnung erlassen. Ein Herr Obmann, Ammann und Rechenschreiber mussten bei Áusteilung der Häuen im Forst vorreiten. und Häue, Fadtamen und Hoffnungshurdinen in bestimmter Weise ausgeben. Alijährlich versammelten sich alle, so Hub-und Schupposgenössige Güter besassen, auf die Mayen Tädung (Gericht), die im Beisein beider Herren Bürgermeister und der Rechenherren, des Stiftschreibers, auch Obristenknechtes in nicht wenig zeremoniöser, 
eigenartiger Weise abgehalten wurde. Nachdem dieses Gericht von einem jeweiligen Bürgermeister eröffnet worden war, übergab der Ammann (des Stiftes) der Person, so von den Besitzern der XIl Schupposen hiezu ernannt worden war, den Stab zu führen. Der frägt alsdann um, ob es Tageszeit sei, zu richten. Wenn nun diese erste Frage umgegangen, wird gefragt, ob männiglich nach altem Brauch zum Gerichte eingeladen, oder ob jemand fährlicherweise ausgeblieben sei. Nachdem auf dieses keine Klage eingegangen, frägt der Richter, was nunmehr das erste Geschäft sein solle; darauf wird erteilt, dass das Gericht nach altem Brauch und Herkommen verbannt (beeidigt) werde. Sodann folgt das Verlesen der Offnung unter jedesmaliger Anfrage, ob die Offnung stände wie von alters her. Waren neue Schupposer vorhanden, so wurden sie nunmehr vom Bürgermeister ins Gelübde genommen. Käufe und Handänderungen mussten hiebei vom Pechenschreiher nachgetragen werden. Hernach hatten sich die Förster in Ausstand zu begeben, und wurde Umfrag gehalten, wie sie sich das Jahr hindurch verhalten hätten, und umgekehrt haben nachher die "Vorst-Meister», als welche wohl die Forstgenossen und Nutzniesser anzusehen sind, sich zu entfernen. und werden die Förster über das Verhalten dieser angefragt, ob sie ihrerseits besondere Klage zu führen hätten u. s. f. ${ }^{1}$ ) Das letzte Mayen-Gericht wurde 1640 gehalten. Nachher wurde alljährlich bei der Forstreise der eigens hiezu verordneten Forstkommission zur Einsicht und Verteilung des Holzschlages Bussengericht abgehalten.

Charakteristisch für das Eigentumsverhältnis ist, dass noch im Jahre 1772 verfügt wurde, es dürfen die Hubengenossen auf ihre Gerechtigkeiten Geld entlehnen, allein die Schuldinstrumente müssen ihnen von der Rechenkanzlei ausgefertigt und es dürfe der Kreditor im Falle eines Konkurses nicht Holzgenoss werden. Das Recht des Ankaufes lediger, zum Verkaufe ausgebotener Huben blieb durch alle Wandlungen hindurch in erster Linie immer den "Herren», d. h. dem Fraumünsteramt vorbehalten. Von dieser Instanz aus erfolgte auch die Abbüssung der Frevel. Die Stadt, resp. das Fraumünsteramt war und blieb demnach immer Grundherr und die Forstgenossen traten nicht aus der Rolle der Nutzungsberechtigten heraus.

Gegen Ende des 18. Jahrhunderts befand sich das Ant wieder in dem Besitz von drei zurückerkauften Huben, drei Fadtannen-

1) Rechte und Offnungen des Antes Framuünster, zu dem sog. alten Forst. auch zugehörigen Huben und Schupposen zusammengetragen. Ni. MDCC: 
Gerechtigkeiten und 161 Hofwigthurdinfm. Srine direkt jührliche Nutzung bestand in durchschnittlich 160 Klaftern in Form des sogenannten Sihlhaues, welcher an die Sihl geführt und auf dieser in die Stadt geflösst wurde.

Die Forstgenossen hatten 13 Hubgerechtigkeiten mit 6-8 Klafter Nutzung, 12 Fadtannen-Gerechtigkeiten, 355 Hofwigtburden, und endlich kam die Löhnung der Förster, meist in Holz, und die Gnadenoder Kompetenzhölzer an Pfarrer, Schulmeister, Sigrist und Hebammen von Horgen, Oberrieden und Thalwil, macht zusammen etwa 400 Klafter alljährliche Gesamtnutzung.

So standen die Verhältnisse beim Eintritt ins Jahr 1798.

\section{Bergamtswaldungen.}

Wie für die Sihlamts- und die Fraumünsteramts-Hölzer mit dem 16. Jahrhundert eine neue Aera anbrach. so war dieses auch der Fall mit demjenigen Waldteil, der heute noch als Adlisberg dazumal den hescheidenen Bruchteil eines riel umfangreicheren Grumdeigentums der Stadt auf den Höhen des Zürich- und Adlisberges bildete.

Die wenigen Markgenossen oder Freien am Zürichberg, welche ursprünglich mitsamt einem Teil der Bürgerschaft der Stadt die Allmend auf dem Zïrichberg benutzt hatten, hatten sich vermehrt; an die Stelle einzelner Gehöfte waren die Wachten Hottingen und Fluntern getreten. Die Weidansprüche aus der Stadt selbst waren der Natur der Sache nach geringer geworden, diejenigen dieser Ausbewohner grösser. Das Kloster St. Martin war eingegangen und zum Obmannamte geschlagen worden. Da erliess der Rat im Jahr 1540 eine besondere Organisation für das Besitztum auf dem Zürich- und Adlisberg. Es wurde das sog. Bergamt geschaffen und verordnet:

1. Dass 66 ha Waldungen zu Diensten der Stadt ausgeschieden sein sollen; das waren die nachherigen Bergamtshölzer.

2. Dass 37 ha den in den Wachten Hottingen und Fluntern gesessenen und allenfalls auch andern Stadtbürgern zur Benutzung als Weidgang angewiesen sein sollen; es war das die nachherige Allmend.

3. Der dritte Teil des Gaues auf dem Zürichberg endlich wurde zu einem Lehenshof, dem sog: Klösterli umgewandelt, und dieser dem Obmannamt zur Verwaltung übergeben. 
Detaillierte Bestimmungen über die Befugnisse der Bergamtsverwaltung, des Bergherrn, wie der Förster und der Hirten, zeigen, dass man vom besten Willen beseelt war, auch dieses Eigentum so gut wie möglich zu bewirtschaften.

Der sub 1 angeführte Teil wurde bald durch eine Reihe bedeutender Ankäufe vergrössert:

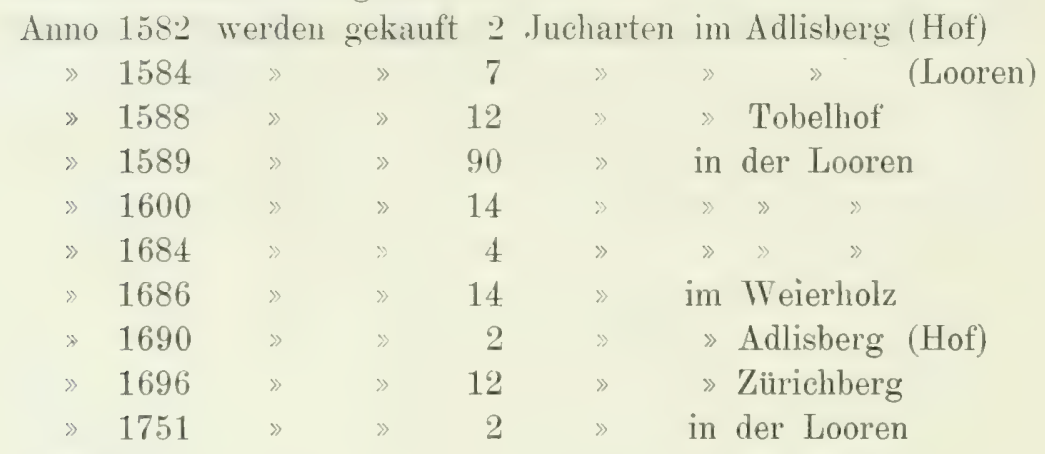

Daneben aber machte sich, ähnlich wie im Forst, mit der Zunahme der Bevölkerung eine stetig wachsende Tendenz der nutzungsberechtigten Wachten geltend, von dem Zürich- und Adlisberg-Eigentum ein grösstmögliches Nutzungsquantum für sich zu beziehen. Das Holz wurde alljährlich von den Holzbedürftigen der Gemeinden Hottingen und Fluntern geschlagen, und dafür wurde ihnen Stock- und Grotzenholz überlassen. Das beim Erdünnern erhältliche Standenholz wurde gleichfalls den Akkordanten zugeteilt. Man suchte, wie sich aus den mehrfachen Waldbeschreibungen ergibt, die Zuwachs- und Holzvorratsverhältnisse zu verbessern, und führte namentlich mit Bezug auf das Hiebsquantum eine ziemlich haushälterische Wirtschaft. Nit Anfang des Jahres 1798 betrug der Umfang der Zürich- und Adlisberghölzer 212,89 Hektaren. 


\title{
C. Entwicklung der Eigentumsverhäitnisse
}

\author{
von $1798-1880$.
}

\section{Uebergang des heutigen Waldbesitzes an die Stadtbürgergemeinde.}

Die politischen Ereignisse des Jahres 1798 brachten auch für das Waldareal bewegte 'Tage. Mit dem Umsturz der bisherigen Ziurcherischen staatsverfassung trat die Stadt als Landesherr gegenüber einem äusseren Landesteil zurück in die einfache Stellung einer gewöhnlichen Munizipalität. Dadurch musste notwendigerweise die Frage entstehen, wem gehört nunmehr das von der souveränen Stadtherrschaft bisher verwaltete und benutzte, allgemeine Eigentum, wem gehören vorab auch die Waldungen? Die Helvetik hatte das sämtliche Staatseigentum als National-Eigentum erklärt, und dasselbe einer Verwaltungskammer unterstellt. Die Neigung lag vor, auch die von der Stadt im engeren Sinne, d. h. von der Bürgerschaft als solcher benutzten Waldungen in diese Kategorie einzureihen. Es wurde daher im Anfang auf das gesamte Areal und sogar auf das im Sihlamt sich vorfindende Holz Sequester gelegt, bis die Stadtmunizipalität der Verwaltungskammer diejenigen Titel vorlegen könne, wodurch sie ihr ausschliessliches Recht auf den Sihlwald und die übrigen Hölzer zu zeigen im stande sei. ${ }^{1}$ ) Unterm 14. August 1798 entschied sich indessen das helvetische Vollziehungsdirektorium dahin, es seien der Munizipalität Zürich diejenigen Wirtschaftsbezirke bis auf weiteres zu fernerer Bewirtschaftung und Benutzung zu überlassen, welche in dem von der Verwaltungskammer eingereichten Verzeichnisse nicht als Nationalwaldungen bezeichnet worden waren. Letztere übergab demgemäss unterm 1. September 1798 die Sihl- und Bergamtshölzer der stådtischen Verwaltung, während der alte Fraumünsteramtsforst und die sogen. Bauamts-Waldungen als Nationalwaldungen erklärt, und der Forstkommission, beziehungsweise dem "Bürger Forstinspektor» zur Verwaltung übergeben wurden.

1) Zuschrift der Verwaltungskammer, den 3. Mai 1798. 
Unterm 2. April 1799 erliess die helvetische Regierung ein Gesetz, welches über die Trennung der Staats- und Stadtgïter bestimmte Rechts-Grumlsätze aufstellte. Die Lösung des vorliegenden Verhältnisses bot indessen so viele Schwierigkeiten, dass unterm 13. August 1800 eine allgemeine Sonderungskommission ernamnt werden musste. Das helvetische Finanzministerium ersuchte daraufhin die städtische Gemeindeverwaltung zu seinen Handen um beförderlichste Eingabe eines vollständigen, begründeten Verzeichnisses ihrer sämtlichen Ansprachen. Im Jahre 1801 legte die Stadt diese Ansprüche vor, in dem sorgfältig ausgearbeiteten (gedruckten) Hemorial der Gemeindeverwaltung von Zürich an die helvetische Regierung betreffend die Sönderung des Zürcherischen Staatsgutes vom Stadtgut. In diesem wichtigen Aktenstücke werden mit Bezug auf das Waldareal, "teils als bisher von der Stadtbürgerschaft besessen und beworben, teils als für rein städtische Einkïnfte verwendet», verlangt:

Die Zuteilung: des Sihlwaldes,

der Albishölzer,

der Allmend auf dem Zürichberg,

der Hölzer auf dem Zürichberg und Adlisberg, des Fraumünster-Amt-Forstes unid der Bauamtswaldungen.

Sei es, dass die Helvetik zu kurze Zeit dauerte, oder dass die Schwierigkeiten der Arbeit für die Sönderungskommission der helvetischen Regierung zu gross waren, im Jahre 1803, da die Mediationsakte neue politische Verhältnisse schuf, war die Ausscheidung noch nicht zu stande gekommen. Es schrieb deshalb die Mediationsakte vom Jahre 1803 eine besondere Liquidationskommission vor, welche den Auftrag hatte, die helvetische Nationalschuld zu liquidieren, den ehemals souveränen Städten ein verhältnismässiges Einkommen zu schaffen und wieder ein städtisches gesondertes Vermögen $\mathrm{zu}$ errichten, und endlich das übrige Vermögen dem Kanton als Kantons-Vermögen zuzuweisen.

In Erfüllung dieses Auftrages konnte die Liquidationskommission an der Hand des städtischen Memorials bereits sub 1. September des Jahres 1803 das Ergebnis ihrer Ausscheidungsarbeit in Form der sog. A ussteuerungsurkunde endgültig darlegen. Infolge dieses Ausscheidungsmorlus erhielt die stant mit Bezue auf die Waldungen ziemlich dasjenige, was sie mit ihrer Begründung in dem Memorial des Jahres 1801 verlangt hatte. Zur Beratung dieser Vorlage 
wurden unterm 6. September 1803 durch oinen Bachluss des kleinen Rates zum endguiltigen Vertragsabschluss anf Basis dor Liquirationsurkunde eine Finanzkommission und ein vom Startrat diesseits ernannter Ausschuss niedergesetzt. Dieser Ausschuss gelangte dazu, die eidgenössische Vorlage zur Annahme zu empfehlen und sub 22. Juni des Jahres 1805 formulierten und akzeptierten Staat und Stadt in dem sogenannten Abchurumysinstrument die näheren Details zu einem unverzüglichen Inkrafttreten des durch die Aussteuerungsurkunde geschaffenen Verhältnisses.

Die Stadtbürgergemeinde Zürich besass nunmehr:

1. Die Bauamtswaldungen:

ha

Fuderholz, Dachsberg und Rüitibühel bei

Erlenbach,

Das Kopfholz bei Rủschlikon,

Das Geerenhölzli bei Wiedikon,

2. Den Fraumiinsteramts-Forst:

3. Den Sihlwald:

4. Die Albishölzer:

Winzelen, Langenberg und Schweizertobel 94,17

5. Die Bergamtshölzer:

Adlisberg, Zürichberg und Allmend 212,89

Total ha: 1272,30

mit der Terpflichtung, aus den Erträgnissen die Holzlieferungen an die Bürgerschaft, das Bauholz für den Unterhalt der Gebäude und des Sihlkanals, und die Feuerung aller zur Administration erforderlichen Zimmer zu besorgen.

Es waren durch die derart überbundenen Lasten von vorneherein zwei Kategorien ron Wraldungen geschaffen: Waldungen tiil allgemeine Gemeindezwecte und Traldungen für rein bïrgerliche Zueclit. Im Anfange wurden, entsprechend der früheren Verwendung der Walderträge, die Bedürfnisse für die ersteren wesentlich aus den sogenannten Batuants- und den Framüunsterantswaldungen sedeckt. während die anderen Komplexe als Bürger-Korporationsgut zu rein bürgerlicher Nutzniessung verwendet wurden; eine scharfe Ausscheidung existierte indessen nicht. Dem Entwicklungsgang, welchen die Gemeindegüter unseres Kantons bis gegen Mitte der fünfziger 
Jahre folgten, vorauseilend, machte sich in der Stadt Zürich schon früher das starke Hervortreten der Einwohnergemeinde gegenüber der reinen Bürgergemeinde und damit auch die Tendenz geltend, die Oekonomie dieses Hauptteiles zu ordnen. Es erfolgte deshalb bereits Anno 1844 die definitive Ausscheidung des für öffentliche Zwecke dienenden Gemeindegutes und des Bürgergutes. Die Einwohnergemeinde erhielt 214 ha in Form der Bauamtswaldungen und des mittlerweile durch die Servituten-Ausscheidung reduzierten Fraumünster-Forstes und Neuforstes. Das Bürgergut erhielt 985 ha in Form der Sihltal- und Adlisbergwaldungen. Sehr bald macht sich indes die gedoppelte Betriebs- und Rechnungsführung mit allen ihren Nachteilen um so mehr geltend, als die bisherige wirtschaftliche Auffassung dahin gegangen war, den Wald als ein Ganzes zu behandeln; Altersklassen- und Hiebsfolge, sowie die Zuwachsverhältnisse litten unter dem jetzigen Trennungszustande. Schon vom Jahre 1849 an trachtete daber die Administration dahin, diese Verhältnisse zu sanieren, durch Verkauf abgelegener Parzellen einerseits, und anderseits durch Unterbringung des Restes in eine Hand. Bis zum Jahre 1857 wurden nach und nach verkauft: das Fuderholz, das Geerenholz, der Dachsberg, das Laubholz, die Schweikrüti und der Neuforst, zusammen 54,7 ha, so dass nur noch vorhanden waren 167 ha. Durch Gemeindebeschluss vom 1. Februar 1858 übernahm dann die Bürgergemeinde den Rest der noch vorhandenen Waldungen der Eimwohnergemeinde um die Aversalsumme von $136,000 \mathrm{Fr}$., verzinsbar zu $4^{\circ} \%$; und damit fand der Wandlungsprozess, den das städtische Waldbesitztum seit bald sechs Jahrhunderten durchlaufen hat, einen gewissen Abschluss mit Bezug auf die Person des Eigentümers, dagegen noch nicht mit Bezug auf das Eigentumsobjekt, das durch die in die gleiche Zeit fallende Ablösung der Servituten und der damit Hand in Hand gehenden Verkäufe und Ankäufe bedeutungsvollen Veränderungen entgegengeführt wurde.

Die formelle Zuerkennung der verschiedenen Waldparzellen an die Stadtbürgergemeinde durch die notarialische Eintragung in die Grundbücher fand nummehr auch statt, und die stadthügergemeinde befindet sich mit dem Jahre 1880 im unbestreitbaren rechtlichen Besitze von 1149,60 ha in Form derjenigen Eigentumstitel, welche die Arealtabelle einzeln nachweist. 


\section{Die Veränderungen des Arealbestandes von 1798-1900.}

Mit dem Inkrafttreten des sogenannten Abchurungs-Instrumentes war der Gesamtarealbestand 1272,30 ha. Es blieb derselbe indessen nicht allzulange ohne wesentliche Veränderungen und bis zum Jahre 1835 sind stetige Vergrösserungen durch Ankäufe zu konstatieren:

1811 wurden 0,40 ha des Sihlhaldenholzes angekauft;

1812-1814 wurde das Kopfholz um 8,7 ha vergrössert;

1808 wurden zum Schweizertobel 3,00 ha hinzugekauft;

1825-1829 wurden die Schnabelberger Hofgüter erworben, zusammen 81,36 ha.

Im Jahre 1834 erreichte das städtische Waldareal seine Maximalstärke mit Summa 1348 ha; es hat diese bisher nicht wieder erreicht. Denn mit dem Jahre 1834 begann die Ablösung der Belastungen der einzelnen Walddistrikte. Sie nahm ihron Anfang mit dem Forst, der im Jahre 1835 zunächst 122,17 ha durch Ablösung der Ansprüche der Forstgenossen von Thalwil, Oberrieden und Horgen verlor. Bald darauf folgte die analoge Operation mit den Bergamtswaldungen, wo 95 ha an die Wachten Hottingen und Fluntern abgetreten wurden.

Nun begann von Mitte der vierziger Jahre an infolge der Konzentrationsbestimmungen des Betriebes der Gemeinde- und Bürgergutswaldungen einerseits, wegen Servitutsablösung anderseits, eine Periode grosser Bewegung. Es wurden von 1846 an verkauft:

IV. 1846/47 Fuderholz

$1850 / 51$ Geerenholz

1854/56 die Erlenbacherhölzer

Baueumtshölzè

$1855 / 56$ das Kopfholz

ha

1855/56 im Adlisbery

45,97

1856

das Schweizertobel

27,68

vom Fraumïnsterforst:

44.49

ha

$1856 / 57$ an Thalwil 24,35

1855/57 》 Horgen 28,56

$1856 / 60$ » Private 7,20

$1856 / 60 \gg$ Neuforst 19,65

1874 Dandforst $7,61 \quad 87.37$

Summa 570 Jucharten $=205,51$ 
Was hier verkauft wurde, war meist wohlbestandener, alter, jahrhundertelang besessener Wald. Der Servitutenloskauf als solcher war bei der Gesamtverkaufssumme von $328,100 \mathrm{Fr}$. nur mit 60,680 $\mathrm{Fr}$. $70 \mathrm{Cts}$. beteiligt.

Hand in Hand mit diesen Verkäufen ging nun allerdings die Waldesergänzung. Die gleiche Forstrerwaltung, welche die ersteren durchgeführt, liess es sich auch angelegen sein, dem Gesamtareal etwelchen Ersatz zu bieten, und zwar erstreckten sich die Vergrösserungen soweit möglich auf alle drei Gruppen.

Der Sihlwald wurde vergrössert: ha 1855/56 durch den Ankauf der Risletengüter um 57,19 $1870 / 74$ des Albisplateau um 25,00

zum Forst:

1855/63 Stengelen- und Tabletengüter und Sparrenau um

1873 auf der Stengelen

die Steinmatt

1870/75 zum Adlisberg:

1870/75 zum Langenberg:

Summa 154,03

In den Jahren 1875-1880 wurden unter der derzeitigen Verwaltung weiter angekauft: ha

$$
\begin{aligned}
& \text { a) zum Sihlwald: an Risletengütern 1,60 } \\
& \text { b) auf der Forstseite: der Steinkratten 1,90 } \\
& \text { c) im Adlisberg: in der Looren } \quad 8,00 \\
& \text { Ankäufe von } 1875-1880 \text { Total } 11,50 \\
& \text { dazu 》 》 } 1846-1875 \text { » } 154,03 \\
& \text { Also Vergrösserung 'Total 165,53 }
\end{aligned}
$$

Gegenüber dem Zustand vom Jahre $1883^{\prime}$ ) hat das Areal der Waldungen des städtischen Stiftungsgutes im Verlauf der letzten zwei Dezennien durch die anlässlich der Erstellung der Sihltalbahm und der auf eine kurze Strecke den Sihlwald durchquerenden Linie Thalwil-Zug veranlassten Abtretungen und anderseits durch verschiedene Ankäufe zum Zwecke der Arrondierung etwelche, wenn auch nicht bedeutende Veränderungen erfahren. Es wurden im Verlaufe dieser zwanzigjährigen Periode nachfolgende Ankäufe gemacht:

1) Erste Auflage. 
Sihlwald 11. Adlisberg Taugenberg

1884 im Forst (Steinkratten)

hit hat

1889 Albishölzer (Riengg)

0,22

1890 im Forst (Enklave Schäppi)

14,23

0,05

$1892 》$ Adlisberg (Enklave Tuggener Rordorf) 1,31

1896 » Rengg (Hüttenmatte) Albisplateau 1,17

1898 am Albishorn

0,45

1900 in der Winzelen

1,85

1901 im Adlisberg (Enklave Gut und Möcklin

In Abgang kamen:

$20,01 \quad 0,53$

Abtretungen an Sihltalbahn und Thalwil-Zug

11,95

0,19

Uebergang $d$. früh. Privatstrasse in öffentl. B.

4,77

Verkauf im Adlisberg

0,44

17,16

0,34

somit ergibt sich für das Jahr 1900 ein Areal-

bestand von

45,00

Die nachfolgende Uebersicht der Arealverhältnisse von 1805, $1837,1850,1860,1880$ und 1900 dürfte am ehesten im stande sein, die angeführten Bewegungen klar vor Augen zu führen:

Arealbestand:

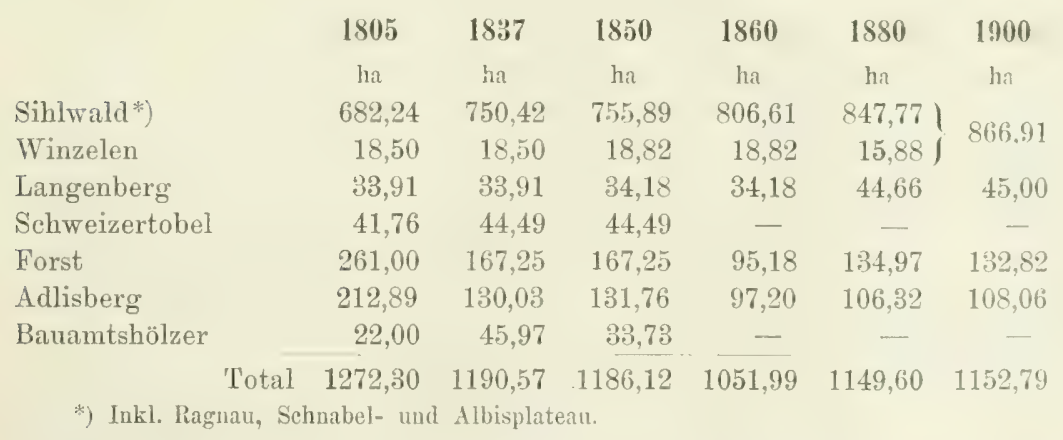

Ganz abgesehen von den Ablösungen der nutzungsberechtigten Forstgenossen von Thalwil, Oberrieden und Horgen im Forst, und der Wachten Hottingen und Fluntern ist demgemäss gegenüber dem Zustand von 1837, trotz den sehr erheblichen Ankäufen, eine Verminderung des Waldareals zu konstatieren. Qualitativ ist der Verlust natürlich noch grösser, wenn man Lage, Zuwachs- und Vorratsverhältnisse speziell der im Fraumünsterforst und Adlisberg. 
(Buschberg) anlässlich der Servitutaahlösungen ahgetretenen Waldteile ins Auge fasst. Das was angekauft wurde, waren bisher landwirtschaftlich beworbene Grundstiicke mit kleineren Parzellen schlecht gepflegter Waldung. Die bedeutendsten Partien dieser Ankäufe sind zwar heute aufgeforstet, aber auch der aufgeforstete Teil wird den Charakter eines wohlbestandenen Waldes erst dann erhalten, wenn jene eigentïmliche Wirkung, welche die nach Jahrhunderten zählende pflegliche Behandlung des Waldes anszuïben im Falle ist, sich geltend gemacht haben wird am "Neuland», welches das 19. Jahrhundert dem tausendjährigen Walde angefügt hat.

\section{Die Entledigung des Eigentums von Ansprüchen Dritter.}

Von ebenso tief einschneidender Bedeutung für die quantitative Gestaltung des Waldareals und seine qualitativen Eigentumsverhältnisse, wie umgekehrt von hohem Interesse in forstgeschichtlicher Bedeutung ist der Entwicklungsprozess, den die Servitutsverhältnisse der städtischen Waldungen genommen hahen. Sowohl der Fraumünsterforst, als die eigentlichen Sihlamts- wie die Bergamtswaldungen galten durch die Jahrhunderte hindurch und sogar noch im 18. Jahrhundert als servitutfreies Eigentum. Durch Einräumung von Vergünstigungen an umliegende Gemeinden und Private waren sie aber trotzdem im 19. Jahrhundert mit Anrechten Dritter stark belastetes Eigentım. Noch im Jahre 1798 schreibt Sihlherr Pestalutz: «Auf dem Silwald haften keinerlei Servituten.» Was die benachbarten Gemeinden an mancherlei Unterstützungen von jeher aus demselben genossen, ist immer als wohltätige Uebung von der Stadt anerkannt und niemals als ein Recht angesprochen worden. Einzig von den Albishölzern wurde das Witfrauen- und das Durchforstungsholz niemals in die Stadt geführt, sondern im ungefähren Betrage von 40 à 50 Klafter an die Pfarrer von Langnau und Kilchberg, die Schule und die armen Leute von Adliswil und Langnau vergeben.

Die Erfahrungen, welche man in der politischen Bewegung von 1798 bis 1801 machen konnte, die Entwicklung der Ansichten, welche sich in den ersten Dezennien des laufenden Jahrhunderts iiber den Begriff einer intensiven Forstwirtschaft Bahn gebrochen hat, endlich der Wert, den die vorher sorglos eingeräumten Holz- 
begïnstigungen mit dem Steigen der. Waldprodukte erhielten, zeigten zu spät, dass das Waldeigentum infolge dieser Vergünstigungen faktisch mit Servituten belastet worden war. Man hatte nur noch die Wahl dieselben in eine kontrollierbare Form der Ausübung zu bringen, oder abzulösen, sofern man bestrebt sein wollte, die Waldwirtschaft auf einen der Wissenschaft und den Gesetzen einer gesunden Finanzwirtschaft entsprechenden Standpunkt zu bringen.

Die Periode von $1830-1860$ ist ausgefüllt mit Bestrebungen dieser Art und der Weg; welcher gewählt wurde, führte korrekterweise zur Befreiung des Waldeigentums von allen Ansprüchen dritter Personen. Glücklicherweise erhielt sich jener schöne und richtige Grundsatz, den die helvetische Verfassung in ihrem Art. 13 aufstellte:

«Der Grund und Boden kann mit keiner Last. Zins oder Dienstbarkeit beschwert werden. wovon man sich nicht loskaufen könnte.»

in der Zürcherischen Gesetzgebung, auch nachdem die helvetische Verfassung längst als verfrihtes Streben dahingefallen war, doch als wirtschaftliches Axiom, an dessen konsequenter Durchführung vorab die in den dreissiger Jahren bahnbrechende Forstgesetzgebun $\underline{g}$ tätigsten Anteil nahm.

a) Die Ledigung des Fraumünsterforstes.

Der alte Fraumünsterforst war durch die Aussteuerungsurkunde vom Jahre 1803 mit allem V.orbehalt der Rechte Dritter der Stadt Zürich übergeben worden. Die zugunsten der Forstgenossen Thalwil. Oberrieden und Horgen bestehenden Holznutzungen waren in den durch den Stadtrat als Grundeigentümer gefertigten sogenannten Lehen- und Tragerbriefen angegeben. Daneben wurde schon seit langer Zeit den Armen der genannten Ortschaften gestattet, aus dem alten Fraumünsterforst das abschätzige Holz zu sammein und die Wurzelstőcke auszustocken. Diese Vergünstigungen wurden in der Zeit, da der Forst Nationalwald war, ron den Holzarmen wiederholt rechtlich verlangt. Endlich bestand seit dem Jahre 1591 für die Gemeinden Thalwil, Oberrieden und Horgen das Recht des Weidgangs im alten Fraumünsterforst. Horgen war aber im Jahre 1649 von diesem ausgeschlossen worden. weil es den anderen Gemeinden den Weidgang in der ihr zustehenden Horger-Egg verboten 
hatte. Eine Reihe von Verordnungen von 1770-1801 etc., später die Forstgesetzgebung, hatte diese Servitut ziemlich normiert, nicht abel unschädlich gemacht.

Nun liessen unterm 18. Februar des Jahres 1832 die Forstgenossen der Stadt als Besitzerin des alten Fraumünsterforstes Forderungen zugehen, die freies Eigentumsrecht und Verkaufsrecht ihrer Huben, stärkeren Lattenhieb, bessere Kontrolle der städtischen Holzkompetenzen, und endlich Wegfall des Hühnergeldes in sich schlossen. Da der Stadtrat diesen Forderungen nicht glaubte entsprechen zu können, so bewirkten die Nutzniesser beim Bezirksgericht Horgen eine Sistierung der weiteren Benutzung des Forstes durch die Stadt, bis ihren Wünschen entsprochen sei, und der Stadtrat liess nun seinerseits ein Verbot ergehen, dass einstweilen jedermann der Besuch des Forstes behufs irgend welcher Nutzung untersagt sei. So standen die Dinge Ende des Jahres 1832; man befand sich auf feindseligem Fusse, sah aber beidseitig ein, dass eine Fortdauer des bisherigen Zustandes unhaltbar sei. Unterm 4. Dezember des Jahres 1832 erteilte nun der Stadtrat der dazumaligen Forstkommission den Auftrag: zu untersuchen und vorzuschlagen, wie mit billiger Berücksichtigung der bisher bestandenen Verhältnisse die Beseitigung der zwischen Stadt und Forstgenossen von Horgen, Oberrieden und Thalwil wegen Rechten und Nutzungen des Fraumïnsterforstes obwaltenden Aistände erzielt werden könnte?

Nach reitlicher Prüfung aller Faktoren wurde gefunden, dass die völlige Ausscheidung der Nutzungsansprüche auf dem Wege der Realteilung des Waldes einer blossen Servituten- und Nutzungsregulierung vorzuzieher sei, so sehr sich auch Bedenken gegen die Abtretung des ebenso wohlgepflegten als schönen Waldes geltend machten. Als Basis für eine Realteilung wurde das bisherige Nutzungsverhältnis angenommen. wornach der staut im Durchschnitt alljährlich 220 Klafter, den Forstgenossen dagegen 270 Klafter zugefallen waren. Indem nun gesucht wurde für den der Stadt zufallenden Teil eine diesem jährlichen Ertrage entsprechencle Fläche auf der Sihlseite zu finden, erhielt dieselbe infolge einer sorgfältigen taxatorischen Ermittlung durch Forstmeister Ammann fiei und zu eigen 141,80 ha und die Forstgenossen 122,17 ha (Art. 2). Auch verzichtete die Stadt auf den ferneren Bezug des ihr durch die alten Offnungen, als Nachfolger des Lehensherrn zugesicherten Hiuhnergeldes (Ersat\% für das alljähnliche Fastuarchthuhn). To lange der Weidgang fortbestehen sollte und nicht auf die eine oder andere 


\section{$8: 3$}

Art aufgehoben würde, soll er in dem ganzen alten Forst ausgeübt werden (Art. 9).

Hinsichtlich der Holzarmen-Ansprüche der Gemeinden Horgen, Oberrieden und Thalwil soll der Anteil der Forstgenossen den gleichen Verhältnissen unterworfen sein, wie derjenige der Bürgerschaft der Stadt Zürich. - Unterm 18. April des Jahres 1835 wurde dieser Vertrag rechtskräftig von beiden T'eilen bestätigt. Durch einen zweiten Vertrag mit den drei Gemeinden wurde dann auch das Verhältnis zu der ärmeren Klasse in den Gemeinden Thal wil. Oberrieden und Horgen betreffend das Sammeln von Raff- und Leseholz, das Reinigen des Waldes, das Ausstocken und Ausgraben der Wurzelstöcke geregelt. Dieser Stand der Dinge dauerte unverändert fort bis im Juni des Jahres 1843, wo nach vielfach vergeblichen Bemühungen die Weidgang-Servitut abgelöst werden konnte. Die Stadt hatte $1458 \mathrm{fl}$. und die Landforstgenossenschaft $1182 \mathrm{H}$. als Loskaufssumme zu bezahlen. Die Lese-, Reinigungs-und S'tockholzservitut dagegen dauerte bis zum Jahre 1860, wo durch Vertrag vom 15. Dezember 1859 sämtliche, im Sinne des Vertrages vom Jahre 1834 zugunsten der Gemeinden Thalwil, Oberrieden und Horgen auf dem alten Fraumünsterforst lasstenden Nutzungsrechte um die Summe von $5000 \mathrm{Fr}$. abgelöst wurden. In einem 2. Artikel dieses Vertrages wird die Fortbenutzung des Raff- und Leseholzes nach den Bestimmungen des modifizierten Sihlwaldrertrayes (siehe pag. 92) gestattet.

Eine Landabtretung wurde sowohl bei Ablösung des Weidganges, als der Wurzelstock- und Reinigungs-Servitut vermieden. Der Fraumiunsterforst ist nunmehr mit dem kleinen Bruchstück des alten Forstes, das der Stadt noch verblieben ist, absolut servitutfreies Eigentum des städtischen Stiftungsgutes.

b) Die Ablösung der Belastung der Sihlamtshölzer.

Während im Jahre 1798 beim Uebergange des Fraumünsteramtsforstes an die Nationalwaidungen die Holzarmen von Thalwil. Oberrieden und Horgen in einem unterm 4. Juli der Verwaltungskammer eingereichten Memorial förmliche Ansprüche an den Forst geltend gemacht hatten, trat die gleiche Erscheinung mit Bezug auf den Sihlwald nicht zutage: «es sei hier über keine Schmälerung 
der Rechte Klage zu führen». Eine besondere Anmeldung von Berechtigungen fand trotzdem nicht statt, mit Ausnahme derjenigen der Gemeinden Adliswil und Langnau hinsichtlich der Albishölzer. Offenbar rührte diese abgeklärtere Stimmung von einer schon früher mehrfach erfolgten Regulierung des Holzauflesens im Sihlwald im Sinne einer wirklichen Begünstigung her. So bestimmt ein Ratserlass vom 13. Februar 1792 in Ziffer 3.

«dass auch würklich diejenigen, denen auf Zusehen hin ihrer Dïrftigkeit halber in dem Sihlwald Holz zusammenzulesen weiters gestattet ist, mehr nicht als ein Mal des Tages und zwar zufolge alles älterer. Terordnungen, nur drei Tage in der Woche dahin zu gehen befugt seien - etc.» Auf Servituten weist diese Bestimmung nicht hin. Bereits im Jahre 1811 scheint aber diese Verordnung wenig gehandhabt worden zu sein. Die Stadt muss durch das Statthalteramt Schritte tun lassen, damit der Missbrauch «mit Wegführen von Knebeln, Stauden, sogar ganzen Quantitäten groben Holzes» aufhört. Unterm 30. Mai des gleichen Jahres wird eine besondere Verordnung für die Holzarmen erlassen; der Andrang derselben war offenbar schon sehr gross. - Die den Armen der umliegenden Gemeinden sich bietende Gelegenheit einer leichten Beholzung im Sihlwald scheint einen stets rascheren Aufschwung genommen zu haben. Ein Bericht des Forstinspektors vom Jahre 1825 konstatierte die rapide Zunahme der Holzarmenzahl. Von 8 Gemeinden des Amtes Wädenswil. jetziger Bezirk Horgen. henutzten ifo Haushaltungen den Sihlwald und von den zwei Gemeinden des Knonauer Amtes (Bezirk Affoltern) deren 54 .

Eine Verordnung vom Jahre 1834, betitelt: Reglement fïr die Holzer im Sihlwould, sagt: "Denjenigen armen unvermögenden Leuten, die zu dem Besuche des Sihlwaldes zugelassen werden, ist das Sammeln des Raff- und Leseholzes und das Reinigen des Waldes unter nachfolgenden Bestimmungen gestattet; dagegen ist das Grasen, Miesen, Laubrechen, das Stïcken, das Ausstocken ohne spezielle Bewilligung untersagt.»

Diese vom Sihlwaldvertrag von 1838 unendlich verschiedene Auffassung anerkennt nicht nur keine der später zugegebenen Berechtigungen, weder die auf Raff- und Leseholz, noch die des Holzreinigens, sondern sie lässt die später aufgenommene Stockholz- und Laubstreuservitut ganz weg, d. h. sie macht die bezügliche Nutzung ausdrücklich von einer speziellen Erlaubnis abhängig. Da kam im 
Jahre 1837 das neue kantonale, zurzeit noch in Kraft bestehende Forstgesetz mit seinen in $\$ 48$ enthaltencm polizeilichen Butimmungen über den Raff- und Leseholzbezug. Die vergünstigungsweise eingeräumte Nutzung sollte nunmehr weiter eingeschränkt werden. Gestiitzt auf diesen $\$ 48$ des Forstgesetzes änderte der Stadtrat unterm 1. Hornung 1838 die Verordnung vom Jahre 1834 und verfügte:

1. Das in den Schlägen sich ergebende Abfallholz soll einstweilen bis auf die Stärke von $1 \frac{1}{2} 2^{\prime \prime}$ durch die Leute des Forstamtes in Wellen von $3^{\prime}$ Länge aufgearbeitet werden.

2. Es liegt in der Absicht des Stadtrates von Ziurich, dieses Material zu einem billigen, jedoch beliebig festzusetzenden Preise, den mit Erlaubniskarten versehenen Holzarmen zukommen zu lassen. Das Naximum der abzugebenden Wellen darf drei nicht übersteigen. Preis 1 Schilling per Welle. Diese Verordnung bewirkte grosse Aufregung. Die Holzarmen, resp. die Gemeinderäte der betroffenen Gemeinden legten Rekurs gegen dieselbe ein. Das Obergericht entschied in letzter Instanz zu Gunsten des Waldeigentümers, wies die Parteien aber an, sich über die Frage: ob und welche weitere Ausdehnung der \$ 48 auf die Nutzungen der Holzarmen habe, auf gütlichem oder rechtlichem Wege auseinanderzusetzen. Die Verhandlungen führten dann noch im gleichen Jahre zu dem in der Folge bedeutungsvollen Sihlwaldvertrag vom 22. November 1838, der auf einmal eine ganz neue Situation zutage förderte. - Dieser Vertrag spricht in $\$ 1$ den Holzern der Gemeinden Thalwil, Oberrieden, Horgen, Hirzel, Ebertswil und Langnau nachfolgende Rechte zu:

A. a) auf das Raff- und Leseholz;

b) auf die Nutzungen infolge der Reinigungen des Waldes;

c) auf das Astholz in den neuangelegten Schlägen und Durchforstungen :

d) auf das Auskesseln der Stöcke in den jüngsten $\mathrm{Holz}$ schlägen.

B. Die Einwohner der genannten Gemeinden sind berechtigt. Buchenlaubstreu in die Betten. sowie Bindewieden und Nielen fiir ihren Bedarf zu sammeln.

In weiteren Ausführungen enthält sodann der Vertrag eine ganze Reihe detaillierter Bestimmungen über die Art und Weise der Ausübung dieser Servituten.

Nun war allerdings ein Rechtszustand geschaffen: unzweifelhaft nicht ein für die Stadt sehr günstiger. Weitergehend, als in irgend 
einer früheren Bestimmung wurden die bisherigen Vergïnstigungen in förmliche Belastungen umgewandelt, und die Folgezeit bewies bald nur zu deutlich, dass trotz den schützenden Detailbestimmungen ein Zustand geschaffen war, der sich als viel unhaltbarer denn der frühere erwies. Speziell mit Bezug auf die drei Albishölzer, Winzelen, Schweizertobel und Langenberg wurden den Gemeinden Langnau und Adliswil in einem speziellen Vertrage, d. d. 18. Nai 1839 noch zuerkannt: 1. Alljährlich je 10 Klafter Prügelholz zu 1 fl. 20 fo per Klafter, 2. spricht die Stadt die Geneigtheit aus, soweit die Rücksicht auf ihre eigene Benutzung des Waldes solches zulässig macht, aus diesen Waldungen den Bürgern von Langnau und Adliswil gegen Bezahlung eines billigen Preises sogenanntes Handwerksholz, Bauholz, vorzüglich in Unglücks- und Notfällen. Holz zu Stickeln und Baumstützen zu verabfolgen. Daneben wurden die in $\$ 1$ des Sihlwaldvertrages zugestandenen Berechtigungen den beiden Gemeinden anch für die drei Hölzer zuerkannt. Im Jahre 1848 wurde indessen durch Vertrag vom 1. April d. J. diese Servitut abgelöst. Die Gemeinden Adliswil und Langnau verzichteten damit auf die ihnen zustehende Brennholzherechtigung aus den stadtwaldungen Langenberg, Schweizertobel und Winzelen gegen eine Aversalsumme von je $700 \mathrm{Hl}$. per jede Gemeinde.

Die Forstverwaltung legte in der auf den Abschluss des Sihlwaldvertrages folgenden Periode alle mögliche Energie an den Tag. um die in demselben enthaltenen Bestimmungen korrekt durchzuführen, beziehungsweise, sie nicht abermalen zuungunsten des Waldes anwachsen zu lassen. Von Anfang der fünfziger Jahre an zeigte sich aber die Unhaltbarkeit dieser Servituten neben der Durchführung der eigentlichen 'Zweckbestimmung des Waldbetriebes und der in Aussicht genommenen Anbahnung eines befriedigenden Waldzustandes. Man sah städtischerseits ein. dass ein Loskauf von den fatalen Servituten das einzige Mittel sei, um den Wald vor einer sichern Devastation zu bewahren und in diesem Sinne wurde dann fortan gehandelt. Unterm 14. Februar 1854 beschloss der Stadtrat im Prinzip und gestützt auf $\$ 71$ des Forstgesetzes, den Loskauf der auf dem Sihlwald haftenden Servituten, soweit dieselben mit einer guten Forstwirtschaft unverträglich geworden seien, mit allen Mitteln anzustreben. - Die Durchführung dieses Beschlusses war nicht leicht, indem bei den servitutsberechtigten Gemeinden nichts weniger als grosse Neigung vorhanden war, ihre günstige Position aufzugeben; gerichtliche Schritte mischten sich mit gütlichen Verhand- 
lungen, um die Intentionen des Stadtrates durchzuführen. Der Anfang wurde gemacht und zu stande gebracht mit der Ablösung der wichtigsten und fatalsten Servitut, mit derjenigen auf das Abholz der Schläge und Durchforstungen: litt. A. d. des Sihlwaldvertrages. Es geschah dies durch den Vertrag vom 29. Juli 1857 mit den holzberechtigten Gemeinden Horgen, Oberrieden, 'Thalwil. Langnau. Ebertswil und Hirzel. Die Lösung ergab sich durch Festsetzung eines festen jährlichen Holzdeputates von 14,662 Stück Laubholzund 2150 Stück Nadelholzwellen, unter Vergütung von 5 Cts. Aufmacherlohn von seiten der Berechtigten. Diese Leistungen durften vor Ablauf der nächsten zehn Jahre nicht losgekauft werden. Nach Ablauf dieser Frist konnte das Forstamt die Berechtigung nach vorangegangener einjähriger Kündigung loskaufen, und es wurde die Loskaufssumme hiefür testgestellt wie folgt:

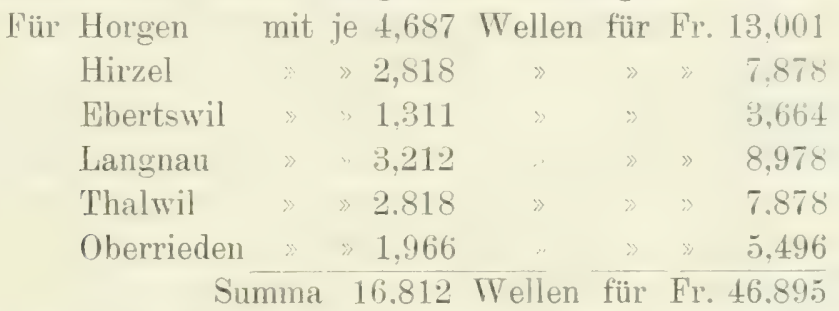

Durch Separatverträge wurde indes der Auskauf mit jeder einzelnen Gemeinde unverzüglich vereinbart und hiebei dit Deputatwellenabgabe nach spezieller Vereinbarung auf eine bestimmte Anzahl von Jahren zu festgesetzten Preisansätzen limitiert.

Unterm 15. Dezember $1859 \mathrm{kam}$ sodann auch die Ablösung der Berechtigung von $\$ 1$ litt. A. b., D. und B. des Vertrages vom Jahre 1838 zu stande, die Beseitigung der Nutzniessungen, welche in der Reinigung des Waldes, in dem Rechte zum Auskesseln der Stöcke, im Laubstreubezug. im Hauen von Bindewieden und Nielen bestand. Es wurde ein Aversalbetrag von Fr. 23,498 angenommen. der sich folgendermassen auf die einzelnen Gemeinden rerteilte:

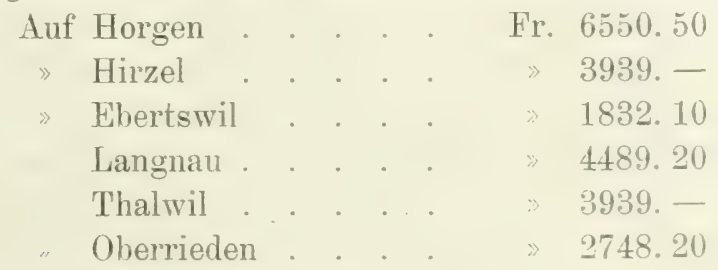

Wohl um diese Verträge mit den Gemeinden leichter durchfïhıren zu können, vielleicht auch um die städtischen Finanzen 
weniger zu belasten, wurde zu dem Mittel gegriffen, diese Verabfindung mit den Gemeinden Horgen und Thalwil, Oberrieden und Langnau - statt mit Geld durch Abtreturg von Wald, teilweise mit den darauf befindlichen. Toriäten, teilweise erst nach der noch zu erfolgenden Abholzung durch die Stadtforstverwaltung zu bewerkstelligen. Auf diese Art erhielt Horgen für seine Gesamtservitutberechtigungssumme von Fr. 19.651.50: 79.3 Jucharten Waldboden im Forst im Werte ron Fr. 29.651. 50. Thalwil für eine Servitutforderung von Fr. 11,817. - : 67,7 Jucharten im Forst zum Kaufpreise von Fr. 31,817. - Oberrieden 7 Jucharten in Neuforst fül seinen Servitutenbetrag von Fr. 8.244.60 für den Kaufbetrag von Fr. 20,244. Damit verlor der Fraumiunsterforst seine für die Stadt Zürich wertvollsten Partien und es darf heute füglich gesagt werden, dass die Art und Weise der Ablösung der Sihlwaldservituten für den Wert der Sihlwaldwaldungen eine verhängnisvolle geworden ist.

Die Servitutverhältnisse der Albishölzer: Langenberg, Winzelen und Schweizertobel wurden, soweit sie nach den beiden Verträgen vom 18. Mai 1839 und 1. April 1848 noch rechtskräftige Ansprüche enthielten, ebenfalls reguliert. Unterm 4. April 1859 verzichteten Adliswil und Langnau auf alle diejenigen Berechtigungen, welche ihnen bisher in den Walddistrikten Winzelen und Schweizertobel vertragsgemäss zugestanden waren. Die Stadt trat ihnen dafür 33 Jucharten Holz und Boden im Schweizertobel. teilweise noch von ihr abzuholzen, ab. Da diese westwärts des Gontenbach gelegene Fläche auf Adliswiler Gemarkung gelegen war, wurde dieselbe für die Gegenleistung von Fr. 4,500 von seiten Adliswil an Langnau, ganz der ersteren Geneind überlassen. Langnau erhielt sodann. indem es diese Proposition annahm und in die sofortige Ablösung der Berechtigungen auf den Sihlwald, wie selbige durch den Vertrag betreffend Deputathölzer festgesetzt war, einwilligte, den Rest des Schweizertobels mit 90,8 Jucharten zum Kaufpreise von Fr. 66,967.60. Sein Ablösungsguthaben von Summa Fr. 13,467.60 wurde hievon abgerechnet. Indem die Gemeinde unterm 29. Oktober 1859 dem modifizierten Sihlwaldvertrag ebenfalls beitrat, wurde ihr noch die Begünstigung eingeräumt, unter den gleichen Bedingungen, wie sie in diesem Vertrage niedergelegt sind, clas Raff- und Leseholz auch zu beziehen

1. in den ehemaligen Schnabelgütern.

$\stackrel{-}{-}$ in der Winzelen.

$\therefore$ im Langenberg. 
Nachdem alle Servituten bis auf diejenige des Raff- und Leseholzes abgelöst waren, wurde nun unterm 15. Dezember 1859 der Sihlwaldvertrag vom Jahre 1838 modifiziert wie folgt:

1. Die Holzarmen der Gemeinden 'Thalwil, Oberrieden, Horgen, Hirzel, Ebertswil und Langnau sind im Sihlwald, mit Ausschluss der: angekauften Schnabel- und Risletenhöfe, einzig und allein auf die Nutzung von Raff- und Leseholz innerhalb der beschränkenden forstgesetzlichen Bestimmungen angewiesen.

2. Die Empfehlungen der betreffenden Gemeinderäte für neu sich meldende Holzarme, welche unter Angabe der Namen. des Geburtsjahres, Berufes, Heimat- und Wohnortes, deren Armut bezeugen sollen, sind in der Regel Anfang Janual dem Stadtforstmeister einzureichen.

$\therefore$ Die Ausübung der Berechtigung auf Raff- und Leseholz ist nur am Mittwoch, wenn ein Feiertag auf den Mittwoch fällt, am darauffolgenden Samstag gestattet, und dafür während der Monate April bis und mit September die Stunden von 6 Uhr morgens bis 6 Uhr abends, während der übrigen Monate von 6-8 Uhr morgens bis 6-4 Uhr abends in dem Sinne festgesetzt, dass der Sihlwald während letzterer 6 Monate nicht vor 'Tag betreten werden darf und vor einbrechender Dämmerung wieder verlassitll werden muss. Eime Ausnahme von dieser Bestimmung tritt in dem Zeitpunkte ein, wo die Räumung der Schläge von zurủckgelassenem Abholz zu geschehen hat, welche Räumung dann nach vorangegangener Bekanntmachung ohne Unterbrechung in den Wochentagen bewerkstelligt werden muss.

t. Mit Ausnahme sehr armer Witfrauen kann jeder Holzarme alljährlich zu einem Tag Frondienst, gegen ein Sustentationsgeld von 60 Rappen angehalten werden und hat sich ein solcher jederzeit über den Besitz einer Holzerkarte auszuweisen.

$\therefore$ Nicht nur sind im Sihlwald ausser dem Bezug des Ratiund Leseholzes alle anderen Haupt- und Nebemutzungen verboten, sondern es ist auch jedermann das Betreten der Waldung ausserhalb der durch dieselben führenden Wege mit Ausnahme der Holzarmen am Holzertage untersagt.

1. Wer obigen Bestimmungen zuwiderhandelt oder Forstexzesse im Walde begeht, hat, je nach dem Grade der Uebertretung: 
entwerler eine Ordnungsbusse von $1-10 \mathrm{Fr}$., wovon die eine Hälfte der Forstkasse. die andere dem betreffenden Armengute zukommt, zu entrichten, oder wird, insofern er in die Klasse der Berechtigten gehört, von dem Besuche der Stadtwaldungen ausgeschlossen oder endlich dem kompetenten Gerichte zur Bestrafung überwiesen. Gegen die von dem Forstamt verhängten Ordnungsbussen kann imnerhalb acht 'Tagen, vom Tage der Eröffnung an, an das Statthalteramt rekuriert werden.

7. Insofern zwischen dem Forstamte der Stadt Ziurich und den betreffenden Gemeinden über Auslegung der Bestimmungen dieses Vertrages Differenzen entstehen sollten, so wird im Einverständnis beider Parteien eiu Sachverständiger als Schiedsrichter beigezogen. Können sich die Parteien über die Bezeichnung des Schiedsrichters nicht einigen, so wird ein unbeteiligtes Bezirks- oder in wichtigen Fällen das hohe Obergericht um Ernennung desselben ersucht.

8. Eine Kündigung dieses Vertrages vor Ablauf von 24 Jahren kann nur stattfinden, wenn die Handhabung der Vertragsbestimmungen dem Forstamte von seiten der Gemeindebehörden der berechtigten Gemeinden erschwert, anstatt durch die erforderliche Unterstiitzung erleichtert wird.

In einem solchen Falle ist das Forstamt berechtigt, im Sinne von $\$ 7$ auf schiedsrichterlichen Entscheid zu dringen, und derjenigen oder denjenigen Gemeinden zu kiindigen, ivelche der Illoyalität überführt sind.

Der Stadtiat erklärt überdies, dass, wenn er auch die Servitut des Raff- und Leseholzes nicht als eine ewige anerkennt, or doch keineswegs gesonnen ist, den Vertrag nach Ablauf der festgesetzten 24 Jahre zu kündigen.

9. Diese Bestimmungen sollen von Zeit zu Zeit von dem Forstamt der Stadt Zürich zur öffentlichen Kenntnis gebracht werden.

Der Vertrag betreffend die Vergünstigungen im Forst, wie er 1834 abgeschlossen worden war, wurde ebenfalls aufgehoben, und durch den unterm 15. Dezember 1859 mit Horgen, Oberrieden und Thalwil abgeschlossenen Vertrag ersetzt, der dahin lautet:

1. Sämtliche im Sinne des Vertrages vom Jahre 1834 zugunsten der bezeichneten Gemeinden auf dem alten Frauminster- 
forst-Stadtteil lastenden Nutzungsrechte werden gegen eine Summe von fünftausend Franken abgelöst.

2. Mit Ausschluss desjenigen Areals, welches den Gemeinden Horgen und Thalwil abgetreten wird, ist im alten l'orstStadtteil die Benutzung des Raff- und Leseholzes nach den Bestimmungen des modifizierten Sihlwaldvertrages gestattet und als Holzertag der Samstag bestimnt.

Mit diesen beiden Verträgen gelangte die unruhige Periode der Servitutenablösung endlich zu einem Abschluss. Die Servitut des Raff- und Leseholzes, welche in dem Vertrage vom 15. Dezember 1859 umschrieben wird, ist nunmehr die einzige Verbindlichkeit, welche auf dem Sihlwald und Forst haftet. Ledig aller weitern Belastung darf diese Vergünstigung des Raff- und Leseholzsammelns indessen nicht als Servitut im strengen Sinne des Wortes aufgefasst werden, umsoweniger, als die Stadt mit dem Jahre 1884 zu den Vertragskontrahenten in ein anderes Verhältnis zu treten die Freiheit erlangt. Die Ausübung des Raff- und Leseholzsammelns geschah nun in einer den Forstbetrieb nicht bloss nicht hindernden, sondern denselben eher unterstïtzenden Art und Weise, und solange das Sihltal als solches nicht durch neue Kommunikationen, durch Ausnützung der noch disponibeln Wasserkräfte zugänglicher gemacht und bevölkerter wird, ist die Ueberlassung des Raff- und Leseholzes an holzbedürftige Arme ein Entgegenkommen des Waldeigentümers, das auf der anderen Seite durch den Wegfall jeglichen Holzfrevels mehr als aufgewogen werden dürfte.

Nach Ablauf der in Ziff. 8 des vorerwähnten Vertrages vorgesehenen 24jährigen Frist, wurde, den gemachten Erfahrungen entsprechend, eine Kündigung des Vertrages zum Zwecke der Revision einzelner Bestimmungen desselben vorgenommen. Zunächst gelangte man dazu, den Begriff der «Holzarmen»näher zu präzisieren, indem sich beim bisherigen. Bezug von Holzerkarten ergeben hatte, dass dieselben auch von solchen beansprucht wurden, die wenn auch wohlhabend, keinen eigenen Wald besassen und diesen Umstand benutzten, um sich als holzarm zu qualifizieren. Zufolge dessen wurden als holzarm nur solche bezeichnet, die einen eigenen Rauch führen, ein Vermögen von nicht über $3000 \mathrm{Fr}$. oder ein Einkommen von nicht über $1200 \mathrm{Fr}$. versteuern. In zweiter Linie erwies sich die durch Art. 4 ausgesprochene Verpflichtung zur Frondienstleistung je länger je mehr als den Zeitverhältnissen nicht 
mehr entsprechend; die "Holzarmen» stellten sich einfach zur Frondienstleistung nicht mehr ein. An Stelle dieser Gegenleistung für die Zuteilung einer Holzerkarte wurde ein Frongeld von drei Franken angenommen, in der Meinung, dass solche Personen, die dennoch einen Frondienst leisten wollen, diesen Betrag zurückerhalten. Endlich wurde die Benützung von Handkarren zum Wegtransport des gesammelten Leseholzmaterials von den jeweilen vom Forstamt hiefür eingeräumten Abfuhrwegen als zulässig erklärt. Die leseholzberechtigten Gemeinden Langnau, Thalwil, Horgen, Hirzel und Ebertswil erklärten sich mit einem auf dieser Grundlage im Jahre 1889 abgeschlossenen neuen Sihlwaldvertrag einverstanden. Die Gemeinde Oberrieden dagegen konnte sich mit den gemachten Propositionen nicht befreunden und so wurde derselben von seiten der Stadt der Sihlwaldvertrag gekündet und auf Grundlage der Bestimmungen der $\$ \$ 60-63$ des kantonalen Forstgesetzes die Ablösung der Leseholzservitut vorgenommen. In dem unterm 17. März 1891 beidseitig unterzeichneten Ablösungsvertrag wurde für die Ablösung nachfolgendes bestimmt:

1. Als Grundlage für die wirkliche Nutzung der Gemeinde Oberieden kommen in Betracht die Jahre 1866-1890. fuir welche sich nach den diesfalls geführten Kontrollen des Forstamtes ein Durchschnitt von 14 Holzlesern (Bürger und Niedergelassene) der Gemeinde Oberrieden ergibt. Im fernern wird angenommen, dass ein Leser an durchschnittlich 30 Tagen per Jahr je 6 IVellen Raff- und Leseholz im Werte von $4^{1 / 2}$ Rappen per Welle, also im Jahr einen Holzwert von Fr. 8. 10 bezog, abzüglich des Frongeldes der letzten 25 Jahre durchschnittlich à 2 Fr. $=$ Fr. 6. 10, was für 14 Leser per Jahr einen Wert von Fr. 85. 40 ergibt. Die 20fache Kapitalisierung würde demnach 1708 Franken betragen.

$\because$ Die Kontrahenten haben sich nun definitiv dahin geeinigt, dass die Bürgergemeinde Zürich an die Gemeinde Oberrieden bezahlt: a) die eigentliche Ablösung der Servitut Fr. 1700.--

b) einen Mehrbetrag zuhanden des

Armengutes Oberrieden von

Total Fr. 1800 . zahlbar bei der notarialischen Fertigung dieses Vertrages, die spätestens vier Wochen nach allseitiger Genehmigung durch die beidseitigen Oberbehörden erfolgen soll. 
3. Hiemit ist die Raff- und Leseholzservitut für Holzarme der Gemeinde Oberrieden des gänzlichen abgelöst und für alle und jede Zeit dahingefallen.

4. Die Kosten der notarialischen Fertigung tragen beide Teile gemeinsam.»

Die notarialische Fertigung dieses Vertrages erfolgte unterm 17. Juni 1891. Von seiten der übrigen Gemeinden wird num seit dem Jahre 1889 das Leseholzsammeln auf Grund des Vertrages von 1889 betrieben und zwar in stetig abnehmendem Umfange. Das Arbeitseinkommen, das beim Leseholzsammeln erhältlich gemacht werden kann, stellt sich niedriger als dasjenige, das heutzutage ohne Schwierigkeiten in der einen oder andern Art erzielt wird, und so finden sich für das mühselige Sammeln des Leseholzes nur noch solche Personen ein, die anderswo keine Beschäftigung finden. Im Jahre 1889 betrug die Zahl der gelösten Karten noch 600, heute nur noch 114.

Als eine Waldbelastung eigener Art, die hier nur der Vervollständigung der Eigentumsverhältnisse wegen angeführt werden soll. muss endlich die im Jahre 1869 durch den Forstmeister C. A. L. von Orelli notarialisch deponierte Wildgartenstiftung bezeichnet werden. Von der Ueberzeugung beseelt, dass seine Mitbürger damit einverstanden seien, dass die städtischen Waldungen durch angemessenen Wildstand belebt, an intensivem Werte gewinnen müssen, will er durch Bevölkerung des schönen Stadtwalddistriktes Langenberg mit passendem Gewild eine längst gehegte Lieblingsidee zur Ausführung bringen. $\mathrm{Zu}$ diesem Behuf soll der Langenherg als Wildpark behandelt, dem übrigen Waldbetrieb entzogen, und der Nettoerlös des aus der Reinigung, Durchforstung. und eventuell in den ältesten Beständen auch Plänterung hervorgehenden Ertrages in erster Linie für Erhaltung und Verschönerung der Anlage verwendet werden. Die Stiftung darf beim Ableben des Stifters nicht aufgehoben werden, wenn nicht auf andere Weise für passenden Ersatz gesorgt werden kann. Sofern jedoch durch ausserordentliche Ereignisse der Fortbestand des Langenbergs zerstört, oder die Forterhaltung der stiftung fïr die Starlt Zürich unrerhältnismä-cige hustrn herbeiführen würde, so sind die Behörden der Bürgerschaft der Stadt Zürich befugt, die Stiftung aufzuheben, den Fonds dem Stifter zurückzuerstatten, oder nach dessen Ableben dem Waisenhaus zuzuwenden. Ein Stiftungsfonds, dem anfangs 20,000 Fr., später im Jahre 1880 weitere 20,000 Fr. von seiten des Stifters zugewendet wurden, eine 
Reihe von Landarrondierungen, den Grenzen des Langenberg entlang und die Erstellung mehrerer Wohngebäude vervollständigten den schönen Stiftungsakt zu einem lebensfähigen Ganzen.

Indem die städtischen Behörden die Schenkung wie die Stiftung akzeptierten, wurde in Würdigung des von dem Stifter an den Tag gelegten gemeinnützigen Sinnes und seiner schönen Bestrebungen städtischerseits demselben, solange er lebt, $d$. h. die Verwaltung des Langenberg-Wildgartens beibehält, zu dessen Instandhaltung, Verschönerung und Ueberwachung überhaupt der Natural- und der Geldertrag des Langenberges und der mit demselben in Verbindung gebrachten, als Waldparzellen zu erziehenden Winzelen und Albisplatean (zusammen 106,68 ha ${ }^{1}$ ) zuerkannt. Mit dem Anno 1890 erfolgten Hinschied des verdienten Stifters des Wildparkes fielen die Komplexe Winzelen und Albisplateau wieder an die Forstverwaltung zurück und es befindet sich die Wildgarten-Stiftung einzig im Besitz des ihr durch die Stiftungsurkunde zugewiesenen Langenberges.

c) Die Servituten der Bergamtswaldungen.

Die Wachten Hottingen und Fluntern betrachteten sich noch im Jahre 1798 als förmlich nutzungsberechtigt an den Hölzern des Zïrich-und Adlisberges und der Allmend. Wie diese nun bei den Eigentumsverschiebungen, welche die helvetische Verfassung bedingte, vorläufig der Stadt verblieben, sahen sie ihre Ansprüche gefährdet und wandten sich unterm 4. Februar 1799 direkt ans helvetische Vollziehungsdirektorium zur Erledigung des Streites; die Sache blieb aber liegen. Inzwischen wurden durch Anlage der Verhaue am Zürichberge die Hölzer alldort nahezu abgeschlagen; es kam die erste Schlacht bei Zürich, und erst als die Franzosen nach der zweiten Schlacht sich wieder in den Besitz der Stadt gesetzt hatten, erfolgte ein Entscheid, dahin gehend, dass die Verwaltung des Zürich- und Adlisberges und der Allmend bis zum rechtlichen Entscheid der Stadt Zürich, hingegen ein grosser Teil des abgeschlagenen Holzes den Gemeinden gehöre. Die Liquidationsurkunde vom Jahre 1803 brachte diesen Entscheid nicht, sie sprach die Allmend, wie die Hölzer vom Zürich- und Adlisberg einfach der Stadtbürgergemeinde Zürich zu, unter der Wahrung der Rechte Dritter. Fluntern und Hottingen liessen sich indessen durch diesen Entscheid

$\left.{ }^{1}\right)$ Gefertigter Eigentumsvertrag v. 24. September 1874. 
nicht beruhigen, sondern machten ihre Ansprüche erneut heim kleinen Rat geltend, der dann nach vergeblichen Bemühungen, einen gütlichen Vergleich zu erzielen, unterm 2. August 1806 dahin entschied:

«1. Der Stadtrat hat als Eigentümer dieser Grundstiicke das unbedingte Dispositivum über dieselben, mithin anch über die Bestimmung des jährlichen Holzschlages.

2. Von diesem Holzschlag ist den Gemeinden Hottingen und Fluntern, insoweit es das Brennholz betrifft, die Hälfte zu überlassen. Sie bezahlen diese Hälfte nach bisher gewohntem Preis von $3 \pi$ per Klafter Buchenholz, und 20 gute Batzen für ein Klafter Laub- oder 'T'annenholz. Vom Bauholz sol] der Stadtrat nach Befriedigung des eigenen Bedürfnisses. Hottingen und Fluntern, soweit sie es benötigen, ehenfalls $\mathrm{zu}$ billigem Preis abgeben.

3. Die Waldungen sollen durch die Gemeinden Hottingen und Fluntern gesäubert werden und ihnen dagegen das Staudenholz, Stöcke und Grötzen überlassen sein.

4. Mit Bezug auf den IVeidgang soll es sein bisheriges Verbleiben haben.>

Die Durchführung dieser Bestimmungen, speziell des Punkt 2, führte viele Reibungen herbei und bereits im Jahre 1829 beschloss der Stadtrat die Frage zu untersuchen: ob nicht der Zeitpunkt vorhanden sein dürfte, sich von den auf den Bergamtsliegenschaften so drückend lastenden fremden Nutzniessungen loszukaufen und wäre es auch durch vollständige Abtretung eines Teiles derselben an die Gemeinden Hottingen und Fluntern? Die Verhandlungen und Untersuchungen dauerten bis zum Jahre 1837 und endigten mit dem Teilungsvertrag vom 24. September bezw. 20. November 1837.

Wesentlich auf Grundlage der Bestimmungen des Entscheides vom Jahre 1806 fussend, nahm dieser Vertrag Teilung zur Hälfte an und es erhielten demgemäss die Gemeinden Hottingen und Fluntern für den Loskauf der ihnen zugestandenen Rechte zu unbedingtem Eigentum :

1. den ganzen Zïrichberg mit 40,0

2. vom Buschberg 24,3

3. von der Allmend 30.7

Der Stadt verblieben:

in Summa $\overline{95.0}$
der Adlisbery
der Buschbery
130.90
von der Allmend. 
So verblieben die Besitzverhältnisse im grossen und ganzen his zum Jahre 1856, wo der Verkauf des der Start noch verbliebenen Restes des Buschberges einen neven Riss in die Altersklassen- und Vorratsverhältnisse brachte. Der Adlisberg aber wurde und ist es anch heute, servitutfreies Eigentum. Die an keinerlei vertragliche Verpflichtung gebundene Vergünstigung des Raff- und Leseholzsammelns an Holzarme der Umgegend kann auch hier in keiner Weise die Bedeutung einer Servitut weder jetzt, noch in Zukunft annehmen, da sie in ganz analoger Weise, wie die übrigen Waldbesitzer vom Zürich- und Adlisberg es geschehen lassen, nur auf Zusehen hin ausgeübt werden darf.

Neue Verhältnisse schuf die im Jahre 1893 in Kraft tretende Vereinigung mit den elf Ausgemeinden. Infolge des Ueberganges sämtlicher Aktiven und Passiven der bisherigen Ausgemeinden an den neuen Gemeindekörper gelangten auch deren Liegensehaften und mit diesen die betreffenden Waldungen in den Besitz der jetzigen Stadtgemeinde. Die politische Gemeinde, die vorher keine Waldungen besessen hatte, erhielt von der Gemeinde Wiedikon die 32,49 ha grosse Waldung Döltschi, am nördlichen Hang des Uetliberges gelegen, von Wipkingen drei Waldkomplexe mit 5,99 ha auf dem Käferberg, von Wollishofen zwei kleinere Parzellen auf dem rechten Silılufer. in siudwestlichen Gehietsteil mit 2.2 Aren. zusammen 38.7 ha.

Bedeutsamer waren die Veränderungen, welche sich im Besitztum der Bürgergemeinde vollzogen. Der bisherige, aus den Sihltalund den Adlisberg-Waldungen bestehende Waldbesitz wurde der «Stiftung des staltzürcherischen Nutzungsgutes zugewiesen und demgemäss in ein Separatgut umgewandelt, das gemäss $\$ 4$ des Zuteilungsgesetzes zur Förderung und Aeufnung solcher Anstalten und Stiftungen zu verwenden ist, welche für Zwecke der Jugendbildung. Wohltätigkeit, Wissenschaft und Kunst schon bestehen oder noch gegründet werden.» Damit wurde es möglich gemacht, den städtischen Sammlungen, wie vorab der Stadtbibliothek, dem Bürgerasyl, dem städtischen Waisenhaus, der Antiquarischen, der Naturforschenden, der Kunstgesellschaft u. s. f. unabhängig vom Gesamthaushalte des Gemeindewesens und ohne Inanspruchnahme der Steuerkraft jährliche für eine gesicherte Fortführung dieser Institute unentbehrliche Beiträge zu verabfolgen.

Die von den Gemeinden Oberstrass, Fluntern und Hottingen der Stadt beigebrachten Bürgerwaldungen mit zusammen 161,02 ha gelangten als eigentliche bürgerliche Waldungen an die nene Stadt- 
gemeinde. Ueber die Verwendung ihrer Erträgnisse sind Bestimmungen erst noch aufzustellen.

Mit dem Uebergang dieser sämtlich auf dem Z/ürichberg und der Zürichberg Allmend gelegenen Liegenschaften trat das. was im Verlaufe der Jahrhunderte infolge der Veränderung der Besiedelungsverhältnisse und infolge der Neubildung von Gemeinwesen sich allmählich vom eigentlichen, alten Zürich abgeiöst hatte, zu Ende des 19. Jahrhunderts wieder in den alten Besitzstand zurïck. Die Unklarheit in den Nutzniessungsverhältnissen, die vielen Prozesse und Schiedssprïche, die infolge dieser aufgeregten Zeiten die Gemüter bewegten, sie alle sind für uns heute nur noch historische Belege für den Wandel aller. Dinge, von dem auch die scheinbar festgegrindetste Kategorie der Eigentumsverhältnisse: (irund und Bonden nicht ausgeschlossen ist.

\section{Die Verwendung der Erträge des städtischen Waldeigentums.}

Soweit die Geschichte des städtischen Waldeigentums zurückreicht, ergibt sich aus den vorhandenen Aufzeichnungen, dass die Naterialerträge Jahrhunderte hindurch zunächst in Form von Kompetenzhölzern an einzelne Beamte oder Pfrunden, oder damn, soweit Ueberschüsse vorhanden waren, gegen ermässigte Taxe an die Bürger der Stadt abgegeben wurden, und nur ein kleiner 'Teil als Bau- oder Nutzholz teils für einige Bedürfnisse verbraucht. teils auch verkauft wurde. Die ältesten Bestimmungen, die uns bekannt sind, diejenigen des Richtebriefes von 1304, wie diejenigen der Forstordnung von 1417 lauten ganz in diesem Sinne. Der Wald war in der öffentlichen Meinung und in den für die Leitung des Staatswesens massgebenden Anschauungen eine notwendige Vorratskammer für die Deckung eines für den Haushalt der städtischen Berölkerung absolut notwendigen Bedürfnisses, gerade wie die Lebensmittel. So lange die Berölkermng der stalt nicht hescheidene Ziffern überstieg. entsprach die Vorratskammer diesen Anforderungen; allein wie in der Mitte des 16. Jahrhunderts reges materielles und geistiges Leben die enge Hülle der Stadt erweiterte, und die Berölkerung rasch anwachsen liess, da reichte das vorhandene Besitztum zur Befriedigung des Holzbedarfes nicht mehr aus. Die Verkehrsverhältnisse ron dazumal gestatteten noch nicht eine anderweitige leichte Speisung: 
des Holzmarktes aus der Nähe, um dem Mangel an Holz gerecht zu werden: deshalb legte sich der Staat ins Mittel und übernahm, ähnlich wie im Kornhandel, die Vermittlerrolle zwischen Angebot und Nachfrage durch die Beschaffung eines eigenen Lagers.

Von 1567 an ward der sogenannte Blütschen- oder Schwyzerhandel organisiert und alljährlich ein erhebliches Quantum, 1000 bis 1500 Klafter, Holz auf diese Art der Stadt zugeführt. Wem kein Sihl- oder Bergamtsholz gegeben werden konnte, erhielt zu nämlichen Taxen Schwyzerholz. Der diesfällige Handel wurde fortgesetzt bis zum Jahre 1826. Bis 1799 wurden die Erträgnisse der Sihlamtsund Bergamtswaldungen zum grössten Teil in Form von Kompetenzhölzern, als Ausgleich für Besoldungen verabgabt. So sind z. B. von 1792 bis 1798 nachfolgende Abgaben zu konstatieren:

\begin{tabular}{|c|c|c|}
\hline & Zwölferholz & Witfranenhol \\
\hline & ǩlatter & Klafter \\
\hline . & 608 & - \\
\hline & 4:) & \\
\hline . & 54 & 30 \\
\hline & 22 & 36 \\
\hline stitute & 24 & 85) \\
\hline $\begin{array}{l}\text { Stellen } \\
\text { und der }\end{array}$ & & \\
\hline . . . & 55 & 66 \\
\hline .. . & 89 & - \\
\hline Summa & 895 & 217 \\
\hline
\end{tabular}

1. Den Ratsmitgliedern . . . . . 608

2. Der Startkanzlei . . . . . . 4:

3. Den Stadtbeamten. . . . . . . . 5

4. An Kirchen- und Schuldiener . . . 2

5. An diverse Gesellschaften und Institute

6. An einzelne Inhaber öffentlicher Stellen vom Stadtarzt bis zur Hebamme und der Brückenwischerin

Nach Deckung dieses starken Bedarfes blieb von dem Etat von 1200 Klaftern Zwölferholz nicht mehr viel zum Verkaufe übrig.

Das Holz des Fraumünsteramtes, soweit solches nach Abzug der Huben. Fadtannen und Hofwigtanteile noch ïbrig blieh. wanderte mit zirka 170 Klafter gleichfalls auf der Sihl nach Zürich, um für Zwecke des Amtes verwendet zu werden. Und das wenige, das in len Bergantswaldungen geschlagen wurde. bestand teils in Bauholz. teils in Brennholz, das zu billiger Taxe zum Teil an Stadtbürger, zum Teil an die Wachten Hottingen und Fluntern abgegeben wurde.

So konnte denn bis 1798 von einem eigentlichen Geldertrag der städtischen Waldungen nicht die Rede sein. Eine erste klare Uebersicht dieses Verhältnisses lieferte Sihlherr Pestalutz.

Seine Forstrechnungen von $1792-1798$ sind mit musterhafter Klarheit gestellt, und zeigen, dass die Erkenntnis der wirtschaft- 
lichen Prinzipien, auf die das forstliche Gewerbe aufgebaut werden soll, bereits ihren Ausdruck gefunden hat.

Einnahmen:

1135 Klafter Zwölferholz.

Witfrauenholz

Wuhrholz

Werk- oder Nutzholz (t)

12,558

3,002

689

521

Total $\overline{16,770}$

A us a a en:

1. Fällung, Aufarbeitung u. Lie-

ferung des Brennholzes . . 5,555

2. Unkosten des Wuhrholzes . 195

3. Besoldung der Forstbeamten:

Sihlherr, Förster u. Sihlknecht $\quad 765$

4. Baukosten:

Hochbau und Wasserbau 1,290

5. Diversi . . . . . 365

Reinertrag . . . . 8,600

'Total 16,770

Da nun in Wirklichkeit dem Forstamt die sogenannten Kompetenzhölzer nicht verguitet wurden und der Bliitschenholzhandel von 1792-1798 einen Totalverlust von $8624 \widetilde{t b}$ ergab, so resultierte ein jährliches Defizit von 5530 דో, welches jeweilen durch 'Luschüsse des Seckelamtes gedeckt wurde.

Mit den Veränderungen, welche durch die Revolutionsjahre gebracht wurden, fiel auch im Sihlamt die alte Ordnung der Dinge dahin. Die Kompetenzhölzer mussten schon im Jahre 1799 nicht mehr abgegeben werden. Das Sihlholz wurde in diesem Uebergangsjahre ganz einfach gegen die Entrichtung einer 'Taxe (pro Klafter Buchenspälten $8 \mathrm{fl}$.) an die Bürger abgegeben. Leere Billets, d. h. Begehren, die durch den disponiblen Vorrat nicht befriedigt werden konnten, verwies man auf das kommende Jahr. Im Jahre 1800 wurde die 'Taxe von $8 \mathrm{fl}$. auf $6 \mathrm{fl}$. herabgesetzt und 1803 entschied die Gemeindekammer dahin:

"Jede Biirgerhaushaltung in der Stadt oder innert den drei Kreuzen erhält gegen bare Bezahlung durch Verloosung: entweder 1 Klafter Spälten à 6 fl. oder 2 Klafter Wittfrauenholz um $6 \mathrm{fl}$. oder 1 Klafter reines Holz und 1 Tannen um diesen gleichen Preis.»

Das war der Anfang des sogenannten Bïrgertiolzes, das in allen denkbaren Variationen quantitativ und qualitativ bis zum Jahre 1876 den in der Stadt wohnenden Bürgerhaushaltungen abgegeben worden ist.

Im Jahre 1876 wurde alsdann dieser Usus aufgehoben, zum Vorteil des Bürgernutzungsgutes, welches das vom Forstamt abgegebene Holz der Forstverwaltung zu bezahlen hatte, wie irgend einem andern Lieferanten. Die Forstverwaltung verlor durch die Auf- 
hebung der Bürgerholzabgabe einen ebenso soliden, als bedeutsamen Abnehmer, ohne dass ihre Administrationsspesen dadurch in irgend einer Weise vermindert worden wären, denn die Sihlamtsverwaltung in Zürich war schon vorher auf einfachere Grundlagen zurückgeführt worden, nachdem das Aufhören der Flösserei im Jahre 1864 den bisherigen Apparat entbehrlich gemacht hatte. So wird denn heute unter gänzlich veränderten, äusseren und inneren Verhältnissen das der Staltbürgergemeinde gehörende IV aldeigentum unter grundsätzlicher Erhaltung des Waldes im Normalzustand beworben einzig nur im Sinne der Erzielung des höchsten Geldertrages. Der Reinertrag fällt dem Bürgernutzungsgute zu und findet von hier aus seine gern gesuchte Verwendung, sei es zur Deckung der Bedürfnisse der bürgerlichen Stiftungen, sei es zur Befriedigung von Anforderungen. die das allgemeine Bildungswesen oder verwandte Gebiete der öffentlichen Wohlfahrt betreffen. 


\section{V. \\ Bisherige Bewirtschaftung \\ und gegenwärtiger Zustand.}

Die so verschiedenartige Form des Erwerbes und die im Verlaufe der Jahrhunderte sich herausbildende eigenartige Benutzungsweise der heutigen Stadtwaldungen von Zürich konnte nicht verfehlen, dem Charakter ihrer Bewirtschaftung einen entsprechenden Stempel aufzudrücken. Die aussergewölmlich lange Dauer, durch welche hindurch die zürcherinchen stalt waldungen einer systematisch und konsequent geführten Wirtschaft unterworfen sind, gibt der Geschichte derselben unter diesen Verhältnissen eine Bedeutung. welche die engen Grenzen der blossen Gemeindeinteressen überspringend, für die Geschichte der Forstwirtschaft überhaupt die wertvollsten Beiträge liefert. Hiebei ist vor allem aus des Einflusses zu erwähnen, den die Kontinuität der auf ein gleiches Ziel hinsteuernden wirtschaftlichen Bestrebungen auf die Gestaltung des Objektes auszuüben im Falle war. Ueberall da, wo das Waldeigentum genossenschaftlichen Charakter hat, oder aber als Allmend behandelt wird, ist der wirtschaftlichen Auffassung einzelner ein viel grösserer Spielraum gegeben, als da, wo das Objekt nur der Einwirkung eines, für die Verwaltung besonders bestellten, an dem Nutzungsquantum nicht interessierten Organes übertragen ist. Die Schwankungen, welche bei den stets wechselnden Anschauungen der einzelnen oder der Privatwirtschaft zutage treten, machen sich bei der Gemeindewirtschaft in viel geringerem Masse geltend.

Darum musste sich aus der konstanten Wahrung der Eigentümlichkeit des Waldbetriebes und der zweckmässig-ten Forbinhng derselben mit den Interessen der Nutzniesserin nach und nach ein Normalzustand herausentwickeln, dessen Ursachen und Konsequenzen mit den Grundlinien zusammenfallen, welche die gleichzeitig auf dem 
Wege der Empirie sich herausbildende Forstwissenschaft für die Allgemeinheit als Gesetz aufstellt.

Es mag angesichts dieser Verhältnisse angezeigt sein, die einzelnen seiten der hisherigen Bewirtschaltung der zürcherischen Starltwaldungen ihrer chronologischen Entwicklung nach zu betrachten.

\section{A. Organisation der Wirtschaft.}

\section{Allgemeine Aufsicht und Verwaltung.}

In der zweiten Hälfte des 13. Jahrhunderts verfügte über den Forst die Aebtissin des Fraumünsterstiftes durch das Organ des Kirchenvogtes. Rat und Bürger anderseits schalteten und walteten über den Sihlwald und die Bergamtswald ungen im Adlisberg.

Schon im ersten "Richtebrief» der Stadt Zürich finden sich Bestimmungen, die das Mass und den Preis des aus dem Sihlwald abzugebenden Holzes festsetzen.

Wer aus der Mitte von "Rath und Burger» den Wald überwachte oder verwaltete, darüber finden sich bis zum Jahre 1314 keine Anhaltspunkte. Damn aber begegnen wir in Zürcher Stadtbuch zum erstenmal einer Bestimmung organisatorischer Art, dahin lautend:

«Kein Vorster soll Holz fällen im Sihlwald, noch die Sihl hinabflössen, weder den Bürgern noch ihm selber.»

Man wollte durch diese Bestimmung offenbar die Stellung der "Vorster» als eine rein überwachende, polizeiliche betrachtet wissen.

Die Brunsche Verfassung setzt auch für die Forstverwaltung einen Denkstein. Wie sie überhaupt in hervorragender Art den Haushalt des frisch aufblühenden Gemeinwesens mit grossem staatsmännischem Blicke zu ordnen verstand, so schenkte sie auch dem wertvollen Sihlwald ihre Aufmerksamkeit. 'Zu den neugeschaffenen Aemtern gehörte daher auch das «Ampt über den Sihlwald» und vom Jahre 1342 an überwacht und leitet die Bewirtschaftung der städtischen Waldungen «ein Mitglied des Rathes» der "Sihlherr».

Das im Jahre 1683 von der Staatsschreiberei der löbl. Stadt Zürich angefertigte "Sihlamts-Urbarium» enthält vom Jahre 1342 
an bis 1798 mit Ausnahme eines Zwischenraumes von 100 .Jahren (1429-1529) die vollständige Serie der Sihlherren. Zufolge einer Notiz vom Jahre 1542 war denselben von jeher eine Wohnung im Silłwald mit dem nötigen Hausrat zugewiesen. Bezeichnend für den Kulturzustand dieser Zeit ist die Beschaffenheit desselben, denn jene Notiz sagt: "Dies ist der Hausplunder, so dem Sihlherr Andreas Schmid in den Sihlwald kauft ist:

Ein Beth

Ein Pfülmen

Ein dutzend Küssi

zwei Hauptküssi

zwo Deckenen

Lin Bettstatt

zwei Tischlachen

Ein dutzend Handzwehlen

zwo lang Handzwehlen

zwei paar Leinlachen

acht hölzi Bächer
Ein Fleischteller

zwei Salzfass

acht Näpf $u$. Wasserschüsseln

Ein Ankenkübel

zwei halbköpfig Sester

Drei Kerzestöck

Ein Dutzend Löffel

zwo Kellen

Ein 2eimerig Fass

Ein Röhrli zum Beth.

Ein alten Kasten.

Ein Dutzend Teller

Unter dem Sihlherm Johannes Füssli wurde im Jahre 1733 das jetzige Forsthaus erbaut. Zufolge der Neuorganisation des Sihlamts wurde dasselbe von 1803 an den nunmehr an die Stelle der Sihlherren tretenden Forstinspektoren und Forstmeistern als Amtswohnung zugewiesen. In den Jahren 1781-1788 wurde dasselbe vom Sihlherrn Salomon Gessner, dem gefeierten Idyllendichter, bewohnt.

Eine eigentliche Forstordnung treffen wir erst Anno 1417. Diese Forstordnung vom Jahre 1417 wurde zwar im Verlaufe der Jahrhunderte ergänzt und erweitert, aber nicht wesentlich umgestaltet $^{1}$ ). Sie ist es auch, die zuerst Aufschluss gibt über die Funktionen und Kompetenzen des Sihlherrn, der dazumal, nach heutiger Deutung der Begriffe Forstreferent. Forstinspektor. For tadministrator und zugleich auch Strafbeamter für die Frevel in einer Person war. Es mag nicht uninteressant sein, die jeweiligen Besoldungsverhältnisse dieses Amtes in den verschiedenen Zeitläufen einander gegenüberzustellen, weil sie gleichzeitig beredtes Zeugnis ablegen für die grossartige Steigerung des dem Walde und seiner Bewirtschaftung beigelegten Wertes.

1) Die ausführlichste Revision dieser Organisation vom Jahre 1417 ist diejenige von Anno 1774 «Amtsordnung und Eyd für den Sihlherr, den Sihlknecht und die Bannwarten». 
1417: jährlich 8 ॠ und 200 Sihlholz.

1529: jährlich $20 \widetilde{t}$ und 250 Sihlholz «nebst 5 Schilling Zehrgeld, wenn er in den Wald reitet».

1542: erhält der Sihlherr eine Wohnung im Sihlwald, nebst einem bestimmten «Hausplunder».

1652: $350 \vec{t}$ und 11 Klafter Buchenholz.

1774: $840 \vec{t}$ und dazu 10 Müth Kemen, 10 Eimer Wein. 11 Klafter Buchenholz und 24 Fälzladen.

1875: 5000 Fr.

1893: $5-6000$ Fr.

Auffallenderweise war der Sihlherr nicht zugleich Jagdherr. Das Jagdrecht war bis zur Aufhebung der Fraumünsterabtei im Forst der Aebtissin und im Sihlwald den Räten und Bürgern der Stadt zugehörend und offenbar zufolge des dazumal noch vorhandenen Wildstandes an Rot- und Schwarzwild, sowie auch an Bären nicht ohne Wert. Eine Notiz im Ratsmanual vom 21. Oktober 1486 sagt:

«Es ist durch min Herrn erkannt: 1) dass die so nit eigen Gejaget han wenn sie Bären oder Schwin fahen in unsern Landen und Gebieten. einem. Bürgermeister den Kopf geben, doch dass Er ihn nit daheim, sondern uf einer offenen Stuben mit Herren und Gesellen essen solle; 2) welich aber eigen Gejaget hand und Seil haben sind das nit schuldig.»

In einer Ratserkenntnis vom 28. März 1496 heisst es:

«Für min Herrn ist kommen der Amann des Gotshus Fraumünster und hat von miner Gnädigen Froven, der Aebtissin gebetten: Iren Gnaden zu erlauben: dass Sy jagen lassen im Sylwald - zu der Hochzit Jnwyhung so auf nächsten Suntag kommend gehalten werden soll, damit Sy den frömden Prälaten und andern so daby syn werden es tun möcht».

Der Rat entschied, dass, weil des Gewilds halber das Jagen zurzeit untunlich und allenthalben verboten sei, die Aebtissin sich an ihren eigenen Forst halte, in welchem sie jagen und sich mit demselben begnügen, nicht aber der Herren Wildbann verwüsten lassen solle. Daraus geht zweierlei deutlich hervor, einmal, dass der Fraumünsterforst entsprechend seinem Charakter als Bannforst eigenes Jagdrecht hatte und den obrigkeitlichen Verordnungen nicht unterstellt war, dass sodann in zweiter Linie die Jagd im Sihlwald noch eine ergiebige gewesen sein muss. 
In dem Eid, den die Förster vom Jahre 1554 an zu leisten hatten, wird vorgeschrieben:

«dass diese auch zu ergaumen hätten, ob Jemand Fremder oder Einheimischer auf das Wildpreth, es wäre mit Schiessen oder Jagen gienge, und das Alles dem Sihlherrn zu leiden und darum ihr bestes zu thun, damit der Wald und die Hölzer durch das Wildpreth in gutem Schutz und Schirm erhalten werden.»

Im Jahre 1680 erscheint nun aber neben dem Sihlherın ein 'I'ierherr:

«Es soll fürderhin Niemand, wer es auch sein möchte. als allein ein jeweiliger Sihlherr und Thierherr Gewalt und Fug haben in dem Sihlwald und eine Stund Wegs herum durch einen einzigen Wildschützen Gewild schiessen oder jagen zu lassen.

Aus den Ratserkenntnissen vom Jahre 1707 erhellt, dass der 'Tierherr auch mit den Attributen des allgemeinen Jägermeisters des Kantons betraut wurde. Der Sihlherr blieb Mitglied der Jägerkommission (1714).

Mit der im Jahre 1803 erfolgten Uebertragung der Stadtwaldungen an die eigentliche Stadtgemeinde scheinen diese Verhältnisse sich von selbst geändert zu haben. Der Sihlwald blieb zwar bis zum Jahre 1831 ein geschlossenes Revier; wie aber im Jahre 1831 die Jayd als eigentliches Staatsregal erklärt, und das Patentsystem eingefïhrt wurde, da fielen Wert und Bedeutung der Jagd dahin.

Die Fischerei mochte in der Sihl von jeher weniger Bedeutung: gehabt haben, als die Jagd in den Sihlwaldungen, darum war hiefür auch keine eigene Aufsichtsstelle vorhanden. Es wurde diese Aufgabe aber auch nicht dem Sihlherm überbunden: denn eine Notiz im Ratsprotokoll vom Jahre 1671 sagt:

«Die Abstrafung wegen Fischens in der Sihl gehört von Alters her den HH. Seevögten und nicht dem Sihlherr, als welchem allein die Holafievel gebühren.

Anlässlich der Ausscheidung des Staats- und Stadtbesitzes scheint vergessen worden zu sein, dem geschlossenen Waldeigentum des Sihlwaldes das Fischereirecht auszubedingen, und die anfangs der zwanziger Jahre gemachten Versuche dasselbe noch nachträglich zugeteilt zu erhalten, blieben fruchtlos. Die im Sihlwaldgebiet liegende Strecke der Sihl bildet ein Pachtrevier des Staates, das jeweilen auf fünf Jahre an den Meistbietenden zur Nutzung ver- 
steigert wird. Seit dem Jahre 1875 ist durch Errichtung einer Fischzuchtanstalt im Sihlwald wesentliche Fürsorge für die Vermehrung und Erhaltung des Forellenbestandes der Sihl getroffen worden.

\section{Die Beförsterung.}

Wie bereits oben erwähnt wurde, ist das Institut der "Vorster» vom Jahre 1314 an nachweisbar.

Zahlreiche Vormerkungen im Ratsprotokoll der Stadt Zürich beweisen, welch ausgedehnte administrative Befugnisse diesen Vorstern oder Bannwarten, wie sie mehrere Jahrhunderte hindurch heissen, zugewiesen wurden, und zwar nicht nur im Sihlwald, sondern auch im Forst und im Adlisberg.

Der Sihlwald war von jeher entsprechend seiner Einteilung in in zwei Forstschutzbezirke geteilt, den oberen und mittleren Sihlwald; einen dritten Forstschutzbezirk bildeten die Albishölzer, als unterer Sihlwald.

Der Forst hatte in seiner Gesamtheit als Fraumünsterforst zwei Förster, und endlich war über die Hölzer am Adlisberg von jeher ein besonderer Förster aufgestellt.

Charakteristisch sind die Bestimmungen über die Beförsterung im Fraumünsterforst, welche vor dem Jahre 1460 aufgestellt worden sein müssen. In der «Offnung derer von Oberrieden» ist diesfalls folgendes enthalten:

«7. Jeder Huber (Inhaber einer der Hofstetten) ist der Aebtissin pflichtig 1 Jahr den Forst zu gaumen und zu hüten, wenn sie ihn dazu gut findet.

8. Jedem Vorster gibt man jährlich 10 Tannen Lohn, die er han mag, wo es am unschädlichsten; darüber gilbt die Aebtissin 15 Zürcherpfennige und einen grauen Rock, und sollen 2 Vorster sein.

Diese zwei Förster blieben auch nach der 1524 erfolgten Verschenkung des Fraumünsterforstes an die Stadt unter der Fraumünsteramts-Verwaltung. Die Verpflichtungen bezw. die Funktionen der Förster sind in den sogenannten «Eiden» enthalten.

Anno 1540 wird für den Förster im Adlisberg, 1554 für die Förster im Sihlwald ein neuer Eid aufgestellt. Bezeichnend für die jahrhundertelang andauernde Stellung der Förster im Sihlwald ist, dass sie die Akkordanten des Holzschrotens, des Holztransportes an die Sihl und der Flösserei bis Zürich waren, und dass ihre Ein- 
nahmen sich wesentlich nur auf diesen Arbeitsverdienst stiitzten. Im 15. und 16. Jahrluundert wurden die Häne im Sihlwald. Forst und in den Albishölzern je zu zwei Jahren von dem jeweiligen Sihlherrm in Gegenwart aller Alt-Sihlherrn, es mochten Bürgermeister oder niedere Häupter und Räte sein, um einen gewissen Lohn für hundert Holz nebst ein halb Eimer Wein und zwei Mütt Kernen auf jedes $1000 \mathrm{Holz}$ verliehen. Der Diensteid vom Jahre 1697 gibt darüber nachfolgenden Aufschluss:

«Ihr Bannwarten sollet schwören: M. G. H. von Zïrich Treu und Wahrheit zu halten, Ihren Nutzen zu fördern und Schaden zu wenden, auch einem jeweilig verordneten Sihlherrn Gehorsam und gewärtig zu sein. Die Hölzer früh und spät zu schirmen und zu vergaumen; dem Hochwild und den Rehen in keiner Weis noch Weg einigen Schaden zu thun, insonderheit auf die Verdächtigen fleissig Achtung zu geben, und wenn ihr der eint oder ander Schadens halber darinnen findet und vergreifet, oder er Euch angezeiget wird, denselben einem jeweiligen Richter unverzüglich zu leiden und anzugeben.

"Dessgleichen kein Holz, wie es immer Namen haben mag, unbefragt zu verkaufen, noch zu verleihen, noch anderwärtig hinzugeben. Auch weiteres und mehreres nicht zu schroten und aufzumachen, als Euch von einem jeweiligen Sihlherrn anbefohlen, und an welchem Ort es geschehen soll, angezeigt wird; das anbefohlen Holz aber wo möglich vor dem Augustmonat zu schroten, das aufgemachte an ein bequem Ort an die Sihl zu fertigen, auf empfangenden Befehl bei rechter Zeit und gutem Wasser in die Sihl innen werfen, fleissig und in Treuen zu flötzen und in den Rechen zu liefern, auch in all ander Weis und Weg gute Sorg zu halten, dass nichts davon entwendet oder veraber'wandelt werde, und sonsten Euer Wägst und Bestes zu thun; die Zäune in guten Ehren zu halten, gar kein Vieh in die jungen Häu Inweiden zu lassen, sondern dieselben von Leit zu Zeit einzuzäunen, und zu Säuberung derselben, wenn es nöthig ist, allen möglichen Fleiss anzuwenden, damit das Buchen-, Eschen- und Tannenholz, wie auch allander. nutzbav und gutes Holz sein besseves Wuchstim haben möge:

Erst in den dreissiger Jahren dieses Jahrhunderts wurde die Stellung des Försters in die des eigentlichen Forsturfsehers unge- 
wandelt, und heute gehören die Stadtförster von Zürich, mit einer jährlichen Besoldung von 1600-2000 Franken und freier Wohnung offenbar zu denjenigen niederen Forstangestellten. welche eine ihren Verpflichtungen durchaus entsprechende Bezahlung erhalten. Als ein keineswegs unrühmliches Zeugnis für die Verwaltung früherer Jahrhunderte verdient die Tatsache erwähnt zu werden, dass ein und dieselbe Familie Banmann während voller dreihundert Jahre, d. h. von 1539-1843, die Repräsentanten zu der Försterstelle des jetzigen Unteren Sihlwaldes lieferte.

\section{Die gegenwärtige Organisation des Betriebes.}

Durch Jahrhunderte hindurch bestand das Gerippe der Organisation wesentlich darin, dass der Sihtherr, und von Anfang dieses Jahrhunderts an, ein forstlich gebildeter, unter ihm stehender Fachmann, den Betrieb direkt leitete, die Förster seine Befehle mit Hülfe eines ständigen Holzhanerpersonals exekutierten, bis das Hol\% der Stadtwaldungen auf dem Wege der Flösserei in der Stadt angelangt war, und endlich der in Zürich stationierende Sihthnecht die Verteilung dieses Holzes erst an die Kompetenzberechtigten, später an die Bürger besorgte. Seit dem. Jahre 1864 hat sich die Situation in erheblicher Weise geändert.

Das mit der Leitung des städtischen Finanzwesens betraute Mitglied des Stadtrates bildet die vermittelnde Instanz zwischen dem Stadtrat und dem Stadtforstmeister; die Verwaltung der Stadtwaldungen dagegen ist mit ihrer ganzen Verantwortlichkeit dem letztern übertragen. Die Verordnung vom Jahre 1881 normiert seine Befugnisse und Verptlichtungen.

Mit Ausnahme des Adlisberg-Komplexes eignet sich die Lage und die nähere Umgebung der Walddistrikte nicht, um, wie es in den meisten Forstadministrationen geschieht, das Material auf dem Wege öffentlicher Versteigerung, am Ort, wo es geschlagen wird, abgeben zu können. Die städtische Forstadministration hat daher für den Hauptteil der Waldungen das System des Verkaufes nack norangegangener. Verabeitung und Veberführung in den konsumfïhigen Znustend des Holzes eingeführt, und so betreibt sie heute: ein Sügewerk für die Verarbeitung des Bau-, Säg- und Nutzholzes, neben diesem eine Imprägnierungsanstalt nach dem System Boucherie. un geeignete sortimente für irgendwelche bauliche Zwecke durch 
die Imprägnierung zu veredeln; eine mechanische Dreherei, um die vorhandenen reichen Laubholz-, speziell Eschenmutzholzvorräte in die Form der leichten Absatz findenden Werlzentstiele überzuführen. sodann die Fabrikation von Holzwolle und endlich eine mechernische Spalterei zur Verarbeitung des Scheitholzes in klein gespaltenes Kochherd- und Ofenholz, das in Form der gesetzlich normierten Reifwellen gebracht, seine direkten Abnehmer in Zürich oder Umgebung im Sihltal oder am linken Seeufer findet und dem Abnehmer direkt zu Haus und Hof gebracht wird. Für den Platz Kiirich besteht daselbst ein besonderes Depot mit einem demselhen vorstehenden Verwalter.

Dieses System der intensiven Ausnützung und Verarbeitung des Rohmaterials macht ein. vermehrtes Personal und eine kompliziertere Organisation nötig, als dies beim gewöhnlichen Forstbetrieb der Fall ist. Neben den eigentlichen Forstern und einem ständigen Waldarbeiterpersonal dirigiert ein Chef des Werkiplatzes mit einem für den Betrieb der Maschinen und die Bedienung des Platzes erforderliche Arbeiterkorps die gesamte Verarheitung. Eine Regiefuhrhalterei vermittelt den Verkehr vom Wald zum Werkplatz und von da zur Absatzquelle. Damit gewinnt natürlich auch die gesamte Buchführuny und der Inkasso dieses bis ins äusserste Detail sich zerteilenden Geschäftsverkehrs eine ganz ungewöhnlich Ausdehnung, so dass ein besonderer Forstkassier mit einem Gehülfen notwendig ist. Es gestaltet sich daher die ganze Organisation schematisch wie folgt:

\section{Staltiot.}

Städtischer Finanzvorstand.

Stadtforstmeister.

(event. Adjunkt)

Forstkassier.

(Bureaugehülfe.)

\begin{tabular}{|c|c|}
\hline $\begin{array}{c}\text { WaIdbetrieb. } \\
\text { Förster: }\end{array}$ & $\begin{array}{l}\text { Terarbeitung und Terkauf. } \\
\text { Chef d. Werkplutzes: Holzdepot Würich: }\end{array}$ \\
\hline $\begin{array}{l}\text { Oberer Sihlwald, Unterer Sihlwald, Albis- } \\
\text { hölzer, Forst, Adlisberg. }\end{array}$ & $\begin{array}{c}\text { Sïge. Imprïgn--Anstalt. } \\
\text { Ireherei, Spalterei. }\end{array}$ \\
\hline
\end{tabular}
Fuhrhalterei.

Die Gesamtzahl der ständigen, alle 3 Jahre in Erneuerung fallenden Angestellten ist 9, diejenige der ständigen Arbeiter 80-100.

Die Besoldung des Stadtforstmeisters beträgt 5-6000 Fr.. diejenige der Förster 1600-2000 Fr. Der Tuglohn der Forstarbeiter 
richtet sich nach ihrer Leistungsfähigkeit und bewegt sich heute zwischen Fr. 3.60 und Fr. 3. 80.

Die Gesamtsumme der Terwaltungsausgaben betrug im Durchschnitt von 20 Jahren $(1880-1900)$ Fr. 18.51 per Hektar.

Seit dem Jahre 1877 sind die sämtlichen städtischen Forstangestellten und Arbeiter gegen Unfall versichert. Die Versicherung war anfänglich einer Privatanstalt übertragen. Seit dem tahre 1879 hingegen hat die Forstverwaltung diese Aufgabe selbst übernommen. Gestützt auf ein hiefür entworfenes Regulativ wird alljährlich von seiten der Forstverwaltung eine bestimmte Einlage gemacht und aus deren Zinsen die Unfallsquote bestritten.

Die während 20 Jahren aufs sorgfältigste nachgeführte Statistik der Lnfallsentschädigungskasse giht interessante Aufschlüsse ïher die Ausrlehmung der Unfälle heim Waldbetrieh. Kufolge dieser Statistik beträgt die Zahl der Unfälle im Durchschnitt per Jahr bei den Waldarbeitern 9,8 , beim Werkplatz dagegen nur 8,5, obschon hier mit 6 Fräsen, 2 Bandsägen, 2 Hobelmaschinen, 3 Spaltmaschinen etc. gearbeitet wird. Die Durchschnittsziffer für die Dauer der Arbeitsunfähigkeit steigt bei den Waldarbeitern auf 122 Tage, bei den Maschinenarbeitern nur auf 97,7 Tage. Die jährlich für Unfälle in Form von Kurkosten, Arbeitsausfall und Invalidenentschädigung zu verabreichenden Beträge entsprechen $1 \%$ der in der Gesamtheit zur Auszahlung gelangenden Besoldungen und Taglöhne.

Die für das Aufsichts- und Avbeiterpersonal bestehende Krankenkasse steht unter dem Patronat des Forstamtes, gehört dagegen den Aufsehern und Arbeitern, und wird auch hauptsächlich von diesen alimentiert; die Verwaltung beteiligt sich mit zirka einem Drittel der Kosten. Aehnlich wie bei der Unfallkasse werden dem Beschädigten Arzt- und Arzneikosten und Fr. 1.80 Taglohn als Lohnausfall vergütet.

Seit dem Jahre 1887 wurden, gestützt auf die schwerwiegende Einwirkung; welche Erkrankungen der Frauen verheirateter Arbeiter im Haushalt des letztern auszuüben vermögen, auch diese Frauen in die Krankenkasse als Mitglieder aufgenommen. Dieselbe entrichtet im t'alle der Erkrankung pro Tag $1 \mathrm{Fr}$. für Lohnausfall bezw. für Einstellung einer Aushülfe im Haushalt, und im weitern iibernimmt sie wie bei den Arbeitern die Kurkosten. Die bisher mit dieser Einrichtung gemachten Erfahrungen erweisen sich als sehr wohltätige. Bei einem Jahresdurchschnitt von 112 Arbeitern und 67 Arbeiterfrauen betragen die auf den einzelnen Arbeiter 
fallenden Unkosten Fr. 13. 14 und diejenigen der Arbeiterfrau, trot\%dem eine geringere Lohnausfallentschädigung ausgerichtet wird, Fr. 11.56. Die ca. Fr. 1000. - betragende Summe, welche alljälırlich für Erkrankungen der Frauen ausbezahlt werden muss, gelangt in den dadurch gebesserten ökonomischen Verhältnissen der einzelnen Arbeiter zu sichtbarem Ausdruck.

Der von der Forstverwaltung angeregte Gedanke, eine AltersUnterstiitzungshasse für das gesamte Forstpersonal anzulegen, dürfte als eine, sowohl im Interesse der Arbeiter als der Administration liegende Autgabe. mit der \%eit wohl eine entsprechende $1_{2} i$-mo finden.

Die Abgeschiedenheit der Sihltalwaldungen, speziell des Werkplatzes Sihlwald, bringt es mit sich, dass für die Unterbringung des ständigen Arbeiterpersonals Wolmmngen erstellt werden mussten. Lieselben werden ihren Mietern je nach der Qualität der Behausunw zu 1 bis $2 \mathrm{Fr}$. Mietsgeld per Woche überwiesen. Die im Jahre 1895 im sihlwald etahlierte staatliche Primarschule crmeiglicht ilen Kindern des Sihlwaldpersonals den Schulbesuch in allernächster Nähe. Post, Telegraph und Telephon, sämtlich in der Sihlwaldkolonie installiert, entreissen die Bewohner des einsamen Waldtales der früheren Abgeschiedenheit von der Aussenwelt und die seit dem Jahre 1891 das Tal durchfahrende Eisenbahn vereinigt sich mit diesen Instituten, um einerseits den Geschäftsverkehr zu erleichtern und anderseits den Freunden des Waldes die Schönheiten desselben zugänglich zu machen.

Sowohl der Stadtforstmeister als die übrigen Angestellten haben. Amtswohnungen im Sihlwald und im Adlisberg.

\section{B. Die Wirtschaftsführung.}

Wir begegnen in den Zürcher Stadtwaldungen bereits im 13 . einzelnen, vollends aber im 14. Jahrhundert einer Reihe von wirtschaftlichen Massregeln, welche auf die Dauer aufrecht erhalten wurden und deren Durchführung unbedingt der heutige Normalzustand und die hohe Ertragsfähigkeit des Besitztums zugeschrieben werden muss. Der Normalzustand einer IValdung ist ja niemals bloss das Produkt wirtschaftlicher Arbeit einiger Dezennien, oder 
eines einzelnen Wirtschafters. Diese liefert nur vereinzelte Bansteine zum einstigen Ausbau des Gebäudes. Das Vorhandensein des Normalzustandes, des demselben entsprechenden Holzvorrates und Zuwachses, wie das Vorhandensein einer richtigen Altersabstufung sind immer das Ergebnis wirtschaftlicher Bestrebungen vieler Jahrhunderte, und selbst da, wo Aktenstücke über dieses wirtschaftliche Eingreifen früherer Zeiten mangeln, liest sich aus dem gegenwärtigen normalen Zustand klar und deutlich heraus, was man früher angestrebt und wie man seine Absicht durchgeführt hat.

Es unterliegt keinem Zweifel, dass die Stadtwaldungen, vorab der Sihlwald und der Forst von jeher als Hochwald behandelt worden sind. Die Bezeichnung findet sich in den früheren Akten allerdings nicht vor, allein da wir unter Hochwaldbetrieb diejenige Wirtschaftsform verstehen, welche den Wald ein samenfähiges Alter und damit die Fähigkeit erreichen lässt, sich selbst zu verjüngen, die dabei Nutz- und Bauholz, starke Brennholzsortimente liefert, so stimmen alle historischen Aufzeichnungen mit dem überein, was wir in der heute massgebenden Nomenklatur in den Begriff des Hochwaldbetriebes einschliessen.

Die Ende des 13. Jahrhunderts vorhandenen und in den Akten angeführten Holzarten, Tannen und Buchen, sind nicht etwa als Oberständer eines allfällig vorhandenen Mittelwaldhetriehes aufzufassen; denn als im Jahre 1280 die Stadt Zürich zum grösseren T'eile abgebrannt war, lieferte der mit Nadelholzhochwald bestockte Sillwald das zum Wiederaufloau notwendige Banholz. Das beweisen die Bestimmungen des Richtebriefes von 1304:

(Der Rath und die Bürger sind übereinkommen, dass sie endheim (einem jeden) Bürger aus dem Sihlwald Holz geben, wen der für Für bouwen soll.

«Wird jemand aus dem Sihlwald Zimmerholz gegeben, der soll es zu hant hawen und usvertigen.» ${ }^{1}$ )

Die Art und Weise, wie 1376 ausdrücklich die Viehweide zur Schonung des Schlages verboten, die Art und Weise, wie in der evsten Forstordmung vom Jahre 1417 angeordnet wird:

«Es soll auch hinnenhin kein Sihlwaldmeister an kein Kohl-Holz in dem Sihlwald verkaufen, durch dass es kolet werde, wann davon bissher dem Sihlwald gebracht und schad ist kommen, sunderlich dass der Koler Ross in den

1) Richtebrief der Stadt Zürich vom Jahre 1304. 
Sihlwald gand und jung Tamnen stumpend und bissend. Es soll auch Niemand, wer es ist, kein Vieh wellerlei es ist, in den Sihlwald schlahen noch tryben -»,

weist schon ganz auf den Hochwaldbetrieb hin. Vollends durchschlagend für die Annahme des Hochwaldbetriebes sind zwei urkundliche Nachweise. Zunächst die Bemerkung in einer handschviftlichen Ziurcherchonik des 15. Jahrhunderts (Stadtbibliothek Zürich. Manuskript B. 95/192, Blatt 526).

"Als man anfing den Silwald zu houwen. Das geschah do man zalte von gottespurte MCCCLXXXIV (1384) Jar, da fing man den Silwald an zu houwen hie vor by des Pfungen Hof by Rengge untz himuff an die Bennow und houwet man alle jar darin und dz holtz gat das Wasser ab das da heisset die Sil bis gen Zürich an die Stat.»

Fasst man diese chronistische Aufzeichnung mit derjenigen zusammen, die in Gerold Edlibachs Chronik S. 262 vorhanden ist: «Anno domini 1536 uff den letzten Donstag im martzen (30. März) fing man an den Sillwald under dem nidren Silhüsly abhowen daz han ich Hans edlibach (Sohn Gerolds) selbs gsen und kunt man zu hundert jaren us oder noch eer. so gelangt man auf Grund der örtlichen Verhältnisse dazu, den 80-100jährigen Umtrieb damaliger Zeit zu konstatieren.

Dass es der schlagweise Hochwaldbetrieb war, der nit diesem Turnus durchgeführt ist, geht aus einer Ratsvorschrift vom Jahre 1542 hervor, wo es heisst:

"Die Sihlwaldmeister sollen den Hau den ihnen der Sihlherr gezeigt, ödentlich thum, und das alt Holz nit wie etwo beschehn ist, stehn lahn.»

Es bedeutet das wohl nichts anderes, als es soll Kahlschlagwirtschaft geführt werden. - So wurden denn alljährlich bestimmte Schlagflächen kahl abgetrieben und da wohl schon in dieser Zeit die Erdiunnerungen, oder wie sie heute heissen: Durchforstungen vorgenommen worden waren, hielt es bei der grossen Begünstigung; welche Boden und Lage des Sihlwaldes der natürlichen Verjüngung zuweisen, nicht schwer, den Wald ohne besonderes Zutun vermöge des Kahlschlagbetriebes zu verjüngen und ohne künstliche Nachbesserung auch in dichtem Bestande zu erhalten. Dieser schlagweise Hochwaldbetrieb dauerte bis Ende der dreissiger Jahre des letzten Jahrhunderts; von 1807 an finden sich sogar die Jahresschläge in den Waldkarten eingezeichnet. Mit dem Jahre 1838 wurde 
alsdann dieses Terjüngungssystem ziemlich aufgegeben und dafür das System der natülichen Verjüngung mit allmëhtichem Abtrieb eingeführt. Das alte System mit seinen Kahlschlägen hatte sich dermassen eingelebt, dass der Ursprung der örtlichen Nomenklatur der verschientenen Sihlwalduartien grösstenteils auf die Namen derjenigen Holzhauer oder Holzhauerfamilien zurückgeführt werden muss, die ziemlich ununterbrochen von Generation zu Generation die Schläge akkordweise übernommen hatten. So z. B. Egliboden = Boden des Egli, Birriboden = Schlag oder Boden des Birri, Habersaatenhau $=$ Hau des Habersaat: Thomasrain = Rain des Holzakkordanten Thomas u. S. w.

Im Forst. der seine Natur als Nadelholzhochwald nicht verändert hat, ist der schlagweise Hochwaldbetrieb ebenfalls nachweisbar seit dem Jahre 1460. Die künstliche Wiederaufforstung der Schläge ist vom Jahre 1737 an zur Ausführung gelangt.

Der durch allmähliche Ankäufe zusammengetragene Adlisbergkomplex ermangelt zu sehr einer einheitlichen Geschichte, als dass er in ähnlicher Weise wie die übrigen Stadtwaldungen mit Bezug auf seine bisherige Bewirtschaftung weiter als über den Anfang des letzten Jahrhunderts zurück verfolgt werden könnte. Zur Stunde steht auch diese Partie ganz im Hochwaldbetrieb.

Die weiter oben angeführte Notiz der handschriftlichen Chronik von 1384 gestattet unzweifelhaft die Annahme, dass schon dazumal in geregelter. längst innegehaltener Hiehsfolge eine mehr orter minder alljährlich gleich grosse Waldfläche abgetrieben wurde.

Dadurch ist der montsyesetzte Nachhaltiglieitsbetrieb und bis auf einen gewissen Grad auch die Hiebsfolge des Sihlwaldes weit hinauf konstatiert. Eine bestimmte Angabe über das Hiebsquantum findet sich dagegen erst im 15. Jahrhundert. Das Ratsprotokoll vom Jahre 1422 setzt den Etat des Sihlwaldes auf 20,000 Holz.

Von Anno 1491 heisst es:

«Der Sihlwald soll auf das nächst Jahr ruhn und darin

kein Holz gehauen werden, anderst als die schon bestellten $10.000 \mathrm{Holz}$.

Im Jahre 1495 wurden sodann 12,000 Holz, Anno 1533 27,000 Holz, Anno 1547 30,000 Holz geschlagen, und hernach wurde bestimmt:

«Um dass der Silhluald, Forst und andere Stadthölzer nit ïberhanen, noch geschädigt, sondern ein Ordnung darin, wie riel man jährlich haten soll, grhalten und fiir unsere. 


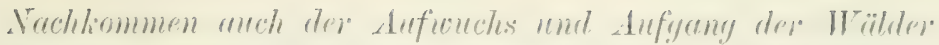
bedacht werde, ist eingesehen, dass hinfür jührlich ein Sihlherr weiter und ferner nit bestellen noch howen soll und lassen denn

$\begin{array}{lc}\text { im Sihlwald: } & 30,000 \mathrm{Holz} \\ \text { Forst: } & 10,000 \gg \\ \text { Albishölzer: } & 6,000 \gg\end{array}$

Bis zum Jahre 1574 blieb dieser Etat, dann stieg man auf 35.000 Holz, 1579 auf 40,000 und so kam es, dass im Jahre 1581 eine Fachkommission erklärte, "der Sihlwald sei überhauen und habe derselbe auf unbestimmte Zeit zu ruhen». Lange mag indessen diese Sistierung nicht gedauert haben.

Vom Jahre 1585 an erscheinen die Klafter als Masseinheit und zwar wird der Etat auf 1000 Klafter angesetzt. Vom Jahre 1630 an ist sodann das jährliche Hiebsergebnis in Form eines Wirtschaftsbuches bis zur heutigen Stunde nachgeführt; dasselbe gibt ïber die alhmähliche Heranbilung de jetzigen Tormalzuntandes die interessantesten Aufschlüsse. Ehe indessen auf diese Aufzeichnung näher eingetreten wird, mag es am Platze sein, die Periode vor 1630 noch näher ins Auge zu fassen.

Vor allem aus wäre der Begriff von 100 oder 1000 Holz, als derjenigen Einheit, nach der das Hiebsquantum, wie auch der Verkauf sich vier Jahrhunderte hindurch berechnet hat, festzusetzen. Leider mangelt aber jedwede direkte Auskunft hierüber und wir sind darauf angewiesen, eine besondere Erklärung zu konstruieren. Bei den Verkaufstaxen im 14. Jahrhundert sind je $100 \mathrm{Holz}$ als Einheit angeführt. Es heisst dort auch: "Wer solche Hölzer haut, die nit 14 Schuh lany sind, dem soll man sie brennen.» Statt des Wortes Holz kommt häufig das Wort «Burdinen» vor, und zwar gab es halbe und ganze Burdinen; die halbe war 7 Schuh lang. Das «Zinsholz» von den Leuten, die Lehen von der Fraumünsterabtei hatten, wurde in Form von Burdinen bezahlt. Diese sollen nach dem Hofwirt-Podel von Oberieden, datiert vom Jahre MCCCCLXXIII «so gross syn. dass ein man zwo Burdinen ab dem Stumpen an den See tragen mag». Hienach müsste allerdings das Holz von 14 Schuh ungefähr zwei Burdinen, oder einer Doppet-Burtine entsprochen haben und wir haben unter «Holz» offenbar nicht ein rundes Stück Stammholz zu verstehen, da der Ausdruck «Sagbäume und Hölzer» häufig parallel miterscheint; sondern im Gegenteil gespaltene Brennholzstïctie ion \% Schuh Lünge, bald lose, bald in eine Bürde gebunden. In einem 
Ratserlass von 1581 kommt deshalb auch das Wort «Spälten» ausdrücklich vor; es heisst: "es seien im Forst und Ragnau 4000 Spälten zu machen». Noch hat sich bis heute in einigen zürcherischen Korporationswaldungen am Zürichberg die Gewohnheit erhalten, das jährlich an die Bürger abgegebene Holz auf 6 Fuss abzulängen, und es könnte dieses Mass unter Umständen als eine Forterhaltung des ursprünglichen «Holzes», wie die Sihlwald-Rödel es enthalten, betrachtet werden.

In Bayern war ehemals die Masseinheit von «1000 Holz» ebenfalls vorhanden. ${ }^{1}$ ) Schmeller führt in seinem bayrischen Wörterbuche an, dass $1000 \mathrm{Holz}$ ungefähr 50 Klafter gleichkommen. Auch von $\left.B e r g^{2}\right)$ in seiner Geschichte der deutschen Wälder zitiert dieses Mass, fügt indessen bei, es mangle an festen Anhaltspunkten für die Charakteristik desselben.

Etwas Genaues lässt sich aus allen diesen einzelnen Daten nicht ableiten, und für die Geschichte der Zürcherischen Stadtwaldungen ist die Anführung des Hiebsquantums in Form der Einleit von 1000 Holz anders nicht zu verwerten, denn als Beweis dafür, dass eine Etatsbestimmung bereits vom Jahre 1422 an nachweisbar ist, und dass diese demgemäss zu den ältesten Etatsbestimmmngen der deutschen Forstgeschichte gehört. ${ }^{3}$ ) Umso wertvoller sind daher für die Bemessung der Ertragsfähigkeit des Sihlwaldes die Aufzeichnungen, welche mit 1630 beginnen. Die mit dem Jahre 1630 beginnende und bis auf den heutigen Tag fortgesetzte Buchführung über die Sihlwaldschläge zeigt ein ziemlich genaues Mass und damit auch eine befriedigende Konstatierung des jährlichen Etats. Die bezügliche Tabelle enthält das jährliche Hiebsquantum der drei Hiebsfolgen: Oberer und Unterer Sihlwald und Albishölzer, ausgeschieden nach Hauptnutzung und Durchforstung (Witfrauenholz) und mit den Sortimenten: "Buchis und Tamnis.

Das Klafter mit einer Scheitlänge von durchschnittlich drei Schuh ist die Haupteinheit. Der Etat wird in diesem Mass ausgedrückt und nach der Ertragsfähigkeit des Waldes bemessen.

Im Jahre 1696 verordnete der Rat eine Kommission zur Aufnahme einer eigentlichen Waldbeschreibung und Zunvachsschätzung;

1) Siehe Lori, Urkunde zur Geschichte des Lechrains.

2) von Berg, Geschichte der deutschen Länder bis zum Schlusse des .llittelalters. S. : 449 .

con Berg zählt die Schlageinteilung der Stalt Erfurt rom Jahre 1359 zu den iiltesten der bekimnten Forsteinrichtungen. 
es darf diese Arbeit als der erste Wirtschaftsplan der Zïrcher Stadtwaldungen bezeichnet werden. In demselben ist das Alter und das Eitragsvermögen eines jeden der mit einem besonderen Namen belegten Komplexe oder Häue des Sihlwaldes angegeben, so z. B. des Thomas-Rains, des Schröterbodens, des Eschibodens etc. etc. Infolge der durch . Tahrhunderte hindurch sich gleich gebliebenen Hiebsführung bildeten sich aus diesen Hiebskomplexen die jetzigen Hiebsfolgen und Abteilungen des Sihlwaldes heraus.

Die sogenannten Sihlamtswaldungen sind in dem ersten Wirtschaftsplan in zwei Hiebsfolgen ausgeschieden. Als Scheidlinie für dieselben wurde der sogenannte Spiessenhauer-oder Scheidbach (in der heutigen Abteilung Nr. 9 liegend) angenommen. Die obere Hiebsfolge umfasste den Oberen Sihlwald, die andere den Unteren Sihlwald nebst den Albishölzern: Winzelen, Langenberg und Schweizertobel. Für dieses Areal von zirka 2194 Jucharten, wie es sich nach der ersten Vermessung von 1680 herausstellte, wurde bei einer Umtriebszeit von 90-100 Jahren ein Etat von 1100-1200 Klafter festgesetzt, und alsdann für diesen Etat eine Flächendeckung dadurch gesucht, dass man Hau für Hau nach seinem wahrscheinlichen Haubarkeitsertrag nach der Anzahl Jahresschläge, welche er wahrscheinlicherweise zu liefern vermöchte, einschätzte. Die von der Expertenkommission mit Zuzug der Förster. vorgenommene sorgfältige Taxation ergab:

für den Oberen Sihlwald: 106 Jahresschläge à 550-600 Klafter

» Unteren Sihlwald: 73

» die Albishölzer:

à $550-600$

à $550-600$

Da man somit über 204 halbe Jahresschläge verfügen konnte, hielt man die Nachhaltigkeit der Wirtschaft bei dem angenommenen Etat hinreichend gesichert, und glaubte dadurch auch gegen das Zurückgehen des Hiebsalters geschützt zu sein. Nach der Bannwarten Meinung

«kömmt ein trüehafter Baum innert dem Lauf von achtzig Jahren zu seinem vollkommenen Alter, daraus wurde geschlossen, dass es dem Sihlwald nimmermehr an Holz gebrechen (kann) sondern ehe man an desselben Ende kommen (wird) wird der Anfang wiederum zeitig (sein), so dass daraus zu holzen dienlich wäre».

Es wird ferner verfügt, dass im nächsten. Jahre 1698 der "Schrot» in der untern Hiebsfolge bei dem Anfang des Sihlwaldes, und derjenige der oberen Hiebsfolge im Sihlzopf gemacht werden 
solle, gerade wie zu der Zeit, da Gerold Edlibach in seiner Chronik berichtet hat, dass er es mitangesehen, wie der Sihlwald unten vom Sihlhüsli an sei angehauen worden, in Ausführung einer hundertjährigen Umtriebszeit. ${ }^{1}$ )

Das der Etatsberechnung des Wirtschaftsplanes von 1697 zugrunde liegende Verfahren fusst allerdings auf keiner wissenschaftlichen Methode; allein es beruht nichtsdestoweniger auf Grundsätzen, die wir in der modernen Etatsregulierungsmethode in mathematischer Weise ausgeführt finden. Die Ermittlung des Haubarkeitsertrages weist hin auf die Nutzung des gesamten Haubarkeitsdurchschnittszmuachses im ältesten Schlage. Sie bildet die Grundlage der Methode, die anderthalb Jahrhunderte später Karl Heyer seiner Ertragsregelungsmethode zugrunde legte. $\left.{ }^{2}\right)$ Der Etat war nun hier allerdings auf dem Wege der reinen Empirie ermittelt, allein die Art und Weise. wie man sich über Vorrat und Zuwachs Rechenschaft gab, war korrekt. Allerdings wurde nicht zwischen einem normalen und einem wirklichen Zuwachs unterschieden. sondern dieser wie der Vorrat wurde als normal angenommen. Nun sagen wir auch heute noch : Mangeln einer Betriebsklasse bei vorhandenem Normalvorrate und bleibendem Normalzuwachse die normale Schlagreihe und Altersabstufung, so stellen sich diese beiden ganz von selbst her, wenn man den jährlichen Normaletat in den ältesten Schlägen fortnutzt und zugleich die Nachzucht besorgt ${ }^{3}$ ) und auf dieser Grundlage fixierte man 1697 die jährliche Schlagmasse. Charakteristisch ist bei dieser Etatsregulierung, dass von dem ein Jahrhundert später auftauchenden Flächenfachwerk absolut und geflissentlich Umgang genommen wurde, indem die Einschätzung der verschiedenen Komplexe in Jahresschläge je nach der Bonität durchaus verschiedene Schlagflächen ergab.

Neben dem Etat der Hauptnutzungen wird auch ein Etat de Zwischennutzungen oder Durchforstungen festgesetzt. Es wird bestimmt, dass alljährlich 500-600 Klafter Durchforstungsholz bezogen werden können.

«Da zu besserer Fortpflanzung der im Wachstum begriffenen Bäume erforderlich ist, dass der Wald je zu 20 bis 25 Jahren völlig durchgangen, die Stürchel und in die Krümme wachsendes Gehölz ausgehauen, was znnach an und. beieinander steht, yedlïmert und abgeschnitten werden soll,

1) Gerold Edlibuch siche pag. 778. Betriebsart und Untriebszeit.

2) u. $\left.{ }^{3}\right)$ Siehe Dr. C. Heyer, Die Wraldertragsregelung $\$ 48$. 
woraus denn alljährlich über das in 1100-1200 Klafter bestehende XII Holz annoch 500-600 Klafter Witfranenholz geliefert werden könne. ${ }^{1}$ )»

Nun verstand man unter XII Holz das eigentliche Spältenholz; das gröbere Astholz fiel in die Kategorie der sogenannten Bengel oder der heutigen Prügel; die kleinen Buchäste hingegen, sowie alle übrigen in den Hau und in die Erdünnerung fallenden geringeren Holzarten, wie Birken, Aspen, Weiden, Erlen, wilde Apfel- und Kirschbäume wurden dem sogenannten Witfrauenholz zugeteilt. Die Spälten hatten eine Länge von drei Schuh, das Witfrauenholz eine solche von $2^{1 / 2}$ Schuh. ${ }^{2}$ )

Der Etat von 1697 blieb für Hauptnutzung und Durchforstung massgebend bis zum Jahre 1835. Es ist deshalb ebensowohl vom Standpunkte der Geschichte der Sihlamtswaldungen aus betrachtet, als vom allgemein historischen Gesichtspunkte ausgehend von höchstem Interesse, die Durchführung dieser Etatsbestimmungen in der langen Periode von 250 Jahren ohne Unterbrechung verfolgen zu kömen. Die Zusammenstellung dieser Schlagergehnisse bietet für dié richtige Beurteilung der Sihlantswaldunֻen das alleruntrüglichste Naterial und hinreichende Anhaltspunkte, um klarzulegen, dass wir den schönen Zustand des jetzigen Sihlwaldes der einsichtsvollen Fürsorge mancher Generation verdanken.

Zufolge der Schlagaufzeichnungen von $1630-1700$, und des im Index zum Sihlamts-Urbarium von Sihlherr Pestalutz und Forstinspektor v. Wyss nachgeführten Wirtschaftsbuches von $1700-1835$ und der nunmehr auch von 1835--1902 gemachten Nachtragungen ist uns das Quantum des jährlichen Hiebsmaterials in den Schlägen und Durchforstungen genau bekannt. Allerdings ist im Durchforstungsmaterial auch noch schwächeres Astholz, das der Hauptnutzung angehört, enthalten, und es ist mithin die Summe der XII Klafter nicht der präzise Ausdruck für das jeweilige Total der Hauptnutzungen, wenigstens nicht bis zum Jahre 1837. Auch mangeln bis 1740 noch die genauen Angaben über das neben dem Brennholz aus den Schlägen mitbezogene Wuhrholz und Nutzholz; doch können die Wuhr- und Bauholzabgaben verhältnismässig nicht gross gewesen sein, weil der Bauholzbedarf mehrteils aus den Bauamtswaldungen, und die Wuhrhölzer vielfach von dem Forst entnommen wurden. Auch Werkholz wurde zu jeder Zeit aus dem

1. Sihlamts-Urbarium pag. 134.

2) Sihlherr Pestalutz, Bericht über die Sihłamtshölzer 1798. 
Sihlwald abgegeben; Nutzhölzer für die Wagner, Küfer, Dreher, Spillen- und Rechenmacher, ohne dass hiefür für die ersten Zeiten genaue Nachweise über das Quantum vorliegen. Da aber die Brennholzabgabe die weitaus überwiegende Nutzung war, so sind die vorhandenen Zahlen, inden sie dieses Material genau enthalten, immerhin ein für die Vergleichung und Bemessung der Ertragsfähigkeit des Sihlwaldes umso zutreffenderes Material, als die Arealverhältnisse des der Vergleichung unterbreiteten Wirtschaftsteiles bis zum Jahre $1850 \mathrm{im}$ grossen und ganzen die gleichen geblieben sind.

Die Tabelle ergibt nun folgende Anhaltspunkte, wenn wir die gleichartigen Wirtschaftsperioden zusammenfassen und die alten Masse in Festmetern wiedergeben:

$\begin{array}{cccc}\text { pro Jahr } & \text { Hauptutzung } & \text { Durchforstung } & \text { I'otal } \\ \text { Fon } & \text { Festmeter } & \text { Festmeter } & \text { Festmeter } \\ 1630-1654 & 2295 & 1167 & 3462 \\ 1655-1700 & 2620 & 1680 & 4300 \\ 1700-1733 & 2464 & 1884 & 4348 \\ 1734-1743 & 3498 & 2274 & 5772 \\ 1744-1763 & 3292 & 2420 & 5712 \\ 1764-1793 & 2486 & 1924 & 4410 \\ 1794-1813 & 2236 & 1766 & 4002 \\ 1814-1837 & 2636 & 1310 & 3946 \\ 1838-1850 & 2818 & 614 & 3432 \\ 1851-1860 & 2825 & 1960 & 4785 \\ 1861-1870 & 2120 & 1709 & 3829 \\ 1871-1880 & 3460 & 1740 & 5200 \\ 1880-1900 & 7557 & 3083 & \left.10640^{1}\right)\end{array}$

Es ist hiebei zu bemerken, dass die Periode von $1850-1870$ der tiefgreifenden Arealveränderungen halber, die sich anlässlich der Servitutsablösungen vollzogen, auch auf die vorstehenden $\mathrm{Ab}$ gabesätze ihren Einfluss ausüben musste, und insofern auch ausgeübt hat, weil die Schläge der Liquidation der abgetretenen Waldpartien halber vielfache Unregelmässigkeiten aufweisen. Allein diese Periode ist doch zu kurz, um die Gesamtheit des Eindruckes der langen Zahlenreihe abschwächen zu können. Es geht aus dieser Hiebsnachweisung deutlich hervor:

1. Dass der Sihlwald und die Albishölzer mit Ausnahme des Zeitraumes von 1734-1763 in streng nachhaltiger Weise,

1) Erstmalige vollständige Buchung des gesamten Materials: Derbholz und Reisig. 
ohne wesentliche Ueberschreitung des Etats von 1697 benutzt worden sind, und dass demgemäss allmählich ein Normalzustand eintreten musste.

2. Dass die Durchforstungen dauernd in einem Umfange eingelegt wurden, der die Beschaffenheit des Waldes in gleichem Masse heben musste, wie er zu dessen Rentabilität beigetragen hat.

Aus der Waldbeschreibung von 1798 erfahren wir, dass die Uebernutzungsperiode von 1734-1763 namentlich zu einer Schädigung des oberen Silllwaldes geführt hat. Dadurch musste sich dort neben einer fatalen Reduktion des Holzvorrates auch eine Verminderung des Hiebsalters fühlbar machen. Es wird dieser Uebelstand noch im Jahre 1833 von Forstinspektor Wyss lebhaft hervorgehoben. Um denselben wieder zu beseitigen, gingen dann im laufenden Jahrhundert die Bestrebungen bis in die Mitte der siebziger Jahre eher ins umgekehrte Extrem hinüber. Man schonte den oberen Wald allzusehr auf Kosten des unteren Waldes und zu seinem eigenen Nachteil und verhinderte dadurch die Herstellung. eines normalen Altersklassen-Verhältnisses, wie dieses unter anderen Umständen heute eigentlich allgemein vorhanden sein könnte.

Der intensive Durchforstungsbetrieb, der uns aus den angeführten Zahlen entgegentritt, hat dann seinerseits neben grossem finanziellem Vorteil auch dazu geführt, dass heute der Charakter der Bestände in überwiegendem Masse nahezu ein normaler ist.

«Die Bannwarten des Sihlwaldes haben sich von jeher durch eine unverbesserliche Methode des Erdünnerns des Holzes so ausgezeichnet, dass andere Bannwarten, wie es schon häufig geschehen ist, nirgends besser als im Silılwald sich hierüber belehren lassen können»,

berichtet uns die Waldbeschreibung von 1798. Und in der Tat mag dieses Lob verdient sein, denn die günstigen Nachwirkungen dieser Tätigkeit müssen auch heute noch in eben demselben Nasse anerkannt werden. Hiebei ist nur noch hervorzuheben. dass sich von der Mitte des vierten bis sechsten Dezenniums des vorigen Jahrhunderts ein erheblicher Rückgang dieser Bestrebungen wie der Durchforstungserträge bemerkbar machte, der bei näherer Untersuchung um so bedeutender ist, wenn man in Betracht zieht, dass dazumal unter der Rubrik Scheidholz auch das geringe Dürr- und Windfallholz mit inbegriffen ist, welches aus den im gleichen Dezennium zum Hiebe gelangenden Abteilungen entnommen werden musste. 
Die Ertragsregulierung der übrigen Stadtwalddistrikte, des Franmiunsterforstes und der Bergantswaldung tritt viel später zutage als diejenige der Sihlamtswaldungen. Wir begegnen einer solchen erst im Jahre 1770. Im Forst war die Materialabgabe allerdings insofern schon früher geordnet, als dort konsequent seit Jahrhunderten immer in drei Hiebsfolgen, d. h. in den seit 1263 bekannten dree Hëren geschlagen worden war, und zwar in einem Betrage von $4-500$ Klafter. Der Etat von 1770 wurde dann definitiv auf 436 Klafter festgesetzt, indem man den Zuwachs des produktiven Bodens zugrunde gelegt. eine ziemlich detaillierte Bestandesbeschreibung angefertigt und eine 90 jährige Untriebszeit angenommen hatte. Vom Jahre 1776 an wurde auch eine sehr detaillierte Wirtschaftskontrolle eingeführt in Form alljährlicher genauer "Relationen über den Holzschlag und die Pflanzungen in dem alten und neuen Forst». Dieses Wirtschaftsbuch wurde bis zum Jahre 1836 fortgeführt. Im Jahre 1796 erfolgte eine Art Revision dieser Waldeinrichtung. Die unproduktive Waldfläche wurde noch genauer ausgeschieden und hiebei der Wald in 16 Abteilungen gebracht und der Etat auf 356 Klafter reduziert. Das Zurückgehen des Etats steht offenbar im innigen Zusammenhang mit der stets verderblicher wirkenden Viehweideservitut.

Im Jahre 1815 fand eine Neuvermessung des Forstes statt und gestützt auf diese erfolgte eine neue Waldeinteilung. Die Aufnahme der Waldbeschreibung wurde diesmal verbunden mit der Aufstellung einer summarischen Alterstilassentabelle. Die Teilung des Forstes im Jahre 1835 änderte alsdann alle Verbältnisse in radikalster Weise.

Die über die Bumantswaidungen vom Jahre 1770 an entworfenen und noch vorhandenen Beschreibungen, sowie die Wirtschaftseinrichtungen tragen ungefähr den gleichen Charakter wie diejenigen des Forstes. Die Bestandesbeschreibung ist auch in diesen Operaten die Hauptsache. T'iefergehende wirtschaftliche Erwägungen sind überhaupt nur in dem Operate über die Sihlamtswaldungen rom Tahre 1798 zu treffen. Hiefür nur ein Beispiel: Es machte sich dazumal in forstlichen Kreisen eine stark zutage tretende Strömung zu Gunsten des Flächonfachuer ges geltend. Die von mehreren Autoren ${ }^{1}$ ) befürwortete definitive Einteilung der Wälder in eine der Umtriebszeit entsprechende Anzahl Schläge ward darum auch

1) Hartig, Anweisung zur 'laxation und Beschreibung der Forste 1795. Hennert, Anweisung zur Taxation der Forste 1791-95. - Silcher, Die zweckmässigste Methode, den Frtrag der Waldungen zu bestimmen 1796. 
mit Rücksicht auf den Sihlwald erörtert. Sihlher' Pestalutz stellt sich die Frage: Ob es für die Zukunft ratsamer sei, bei der bisherigen einfachen Norm stehen zu bleiben (Kontrolle der Massenerträge), deren Befolgung so leicht duxchzuführen ist, oder ob die weitläufige IValdung einer regulüren Eintrilum! in gleiche Waldschläys zu unterwerfen sei? Die der Frage folgenden Råsonnements sprachen sich nun des Entschiedensten gegen eine solche Schematisierung der Wirtschaft aus und der Etat von 1697 nebst der Massenkontrolle wurde neuerdings beibehalten, trotz und neben der bis 1838 geführten Kahlschlagrirtschaft.

Der erste allgemeine städtische Wirtschaftsplan, der die Einschätzung sämtlicher städtischer Waldungen als eines Wirtschaftsganzen enthält, wurde im Jahre 1834 entworfen, unmittelbar vor den grossen Servitutablösungen im Sihlwald, Forst und Adlisberg. Aus diesem Grunde konnte das Operat nicht lange in Guiltigkeit bleiben. Das vom nachherigen städtischen Forstmeister C. A. L. von Orelli im Jahre 1837 entworfene «Klassifikations-, Orduungsund Taxationsregister» muss daher als Ausgangspunkt der neueren, seit über 40 Jahren geltenden Etatsordnung angesehen werden. Der obere Sihlwald wurde in 25, der untere in 13 Abteilungen gebracht; sodann wurde der durchschnittliche jährliche Zuwachs so genau als möglich ermittelt und unter Annahme einer 90jährigen Umtriebszeit für diese Dauer ein allgemeiner Hauungsplan cuf Grundlage des Massenfachuerties aufgestellt. Da das damalige Areal mit Ausnahme des oberen Waldes heute nicht mehr vorhanden ist. führen wir nur an, dass der Etat des oberen und unteren Sihlwaldes auf 3082 Festmeter angesetzt war. Im Jahre 1850 erfolgte die Revision dieses Wirtschaftsplanes. Sie wurde im Sinne der modernen Etatsregulierung mit einer «Allgemeinen Beschreibung» des Waldes verbunden. Sie unterschied zwischen wirklichem und normalem Zuwachs und setzte die Umtriebszeit auf 100 .Jahre. obschon das Hiebsalter der in der ersten Periode zum Hiebe gelangenden Bestände nicht höher als auf 80 Jahre ging. Um das für diese erhöhte Umtriebszeit erforderliche mittlere Durchschnittsalter zu erhalten, wurde der Etat herabgesetzt und zwar für den eigentlichen Sihlwald auf 2520 Festmeter. Mit dem Jahre 1860. also nach Ablauf der ersten zwanzigjährigen Periode, nach Durchfülnung der Servitutablösung und der Reduktion des städtischen Areals auf die gegenwärtigen Komplexe, endlich auch, nachdem dieselben sämtlich in die Hand der Bürgergemeinde vereinigt waren, erfolgte 
eine Hauptrevision des Wirtschaftsplanes. Das durchschnittliche Bestandesalter stellte sich hiebei auf 45 Jahre und so wurde die Umtriebszeit von 90 Jahren gewählt. Durch eine sorgfältige, auf die bisherigen Erfahrungen und Schlagergebnisse sich stützende Zuwachs-Einschätzung gelangte das Operat dazu, für das Dezennium 1860-1869 einen Etat von 1138 Normalklafter oder $3076 \mathrm{~m}^{3}$ anzusetzen, dem Dezennium 1870-1879 dagegen eine Steigerung auf 1500 Normalklafter oder $4057 \mathrm{~m}^{3}$ zuzuweisen. Sämtliche übrige 10jährige Perioden bis $1949 / 50$ sind mit diesem gleichen Ansatz im allgemeinen Hauungsplan dotiert. Die zur Liquidation bestimmten abgetretenen Waldteile von Schweizertobel und Forst, mit einem Flächeninhalt von 100,2 ha und einem geschätzten Hiebsquantum von mindestens 3000 Normalklaftern oder $8100 \mathrm{~m}^{3}$, wurden dem ersten Dezennium als Ersatz für seine geringe Etatsstärke zugewiesen.

Die Durchforstungserträge wurden nicht mehr wie früher den schlagergebnissen parallel veranschlagt, sondern im ungefähren Betrage von $20 \%$ des Hauptnutzungsbetrages in Aussicht genommen.

Das derart beschaffene Operat förderte vom Standpunkte derjenigen Anforderungen aus betrachtet, welche wir gegenwärtig an eine Ertragsregulierung stellen, wohl eine genaue Uebersicht der Altersklassenverhältnisse und ein genaues Bild des konkreten Zuwachses zutage; allein damit war weder das Bild des angestrebten Normalzustandes gegeben, noch erhielt man eine Garantie dafür, imnerhalb welcher Dauer der Normalzustand erreicht werden könne. Der Etat war berechnet nach der wenig bekannten Formel $\mathrm{E}=\frac{\mathrm{V}+\mathrm{h} \frac{\mathrm{F}}{2}}{\mathrm{~h}}$. Unter V wurde verstanden die auf die wirkliche Bonität reduzierte Bestandesfläche mal Bestandesalter. F repräsentierte die auf die Bonität I reduzierte konkrete Fläche; h die Umtriebszeit. Der dermassen auf Grund dieser Faktoren herausgerechnete Etat betrug 1464 Normalklafter, während der dem Dezennium durch die Fachwerkseinteilung zugewiesene Ansatz sich auf 1138 Normalklafter oder $3080 \mathrm{~m}^{3}$ belief. Wie das wirtschaftliche Dezennium mit dem Jahre 1869/70 zum Abschluss gelangte, ergab sich für diesen Abschnitt eine durchschnittliche jährliche Nutzung von

1103 Klafter in Form von Schlagmaterial,

511 》 ab dem liquidierbaren Waldboden

$720 \gg$ in Form von Durchforstungsmaterial,

per Jahr demgemäss 2334 Normalklafter $=6320$ Festmeter exklusive Reisig. 
Mit Beginn des Dezenniums 1870 - 1879 wurde eine Revision des Wirtschaftsplanes nicht vorgenommen. da die hereits eingeleitete Neuvermessung der Waldungen es als wünschbar erscheinen liess, zuerst das Ergebnis derselben abzuwarten. Immerhin erfolgte eine Regulierung des Abgabesatzes in dem Sinne, dass die im Dezennium 1860-1869 gemachten Ersparnisse von Summa $3151 \mathrm{~m}^{3}$ zu dem im Wirtschaftsplan von 1860 für das Dezennium 1870-1879 festgesetzten Hiebsbeträge von 15,000 Normalklafter oder $40,500 \mathrm{~m}^{3}$ hinzugefügt wurden, sodass sich dadurch ein Etat von $4350 \mathrm{~m}^{3}$ ergab. Im Jahre 1875, bei dem Uebergang der Verwaltung des Herrn Forstmeister von Orelli an den Stadtforstmeister U. Meister war die Situation wie folgt: $\left.{ }^{1}\right)$

$$
\begin{aligned}
& \text { Normalansatz pro } 1870 / 71-1879 / 80=40,500,00 \mathrm{~m}^{3} \\
& \text { Ersparnisse der letzten Periode }=3,151,00 \\
& \text { Mehrertråge aus den im Sihlwald u. Adlis- } \\
& \text { berg gänzlich abgetriebenen Abteilun- } \\
& \text { gen über die Schätzung von } 1860 \text { hinaus }=6,717,27 \\
& \text { Summa }=50,368,27 \mathrm{~m}^{3} \\
& =25,309,43 \\
& \text { des II. Dezennimus 1875/76-1879/80 }=25,058,81 \mathrm{~m}^{*} \\
& \text { oder pro Jahr }=5,011,7 \pi
\end{aligned}
$$

Mit dem Abschluss des Dezenniums ergab sich, dass von 1875/76 bis $1879 / 80$ im ganzen bezogen worden waren $23,951,19 \mathrm{~m}^{3}$ oder 4790,24 $\mathrm{m}^{3}$ per Jahr und es müsste demgemäss auch hier eine Ersparnis von $1107,65 \mathrm{~m}^{3}$ gemacht worden sein.

Wenn bei dieser Einsparung nur die veränderten Verhältnisse, welche sich infolge der Wildgartenstiftung im städtischen Forstbetrieb im Sinne einer Reduktion des jährlichen Etats geltend machen mussten, tatsächliche Berücksichtigung fanden, so liesse sich aus dieser Differenz für sich allein nicht wohl von einem wirklichen Vorschlag im letzten Dezennium sprechen. Da indessen auch ein erheblicher Rest noch nicht abgetriebener, dem zweiten Dezennium von 1870/71-1879/80 zugeteilter Flächen noch intakt vorhanden war, so die jetzige Abteilung Nr.8 (ehemals Nr.9) Birriboden und Abteilung 11 (ehemals 12) Häuliboden, so wurde offenbar nicht der volle Zuwachs zur Nutzung gebracht und es sind somit tatsächlich Ersparnisse gemacht worden.

1) Geschäftsbericht des Stadtrites pro 1874, pag. 139. 
Der im Jahre 1880 neu erstellte Wirtschaftsplan ${ }^{1}$ ) war der erste Versuch, die Ertragsverhältnisse der Stadtwaldungen auf Grund sorgfältigster Ermittlung des Vorrates und des Zuwachses festzustellen. Zudem bot die vorangegangene Neuvermessung des gesanten Waldgebietes die notwendige Sicherheit in der Bemessung der Flächenverhältnisse. Die zum Zwecke der Vorrats- und Zuwachsermittlung anfestellte Ertragstafel der Rothuche schied vier Bonitätsklassen aus, die auf die Differenzen der mittleren Bestandeshöhen fussten. Alle diejenigen Bestände, welche in den nächsten zehn Jahren zum Hiebe gelangen sollten, wurden kluppiert und durch die Fällung einer grossen Anzahl von Probestämmen nach ihrem Massengehalt ermittelt. Die Ansetzung der Bonität in den übrigen Beständen erfolgte teils an der Hand der für die Ertragstafeln bereits ausgeschiedenen, teils mit Hülfe neuer Probeflächen, indem für den konkreten Zuwachs oder das Ertragsvermögen Prozentansätze des normalen Haubarkeits-Durchschittszuwachses der zugehörenden Bonitätsklasse angenommen wurden. Für die normale Bonität oder die Ertragsfähigkeit gelangte der der Ertragstafel entsprechende Haubarkeits-Durchschnittszuwachs zur Anwendung unter genauer Berücksichtigung der für die Klassifikation massgebenden Höhen und Stammzahlen. Gestützt auf dieses Vorgehen ergab sich ein wirklicher Zuwachs von Summa $5975 \mathrm{~m}^{3}$ oder $6,29 \mathrm{~m}^{3}$ per ha, bei einem normalen $\mathrm{Zu}$ wachs von Summa $6266 \mathrm{~m}^{3}$ oder 6,60 $\mathrm{m}^{3}$ per ha. Die Vorratsverhältnisse ergaben den hohen Betrag von $268,488 \mathrm{~m}^{3}$. Hiebei muss bemerkt werden, dass sowohl bei den Probeflächen als bei den Beständen überhaupt Durchforstungen allerdings vorangegangen waren, jedoch nicht in der intensiven Art der Durchführung der achtziger und neunziger Jahre des letzten Jahrhunderts und der Gegenwart. Diesem Umstande ist wohl die Erscheinung zuzuschreiben, dass die Massenvorräte der Ertragstafel von 1880 und der dazumal nicht kluppierten Bestände etwas zu hoch angesetzt wurden.

Die Umtriebszeit wurde unverändert für alle Betriebsklassen auf 90 Jahre angesetzt. Es wurde hiebei angenommen, dass diese Höhe fïr die ïherwiegende Bremuholzerziehung meln als genügend sei; für die Nutzhölzer wäre durch die parallel gehende natürliche Verjingung die Möglichkeit geboten, einem verstärkten Leistungs-

1) Die Stadtwaldungen von Ziivich. Thre Geschichte, Einrichtung und Zu1wachsverhältnisse nebst Errtragstafeln für die Rotbuche, von Ulvich Meister, stadtforstmeister, Zürich. Verlag von Orell Küssli d Co. 1883. 
zuwachs und damit ausreichenden Nutzholzstärken zu rufen. In der grössern Flächenausdehnung, die den Abteilungen boi ihrer dazumaligen Neubildung gegeben war, wurde ein weiteres Mittel erblickt, den nötigen Spielraum zu erhalten, geeigneten Sortimenten einen längern Verjüngungszeitraum zuweisen zu können. Fiur die einem frühern Hiebsalter sich zuneigenden Ahorne, Eschen und Ulmen wurde ein frïherer Vorkieb in Aussicht genommen, in der Meinung, dass alle Nutzungen aus den in den nächsten zwanzig Jahren zum Abtrieb gelangenden Beständen, als Bestandteile der ILamptnutzum, in der Wirtschaftskontrolle nackgeführt würden.

Das Hiebsquantum wurde für jede einzelne Hiebsfolge und Betriebsklasse festgesetzt, wobei angenommen wurde, dass damit nicht ausgeschlossen sein solle, dass vorübergehend ein Vikarisieren der einen Betriebsklasse für die andere statthaft sei. so namentlich dann, wenn Vorratsüberschüsse der einen Klasse zweckdienlich für die Defizite der andern Verwendung finden könnten. Der Etat wurde berechnet nach der Formel:

$$
\mathrm{F}=\mathrm{SW} / \mathrm{NV} \cdot \mathrm{Wr}
$$

Auf diese Art und Weise ergab sich ein Gesamtetat von $5740 \mathrm{~m}$ oder bei einer Nutzungsfläche von 1043 ha $=5,5 \mathrm{~m}^{3}$ per ha.

Ein Durchforstungsetat konnte dazumal noch nicht konstruiert werden; es mangelte an dem hiefür nötigen Material, umso mehr, als nur die Durchforstungsergebnisse der letzten fünf Jahre zur Verfügung standen. Diese bezifferten sich auf durchsehnittlich $35 \%$ des Hauptnutzungsertrages. Vor dem Jahre 1875 bezw. in den zwei vorangegangenen Dezennien war der Durchforstungsbetrieb nicht in dem wünschbaren Umfange durchgeführt worden, sodass die nachfolgende Periode rückständige Durchforstungen nachzuholen hatte. Demzufolge wurde für die nächste Etatsperiode ein Durchforstungsquantum von $40 \%$ des Hauptnutzungsetat $=2290$ Festmeter $=2,2 \mathrm{~m}^{3}$ per ha angenommen. Der Gesamtetat wies somit eine Gesamtnutzung von $8030 \mathrm{~m}^{3}=7,7 \mathrm{~m}^{3}$ per ha, das Reisigmaterial mit inbegriffen, auf. Ein allgemeiner. Hanungsplan für die ganze Dauer der Umtriebszeit sicherte die Flächendeckung der einzelnen zehnjährigen Perioden und ein spezieller Hauungsplan bezeichnete im einzelnen die den Dezennien 1881 bis 1890 und 1891 bis 1900 zufallenden Hiebsflächen und Hiebsmassen. Der auf diesen Grundlagen entworfene Wirtschaftsplan wurde den Herren Dr. Carl von Fischbach, fürstlich hohenzollerschem Oberforstrat in 
Sigmaringen und Oberforstmeister Prof. Landolt in Zürich zur Prüfung unterbreitet und von denselben in zustimmendem Sinne begutachtet.

Auf dieser Basis vollzog sich der Betrieb bis und mit dem Wirtschaftsjahr 1884/85 in regelmässigem Verlauf. Es wurden in dieser Periode durchschnittlich in Form der Hauptnutzung 5,26 $\mathrm{m}^{3}$ per Jahr und per ha und in Form der Durchforstungen 2,92 $\mathrm{m}^{3}$ per Jahr und per ha zur Nutzung gebracht. Die Hauptnutzungen in den durch den speziellen Hiebsplan hiefür vorgeschriebenen Abteilungen. die Durchforstungen gemäss den Bestandesverhältnissen jedoch in einer auf einen rexelmässigen Turmus hinzielenden ()rdnung. $\mathrm{Zu}$ diesem Zwecke wurde eine eigentliche Durchforstungskarte angelegt, in welcher die durchforsteten Flächen jedes Jahr eingetragen wurden. Für eine konsequente, willkürliche Abänderungen von vornherein ausschliessende Nachführung der Material- und Geldertragskontrolle wurde eine detaillierte Forststatistik angelegt und in derselben alles und jedes Nutzungsmaterial eingetragen. Für jede einzelne Abteilung bot die hiefür angefertigte Abteilungskarte im Massstab 1:2000 die Möglichkeit, die Verjüngungs- und Abtriebsschläge in einer für die Bestandesgeschichte zweckdienlichen Art vorzumerken. So war denn alle Aussicht vorhanden, durch die Innehaltung dieses Wirtuchaftsganges den $\mathrm{T}^{\text {rald }}$ seiner vollständigen Normalität entgegenzuführen und insbesondere auch die noch nicht völlig regelmässige Altersklassenabstufung herzustellen.

Dieselbe war dazumal wie folgt:

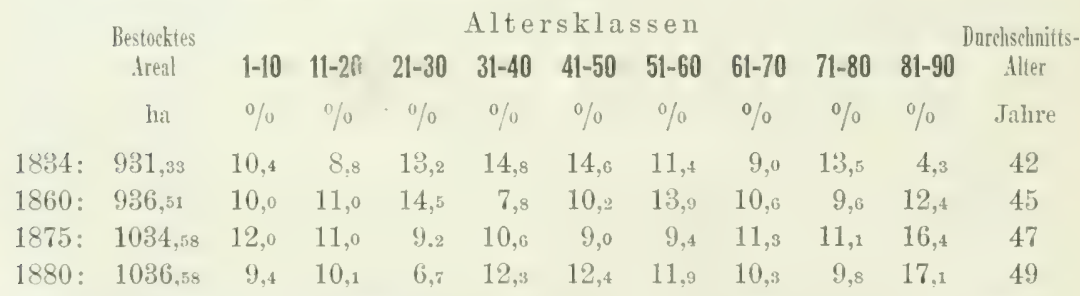

Da kam die verhängnisvolle Schneebruchkatastrophe vom 28. September 1885 und mit einem Schlag war die durch die Fürsorge von Jahrhunderten herbeigeführte annähernde Normalität der Sihltalwaldungen, speziell des so schönen Siblwaldes, dahin. Durch den Obern Sihlwald zog sich von Nord nach Siid durch die Abteilungen 6, 5 und 4 ein $300-400 \mathrm{~m}$ breiter und $1500 \mathrm{~m}$ langer Streifen,

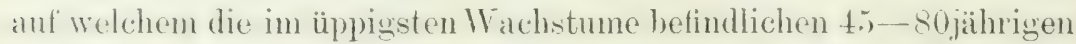
Laubholzbestände absolut ${ }^{1}$ ) zerstört waren. In der $80-90$ jährigen

1) Vide 'T'abula VI, VII, VIII, IX und X. 


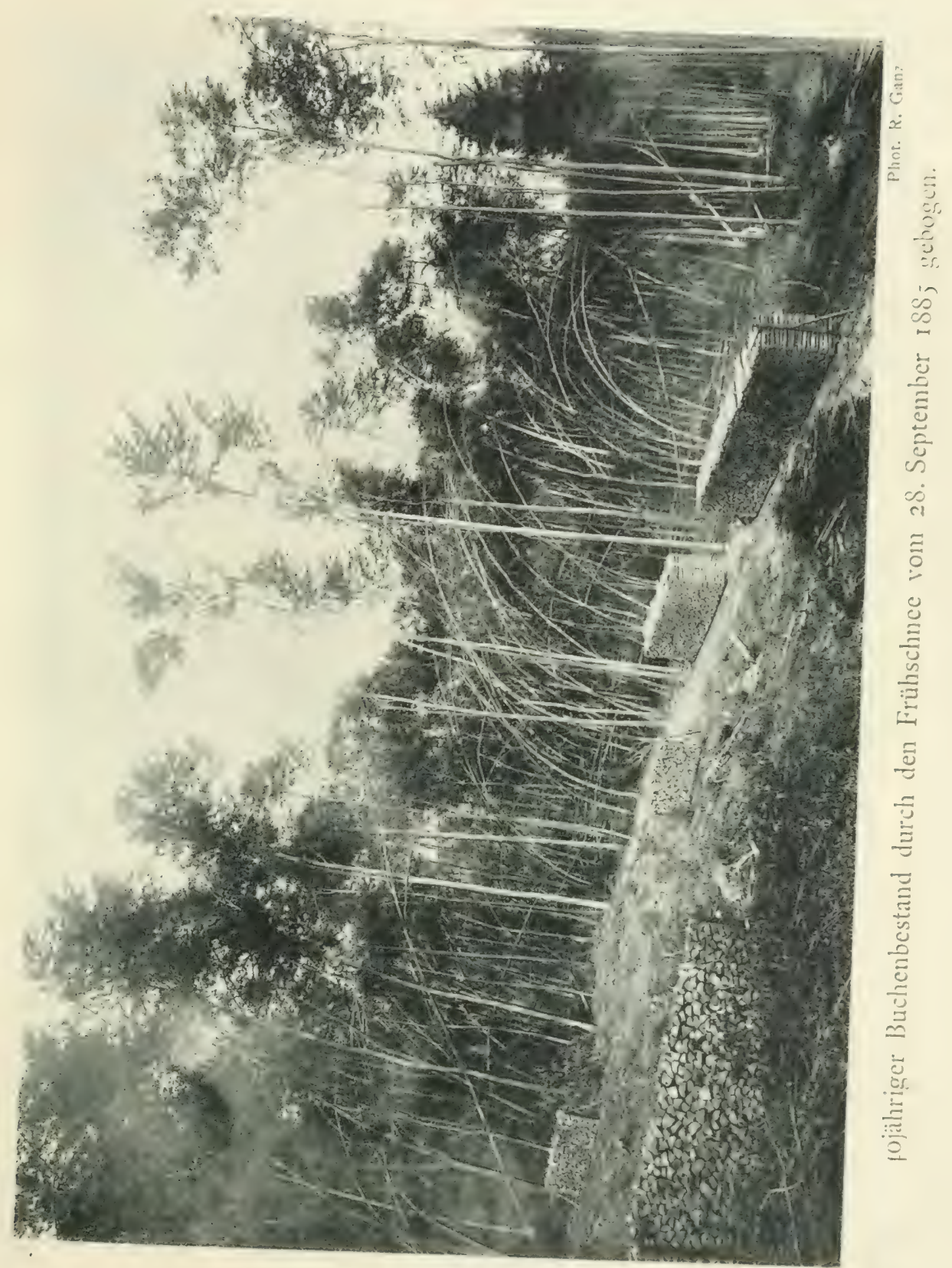





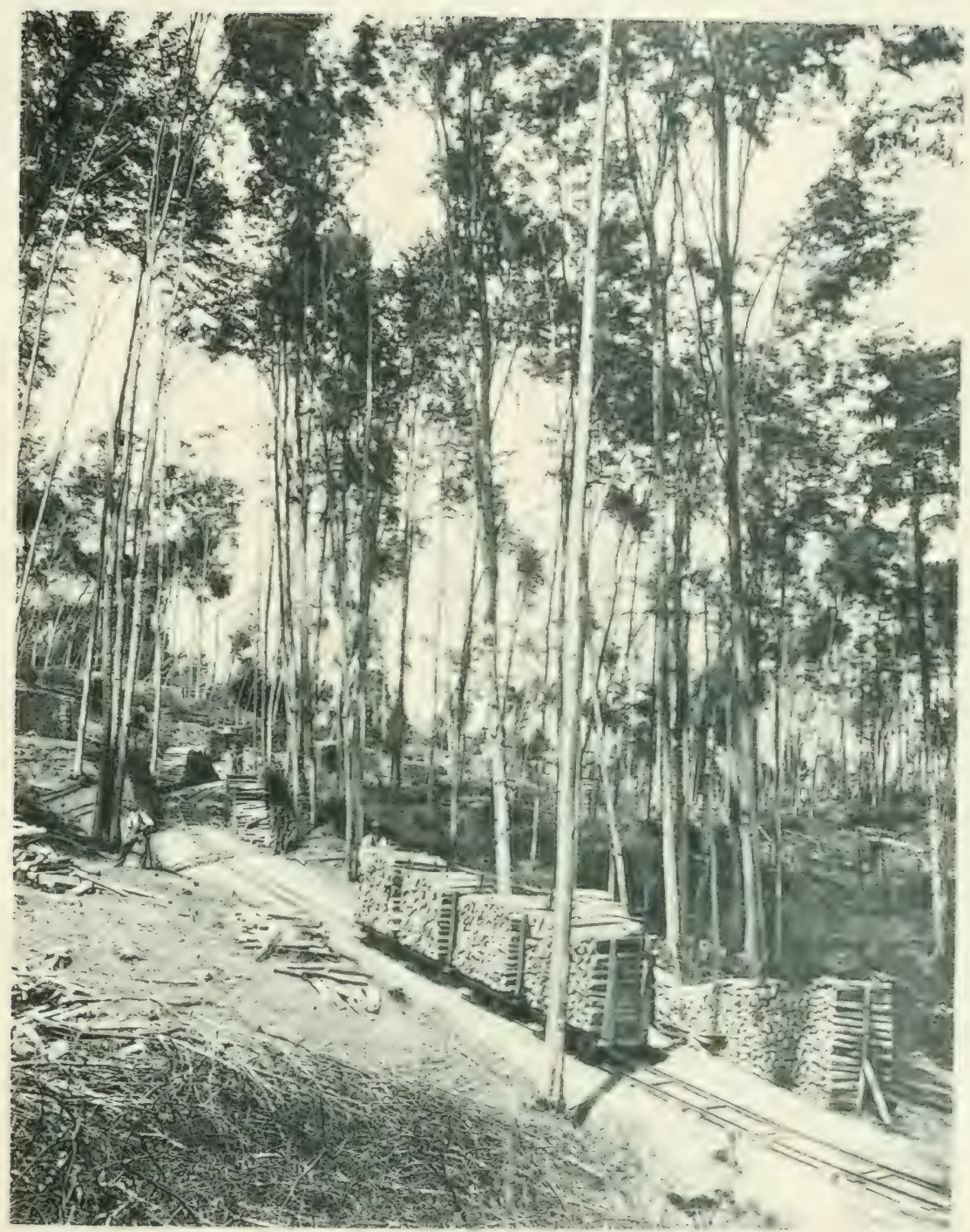

Phot. R. Ganz

Durch Schneebruch rom 28. September I88; gelichteter ;8jähriger Bestand nach der Aufarbeitung des Materiales; im Vordergrund Waldeisenbaln mit Brennhol\%. beladen, II $\%$ Gefälle. 



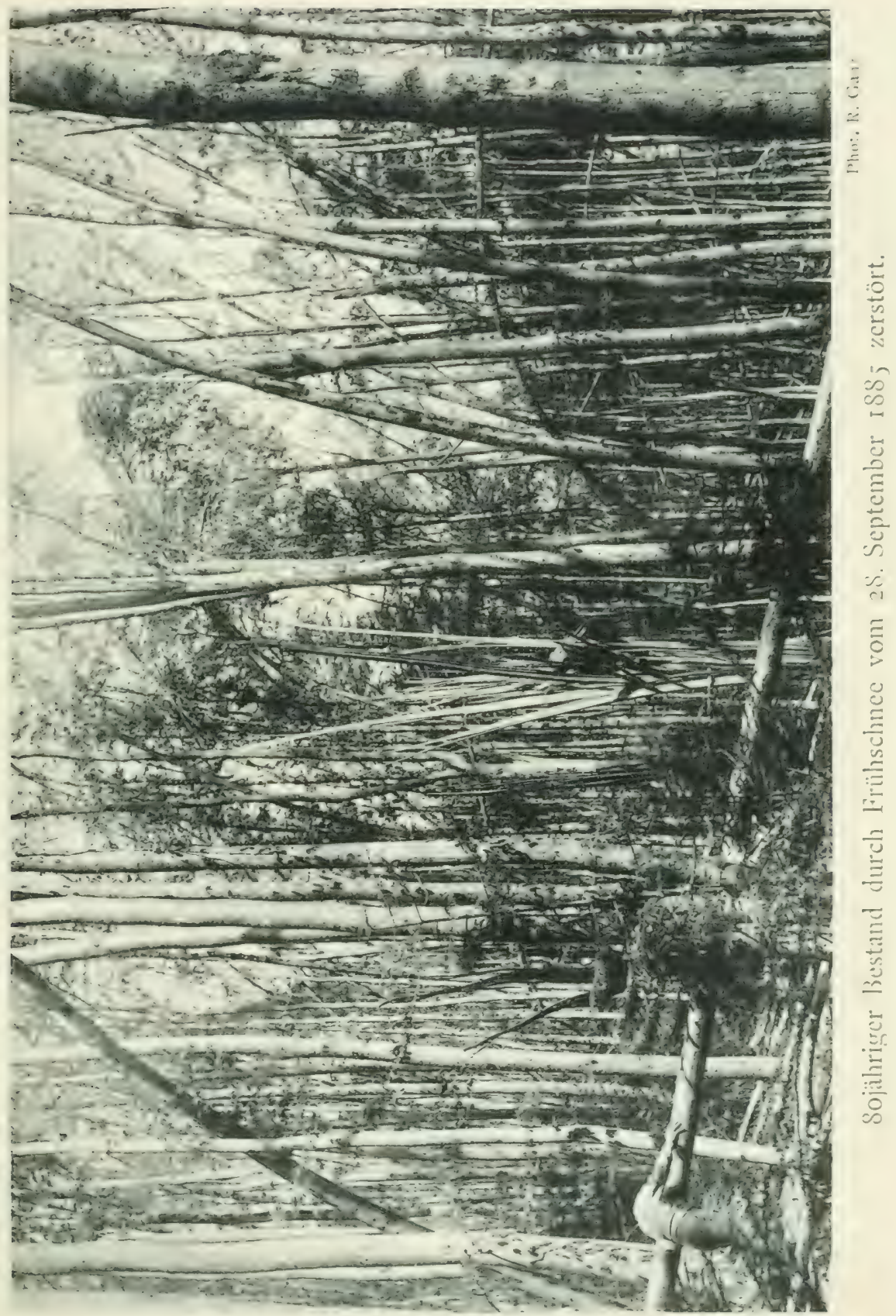




TAFEL $X$

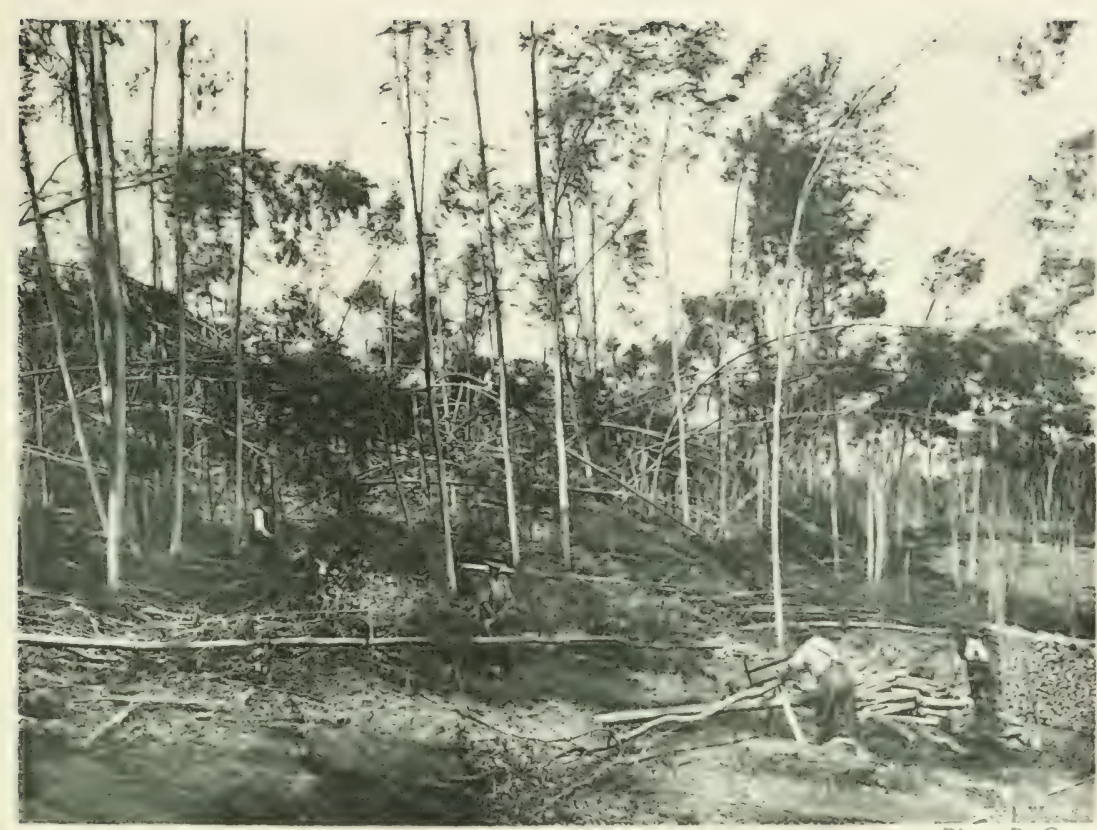

Sclneedruck vom 28. September I88;. 42jühriger Bestand.

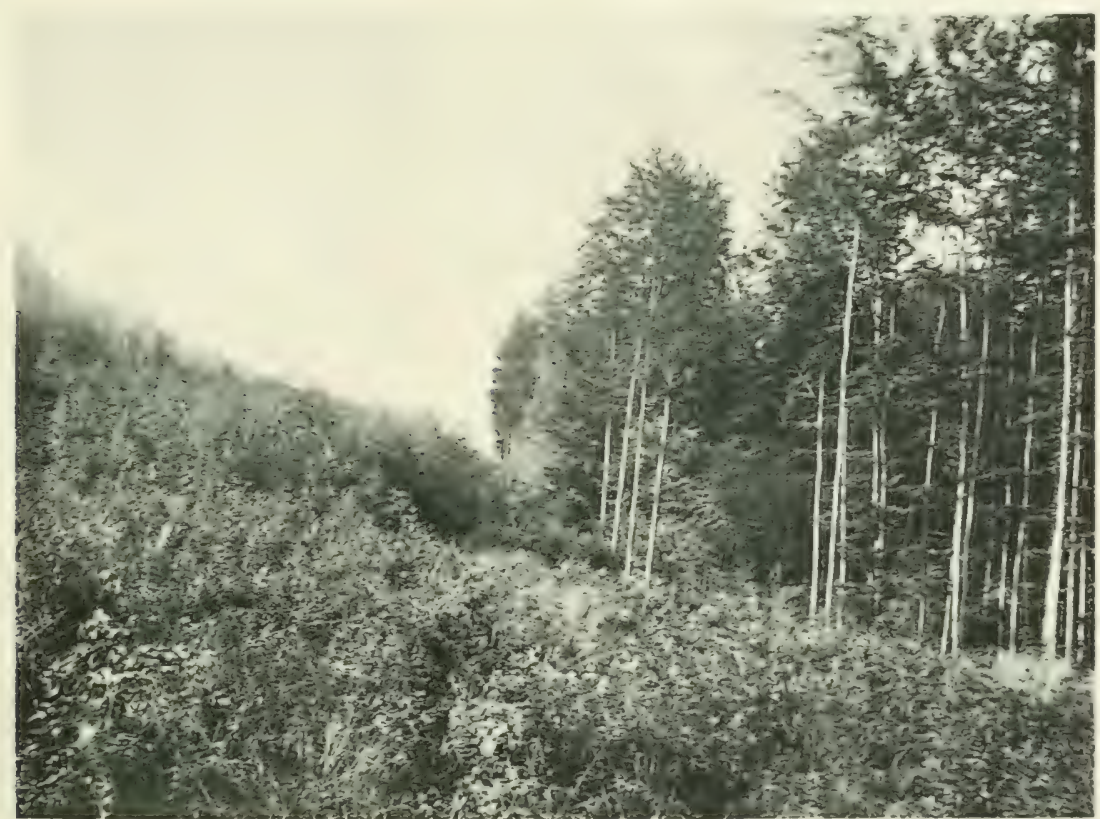

Phot. R. Ganz

Gegenwïrtiger Zustand der Schncebruchlliche, angrenzend an den verschonten Bestand. 

Abteilung 3 endete die Zerstörung. Sie erstreckte sich nur noch auf einzelne Gruppen, jedoch in einem solchen Umfange, dass dadurch die Möglichkeit eines längeren Ueberhaltes des verblicbenen Teiles ausgeschlossen war. Im Untern Sihlwald hatte das Zerstörungswerk nicht in gleichem Umfange veränderte Terhältnisse geschaffen. Die von demselben betroffenen Waldteile waren nicht vollständig vernichtet, sondern nur mehr oder weniger nesterweise gelichtet; am meisten derjenige Teil von Abteilung 15, in welchem eine Hektar grosse Probefläche angelegt war. Jene Probefläche, die bei einer Stammzahl von 815 , einer Kreisfläche von $37,58 \mathrm{~m}^{2}$ und $629 \mathrm{~m}^{3}$ Masse mit Recht der I. Bonität zugewiesen war und wohl geeignet ist, ein zutreffendes Bild vom dazumaligen Waldzustand zu geben. Dass nach einem solchen Vorgang an dem kurz vorher aufgestellten Wirtschaftsplan vorerst nicht mehr festgehalten werden konnte, liegt auf der Hand. Hiebsordnung und Hiebsquantum mussten sich unabänderlich dem gewaltigen Diktat des Naturphänomens fügen. Es galt zunächst, das zerstörte Bestandesmaterial bestmöglichst zu retten und zur Verwendung $\mathrm{zu}$ bringen und sodann in zweiter Linie in tunlichster Bälde wieder den grösstmöglichen Zuwachs zu erzielen. Die grössern Nutzungsquoten, die sich aus diesem Vorgehen ergeben mussten, waren durch Reduktion oder völlige Einstellung der Hauptnutzungen in den übrigen Betriebsklassen auszugleichen. Die Durchforstungen mussten entweder ganz oder zum grös-1.n Teile sistiert werden.

Die Durchführung dieses wirtschaftlichen Programmes brachte es mit sich, dass nach verschiedenen Richtungen hin auf einmal Massnahmen getroffen werden mussten, die sich sonst beim geregelten Gang einer Wirtschaft auf Jahrzehnte hinaus verteilen. Zunächst musste ein vermehrtes Arbeiterpersonal zur Aufarbeitung des zu beseitigenden Holzmateriales herangezogen werden. Dies war nur möglich durch eine Erhöhung der bisherigen Holzhaverlöhne. Für den Wegtransport der aufgearbeiteten Massen waren Transportmittel aussergewöhnlicher Art erst zu beschaffen, denn für die ganze, zirka 60 Hektar umfassende, anderthalb Kilometer lange, durchschnittlich 100 Meter über der Talsohle liegende Fläche war nur ein einziger, nicht chaussierter Abfuhrweg vorhanden. Für Erstellung neuer, genügend fahrbarer Waldstrassen boten einerseits die topographische Gestaltung des Terrains, anderseits der Mangel an Material für Steinbett und Bekiesung unüberwindliche Schwierigkeiten. Alle diese Umstände wiesen die Verwaltung darauf hin, 
für den Transport zu Tal das Mittel der Holzriese als den kürzesten Weg und für den Transport an die Holzriese die Waldeisenbahnen zu benutzen. Unter Inanspruchnahme dieser Transportmittel konnte zur Verwertung des ungewöhnlich grossen Schneebruchmaterials geschritten werden.

Die Schneedruckwirkung hatte sich je nach dem Alter der betreffenden Bestände in verschiedenartiger Weise geltend gemacht. Bei den siebzig- und mehrjährigen Hölzern hatte die Ueberschreitung des Druckkoeffizienten meist einer Zersplitterung der Stammpartie gerufen; bei den jüngern Hölzern vollzog sich ein Abbrechen bald im untern, bald im mittleren, bald im obern Teile des Schaftes; schwächere Stämme wurden vollständig ungebogen. Die Nutzholzausbeute war daher von vornherein ausgeschlossen. Der Verwertung als Brennholz stellte sich, neben der übergrossen Masse, welche auf einmal auf den Markt geworfen werden musste, noch die starke Beimischung von Ahorn, Esche und Ulme hindernd entgegen. Die Verwendung zu Holzstoff für die Papierfabrikation erwies sich, nach Anfragen bei Papierfabriken als aussichtslos. So blieb denn kein anderer Ausweg übrig, als die Verkohlung auf dem Wege des gewöhnlichen Meilereibetriebes für die Verwertung der geringsten Sortimentsklasse in Anspruch zu nehmen, das Reisigsortiment, das sich am meisten absatzfähig erwies, möglichst auszudehnen und sodamn dem Prügel- und schnittholzsortiment durch tunlichste Herahsetzung der Preise die nötige Abnahme zu verschaffen. In dieser Art wurde das Aufarbeitungs- und Verwertungsprogramm der Schneebruchmassen ausgeführt.

Die Durchführung wurde noch dadurch erschwert, dass das anfänglich in Aussicht genommene Teloerhalten unbeschädigter Bäume sich nicht als statthaft erwies. Wo solche Stämme nicht horstweise vereinigt waren, erfolgten im ersten oder zweiten Jahre nach dem ersten Schneedruck weitere Schneebrüche, sodass mit Ausnahme der Nadelholzgruppen nachträglich ler vollständige Abtrieb der' Schneedruckfläche des obern Waldes hewerkstelligt werden musste. Nicht weniger als 44,790 $\mathrm{m}^{3}$ mussten auf diese Art aufgearbeitet, aus dem Walde geschafft und zur Verwertung gebracht werden. Mit Einschluss des Lntern Sihlwaldes beanspruchte die Bewältigung dieser Aufgaben einen Zeitraum von sechs Jahren. Die Nettoverwertung pro $\mathrm{m}^{3}$ in dem Sinne, dass dabei alle und jede Betriebskosten: Verwaltung. Holzgewinnung, strassen- und Gehäudeunterhalt. Kulturen in Abzug gebracht sind, ergab für diese Dauer $6 \mathrm{Fr}$. per $\mathrm{m}^{3}$; die 
Nettoverwertung der fünf vorangegangenen Jahre belief sich auf Fr. 9.50 per $\mathrm{m}^{3}$. Die divekt nachweisbare Einbusse, welche die Schneebruchkatastrophe dem Betriebe verursacht hat. beträgt demnach $44,790 \times 350=156,765$ Franken.

Die indivekte Schädigung des Waldbestandes und der daraus resultierenden, nachfolgenden Wirtschaft ist schwer $\mathrm{zu}$ bemessen; sie ist wohl nicht minder gross. Indem ein wesentlicher Teil der aus den ungewöhnlich grossen Holzschlägen sich ergebenden Erträge zum Ankauf von 14,35 ha Waldareal in der Rengg. angrenzend an die Albishölzer, verwendet wurde, ist den künftigen Betriebsergebnissen etwelche Kompensation für die Schädigung geboten worden. Die Wiederaufforstung der Schneebruchfläche und damit die Herstellung normaler Zuwachsverhältnisse wurde unmittelhar nach der Räumung der Schläge vorgenommen. In den ältern Abteilungen 3 und 4 handelte es sich dabei nur um eine Ergänzung des bereits reichlich vorhandenen natürlichen Laubholz-Aufwuchses, sie wurde mehrmals durch Einpflanzung von Nadelhölzern hewerkstelligt. In den Abteilungen 5 und 6 hatte die Besamung noch nicht stattgefunden, sodass die gesamte Plïche durch Einpflanzung einer entsprechenden Nischung ron Nadelliolz und Laubholz aufgeforstet werden musste.

Nach all diesen Vorgängen wurde im Jahre 1893 zur Vornahme einer $Z$ wischenrevision des im Jahre 1880 aufgestellten 1 intschiftsplanes geschritten und, gestützt auf die vorgenommene Massenermittlung in den über 70 Jahre alten Beständen, der Etat neu festgestellt, unter Berïcksichtigung des inzwischen erfolgten Ueberganges des früheren Wildgartendistriktes Winzelen und weiterer eingetretener Arealveränderungen. Für die 1010,50 ha nutzbaren Waldareals ergab sich nach dem System der Etatsberechnung vom Jahre 1880 ein Hauptnutzungsetat von $.900 \mathrm{~m}^{3}$ bei Festhaltung an der neunzigjährigen Umtriebszeit. Die Durchforstungserträge wurden wiederum nicht in die Etatsermittlung hineingezogen.

Der wirkliche Zuwachs, der für das Jahr 1894 festgestellt wurde, zeigt gegenüber demjenigen vom Jahre 1880 eine kleine Vermehrung, $6,3 \mathrm{~m}^{3}$ statt $6,29 \mathrm{~m}^{3}$, welcher Umstand wohl auf Rechnung der intensiveren Bestandespflege und der mit Erfolg durchgeführten Neuaufforstung der Schneebruchfliiche zurïckzuführen ist. 


\section{Waldbauliche Grundsätze.}

\section{Bestandesgrïndung.}

Ohne dass genaue Daten vorliegen, darf als feststehend angenommen werden. dass die Bestandesgründung in den stadtwaldungen von Zürich, soweit es den Sihlwald betrifft, von jeher auf dem Wege der natiirlichen Verjïngung stattgefunden hat. Nachweisbar ist dieselbe vom Jahre 1838 an auf dem Wege des allmählichen Abtriebes erfolgt. Im Nadelholzbezirk Forst, Betriebsklasse IV, wurde der künstliche Holzanbau zum erstenmal Anno 1737 in Form von Lärchen- und Föhrensaaten (pag. 32) eingeführt und dann bis zum Jahre 1875 festgehalten. Nachher wurde auch dort darauf hingearbeitet, die natürliche Verjüngung mit einer längeren Verjüngungsdauer zu erzielen.

Sowohl die Standortsverhältnisse der Sihltalwaldungen, als diejenigen ler oberhalh Zürich gelegenen Adlishergwaldungen sind der natürlichen Verjüngung in vorzüglicher Art günstig. Wenn auch die Samenjahre an und für sich nicht in häufiger und intensiver Weise eintreten, so vollzieht sich die Verjüngung in der Regel schon frühzeitig un!? ? gelmässig, begünstigt durch die Einwirkungen des vorangegangenen Durchforstungsbetriebes. Offenbar muss aber auch noch ein anderer, noch nicht klargelegter Faktor bei dieser frappanten und sehr oft nicht mit einem Samenjahr in Verbindung: stehenden Verjüngung mithelfen. Die Temperatur- und Feuchtigkeitsverhältnisse des Bodens müssen eine langandauernde Keimkraft der im Boden lagernden Samen begünstigen.

Die leichte Art, mit der sich die Verjüngung in den Sihltalwaldungen vollzieht, macht sich auch durch den Umstand bemerkbar, dass trotz der seit Jahrhunderten im Sihlwald festgehaltenen Hiebsfolge, wonach der eine Teil von Süd nach Nord und der andere von Nord nach Süd verjüngt wird, eine Differenz in den Jungwüchsen nicht zutage tritt. Nur ab und zu straft sich im erstern 'Teil eine zu unvorsichtige rasche Lichtung mit Spätfrostschädigungen. 
Die Erreichung des waldbaulichen Wirtschaftszieles begegnet bei der natürlichen Verjüngung der einen Schwierigkeit, dass die Buche von Anfang an das Terrain vorherrschend in Beschlag nimmt und damit die wünschbare Bestandesmischung erschwert. Allerdings macht sich zurzeit wieder der Beginn des Wechsels der Holzarten, wie er vor 200 Jahren schon einmal stattgefunden hat (vide pag. 28) an vielen Orten augenscheinlich fühlbar; die Weisstanne tritt diesmal an Stelle der Buche. Es ist wahrscheinlich, dass diese Erscheinung durch den nunmehr überall durchgeführten Durchforstungs- und Vorhiebsbetrieb unterstützt wird. Bei weiterer Fortführung dieses Systems dürfte auch das natürliche Aufkommen der Fichte neben der Weisstanne in höherem Masse möglich werden, als es bisher der Fall war.

Bei der Durchführung der Bestandesgründung hat man in Anbetracht aller dieser Verhältnisse vorab zwei Momente ins Auge zu fassen; zunächst die Vervollständigung der schon von der Natur eingeleiteten Bestandesmischung und sodann eine derart surgfältige zeitliche Verteilung der Lichtungshiebe, dass der bereits vorhandene starke Jungwuchs durch das Fällungs- und Abfuhrquantum möglichst wenig beeinträchtigt wird. Die bisherigen Erfahrungen weisen darauf hin, dass diesen Anforderungen in den Laubholzbeständen mit der durchschnittlichen Verjüngungsdauer von sieben Jahren genügt wird. Der Vorbereitungsschlag, wie er meistens üblich ist, wird durch die Durchforstungen und Vorhiebe ersetzt. Dunkel- und Lichtschlag folgen sich in dreijährigen Intervallen, sodass der Absäumungsschlag eine nur noch vom Standpunkt der Bestandesmischung aus zu rektifizierende Verjüngung hinterlässt. Anders gestalten sich die Verhältnisse beim Femelschlagbetrieb in den rechtsufrigen Nadelholzbeständen der Sihltalwaldungen, wo eine Verjüngungsdauer von 15 Jahren den Durchschnitt bildet.

Der Bestandesräumung folgt sofort die Bestandessäuberung durch Entfernung der Aufarbeitungsreste und der Beseitigung der durch die Fällung und den Transport stark beschädigten Vorwüchse. Die Bestandesergänzung wird erst im nächsten Jahre vorgenommen: dadurch soll dem Aufschlag die Möglichkeit geboten werden, sich derart zu erholen, dass die nachfolgenden Einpflanzungen unter entsprechender Würdigung des vorhandenen Jungwuchses im Sinne der gewünschten Bestandesmischung vorgenommen werden können. Hiebei wird vornehmlich die gehörige Durchmischung mit Nadelhölzern: Fichte, Weisstanne und Lärche. 
unter Berücksichtigung der Standortsverhältnissen ins Auge gefasst. Ahorn und Esche sind meistens in ausreichendem Masse vorhanden. Die versuchsweise in rerschiedenen Terjüngungsschlägen vorgenommenen Unterpflanzungen von Fichten und Weisstannen haben sich im allgemeinen als vorteilhaft erwiesen. Die horstweise Einpflanzung der Nadelhölzer ist angesichts des raschen Nachdrängens der Buche eine unerlässliche wirtschaftliche Massregel. Eine Ausnahme hievon findet nur mit Bezug auf die Lärche statt, die immer einzeln und zwar unmittelbar nach der Schlagräumung eingepflanzt wird. Die horstweise Mischung gelangt auch da zur Anwendung, wo bisheriges Kulturland in Wald umgewandelt wird. Die früher allgemein empfohlene und noch zu Anfang der achtziger Jahre festgehaltene reihenweise Mischung hat sich ohne Ausnahme als verfehlt herausgestellt und zwar interessanterweise sowohl in den Sihltalwaldungen als auf dem Adlisberg in dem Sinne, dass sogar bei dem Mischungsverhältnis zwei zu drei die Laubhölzer absolut von den Nadelhölzern verdrängt wurden.

Die mit Bezug auf die Pflanzweite gemachten Erfahrungen führten im Verlaufe der letzten zwanzig Jahre dazu, der engeren Pflanzung den Vorzug zu geben, sodass im Durchschnitt Pflanzabstände von $1,20 \mathrm{~m}$ als Regel festgehalten werden. Hiebei wird insbesondere an den Berghalden von einer Pflanzung nach der Schnur Umgang genommen und mehr oder minder ein Dreiecksverband angestrebt. Auf diesem Wege ermöglicht der künstliche Holzanbau in ähnlicher Weise wie die natürliche Verjüngung starke Vornutzungen in den ersten Durchforstungsperioden und zugleich auch die Erziehung schlazker Nutzholzsortimente. Von analogen Erwägungen geleitet, brachte man in den zwei letzten Dezennien an Stelle der Pflanzungen vielfach wieder die Saaten zu vermehrter Beachtung, teils als Untersaaten in Lichtschlägen, teils in Form von Plattensaaten in Abtriebsschlägen.

Das Material für die Einpflanzungen wird teils den Schlägen, teils den Pflanzschulen entnommen. Die Anlage der Pflanzgårten erfolgt nicht im Walde selbst, sondern in angrenzendem landwirtschaftlichem Gelände. Die nachteiligen Wirkungen, welche die langjährige Benutzung des Waldbodens durch den Pflanzschulhetrieb hatte. wal begründete Veranlassung zu diesem Vorgehen. Besonderes Gewicht wird dem Samenbezug zugewendet und wo immer möglich darauf gehalten, dass das Saatgut im Walde selbst und zwar von den schünsten Baumindiviluen gewonnen werden kann. Offenbar 
hat die Forstwirtschaft diesem in der Landwirtschaft långst beachteten Moment bisher zu wenig TVichtigkeit beigelegt; ein Umstand, der sich da, wo der künstliche Holzanbau ausschliesslich betrieben wird, in nachteiliger Weise äussern muss.

In unentwegt ablehnendem Sinne verhält sich der städtische Forsthetrieh gegenïber der Einbinrgerung der sogenannten exotischen oder fremdländischen Holzarten. Eine erste Veranlassung dazu gibt das Verhalten der im Sihltal nicht autochthonen, sondern erst zu Ende des 18. Jahrhunderts eingebürgerten Lärche. Bei aller Anerkennung ihres rascheren Wachstums in der Jugend spricht gegen diese Holzart doch der Umstand, dass deren Zuwachsverhältnisse im späteren Alter gegenüh,er denjenigen ter einheimischen Kiefer ungünstigere sind. dass die Samenbildung entgegen derjenigen im natürlichen Entwicklungsgebiet der Lürche zurückbleiht und vor allem aus die Tatsache, dass die Qualität des in unserem Waldgebiet erzogenen Lärchenholzes hinter derjenigen der Tïefer zuriickbleibt und derjenigen der Gehirgslärche keinesweys gleichkommt.

Die mit der Schwarzkiefer (pinus austriaca) und der Weymuthskiefer (pinus strobus) gemachten Erfahrungen führen durch analoge Wahrnehmungen zu den gleichen Schlussfolgerungen. Die Entwicklung dieser Arten bleibt auf die Dauer hinter derjenigen der einheimischen zurück. Wenn momentan eine zufällig sich geltend machende Nachfrage nach solchen fremden Holzsortimenten günstigere Marktverhältnisse für dieselhen zu bieten verspricht, so müssen solche Erscheinungen wohl als vorühergehende aufgefasst werden. Eine Einbürgerung exotischer Holzarten kann wohl nur da als statthaft bezeichnet werden, wo unsere heimischen Holzarten den Dienst versagen und eine Bestandesgründung mit denselben nicht durchführbar ist. Zu dieser allerdings sehr begrüssenswerten Neuerung wurde aber bisher keine Gelegenheit geboten. ${ }^{1}$ )

\section{Bestandespflege.}

Wo die Natur der Holzproduktion in so weitgehendem Masse Vorschub leistet, wo der junge Wald in oft überreicher Fülle sofort an Stelle des alten tritt, wie das tatsächlich in den ,ihltalwaldungen

1) Bei den vielen Besuchen speziell amerikanischer und indischer Forstmänner ist uns in dieser Beziehung noch keine einzige Holzart genannt worden, die Aussicht haben könnte, unter unsern Standortsverhältnissen günstigeres zu liefern als die einheimischen Arten. 
der Fall, da hat die nachfolgende Bestandespflege eine umfassende, andauernde, dafür aber auch dankbare Aufgabe zu erfüllen. Die Bodenfruchtharkeit ist wirtschaftlich derart auszunützen. dass nicht nur die durch die Höhe der Umtriebszeit bedingte Haupternte, sondern auch die, anlässlich der Bestandespflege sich ergehende Torernte möglichst hohe Werte liefern. Jedes einzelne bei der Bestandesgründung vorhaudene Baumindividuum muss in derjenigen Periode zur Nutzung herangezogen werden, in welcher durch seine Herausnahme dem verbleibenden Bestand die grïsstmögliche Begünstigung seiner Weiterentwicklung gesichert wird. Anderseits muss dieser Zeitpunkt zusammenfallen mit demjenigen, in welchem der Erlös aus dem zur Verwertung gebrachten Material nicht nur die Erntekosten deckt, sondern dieselben möglichst übersteigt.

Die Bestandespflege ist demgemäss ihrer Natur nach ein integrierender Bestandteil der Forsteinrichtungsaufgabe und der durch diese geregelten Holzernte. In ihrer Durchführung ist sie von waldhaulichen Erwägungen hedingt. Diese selbst sind abhängigr von den Standorts- und Bonitätsverhältnissen, von dem Vorhandensein reiner oder gemischter Bestände, von dem Mischungsverhältnis, von dem Ziel der Wirtschaft an und für sich. Alle diese Faktoren drängen deshalb darauf hin, die Aufgabe der Bestandespflege nicht nach einem allgemein geltenden und überall anwendbaren Schibbolethe zu lösen. Es gibt kein solches, es gibt nur Richtlinien, denen die Bestandespflege zu folgen hat, um den Anforderungen einer maximalen Gesamternte, Vorernte und Haupternte zusammengefasst, Genüge leisten zu können. Auch der Grundsatz: früh, schwach und oft, ist nicht ausieichend, den Durchforstungsbetrieb zu regulieren; er setzt eine weitgehende Individualisierung voraus.

Wenn von der Aufgabe der Bestandespflege die der Bestandesgründung unmittelbar nachfolgenden Süuberungen abgelöst werden, so konzentriert sich dieselbe in ihrem nachherigen Verlauf auf die eigentlichen Durchforstungen. Für die Ausführung derselben stehen zwei Wege offen, die zur Frreichung des oben erwähnten Endzieles führen können. Häufige schwache Durchforstungen unter steter Aufrechterhaltung desjenigen Kronenschlusses, der für die Entwicklung der verbleibenden Individuen einerseits. für die ungeschnälerte Erhaltung der Bodenkraft anderseits nötig ist - oder mehr oder minder starke Lockerung des Kronenschlusses. Letztere kann entweder in der Art geschehen, dass die am Kronenschluss nur noch schwach beteiligten Stammklassen des Ifauptbestandes herausgehauen werden. sodass 

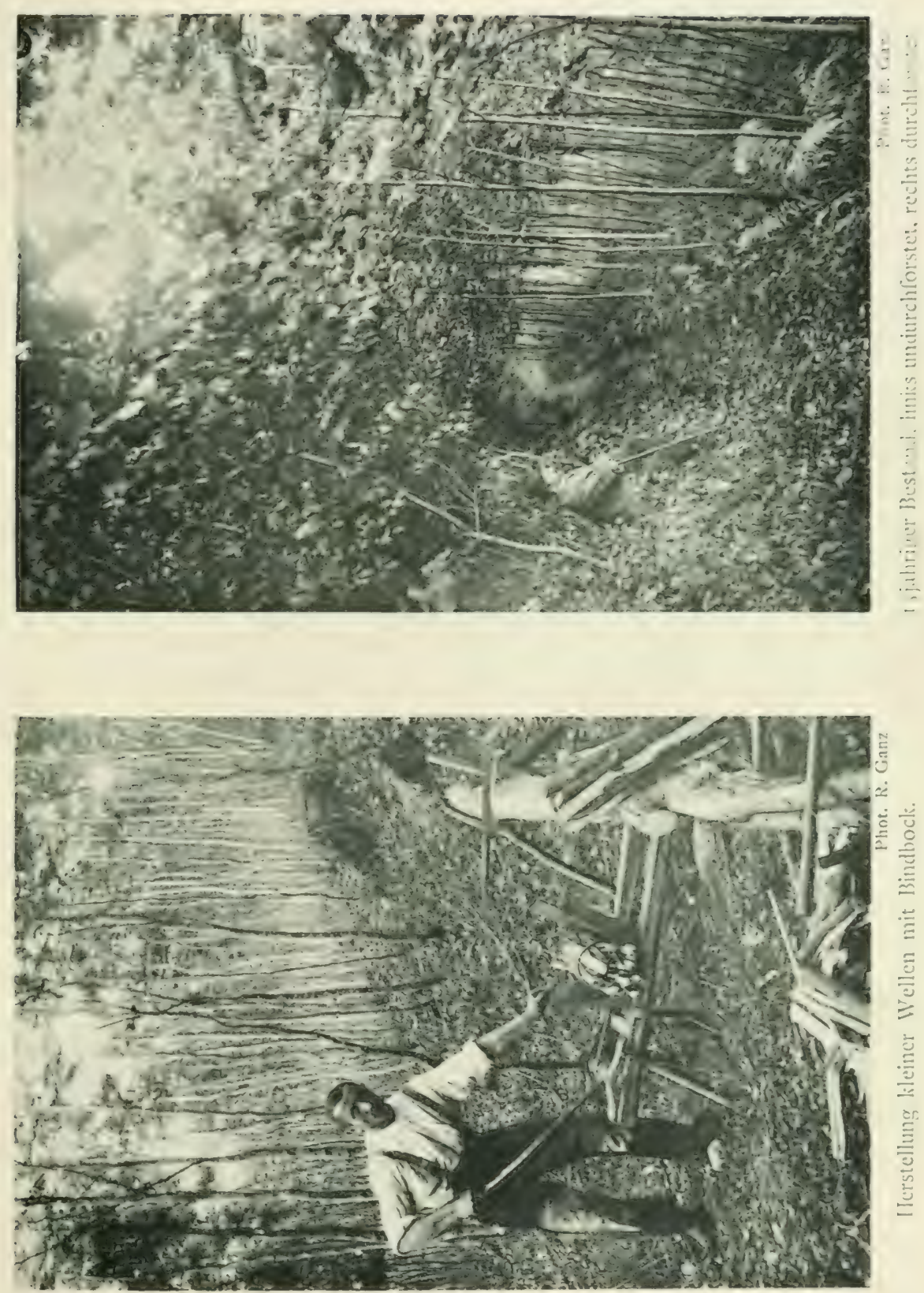

sich der Zuwachs in seiner Hauptmasse auf eine verhältnismässig kleine Zahl von Stämmen des einstigen Schlussbestandes konzentrieren und sich zur Erhaltung der Bodenkraft ein Nebenbestand mitentwickeln kann. Der andere ebenfalls offenstehende und befürwortete Weg ist derjenige weitergehender Kronenlockerung, wozu auch die sogen. Plenterdurchforstung, der Wagenersche Lichtungsbetrieb u. a. m. zu rechnen sind. Hier werden grundsätzlich die mit starken Bestandeskronen versehenen und nicht die schwächsten Individuen herausgenommen; damit soll die Hauptmasse des Zuwachses auf eine grössere Anzahl vorher minder entwickelter Bestandesglieder ausgedehnt werden. Von der einen Seite wird angenommen, dass der Bestand bis zum sechzigsten Altersjahr in gewöhnlicherWeise durchforstet werde und erst von da an im Interesse einer namhaften Steigerung des Waldertrages die Herausnahme solcher Stämme stattfinde, die bei ungünstigen Stammformen die Kronen ihrer Nachbarn eindrängen oder seitwärts drücken; von anderer Seite wird dagegen ein frühzeitiger Eingriff in die stärkste Stammklasse befürwortet. ${ }^{1}$ )

Die Divergenz, welche in diesen von einander sehr abweichenden Anschauungen zutage tritt, ist nicht dazu angetan, der Wirtschaftsführung des Durchforstungsbetriehes eine sichere Grundlage

1) Angesichts der überaus reichen Literatur über den Durchforstungsbetrieb muss davon Ungang genommen werden, auf die einzelnen Werke und ihre Darlegungen einzutreten. Wir verweisen deshalb nur auf nachfolgende, neben den forstlichen Zeitschriften speziell ron uns berücksichtigte Werke:

Dr. Karl Laschke, Geschichtliche Entwicklung des Durchforstungsbetriebes in Wissenschaft und Praxis. Neudamm 1902.

Di. Vinzenz Schiipfer, Die Entwicklung des Durchforstungsbetriebes in 'T'heorie und Praxis seit der zweiten Hälfte des 18. Jahrhunderts. Nünchen 1908. Otto von Benthheim, Reg.- und Forstrat. Anregung zur Fortbildung von Forstwirtschaft und Forstwissenschaft im 20. Jahrhundert. 'T'rier 1901.

B. Borggreve, Oberforstmeister. Die Holzzucht, 2. Auflage. Berlin 1891.

Gustav Wagener, Forstrat. Der Waldbau und seine Fortbildung.

Prof. Dr. Schwappach. Nitteilungen aus dem forstlichen Versuchswesen Preussens. Wachstum und Ertrag normaler Fichtenbestïnde in Preussen. Neudamm 1902.

- Anleitung zu Durchforstungsversuchen angestellt vom Verein deutscher forstlicher Versuchsanstalten 1873.

J. Riniker, Oberförster. Der Zuwachsgang in Fichten- und Buchenbeständen unter dem Einfluss von Lichtungshieben. Daros 1887.

Ph. Fhury, Einfluss verschiedener Durchforstungsgrade auf Zuwichs und Form der Fichte und Buche. Mitteilungen der schweizerischen Zentralanstalt für. das forstliche Versuchswesen. Band VII. 1903. 
zu geben. Auch die von seiten der Versuchsanstalten seit 1873 rorgenommenen Durchforstungsversuche haben noch zu keinem abschliessenden Endergebnis geführt: Durchforstungsertragstafeln liegen weder von den Versuchsanstalten noch von einzelnen Verwaltungen vor. Die bisher vorgenommenen Durchforstungsversuche und die Befürwortung der verschiedenen Methoden und Systeme leiden an dem unbestreitbaren Uebelstande, dass sie einseitig nur die Massenzuwachsverhältnisse und nicht das Produkt aus Masse und jeweiligem Mehrwert im laufenden Zuwachs, also bloss quantitative und nicht auch qualitative Nomente für ihre Argumentation benützen ${ }^{1}$ ) und endlich muss auch als ein sehr wesentlicher Umstand betont werden, dass stets nur die Verhältnisse der reinen Bestände und nicht die für die Forstwirtschaft der Zukunft rorab ins Gewicht fallenden gemischten Bestände als Ausgangspunkt für die aufgestellten Thesen in Betracht fallen.

Der Durchforstungsbetrieb der städtischen Waldungen reicht, wie dies schon früher dargetan wurde ${ }^{2}$ ), auf den Anfang des 17. Jahrhunderts zurück; er hat infolgedessen nicht verfehit, den Bestandesverhältnissen im allgemeinen einen bestimmten normalen Charakter aufzudrücken, wenn er auch in den verschiedenen Zeitläufen verschiedenartig zur Ausführung gelangt sein mochte.

Die Fruchtbarkeit des Bodens, die Standortsverhältnisse überhaupt haben hier von jeher dichten und kräftigen Verjüngungen gerufen. Daher lag es nahe, mit der Bestandespflege frühzeitiger als anderswo zu beginnen. Die sogenannten Reinigungshiebe wurden bis vor zwei Dezennien im 18.-25. Jahre eingelegt, wobei der Aushieb von Weichhölzern und unregelmässigen Vorwüchsen gegen Ueberlassung des Ertrages erfolgte. Es fand sich bald mehr, bald minder eine ausreichende Zahl in der Umgegend sesshafter Landwirte, um die notwendigen Arbeiten zur Winterszeit in der gewünschten Ausdehnung auszuführen. So mangelhaft das System in seiner Ausführung war, so hatte es doch den Vorteil, der Entwicklung der einzelnen Bestandesglieder Vorschub zu leisten und günstigere Bestandescerhältnisse für die spätern Altersstufen herbeizuführen, als dies bei der Unterlassung der frühen Lichtung möglich gewesen wäre. Seit Mitte der siebziger Jahre hat sodann eine grundsätzlichere Auffassung der Aufgabe und der Durchführung des Reini-

1) Prof. Dr. Schwappach in Eberswalde: Wachstum und Ertrag normaler Eichtenbestïnde in Preussen, pag. 106. Die Geldertragstafeln.

2) Siehe pag. 118. 
gungshiebes als erster Durchforstung platzgegrilfen. I)ieselbe erfolgt im 15. - 18. Jahr und wird in Regie durchgeführt. Der Aushieb geschieht im Taglohn durch das ständige Arbeiterpersonal unter strenger Aufsicht und nach Anweisung des Försters. Das Material wird in Form der mit Draht gebundenen «Heizibürdeli» im Akkord aufgearbeitet, sodass auch eine genaue Buchung der sich ergebenden Massen möglich ist. ${ }^{1}$ ) Für die Auswahl der zum Hieb gelangenden Bestandesglieder ist die Begünstigung und Regulierung der Bestanlesnischung einerseits und anderseits die für eine intensive Sortimentswirtschaft schon in dieser Altersperiode notwendige Berücksichtigung der für dieselbe in Betracht fallenden Individuen und Arten massgebend. Missbildungen werden entfernt, dem Licht- und Schattenbedürfnis der einzelnen Holzarten zum Zwecke normaler Entwicklung wird Rechnung getragen; die bei jeder natürlichen Verjüngung vorkommende ungleiche Entwicklungsstufe der einzelnen Bestandesglieder erhält die für die sukzessive Ausgleichung nötige Lichtzuweisung durch die Beseitigung bezw. Aufastung verdämmender Individuen. Das direkte finanzielle Ergebnis dieser durchschnittlich in das 15. Jahr verlegten ersten Durchforstung ist ein solches, dass über die erwachsenden Ausgabeu hinaus noch ein eigentlicher Reinertrag konstatiert werden kann. Die indirekte Förderung der zukünftigen Nutzungen muss, gestützt auf die in bald drei Dezennien gemachten Messungen und Wahrnehmungen, als nicht weniger vorteilhaft bezoichnet werden. Wir verweisen auf die Massenzuwachstabelle, nach welcher der Gesamtbestandeszuwachs vom 15.-25. Jahr von $6,1 \mathrm{~m}^{3}$ auf $7,8 \mathrm{~m}^{3}$ steigt, wobei sich der Nebenbestand mit $1,2 \mathrm{~m}^{3}$ beteiligt. Wenn vielleicht anderwärts unter weniger günstigen Wachstumsverhältnissen durch diesen frühen Eingriff einer gewissen sperrigkeit des Jungwuchses gerufen würde, weil die wünschbare Reinigung noch nicht stattgefunden hat, so tritt dieser Fall bei den Silhltalbeständen nicht ein. In den natürlichen Terjüngungen ist die Bestandesdichtigkeit von vornherein derart. dass die fuir die Nutzholzhestände nütige Glattschäftigkeit schon in dieser Periode gesichert ist, sodass nur für die nötige Kronenentwicklung gesorgt werden muss, um die quantitative wie die qualitative Sortimentsentwicklung zu entsprechender Geltung zu bringen.

Wenn an andern Orten zur Sicherung der Erhaltung der Bodenkraft im weiteren Verlauf des Durchforstungsbetriebes und der an-

1) Vide Tabula XI. 
lässlich desselben sich vollziehenden Kronenlockerung die Heranziehung eines Unterbestandes angestrebt wird, so tritt hier diese Notwendigkeit nicht ein; die rechtzeitige Einlegung der ersten Durchforstung übernimmt diese Rolle. Der Unterbestand wird in einer Zeit berücksichtigt, wo ihm noch die Fähigkeit innewohnt, schon jetzt oder in einer der nächstfolgenden Durchforstungsperioden in den Hauptbestand einzudoublieren. Damit wird aber auch der Gefahr des heutigen Durchforstungsbetriebes: das Torhandensein einer relativ nur geringen Stammzahl im Haubarkeitsalter - vorgebeugt. ${ }^{1}$ )

Dieses Ziel ist aber nur erreichbar, wenn bei der ersten Durchforstung der Aufastung in Sinne einer normalen Kronenentwicklung die nötige Beachtung geschenkt wird. Der gesamte Wachstumsentwicklungsgang des Einzelstammes oder des ganzen Bestandes ist ja in hervorragendem Masse abhängig von der Ausdehnung und dem Zustande der einzelnen Baumkronen. Das Augenmerk der Wirtschaft muss deshalb dahin gerichtet sein. die Kronenentwicklung so zu fördern, dass sie nicht etwa einer blossen Mehrproduktion von Reisholz, sondern einem mehrwertigen Baumschaft ruft. Nach den Ergebnissen der schweizerischen Zentralanstalt für das forstliche Versuchswesen, Band VII pag. 211, nimmt die Kronenlänge dem absoluten und prozentualen Werte nach mit stärker werdendem Durchforstungsgrade sukzessive zu. Wenn deshalb anlässlich der frühzeitigen Bestandeslichtung auch die Kronenregulierung durch eine angemessene Aufastung stattfindet, so beseitigt man umso sicherer die Sperrigkeit und zugleich ist pathologisch eine nachteilige Einwirkung auf die Stammentwicklung ausgeschlossen. Diese bleibt nach Breite und Höhe sowohl im reinen, wie im gemischten Bestand in dem für die angestrebte Entwicklung des Individuums zukömmlichen Verhältnis. $\left.{ }^{2}\right)$

$\left.{ }^{2}\right)$ Dieses Wirtschaftssystem befindet sich in roller Uebereinstimmung mit den Anschauungen ron Bentheimiss (siehe Anregungen zur Fortbildung der Forstwirtschaft, pag. 57), wenn er die Auflockerung des Bestandesschlusses durch Eingriffe in die stärksten Stammklassen nicht in dem späten Alter wie Borggreve befürwortet und in früherer Jugend die Beseitigung der ausgeprägtesten Vor- und Sperrwüchse als unerlässlich erachtet. Dass aber bei diesem System im weitern Verlauf der Bestandeserziehung die Entwicklung und Erhaltung eines Nebenbestandes noch erforderlich sein dürfte, namentlich in gemischten Beständen, dafür liefert die Sihlwaldwirtschaft keine Belege. Unsere erste Durchforstung entspricht deshalb dem D Grad, die späteren dem C Grad.

2). Dr. Karl von Hischbach : "Mit vollem Recht kann der Durchforstungsbetrieb in den 'Zürcher Stadtwaldungen als etwas Musterhaftes bezeichnet wer- 

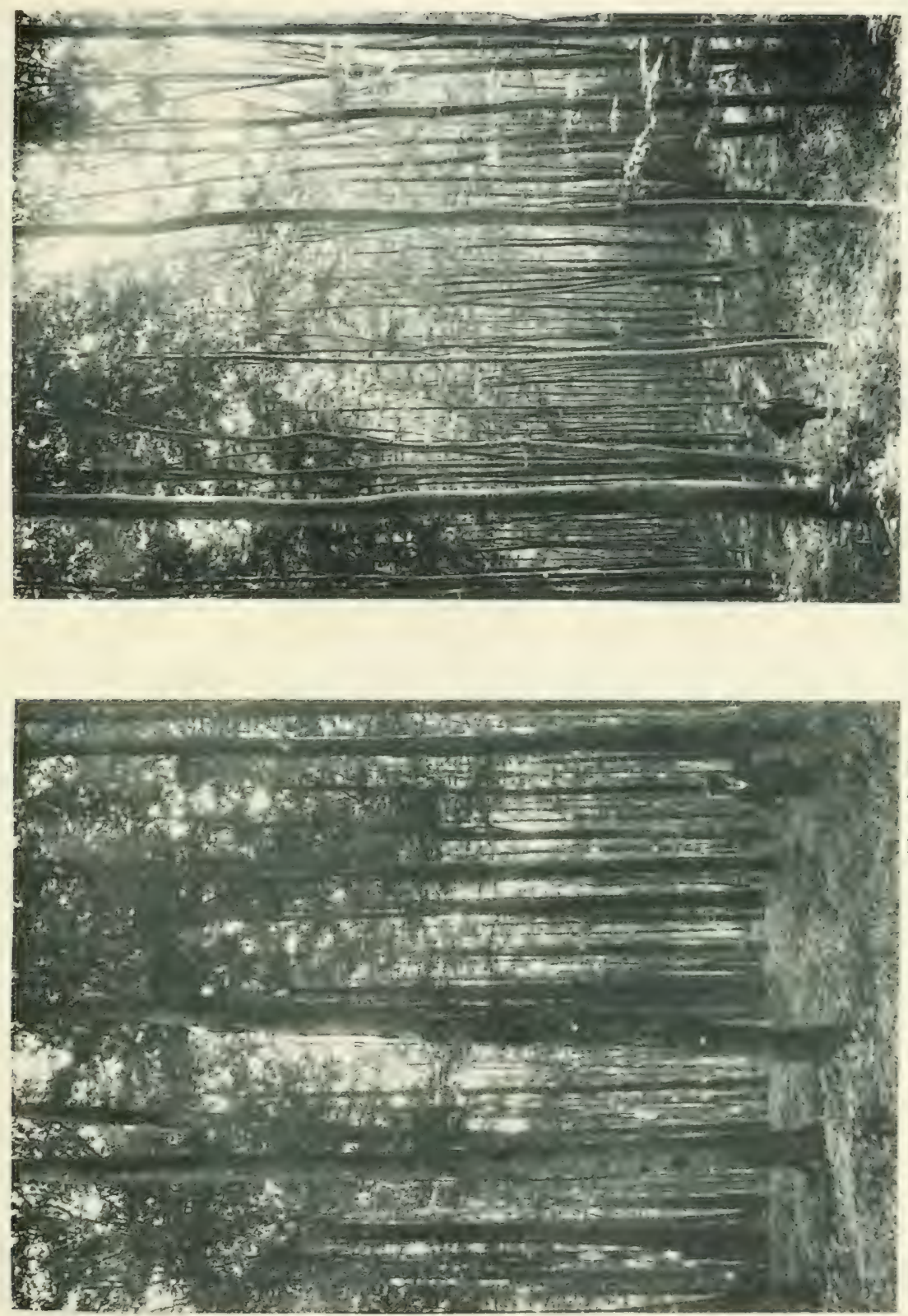

Die Wachstumsverhältnisse der Sihlwaldbestände in Laub- und Nadelholz, seien dieselben rein oder gemischt, rufen sehr bald einer zweiten Durchforstung. Es zeigt sich in den erstmals durchforsteten Beständen ein rasches Nachdrängen des Unterbestandes und eine derart kräftige Entwicklung einzelner Individuen und Arten, dass ein zweiter Aushieb schon nach fünf oder sechs Jahren stattfinden muss, eine Lichtung, die sich den Grundsätzen, welche beim ersten Aushiebe wegleitend waren, anschliesst. Noch mehr als bei der ersten Durchforstung ist es bei den nachfolgenden notwendig, auf die Bestandesmischung korrigierend einzuwirken und dem Lichtbedürfnis einzelner Arten entsprechend Rechnung zu tragen.

Gemäss den gemachten Erfahrungen empfiehlt es sich, hiebei die Kronenlockerung der lichtfordernden Holzarten stetig bis zur Herstellung der vollen Kronenfreiheit auszudehnen. während umgekehrt bei den schattenertragenden Laub- und Nadelhölzern das horstweise Zusammenhalten die Entwicklung einer Art Kollektivkrone begünstigt, die ihrerseits bis zu einem gewissen Grade ebenfalls nur einer Kollektivlockerung, dagegen weniger der Kronenlockerung ihrer einzelnen Teile ruft. Damit wird der wesentliche Vorteil eines dichteren Standes ihrer einzelnen Glieder ermöglicht.

Die Wiederkehr der Durchforstungseinhiebe ist im allgemeinen von den Standortsverhältnissen abhängig. Bis zu dem Zeitpunkt, wo der grösste laufende Höhenzuwachs erreicht ist, im Sihlwald im 30. - 35. Jahr, macht sich dieses Bedürfnis spätestens nach fünf Jahren geltend. Hernach, wenn das Höhenwachstum abnimmt, wird diese Periode auf sieben Jahre ausgedehnt und vom 70. Jahr bis zum Beginn der Abtriebszeit auf zehn Jahre (vide Durchforstungstafel). ${ }^{1}$ )

Die zurzeit befolgte Durchforstungspraxis des Sihlwaldes ist in sukzessiven Uebergängen aus der früheren Art der Durchführung der Durchforstungen $d$. h. der Herausnahme der am Kronenschluss nur schwach beteiligten Stammklassen herausgewachsen. Der Umstaul. dass dieses letztere System in den Beständen von 50 und mehr Jahren die erwartete günstige Einwirkung auf die Bestandesmischung angenscheinlich nicht in dem nötigen Umfange herheizuführen vermochte und vielfach zu einer zu kleinen Zahl von Sortimentsstämmen in

den; ähnliches habe ich, obwohl ich schon viele guten Wirtschaften kennen lernte, noch nirgends getroffen.» Gutachten über den Wirtschaftsplan der Stadtwaldungen von Zürich 1883.

1) Vide Tabula XII. 
den Abtriehsflïchen führte, hat die Teranlassung zum [ebergang der Durchforstungen mit weitergehender hronenlockerung gegeben. Es wird dieses System eine bleibendere Restandesdichtigkeit zur Folge haben. Die hiebei anfallenden Zuwachs- und Massenerträge können in ihrer Totalität in Bezug auf Vorernte und Haupternte erst nach der Durchführung der Bestände durch eine ganze Umtriebszeit in absoluter Weise festgestellt werden. Dafür, dass eine solche stattfinden kann, ist durch die eingeführte Buchung aller und jeder Erträge der einzelnen Abteilungen von den ersten Nutzungen an bis zu Ende derselben Fürsorge getroffen.

\section{Bodensicherung.}

Die im Abschnitt II bei der Darstellung der topographischen und geologischen Gestaltung des Bodens gemachten Ausführungen zeigen, dass die Sicherung des Bodens und die damit in Zusammenhang stehende Produktionskraft desselben vornehmlich nach zwei Richtungen hin wirtschaftlicher Eingriffe bedarf. Einmal mit Bezug auf die Beseitigung der durch die Molasseformation begünstigten Bodenvernässungen und sodann in der Verminderung der durch die starken Niederschläge und die vielen vorhandenen Bachläufe hervorgerufenen Erosionen und Abrutschungen. Nach beiden Richtungen hin ist der Wirtschaftsführung eine keineswegs leichte und eine nicht innerhalb kurzer Perioden zu bewältigende Aufgabe gestellt.

An und für sich sollte die sorgfältige Durchführung der natürlichen Verjüngung. die Vermeidung grosser Kahlschläge ohne vorhandenen starken Aufschiag das nächstliegende Mittel sein, um sowohl schädlichen Vernässungen, als Abrutschungen und weitergehenden Erosionen rorzuheugen. Allein anch bei der vorsichtigsten Wirtschaft ist das Eintreffen derselben angesichts des Charakters der Molasseformation ohne schützende Massnahmen nicht ausgeschlossen. Der undurchlassende Untergrumd. der speziell in den Mulden der einzelnen Plateaus zu Vernässungen Veranlassung gibt, crleichtert allerdings die Anlage von Entwässerungsgräben, dagegen hat die Schatiung derartiger Lntwïsserungsnetze wiederholt den L'ehelstand ergehen. dass die Fortleitung der auf diese Art gesammelten Wasser talwärts rasch zu starken Vertiefungen der Ableitungskanäle und damit im $\mathrm{Zu}-$ sammenhang stehenden Rutschungen geführt hat. Versuche, die in früheren Dezennien mit der Drainage gemacht wurden, haben sich nicht bloss als zu kostspielig, sondern auch als zu wenig wirksam, 

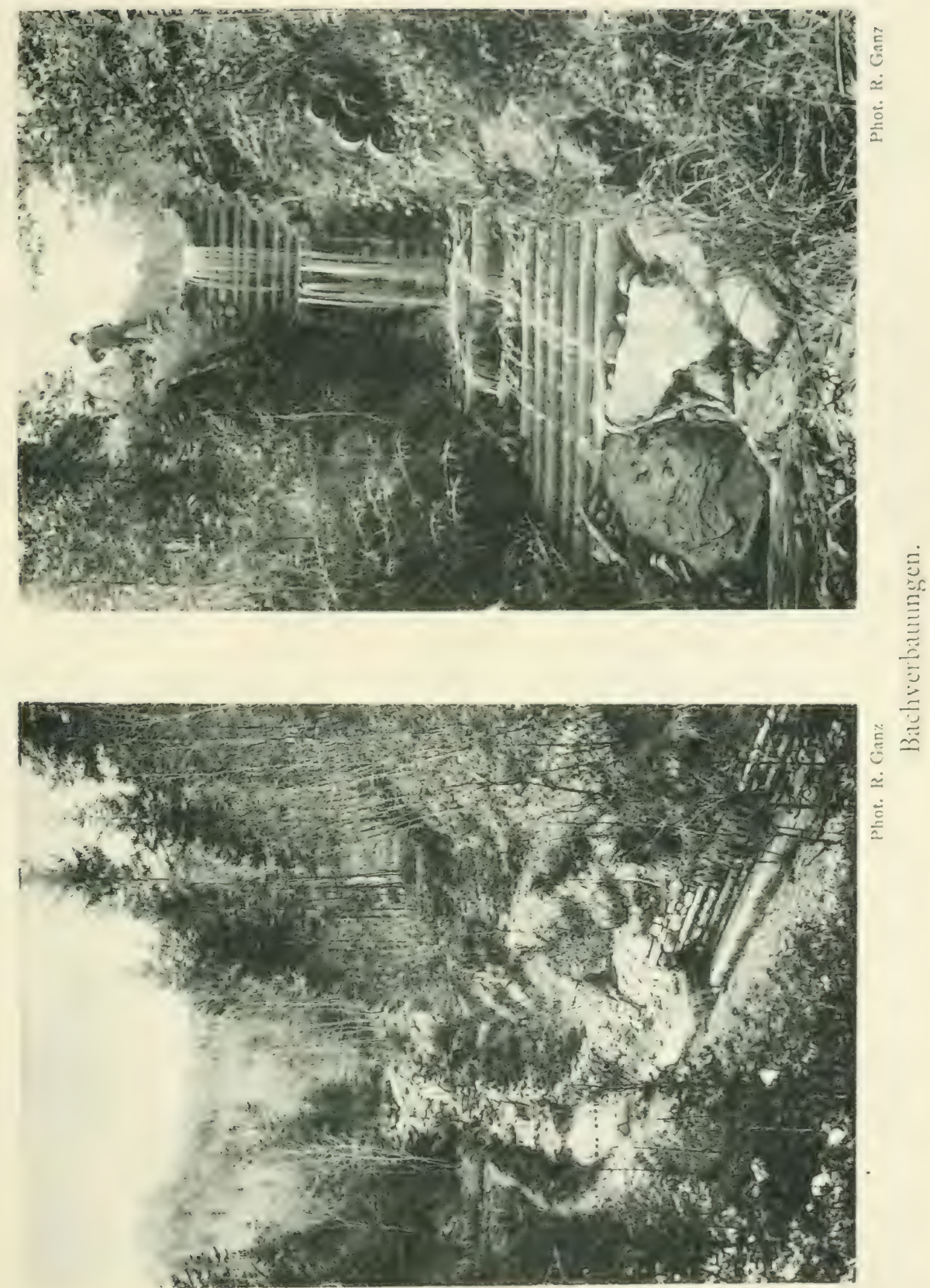


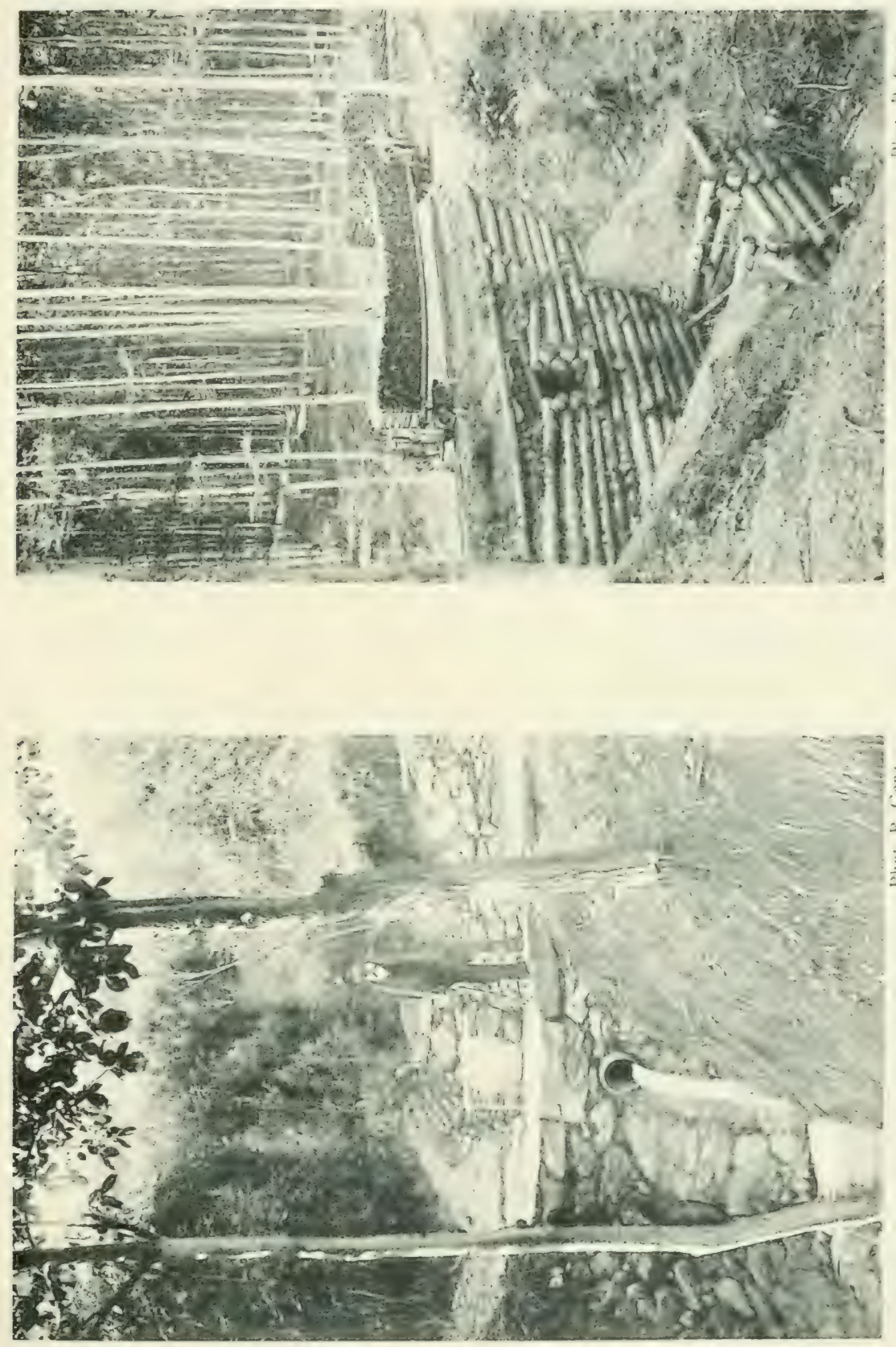

erwiesen, namentlich mit Bezug auf die Dauer. Gestützt auf diese Erfahrungen wird daher tunlichst die seitliche Ablenkung in die vorhandenen Bachläufe angestrebt und daneben die Entwässerung vorhandener Blössen, die ihren Ursprung in Vernässung haben, durch Aufforstung mit geeigneten Holzarten hestmïglichst lewerkstelligt.

Die zahlreichen Wasserläufe der Sihltalwaldungen bieten den Bachverbaunngen ${ }^{1}$ ) ein dankbares Feld, wie man es anderswo selten findet. Aus diesem Grunde ist denselben in den letzten Dezennien besondere Aufmerksamkeit zugewendet worden und die infolgedessen gemachten Erfahrungen weisen darauf hin. dass die weitergehende Pflege dieses Gebietes im höchsten Interesse der Bodensicherung. wie der Erhaltung der Produktionskraft desselben liegt. Wo sich nicht in den einzelnen Bachbetten oder in anliegenden Moränen Trümmergesteine rorfinden, ist die Erstellung der Bachverbaumgen aus Steinmaterial ausgeschlossen. Die ab und zu zutage tretenden Molassefelsen sind, weil zu weich und auf die Dauer zerbröckelnd, für Bauten nicht verwendbar. Infolge dieser Verhältnisse gelangt bei den Sihlwaldbachverbaungen ror wiegend das System von Rundholztal-perren zur Anwendung und nur da, wo Steine aus nächster Nähe zugeführt werden können, wird Trockenmauerwerk in Verbindung mit hölzernem Leitwerk zur Ausführung der Verbauung benützt. Vermöge des hohen Kalkgehaltes des Molassewasser's erfolgt eine natürliche Imprägnierung der verwendeten Hölzer, sodass die hölzernen Talsperren, gegen alles Erwarten, eine grosse Dauer zeigen. Noch erfreulicher ist aber der günstige Einfluss derselben auf die Bodensicherung, sodass bei weiterer Einschaltung von Sperren in die einzelnen Bachläufe in absehbarer Zeit ebensowohl den Bachvertiefungen, als den damit in Zusammenhang stehenden Abrutschungen Einhalt geboten werden kann. Die Ausführung der Verbauungen erfolgt durch das ständige Waldarbeiterpersonal. Einheitliche Ansätze über die damit verbundenen Kosten aufzustelien, ist angesichts der Verschiedenartigkeit der Verhältnisse nicht leicht möglich.

1) Vide Tabula XIII und XIV. 


\section{Die Zuwachsverhältnisse.}

\section{Allgemeines.}

Die heutzutage an die Ertragsregulierung eines intensiv bewirtschafteten Waldes zu stellenden Anforderungen schliessen von vornherein die bloss okulare Einschätzung des Zuwachses und der daraus resultierenden Massen aus. Auch die Inanspruchnahme allgemeiner, auf gro̊ssere Gebiete oder ganze Länder basierter Zuwachsund Massentafeln schützt nicht vor unrichtiger Ansetzung dieser grundlegenden Faktoren. Dieser Anschauung schenkte schon der im Jahre 1880 aufgestellte Wririschaftsplan weitgehende Beachtung. Dazumal wurden zum Zwecke einer genauen Feststellung der $\mathrm{Zu}$ wachs- und Massenverhältnisse der in Betracht fallenden Wirtschaftseinheit lokale Ertragstafeln anfgestellt. die sich auf die Erhebungen von 67 Probeflächen stützten. Die ausgewählten Probeflächen, so normal ihr Charakter war, befanden sich aber damals, wie die Gesamtwaldung überhaupt, noch nicht in einem Zustand, der einer rationellen Durchforstung folgt; sie waren entweder gar nicht durchforstet oder erst unmittelbar vor deren Aufnahme, sodass sich der Einfluss der Durchforstung als solcher noch nicht geltend machen konnte. Infolgedessen mussten die betreffenden Aufnahmen, wie ihre Verwertung zur Aufstellung der Zuwachs- und Massentafeln andere und zwar teilwoise grössere Resultate liefern, als diejenigen, die bei der Aufstellung von Ertragstafeln in regelrecht und seit einer längern Reihe von Jahren durchforsteten Beständen hervorgehen. Es stimmt diese Erscheinung vollständig mit derjenigen überein, die anderwärts bei Aufstellung allgemeiner Ertragstafeh auf Grund einmaliger Aufnahmen gemacht worden sind. ${ }^{1}$ )

Die zwischen den Massentafeln von ehemals und heute sich ergebenden Differenzen in den Hauptbestandesmassen finden ihre Kompensation in den nunmehr für den Haupt- und den Nebenbestand gesondert ausgeschiedenen Zuwachsbeträ̈gen. lnfolge des seit dem Jahre 1875 eingeführten Durchforstungssystemes haben sich nun die Verhältni-se der sihltalwaldungen wesentlich geändert. Eimmal hat seit dieser Zeit ein ununterbrochener intensiver Durchforstungsbetrieb

1) Vergleiche Baur und Lorey. 
stattgefunden, wodurch dis Ermittlung sicherer Inhaltspunkte für die Bemessung der Zuwach-Massenbeträge möglich wurle ; sodann hat die eidgenössische Zentralanstalt für das forstliche Versuchswesen in Zïrich seit dem Jahre 1889 ihre Untersuchung('n wesentlich auch auf die Konstatierung der Massen- und Zuwachsverhåltnisse der städtischen Waldungen ausgedehnt und Erhebungen nach dem Arbeitsplan des internationalen Verbandes der forstlichen Versuchsanstalten durchgeführt. Endlich liefert die von der städtischen Forstverwaltung seit dem Jahre 1880 aufs genaueste fortgeführte Statistik der Wirtschaftsergebnisse Anhaltspunkte für eine zuverlässigere Konstruktion der Ertragstafeln, als sie früher möglich war. Aus allen diesen Gründen wurde für die gegenwårtige Ertragsreguliering zur Aufstellung neuer Ertragstafeln geschritten.

$\mathrm{Zu}$ diesem Zwecke erfolgte einerseits die genaue Vorratsermittlung aller mehr als siebzigjühigen Bestände. anderseits wurden die von der forstlichen Zentralanstalt seit 1889 gewonnenru ligebnisse über den Zuwachsgang benutzt. Der Abtrieb und die Aufarbeitung zweier von letzterer seit 1891 auf die Zuwachs- und Massenverhältnisse untersuchter Probeflächen von 1 ha und 0,5 ha boten weitere feste Anhaltspunkte für die Gewinnung sicherer Resultate. Leider hat der am 28. September 1885 erfolgte Schneebruch die sonst so nahe liegende Benützung der früher angelegten Probeflächen rerummöglicht.

Bei der Aufstellung neuer Ertragstafeln musste von vornherein in Frage kommen, ob wiederum, wie früher, eine Ausscheidungvon Bonitäten, und wenn ja, in welcher Anzahl eine solche erfolgen solle. Die Ertragstafel vom Jahre 1880 hatte vier Bonitäten ausgeschieden. Bei der Beantwortung der gestellten Frage ist offenbar zu berïcksichtigen, dass die bei allgemeinen Ertragstafeln sich geltend machende Verschiedenartigkeit der Standortsverhältnisse und der Wuchsgebiete notwendigerweise zur Ausscheidung von Bonitäten führen muss. In dem Faktor Standort spielen von vornherein Boden und Klima eine hervorragende Rolle, und diese sind nun in einem grössern Ländergebiet naturgemäss vielgestalteter Art. Anders liegen die Verhältnisse, wo es sich, wie hier, nur um die Aufstellung lokalev Ertragstafeln in einem eng begrenzten Wirtschaftsgebiet handelt. In einem solchen werden auch bei aller Verschiedenheit der örtlichen topographischen Gestaltung die klimatischen, wie die Bodenverhältnisse kaum zu wesentlichen Differenzen im Wachstumsgang der einzelnen Holzarten Veranlassung geben. namentlich dann nicht, wenn, wie es hier der Fall ist, die Höhenunter- 
schiede sich nur zwischen $450 \mathrm{~m}$ und $915 \mathrm{~m}$ über Meer bewegen. Das zur Verfügung stehende Untersuchungsmaterial dokumentiert tatsächlich das Zutreffen dieser Voraussetzungen für die neuen Ertragstafeln, sodass in Abweichung von dem frühern Vorgehen füglich von einer Ausscheidung von Bonitäten Umgang genommen werden kann. Damit war selbstverständlich nicht ausgeschlossen, dass wechselnde Bestandesverhältnisse im einzelnen stets zu entsprechender Würdigung gelangten.

Die der neuen Ertragstafel zugrunde liegende cine Standortsklasse zeigt eine auffallende Uebereinstimmung mit der frühern zweiten Bonität, welche als die eritschieden vorwiegende bezeichnet werden muss. Dies geht auch aus der 'Tatsache hervor, dass für die Ertragstafel vom Jahr 1880 neben zwanzig. Probeflächen der ersten Bonität, einunddreissig der zweiten, zwölf der dritten, bloss vier der vierten ausgewählt werden konnten. Die auf dieser Grundlage neu erstellte Lokal-Ertragstafel ist im Anhang enthalten.

\section{Der laufende Zuwachs.}

Die richtige Beurteilung des Entwicklungsganges eines Waldes setzt vor allem aus die Kenntnis des wirklich erfolgenden jährlichen Zuwachses voraus, betreffe er nun den Stärken-, Höhen- oder Massenzuwachs. Die Art, wie sich derselbe gestaltet, ist bestimmend für die Wirtschaftsführung, sowohl mit Bezug auf die Bestandespflege, als auf die Bestandesernte. Wenn bis heute im allgemeinen lediglich der Haubarkeits-Durchschnittszuwachs als Ausgangspunkt für die Ertragsregelung angenommen wurde, so ist dies wohl mehr der mangelnden Kenntnis von der Gestaltung des laufenden Zuwachses, als einer wissenschaftlichen Begründung der hisherigen Methode zuzuschreiben. Mit dem Momente, wo der laufende Zuwachs genau konstatiert wérden kann, muss dieser und nicht der HaubarkeitsJ)urchschnittszuwachs, der Ertraysregulierung als Basin dienen, denn er allein ist der getreue Ausdruck der Bestandesentwicklung.

Die für das Massenwachstum der Bestände in Betracht fallenden Faktoren sind die Stammzahl und der Höhen- und Stärkenzuwachs; es hat daher in erster Linie die Feststellung dieser grundlegenden Elemente zu erfolgen. Die aus diesen Untersuchungen hervorgegangenen Daten geben auf der einen Seite genaue Anhaltspunkte für den Gang des Zuwachsverlaufes im Sihlwald und ander- 
.nil 


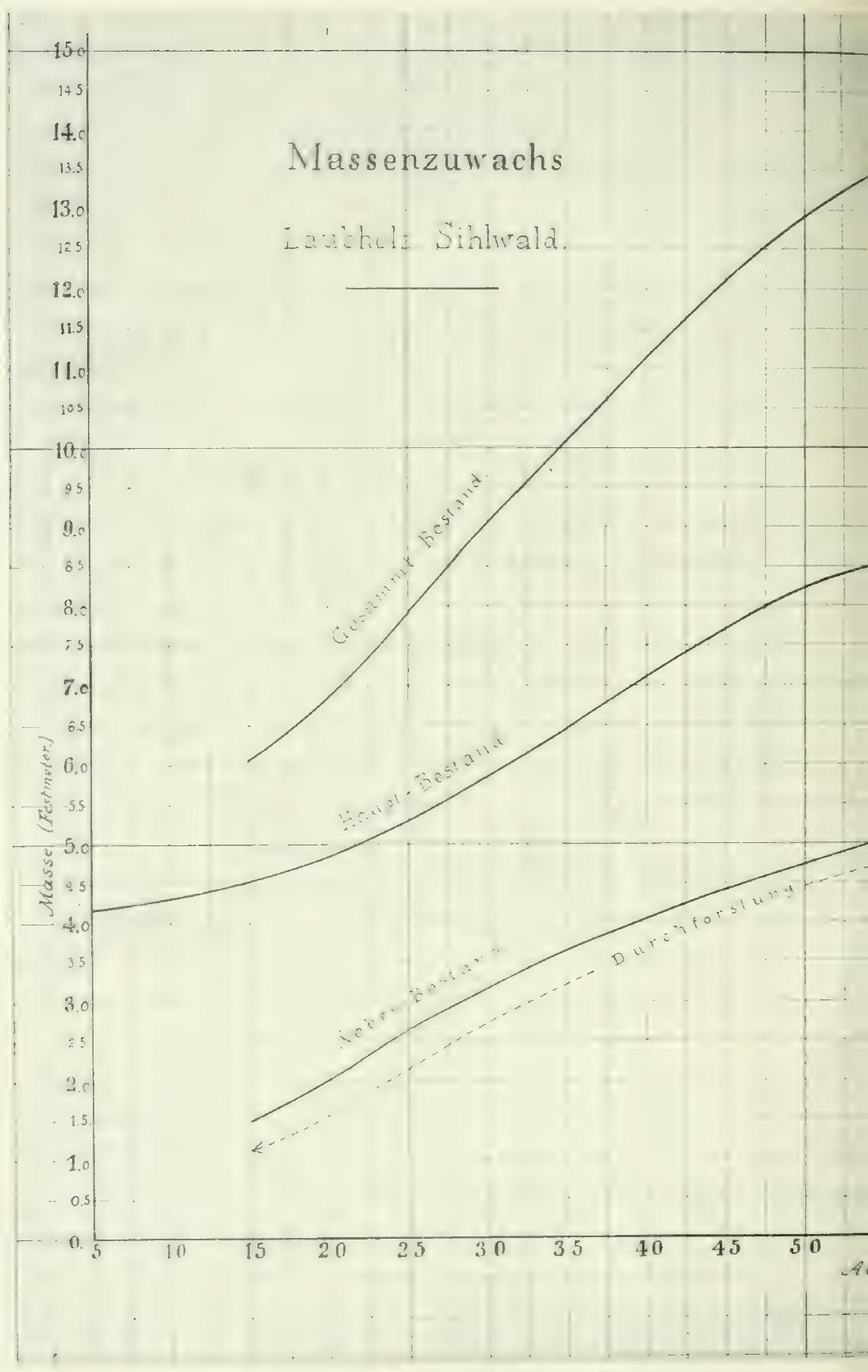




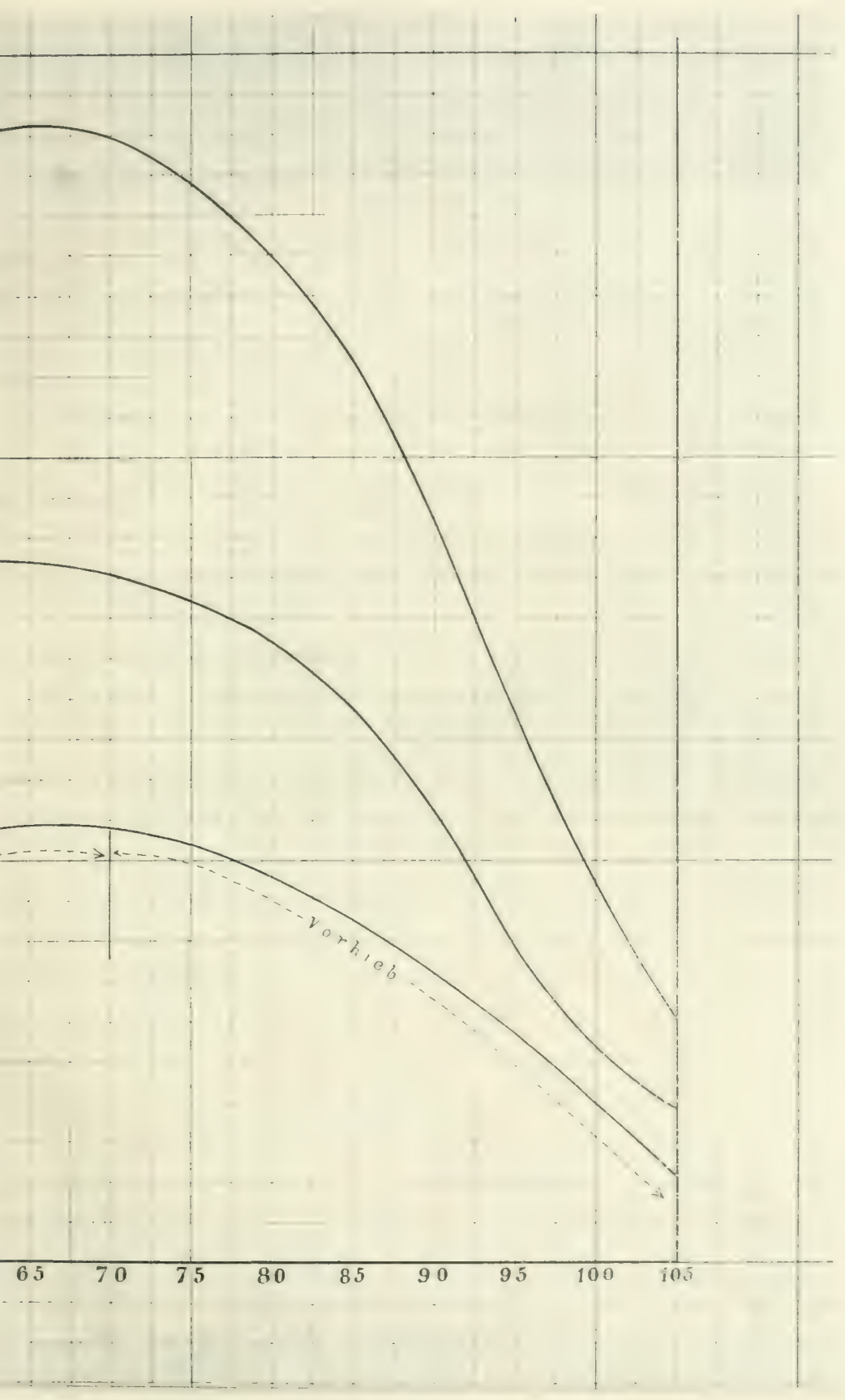



seits gestatten sie Vergleiche mit analogen Erhebungen, sodass damit Stützpunkte für die Verwendlarkeit der gemachten Lirmittlungen gewonnen werden. Abgesehen davon, erhält auch die wissenschaftliche Erkenntnis dadurch neue wünschbare Beiträge.

Die Stammzahl ist in den Sihlwaldbeständen im allgemeinen eine relativ niedrige, trotz der Ueppigkeit, die bei den Bestandesverjüngungen der natürliche Aufschlag aufzuweisen im Falle ist. Sie ist in allen Altersklassen kleiner als diejenige, welche die Buchen-Ertragstafeln von Baden ${ }^{1}$ ), Württemberg ${ }^{2}$ ) und Preussen ${ }^{3}$ ) aufweisen.

$\begin{array}{rcccc}\text { Alter } & \text { Im Sihlwald } & \text { In Baden } & \text { In Württemberg } & \text { In Preussen } \\ 30 & 4100 & 5625 & 7000 & 4420 \\ 50 & 1310 & 1968 & 2000 & 1920 \\ 70 & 195 & 1166 & 1030 & 1085 \\ 100 & 455 & 724 & 610 & 617\end{array}$

In diesen Zahlen, die ihre Bedeutung erst in den Darlegungen über die Stärken- und Massenverhältnisse finden, gelangt in prägnanter Weise der frühzeitig begonnene und andauernd fortgesetzte intensive Durchforstungsbetrieb des Sihlwaldes zum Ausdruck. Die niedrige Stammzahl der jüngern und mittelalten Bestände resultiert aus den bereits mit dem 15. Jahre eingelegten und in Zwischenräumen von 5, 7 und 10 Jahren regelmässig wiederkehrenden Durchforstungen.

Im Interesse einer günstigeren Sortimentserziehung dürfte es liegen, eine noch grössere Reduktion der Stammzahl im Haubarkeitsalter anzustreben. Einen Beleg hiefür bieten die in ähnlichem Wuchsgebiete liegenden Buchenbestände der Forstverwaltung von Murten (Kt. Freiburg). Eine dort von der forstlichen Versuchsanstalt im Jahre 1889 angelegte und im Jahre 1900 abermals durchforstete Versuchsfläche erzeigt beim Vorhandensein eines normalen Bestandesschlusses im Alter von

107 Jahren 372 Stämme per ha mit $652 \mathrm{~m}^{3}$ Gesamtmasse.

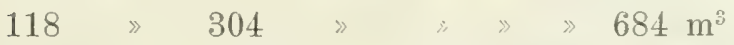

Dabei ist zu bemerken, dass die betreffenden Waldpartien seit 1870 einem geregelten Durchforstungsbetrieb unterstellt sind.

1) Baden, Schuberg Oberforstrat: Aus deutschen Forsten. 1894.

2) Württemberg, Baur.

Eberhard Dr.: Ertragsuntersuchungen in Buchenbestä»den, Allg. Forst- u. Jagdztg. 1899, S. 160.

i) Preussen, Schwappach Prof. Dr. 
Das Stammgrundflächenverhältnis eines Waldes kann erst dann zum richtigen Ausdruck gelangen, wenn alle Bestände während eines längeren Zeitraumes gemäss dem von der Wirtschaftsfïhrung befolgten Betriebssystem behandelt wurden. sodass sich dadurch die von dem Durchforstungsbetrieb erwartete Einwirkung auf die einzelnen Individuen, wie auf den gesamten Bestand herausgestalten kann. Zu spät durchforstete Bestände beanspruchen eine längere Zeit, um von dem ihnen zugewiesenen grösseren Wachsraum Gebrauch zu machen, als solche, denen von Jugend an eine krïftige Kronenentwicklung ermöglicht wurde. Im Sihlwald tritt diese Erscheinung nach beiden Pichtungen hin zutage. Er enthält einerseits grössere Bestandespartien, die vom 15.-20. Altersjahr an regelmässig durchforstet wurden, anderseits nicht minder ausgedehnte Bestände, bei welchen die Lichtung erst im mittleren und angehend haubaren Alter begonnen wurde. Trotzdem macht sich die Einwirkung der Erweiterung des Wachsraumes auch in diesen in unverkennbarer Weise durch ihre Kreisflächenzunahme geltend.

Bemerkenswert hiebei ist nun, dass der in jüngeren Altersklassen vorhandene Fehlbetrag des Sihlwaldes an Stammgrundfläche gegen das höhere Alter hin sukzessive abnimmt, verschwindet oder sich sogar zugunsten des Sihlwaldes umkehrt. Es ergibt sich dies am anschaulichsten aus nachfolgender Zusammenstellung:

\begin{tabular}{|c|c|c|c|c|c|c|c|}
\hline \multirow[b]{2}{*}{ Alter } & \multicolumn{4}{|c|}{ Stammgrundtläche per ha } & \multicolumn{3}{|c|}{ Differenzen $z$ wischen Sinlwald } \\
\hline & Sihlwald & Baden & Württemb. & Preussen & 11. Baden & W'iirttemb. & Preussen \\
\hline 30 & 15,3 & 20,3 & 20,0 & 14,9 & $+5,0$ & $+4, i$ & $-0,4$ \\
\hline 50 & 23,2 & $\underline{27,8}$ & 26,0 & 27.1 & +4.6 & $+2,8$ & $+3,0$ \\
\hline 70 & $29, \mathrm{~s}$ & $3: i, 3$ & $31,:$ & 38,1 & $+3,7$ & $+1, \pi$ & $+3,3$ \\
\hline 100 & 37,6 & 40,0 & 37,0 & 37,5 & $+2,4$ & $-0,6$ & $-0,1$ \\
\hline
\end{tabular}

Besonders typisch ist das sukzessive Einholen und schliessliche Teberwiegen der Sihlwall-itammgrundfläche gegenüber derjenigen von Württemberg, zumal im hundertsten Jahr die Stammzahl von t5. im Sihlwald derjenigen von 610 in II ürttemberg gegenübersteht. Auch gëgenüber den zum Vergleiche herangezogenen Ertragstafeln von Baden und Preussen tritt beim Sihlwald im jüngern Alter ein Fehlbetrag an Stammgrundfläche zutage. Allerdings erscheint bei Preussen im dreissigsten Jahre eine aufallend niedrigere Stammgrundfläche.

Die mittlere Bestandeslı̈he der Sihlwaldbestände ist, wie bereits weiter oben erwähnt wurde, auffallend verschieden von derjenigen der übrigen Wuchsgebiete und zwar im Sinne eines 
entschiedenen Vorsprunges in allen Altersklassen. Dabei ist zu bemerken, dass diese Erscheinung auch für die der Buche beigemischten Nadel- und Lauhholzarten mit Ausnahme ner Eiche zu konstatieren ist. Durchweg ist der astreine Schaft länger. während die Kronenlänge keine aussergewöhnlichen Terhältnisse aufweist. Die nachfolgende tabellarische Zusammenstellung illustriert in deutlichster Weise das ungewöhnliche Höhenwachstum der Sihlwaldbestänle:

\begin{tabular}{rrrrrrrr} 
& \multicolumn{3}{c}{ Absolute Höhe in Metern } & \multicolumn{2}{c}{ Differenzen zwischen Sihlwald } \\
Alter & Sihlwald & Baden & Württemb. Preussen & u. Baden & Württemb. I'reusser \\
30 & 11,1 & 9,9 & 9,1 & 8,2 & $-1,2$ & $-2,0$ & $-2,9$ \\
50 & 18,7 & 16,5 & 16,1 & 15,2 & $-2,2$ & $-2,0$ & $-3,5$ \\
70 & 25,0 & 21,2 & 21,7 & 20,8 & $-3,8$ & $-3,3$ & $-4,2$ \\
100 & 31,7 & 26,2 & 26,8 & 27,0 & $-5,5$ & $-4,9$ & $-4,7$
\end{tabular}

Stellt man den jetzigen Sihlwald-Höhenzahlen, welche der früheren zweiten Bonität entsprechen. diejenigen erster Bonität der genamnten Staaten gegenüher, so ergibt sich eine ziemliche Uebereinstimmung. Die Bestandeshöhen der. württemberwischenn Buche (1899) erster Bonität sind sogar bis zum 70. Jahr mit der zweiten Sihlwaldbonität nahezu identisch: 11,2 18,9 25,0; dagegen bleiben sie vom 75. Jahr an hinter derjenigen des Sihlwaldes zurück. Die Erklärung dieses charakteristischen Verhaltens der Sihlwaldbuche ist in dem auch noch im höhern Alter andauernden starken laufenden Höhenwachstum zu suchen. Der laufende jührliche Höhnnzuwachs innerhalb fünfjähriger Perioden in Millimetern ausgedrückt, beträgt:

$\begin{array}{ccccc}\text { Alter } & \text { Sihlwald } & \text { Baden } & \text { Württemberg } & \text { P'reussen } \\ 25-30 & 460 & 400 & - & 400 \\ 30-35 & 401 & 380 & 380 & 380 \\ 35-40 & 400 & 340 & 360 & 360 \\ 45-50 & 360 & 280 & 340 & 320 \\ 65-70 & 300 & 200 & 240 & 260 \\ 95-100 & 180 & 140 & 140 & 160\end{array}$

Gemäss diesen Zahlenreihen macht sich bei der Sihlwaldbuche im spätern Alter eine geringere Abnahme des Höhenwachstums geltend, wodurch dann der Unterschied in den Bestandeshöhen gegenüber den genannten ein mit steigendem Alter zunehmender wird. Leider gestattet der Mangel höherer als 105jähriger Altersstufen keine weiteren Vergleichungen.

Die Bestandesmasse ist das Endprodukt des Zusammenwirkens der Verhältnisse, die in vorstehendem mit Bezug auf Stammzahl, Stammgrundfläche und Bestandeshöhe dargelegt wurden. 
Es geht daraus in unzweidentiger Weise hervor, dass die Baumform der Sihlwaldbuche eine von den Baumformen der in Betracht gezogenen Waldgebieten abweichende ist. Neben einer ungewöhnlichen Schaftlänge findet sich eine nur geringe seitliche Kronenentwicklung. Diese beiden in der Massenbildung entgegengesetzt wirkenden Faktoren sichern gleichwohl den Sihlwaldbeständen auch hei kleinerer Stammzahl und stammgrundfäche einen höhern Massengehalt als der anderweitig zur Vergleichung herbeigezogener Bestände. Mit zunehmendem Alter wird der Vorsprung der Sihlwaldbuche umso wahrnehmbarer; dies ergibt sich deutlich aus den nachstehenden Zahlenreihen.

\begin{tabular}{rccccccc} 
& \multicolumn{3}{c}{ Gesamtmasse per ha $\mathrm{m}^{3}$} & \multicolumn{3}{c}{ Differenzen zwischen Sihlwald } \\
Alter & Sihlwald & Baden & Wiirttemb. Preussen & Baden & Württemb. Preussen \\
30 & 136 & 145 & 114 & 86 & +9 & -22 & -50 \\
50 & 278 & 283 & 264 & 252 & +5 & -14 & -26 \\
70 & 450 & 414 & 416 & 403 & -36 & -34 & -47 \\
100 & 640 & 588 & 603 & 580 & -52 & -37 & -60
\end{tabular}

Der la ufende Massenzuwachs als Funktion von Stammzahl, Stammgrundfläche und Höhe ergibt sich aus der jeder Altersstufe entsprechenden Holzmasse. Bisher wurde allgemein nur der Zuwachs am Hauptbestand der Ertragsregelung zugrunde gelegt; es mangelten sichere Anhaltspunkte für die Berechnung der Gesamtzuwachsleistung des Bestandes. Diese gesamte Wachstumsleistung komponiert sich einmal aus der beim Abtrieb vorhandenen Holzmasse und sodann ans der Summe derjenigen Ertrüge, welche in Form von periodischen Vormutzungen bis zum Beginne der Verjüngung dem Bestande entnommen werden. Von diesem Gesichtspunkt ausgehend, ist der gesamte laufende Massenzuwachs zu bemessen.

Die vorliegende Arbeit stellt sich im Gegensatz zu dem bisher üblichen Vorgehen auf diesen Standpunkt, indem sie, wie bereits früher ausgeführt wurde, an Stelle des Durchichnittszuwachses den lanfenden jährlichen Zuwachs als Grundlage setzt; hiebei unterscheidet sie:

1. den laufenden Zuwachs am Hauptbestand,

2. den laufenden Kuwachs am Nebenbestand,

3. die Summe beider, als laufenden gesamten Zuwachs.

Der laufende Massenzuwachs des Hauptbestandes ist abzuleiten aus den Massendifferenzen der einzeln aufeinander folgenden Jahre. Er erreicht mit 8,7 $\mathrm{m}^{3}$ sein Maximum im 62. Jahr. Alsdann zeigt sich ein verhältnismässig rasches Sinken, wobei im 100. Jahr per ha noch $2,70 \mathrm{~m}^{3}$ nachweisbar sind. 
Der Ermittlung des laufenden Massenzuwachses des Nebenbestandes musste die Konstruktion der Kurve vorangehen, welche die in den verschiedenen Alterstufen anfallenden Vornutzungen repräsentiert. Es handelte sich nun darum, die nötige Zahl der Glieder zu finden, die erforderlich ist, um ein getreues Bild des Fntwicklungswinges des sich ausscheidenden Nebenbestandes zu liefern. In dieser Beziehung boten einerseits die Probeflächen der forstlichen Versuchsanstalt Material, anderseits aber namentlich die genau gebuchten zwanzigjährigen Ergebnisse des Durchforstungabetriches des rihlwaldes.

Die in der Ertragstafel angegebenen Zahlenwerte sind der auf dieser Grundlage konstruierten Zuwachskurve entnommen. Sie zeigen uns bei Beginn der Durchforstung im 15. Jahr einen ausscheidbaren Nebenbestand, welcher für dieses Alter einen laufenrlen Zuwachs von 1,50 $\mathrm{m}^{3}$ aufweist. Mit fortschreitender Bestandesentwicklung steigt derselbe und erreicht im 67. Jahr sein Maximum mit $5,45 \mathrm{~m}^{3}$, in der gleichen Periode, in welcher der Hauptbestand den grössten laufenden Massenzuwachs zeigt. Von diesem Zeitraum $a b$, der auf das 65. Jahr angesetzt werden kann, findet ein weniger rasches Ausscheiden statt. Dis durch die vorangegangenen Durchforstungen begünstigte Erweiterung des Wachsraumes des Hauptbestandes bringt es mit sich, dass der Nebenbestand sich zunächst infolge der besseren Entwicklung langsamer ausscheidet. sodass sein laufender Zuwachs relativ weniger rasch sinkt. In diesem Stadium setzt sich der Nebenbestand aus zwei Teilen zusammen; der eine, geringere Teil besteht aus den durch den natürlichen Ausscheidungsprozess zurückgedrängten Individuen, der andere Teil wird aus denjenigen Bestandesgliedern gebildet, welche an und für sich noch lebensfähig sind, dagegen der durch den Wirtschaftszweck verlangten Entwicklung des Hauptbestandes mit Bezug auf die Erziehung quantitativ und qualitativ wertvollster Sortimente hindernd im Wege stehen. Der Aushieb des Nebenbestandes in dieser Periode trägt also mehr den Charakter des $\mathrm{Vor}^{-}$ hiebes als den der Durchforstung. Er ist schon ein Teil der Holzernte, wie dies z. B. bei Borgreves Plenterdurchforstung, bei Wageners Lichtungsbetrieb und ebenfalls bei den Vorhieben des Sihlwaldes zutrifft. An letzterem Orte wurde seit zwei Dezennien der Vorhieb hauptsächlich auf solche Holzarten ausgedehnt, welche früher als die Buche einen starken Rückgang im laufenden Zuwachs zeigen und zugleich ihr technisches Haubarkeitsalter erreicht haben, was namentlich bei Ahorn und Esche der Fall ist. Der Begriff des Neben- 
bestandes ist demgemäss in diesem Zeitraume mehr theoretischer Natur und derart dehnbar, dass eine exakte Trennung von Hauptund Nebenbestand in Wirklichkeit ummöglich wird. Angesichts des Umstandes, dass die Massenangaben aller Ertragstafeln sich auf einen vom Nebenbestand befreiten Hauptbestand beziehen, ist die Fortführung des laufenden Zuwachses des Nebenbestandes bis zum Abtriebsalter jedoch als logische Konsequenz dieses Systems notwendig. Bei der Etatberechnung wird sich Gelegenheit bieten. die aus diesem Verhältnisse sich ergebenden Schlussfolgerungen zu ziehen.

Der gesamte laufende Zuvachs als Summe des laufenden '/uwachses ron Haupt- und Tebenbestand ist der Ausdruck der Wachstumsleistung und demgemäss auch des Nutzungsquantums eines Waldes. Seine Ermittlung ergibt sich direkt aus der Addition der Zuwachsquoten von Haupt- und Nebenbestand. Die aus diesen Einzelwerten konstruierte Kurve zeight. dass der Kulminationspunkt des Gesamtzuwachses in die gleiche Altersperiode fällt, wie derjenige des Haupt- und des Nebenbestandes. Sie zeigt uns ferner die überraschende Höhe des in einem Walde erreichbaren Gesamtzuwachses und die enorme ökonomische Bedeutung des Nebenbestandes. Aber gleichzeitig tritt auch zutage, in welch unvollkommener Art das Prinzip der ausschliesslichen Benutzung des Durchschnittszuwachses den tatsächlichen Watchstumsgang zun Ausdruck bringt. Es ist unmöglich bei Anwendung desselben den Nebenbestand zur Darstellung zu bringen. Ueberhaupt gibt es keinen Durchschnittszuwachs für den Nebenbestand, sondern mu einen solchen des Hauptbestandes. Der laufende Zuwachs ist die einzig mögliche Form, um das TWesen des Nebenbestandes zum Ausdruck zu bringen. Derselbe muss seine Wasse von einer Durchforstung zur andern erst bilden und aufspeicher'n, um dam bei der Fommenden Durchforstung vieder zu verschwinden.

Der gesamte laufende Zuwachs zeigt nach seinem Kulminationspunkt ein relativ rasches Sinken. Diese Tatsache muss notwendigerweise zu der Schlussfolgerung führen, dass das weitere Ueberhalten solcher Bestände, vom Standpunkt der Rentabilität aus betrachtet, sich nur dann rechtfertigen lässt, wenn das Zurückgehen des Zuwachses nach Quantität kompensiert wird durch den Zuwachs an Qualität. ${ }^{1}$ )

1. Vide nachfolgende Zuwachstatel. 


\section{VI. \\ Das Transportwesen.}

\section{A. Die an das Transportwesen zu stellenden Anforderungen.}

Die Bestandesverjingung. die Bestandespflege und die Bestandesnutzung eines Maldbetriebes stehen im engsten Zusammenhang mit dem Weg- und Transportsystem desselben. Je intensiver ein Waldbetrieb sich gestaltet, umsomehr muss die Zugänglichkeit eines jeden Waldortes ausgebildet sein. Die Zugänglichkeit ist ja wohl bis zu einem gewissen Grade abhängig von der topographischen Gestaltung des Terrains, auf welchem der Betrieb seine Aktionen zu vollziehen hat. Dieselbe äussert jedoch ihren Einfluss auf die Wirtschaft in der Auswahl der Mittel, die dazu dienen sollen, um in rationeller Weise leicht an jede beliebige Stelle eines Waldes zu gelangen und die von dort zu beziehenden Nutzungsobjekte vorteilhaft aus dem Walde zu schaffen. Nur da. wo man hiefür ein anderes Mittel nicht kennt als die Erstellung von Strassen, übt die Gestaltung des Bodens, wie auch dessen geognostische Fornation nassgehenden Einfluss auf die grösseren oder geringeren Schwierigkeiten der Transportanlagen aus. Die sogenannten Begehungswege kömmen nicht als Bestandteile des Transportsystemes bezeichnet werden, wenn es auch nicht ausgeschlossen ist, dass sie demselben dienen. Ihr Zweck, sowie ihre Zweckerfiullung liegt in der Schaffung der für eine intensive Bestandespflege wie für den Forstschutz notwendigen Zuugänglichkeit der einzelnen Waldteile.

Mit Ausnahme des Adlisberg-Forstbezirkes, der als ein Hochplateau im Hügelland bezeichnet werden darf, hat das Areal der stältischen Waldungen den Tharaktei des Torgebirgt's. Relatir steil 
in die Talsohle abfallende Hänge, durchbrochen von zahlreichen Bachgründen, die sich im Laufe der Zeit zu tiefen Schluchten gestalteten. dazwischenliegende Abschnitte von verhältnismässig geringer Breite, sind die charakteristischen Merkmale des Sihlwaldterrains. Diese Verhältnisse waren wohl neben der geognostischen Beschaffenheit des Bodens die Veranlassung, dass der sonst der Waldwirtschaft so dienliche Strassenbau hier nicht zur Entwicklung und Verwendung gelangte und auch in der jüngsten Periode 1875 bis 1900 nur in der allerersten Zeit berücksichtigt wurde.

Es fehlt an urkundlichen Ausweisen darüber, in welcher Art in früheren Jahrhunderten der Holztransport im Sihlwald bewerkstelligt wurde; doch darf als sicher angenommen werden, dass die Beförderung talwärts sich durch die Benutzung der Schneebahn mit Schlitten und durch Erdriesen vollzog. Dies nach zwei Ablagerungsstellen, von denen aus dann die Vorräte mit Benutzung der Sihl durch die wilde Flösserei nach Zürich transportiert wurden.

In den vierziger Jahren des 19. Jahrhunderts erfolgte dann die Anlage einer grossen Anzahl passagerer Schlittwege mit durchschnittlich schwachem Gefälle, unter Preisgabe der vorher benutzten Erdriesen. In den Jahren 1855-60 wurde die heutige Talstrasse erbaut, welche an Stelle der Wasserstrasse der Sihl den Holztransport an den untern Teil des Waldes, den jetzigen Werkplatz gestattete. Durch das an diese Strasse anschliessende vorhandene öffentliche Strassennetz konnte auf gleiche Art, sowohl mit den Abnahmeorten am linken Seeufer, wie mit den Ortschaften des Sihltales und der Stadt Zürich selber in Verbindung getreten werden. Zu Beginn der Wirtschaftsperiode 1875-90 wurde der Versuch gemacht, in ähnlicher Art, wie dies an den meisten Orten mit intensivern Forsthetriclsen im Gebirge. speziell im schwarzwald. in mustergültiger Art geschieht, die Holzausbringung durch die Erstellung eines rationellen Systems chaussierter Strassen günstiger zu gestalten. Es wurden zunächst bis auf die Höhe des ersten Plateaus (600-630 m ü. M.) zwei Strassen in die zum Abtrieb bestimmten Abteilungen 8 und 11 erbaut, gleichzeitig jedoch auch zum Zwecke einer rascheren Fortbewegung der talwärts zu führenden Massen zum erstenmal im Jahre 1876 eine Taldeisenbahn mit $60 \mathrm{~cm}$ Spurweite angelegt. Es ist wohl zunächst dem schwachen Oberbau der erstellten Strassen zuzuschreiben. dass der Fuhrbetrieb auf denselben fortdauernd unbefriedigende Leistungen aufzuweisen hatte. Die geringe Steinbettlage gestattet nicht, die Ladungen derart stark zu 
machen, dass die für die Zurücklegung des Weges erforderliche Zeit in richtigem Verhältnis zu den damit erwachsenden Kosten zu bringen ist. Für einen stärkeren Oberbau mangelt aber das notwendige Steinbett- und Beschotterungsmaterial. Bei einer Nienlerschlagsmenge von jährlich $1500 \mathrm{~mm}$ mit håufigen wolkenbruchartigen Regengüssen, erweist sich zudem auch der Unterhalt dieser Strassen als ein sehr kostspieliger; ganz abgesehen davon, dass der wünschbare Trockenheits- und Festigkeitsgrad derselben nur selten vorhanden ist.

Angesichts dieser negativen Erfolge mit dem Strassenbau musste sich die Wirtschaftsleitung die Frage stellen, wie das Transportsystem des Sihlwaldes zu gestalten sei, um allen den verschiedenen Anforderungen, welche der intensive Wirtschaftsbetrieb an den Holztransport stellen muss, bestmöglich zu entsprechen. Hiebei war zu berücksichtigen:

1. Der gebirgsartige Charakter des Sihlwaldterrains, der Mangel ausgedehnter, ununterbrochener Hänge, das Vorhandensein der vielen Bachläufe und die Erstreckung der Abteilungen von der Talsohle bis zur Kammhöhe $=487-915 \mathrm{~m}$ ü. M.

2. Das Jahres-Ausbringungsquantum, wie es sich aus Hauptnutzung und Durchforstungen ergibt, ist nicht ein örtlich konzentriertes, sondern dehnt sich auf verschiedene Waldteile oder Abteilungen aus.

3. Die Fällung und Aufarbeitung kann im grossen und ganzen erst gegen Mitte November begonnen werden, da der Laubabfall im Sihlwald spät erfolgt; die Holzhauerei wird deshalb durch den bald darauf folgenden Schneefall oder durch grosse Kälte des öftern unterbrochen, sodass, wenn auch Schneebahn vorhanden ist, dieselbe wegen der noch im Rückstand sich befindenden Aufarbeitung nicht zur Holzausbringung in grösserem Umfange benützt werden kann.

4. Der Verarbeitungsbetrieb Sillwald bedarf zur Deckung der vom Markte gestellten Anforderungen auch Holzmaterial, das nur im Sommer gefällt werden kann, z. B. für den Imprägnierungsbetrieb, sodass Sommer- und Wintertransport ins Auge gefasst werden muss.

5. Der Verkauf des geschlagenen Materials geschieht im Sihlwald nicht wie in den meisten übrigen. Waldbetrieben direkt loco Schlag, oder nächstgelegener Abfuhrstrasse, sondern erst im Tal oder auf dem Werkplatz. Wäre die Käuferschaft 
direkter Abnehmer, so wären die Transporteinrichtungen so zu gestalten, dass jeder einzelne Käufer dieselben mit den ihm zur Verfügung stehenden Transportmitteln benützen könnte. Das ist nun im Sihlwald nicht möglich und nicht notwendig; daher ist es geboten dafür zu sorgen, dass die Forstverwaltung das aufgearbeitete Material möglichst billig und rasch zu Tal oder auf den Werkplatz schaffen kann.

6. Das Vorhandensein eines aus W agen. Pferden, Schlitten, Riesenund Rollbahnmaterial bestehenden Transportmaterial-Inventars, sowie eines ständigen Arbeiterpersonales, das sich desselben zu bedienen versteht, gestattet der Verwaltung eine intensive Ausnützung der jeweilen für die Jahreszeit, die Terrain- und Witterungsverhältnisse wie das auszubringende Material zweckmässigsten Transportmittel.

Aus diesen Erwägungen geht wohl unzweifelhaft hervor, dass ein nur einseitigen Anforderungen entsprechendes Transportsystem sich für den Sihlwaldbetrieb nicht eignen würde, und dass es überhaupt für denselben, wie dies übrigens auch für die meisten anderwärtigen Verhältnisse der Fall sein dürfte. ein einheitliches Transportmittel nicht gibt.

Das Sihlwaldtransportsystem fusst darauf, für den transversalen wie für den Verkehr zu Tal jeweilen das geeignetste Transportmittel zu wählen. Der erst gestellten Anforderung entspricht unbedingt am besten die Rollbahn; für den Transport an die transversale Linie dienen die gewöhnlichen Hülfsmittel: Schlitten, Karren, Traggeschirr u. s. w. Für den Transport zu Tal ist die Wahl der kürzesten Jine unter Verwendung des geeignetsten Riesensystems angezeigt. Wo die Gefällsverhältnisse die Benutzung der Riesen nicht gestatten. ist die diagonale Entwicklung einer Transportlinie von der Höhe zu Tal anzustreben und hiebei der Rollbahn vor der Strassen-Anlage der Vorzug zu geben. Selbstverständlich bleibt die Benutzung der Schneebahn, wenn solche vorhanden ist, weder im einen noch im anderen Falle ausgeschlossen. Endlich wird sich angesichts des Wechsels und der Verschiedenartigkeit der einzelnen Aufgaben der Regiebetrieb für deren Lösung besser eignen als der Akkordbetrieb.

Die beigefügte Tafel zeigt uns, wenn auch in unvollkommener Darstellung. den schematischen Zusammenhang und das Lneinandergreifen der einzelnen Transportaufgaben von der Bergeshöhe bis ins 'Tal. 
Wesen und Wirkung des auf dieser Grundlage entwickelten Betriebssystemes haben sich zufolge zwanzigjïhrigen Erfahrungen klar herausgeschält, sowohl in seinen Vorzïgen als in seinen Schattenseiten. In ihrer Gesamtheit sprechen sie entschieden für las System: sie rechtfertigen seine Fortführung und Weiterentwicklung.

In den nachfolgenden Abschnitten soll versucht werden, die wesentlichsten Bestandteile des Sihlwaldtransportsystems zu näherer Darstellung zu bringen: die Waldeisenbahnen, die verschiedenen Riesen, und die für beide dienlichen weiteren Transporthiilfsmittel.

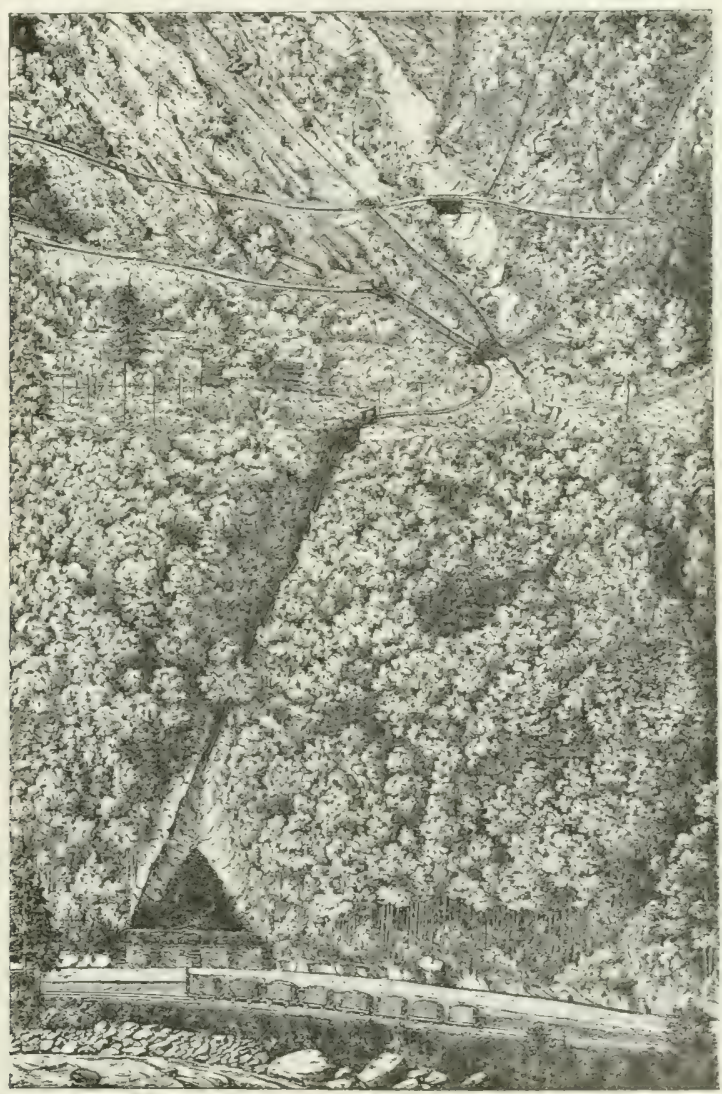

Uebersicht

W. v. Steiner del der

Verbindung des Bahn- und Riesentransportes. 


\section{B. Die Transportmittel.}

\section{Die Waldeisenbahn.}

Die Fortbewegung von Lasten, sei es auf horizontaler oder schiefer Ebene, vollzieht sich mit umso grösserem Nutzeffekt, je fester die Fahrbahnanlage konstruiert und je weniger diese Festigkeit von den Witterungseinfluissen abhängig ist. Der in der Fuhrleistung sich ausdrüickende Unterschied des Nutzeffektes zwischen dem rohen Erdweg, der chaussierten Strasse und dem Schienengeleise, als der relativ festesten Unterlage, springt so in die Augen und spricht so sehr für das Schienengeleise, dass die Verwendung des letztern in der Waldwirtschaft nicht ausser acht gelassen werden darf, sondern vielmehr in ernste Erwägung gezogen werden muss. Nach Forstmeister Adolf Runnebaum ${ }^{1}$ ) stellen sich die Verhältnisse wie folgt:

Zwei Pferde von mittlerer Zugkraft (150 Kg.) bewegen täglich bergan auf $7,5 \mathrm{~km}$ Länge, wobei vorausgesetzt wird, dass dieselben täglich $30 \mathrm{~km}$ arbeitend zurücklegen, zwei leere Touren hin und zwei beladene zurück machen, an Bruttolast:

\begin{tabular}{|c|c|c|c|c|c|}
\hline $\begin{array}{l}\text { Steigungs- } \\
\text { verhähttnisse } \\
\text { des Weges }\end{array}$ & $\begin{array}{c}\text { Sandweg } \\
\text { Ztr. }\end{array}$ & $\begin{array}{c}\text { Besserer } \\
\text { Kiesweg } \\
\text { Ztr. }\end{array}$ & $\begin{array}{c}\text { Holzbahn } \\
\text { Ztr. }\end{array}$ & $\begin{array}{c}\text { Chaussee } \\
\text { Ztr. }\end{array}$ & $\begin{array}{c}\text { Schienen- } \\
\text { geleis } \\
\text { Ztr. }\end{array}$ \\
\hline Horizontal & 20 & 30 & 40 & 90 & 300 \\
\hline $1: 50(2 \%)$ & 16 & 22 & 32 & 50 & 100 \\
\hline $1: 20(5 \%)$ & 12 & 16 & 24 & 30 & 50 \\
\hline
\end{tabular}

Legt man nach den Ansätzen Runnebaums für zwei Pferde, den Fuhrmann und einen Arbeiter zum Auf- und Abladen 10 Mark zugrunde, so stellen sich die Transportkosten per $100 \mathrm{~kg}$ und per Meile auf:

\begin{tabular}{|c|c|c|c|c|c|}
\hline $\begin{array}{c}\text { Steigungs- } \\
\text { verhältnisse } \\
\text { des Weges }\end{array}$ & $\begin{array}{c}\text { Sandweg } \\
\text { Pfg. }\end{array}$ & $\begin{array}{c}\text { Besserer } \\
\text { Kiesweg } \\
\text { Pfg. }\end{array}$ & $\begin{array}{c}\text { Holzbahn } \\
\text { Pfg. }\end{array}$ & $\begin{array}{c}\text { Chaussee } \\
\text { Pfg. }\end{array}$ & $\begin{array}{l}\text { Schienen- } \\
\text { geleis } \\
\text { Pfg. }\end{array}$ \\
\hline Horizontal & 50,0 & 33,4 & 25,0 & 11,0 & 3,4 \\
\hline $1: 50(2 \%)$ & 62,4 & 45,4 & 31,2 & 20,0 & 10,0 \\
\hline $1: 20(5 \%)$ & 83,4 & 62,4 & 41,6 & 33,4 & 20,0 \\
\hline
\end{tabular}

$\left.{ }^{1}\right)$ Die Waldeisenbahnen, Verlag von J. Springer, Berlin. 1886. 


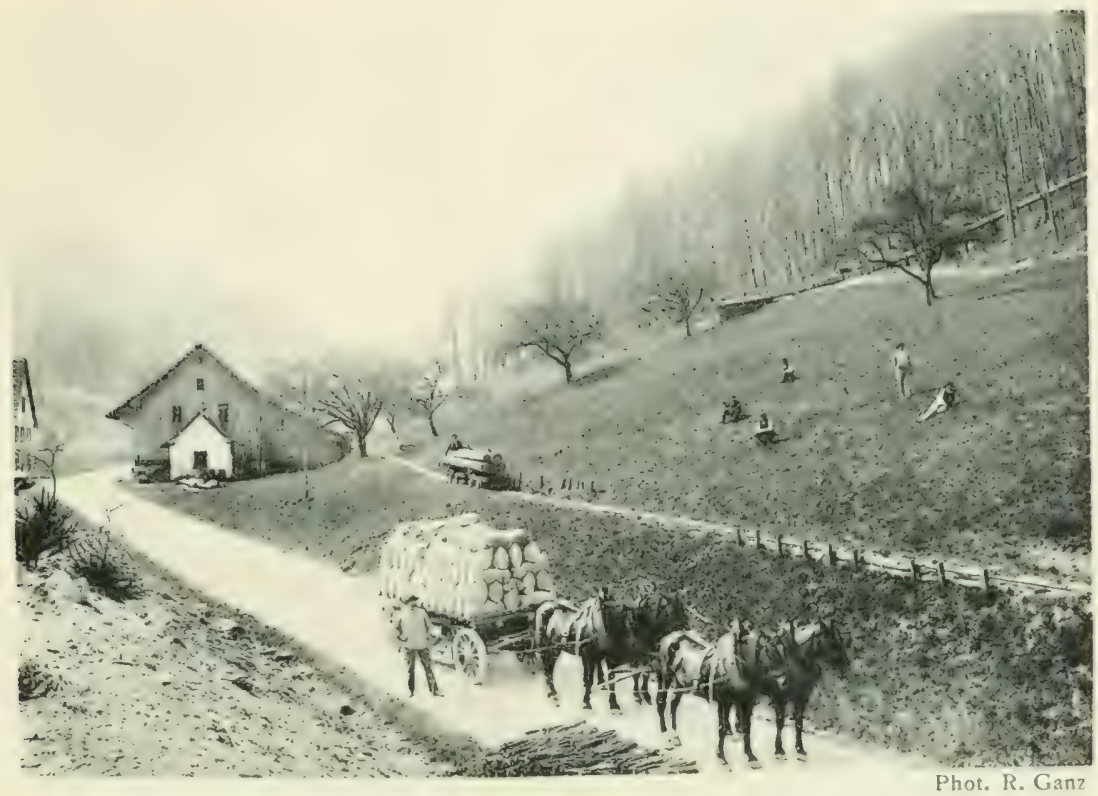

Oberer Sihlwald. Stamm- und Brennholzriese, im Anscliluss die Waldbahn.

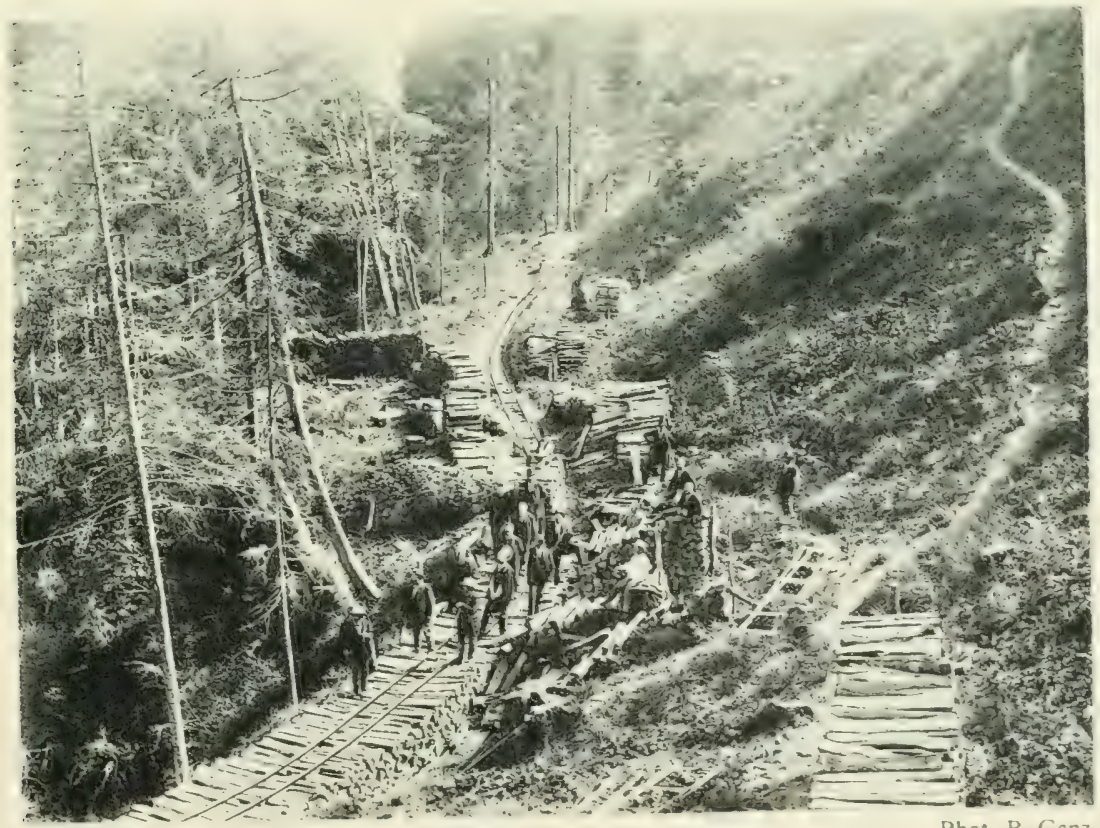

Transportable Waldbahn auf Scheiterholzdamm (Soo mu ü. M.). 

Auffallenderweise hat das Forstgewerbe aus diesen tatsächlichen Verhältnissen viel später lie wünschbaren Schlussfolgerungen gezogen als das Baugewerbe. In der Literatur brachte Prof. Dr. Exner ${ }^{1}$ ) den Schienentransport zum erstenmal im Jahre 1877 zu einlässlicher theoretischer Würdigung. Wie schon weiter oben bemerkt worden ist, fällt die erstmalige Verwendung von Schienengeleisen im städtischen Forstbetrieb in das Jahr 1876. ${ }^{2}$ ) Auf einer $3 \mathrm{~km}$ langen Strecke wurde dazumal ein Schienengeleise mit Holzschwellen gebaut, das heute noch gebraucht wird und in seinem 25jährigen Bestehen die grossen Vorteile der Verwendung des Schienengeleises im Forstbetriebe dartut. Dieser permanenten Geleiseanlage reihten sich dann passagere Anlagen an, teils solche mit Verwendung von transportablem Geleisematerial, teils solche erstellt aus den der Verwaltung zur Verfügung stehenden Schienen unter Verwendung ron Brennholzscheitern als Schwellen. Einen besondern Impuls erhielten dann aber die Geleiseanlagen durch die Schneebruchkalamität vom Jahre 1885; es darf heute wohl füglich gesagt werden, dass die Ausbringung der ungewöhnlich grossen Holzmassen dazumal ohne die Inanspruchnahme und die Leistungen des Rollbahnbetriebes unmöglich gewesen wäre. Wo die Anlage chaussierter Strassen, sowie deren Benützung entweder gar nicht oder nur mit grossem Zeit- und Geldaufwand möglich gewesen wäre, liessen sich umgekehrt an den steilsten und höchsten Berghängen, im durchschluchteten Terrain, wie auf den sanft abfallenden Hängen der einzelnen Plateaus, Schienengeleise in kürzester Zeit unter Erzielung eines billigen und sicheren Betriebes erstellen.

Es kann sich in der vorliegenden Arbeit wohl nicht darum handeln, den Waldeisenbahmbau theoretisch nach allen Richtungen hin zu entwickeln. Wir glauben uns vielmehr darauf beschränken zu müssen, die Grundsätze anzuführen, gestützt auf welche der Bau und der Betrieb der Sihlwaldbahnen durchgeführt wurde und heute noch durchgeführt wird. Die mehr als zwanzigjährigen Erfahrungen sind in ihrer Art gewichtig genug, theoretischen Konklusionen als Stützpunkte zu dienen.

1) Das moderne Transportwesen im Dienste der Land- und Forstwirtschaft, Weimar. 1877.

$\left.{ }^{2}\right)$ Die zu so hoher Entwicklung und Benutzung gelangten Waldbahnanlagen in den Reichslanden nahmen ihren Anfang im Jahre 1883. Siehe Zeitschrift für Forst- und Jagdwesen, von Dr. Dankemann, 32. Jahrgang, 6. Heft: Die festliegenden Waldbahnen in Elsass-Lothringen, von Oberforstmeister Pilz in Strassburg. 
Wir resümieren nachfolgende Ergebnisse:

1. Die Spurweite von $60 \mathrm{~cm}$ erwies sich für Bau und Betrieb vorteilhafter, als die anfänglich verwendete $50 \mathrm{~cm}$ Spurweite; sie gestattet einen leistungsfähigeren und sicherern Betrieb. Eine grössere Spurweite hätte unter den vorhandenen Verhältnissen die Vorteile des Waldeisenbahnbetriebes vermindert statt vermelirt.

2. Sobald es sich um eine grössere Geleisanlage handelt, welche auf mehrere Jahre hinaus und nicht bloss einer vorübergehenden Holzausbringung zu dienen hat, empfiehlt sich eine sorgfältige Planie des Unterbaues; der Betrieb der Anlage wird in eben dem Masse leistungsfähiger und ersetzt damit vielfach die nur einmaligen Mehrkosten der Erstellung.

3. Die früher so sehr in den Vordergrund gestellten Vorzüge des transportablen Geleisematerials (Schienen mit eisernen Stegen oder Schwellen) haben sich gegenüber dem einfachen Schienenmaterial nicht als haltbar herausgestellt. Die grosse Leichtigkeit, mit der sich die Geleiseanlage vermittelst des transportablen Schienenmaterials vollzieht, wird durch die nachher noch für den Betrieb erforderlichen Ergänzungsarbeiten vollständig aufgewogen. Das einfache Schienenmaterial besitzt zudem ein grösseres Vermögen der Akkommodation an die Terraingestaltung, welche Eigenschaft sich besonders beim Ausbau der Kurven geltend macht. Die einfache Schiene ist viel transportabler als die durchschnittlich fünf Meter langen Joche mit einem Gewicht von $80 \mathrm{~kg}$. Nach den Beschaffungskosten dürfte sich der Meter Schienengeleise um etwa die Hälfte billiger stellen als derjenige des transportablen Geleisematerials.

4. Die Stahlschiene von $65 \mathrm{~mm}$ Höhe mit einem Gewicht von $6,8 \mathrm{~kg}$ per Meter oder $14 \mathrm{~kg}$ per Meter fertiges Geleise erwies sich als ausreichend stark auch für die grösste in Betracht fallende Belastung von $750 \mathrm{~kg}$ per Quadratzentimeter Schienenfläche. Die Benutzung von Brennholzscheitern als Schwellenmaterial und die Verwendung kantiger Schwellen nur bei Stossfugen und Kurven gestattet einen einfachen, überall leicht erstellbaren, nach Abbruch des Geleises wieder verwertbaren Oberbau.

5. Die Ueberbrückung von Schluchten und ständigen Wasserrinnsalen lässt sich beim Bau der Waldeisenbahnen in einfacherer Weise durchführen als beim Strassenbau. Die vor- 
übergehende Verwendung des aus den Schlägen fortzuschaffenden Scheitholzmaterials zu Dämmen oder zu Widerlagern über welche Langhölzer als Schienenunterlage gelegt werden, hat dazu geführt, auch unter schwierigsten Verhältnissen den Fahrbetrieb in wenig kostspieliger Weise zu ermöglichen. (Vide Tafel XV).

6. Die Ausführung der Bahnanlage mit durchgehendem Gefäll d. h. ohne Gegensteigungen erweist sich als unbedingt vorteilhaft. Da wo die Distanzverhältnisse, weil zu klein, den Motorbetrieb nicht als empfehlenswert erscheinen lassen, ist das durchgehende Gefäll eine Notwendigkeit für die Erzielung eines leistungsfähigen Betriebes. Der Hinauftransport der entleerten Züge auf kürzeren Strecken wird am vorteilhaftesten mit Ochsen oder Pferden bewerkstelligt. Als Scheidegrenze für die Sistierung des Betriebes mit Zugtieren und die Verwendung der Maschine dürfte die Distanz von fünf Kilometer bezeichnet werden. Dieselbe wurde bisher im Sihlwald nicht erreicht.

7. Die bei den Sihlwald-Bahnanlagen zur Anwendung gelangten Gefällsverhältnisse bewegten sich anfänglich zwischen 2 und 11 Prozent; die hiebei gemachten Erfahrungen wiesen aber darauf hin, dass sich der Betrieb leistungsfähiger gestaltet, wenn das Gefälle in der Regel 7 Prozent nicht übersteigt und sich im allgemeinen zwischen 2-5 Prozent bewegt. Die Minimalgrenze von 2 Prozent ist erforderlich für die Ueberwindung der Friktion bei nicht vorhandener lebendiger Kraft.

५. Das Wagenmaterial der Waldeisenbahnen muss den robusten Anforderungen, welche der Holztransport in sich schliesst, entsprechen; es muss solid und dauerhaft beschaffen sein. Die Erstellung und die Reparatur desselben muss vom Betriebe selbst und unabhängig von den Eisenwerken stattfinden können. Bei den Sihlwaldeisenbahnen wurden nur das Rollmaterial, Räder und Achsen von auswärts bezogen, alles übrige dagegen aus Holz in der eigenen Wagnerei erstellt, die Bremsvorrichtungen in der eigenen Schmiede konstruiert. Auf diese Art und Weise konnte dem Betriebe ohne Unterbruch ein billiges, den Transportverhältnissen entsprechendes Wagenmaterial zur Verfügung gestellt werden.

9. Die Konstruktion des Wagenmaterials der Waldeisenbahnen ist den Anforderungen des Betriebes und den Anlageverhält- 
nissen der Waldeisenbahnen anzupassen. Dasselbe hat eine bequeme Verladung und Entladung, sowie eine sichere Führung zu ermöglichen. Im Sihlwald nimmt der Brennholztransport die erste Stelle ein, daneben der Transport von Stamm- und Stangenhölzern. Maschinelle Ladevorkehrungen sind nicht erforderlich. Die zur Verwendung gebrachten Wagen (vide Figur) erwiesen sich als leistungsfähig. Beim

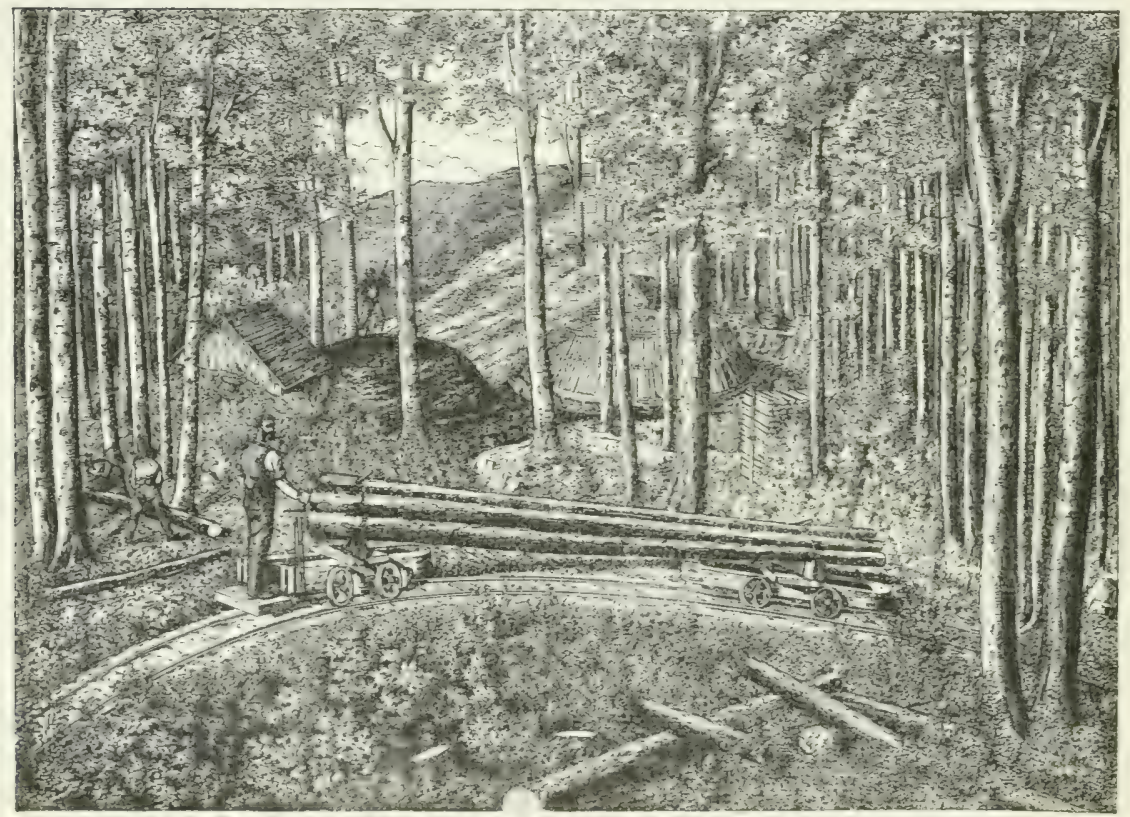

Langholztransport aus den Schlägen

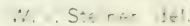

(in der Nithe: Köhlereij.

Brennholztransport wurde von den anfänglich zur Verwendung gebrachten kleineren, drei Ster aufnehmenden Wagen Umgang genommen und dafür das System der Traggeschirrwagen mit drelıbaren Schemeln, zirka fünfzehn Ster aufnehmend, eingeführt.

10. Ein Hauptmoment für den leistungsfähigen Rollbahnbetrieb bildet namentlich bei starkem Gefälle das zur Verwendung gebrachte Bremssystem. Unter den verschiedenen konstruierten Vorrichtungen erwies sich die Spindelbremse mit doppelter 
Kettenübertragung, ausgedehnt auf den Vorder- und den Hinterwagen, als die zweckmässigste und sicherste.

11. Wie die Gefällsverhältnisse, so spielen auch die Kurven bei der Anlage von Waldeisenbahnen im gebirgigen Terrain eine Hauptrolle. Die Erfahrung lehrte, dass bei dem Vorhandensein eines richtig konstruierten Wagenmaterials der Radius der Kurven bis auf 12 Meter reduziert und so auch den schwierigsten Terrainverhältnissen angepasst werden kann. Es ist bereits weiter oben darauf hingedeutet worden, dass diese Anschmiegung an das Terrain nur bei der Verwendung des gewöhnlichen Schienenmaterials im Gegensatz zu den transportablen Geleisen durchführbar ist.

12. Das Transportmittel der Waldeisenbahnen hat vorab und unter allen Verbältnissen gegenüber dem Strassentransport den Vorteil, dass es gestattet, innerhalb kürzester Frist grosse Holzmassen aus dem Walde zu schaffen. Wenige günstige Tage und Wochen sind ausreichend, die Transportaufgabe zu bewältigen, während es bei der Verwendung des Strassentransportes der Monate hiefür bedarf. Sehr oft tritt hiebei ein Augenblick ein, wo der Strassenkörper überhaupt nicht mehr benützt werden kann und der Holztransport zu sistieren ist. Der Waldeisenbahnbetrieb verschafft deshalb der Wirtschaft die nötige Unabhängigkeit im Transportbetrieb von Jahreszeit und Witterung.

13. Die Erstellungskosten der Waldeisenbahn sind je nach dem verwendeten Oberbaumaterial kleiner oder grösser als diejenigen für chaussierte Strassen; durchschnittlich kleiner. Der Unterbau ist unter allen Umständen bei den Waldeisenbahnen billiger. Der für die Spurbreite von $60 \mathrm{~cm}$ nötige Bahnkörper erhält mit $1 \mathrm{~m}$ eine ausreichende Kronenbreite. Auch an den steilsten Berghängen im coupiertesten Terrain ist dieser ohne wesentliche Erdbewegungen und Kunstbauten erstellbar; während umgekehrt der im Minimum $3^{1 / 2} \mathrm{~m}$ breite Strassenkörper grössere Anlagekosten erheischt. Für die Kosten des Oberbaues ist das hiefür verwendete Material massgebend. Bei der bereits erwähnten, im Sihlwald im allgemeinen gebräuchlichen Verwendung von Schienenmaterial mit Brennholzscheitern als Schwellen betrugen die erstmaligen Anschaffungskosten für Schienen, Laschen und Nägel per Heter Geleise Fr. 2.40; für transportables Geleise, je nach der Be- 
zugsquelle, durchschnittlich Fr. 5. - per Meter. Die Anschaffungskosten sind jedoch nur einmalige und sofern sie sofort in die Jahresbetriebsrechnung eingenommen werden, amortisiert. Für die künftigen Rechnungen kann höchstens eine jährliche Abgangs- und Erneuerungsquote in Betracht fallen. Die Neuanlagen von Waldeisenbahnen können demgemäss mit einem durchschnittlichen Kostenaufwand von Fr, 1.- bis Fr. 1.50 per Meter erstellt werden. Die Kosten des Unterhaltes sind bei den Waldeisenbahnen relativ sehr gering. Bau und Unterhalt der Strassenkörper zusammengenommen erheischen unter allen Umständen grössere Ausgaben, als dies bei den Waldeisenbahnen der Fall ist.

14. Die Betriebsleistungen der Waldeisenbahnen sind der Mannigfaltigkeit der Verhältnisse halber schwer in einheitlichen, zu Vergleichungen verwendbaren Ansätzen auszudrücken. Zwischen den Leistungen der Tallinien mit schwachem Gefälle und denjenigen der in zahlreichen Windungen mit starkem Gefälle an Berghängen sich hinziehenden Linien müssen selbstverståndlich grosse Differenzen zutage treten. Nicht minder fällt ins Gewicht, ob die Ausladestation Endstation des Transportes oder nur Umladestelle für einen andern Transport, z. B. für die Riese, ist. Früher, d. h. so lange für den Holztransport eine Fuhrhalterei funktionierte, musste per Ster Fr. 1.60 loco Werkplatz bezahlt werden. Beim Schlittereibetrieb berechnet sich der Transport von den mittleren Berghöhen ins Tal durchschnittlich auf Fr.1.20 per Ster. Die Ermittlung der 'Transportspesen auf verschiedenen, teils noch bestehenden, teils wieder beseitigten Eisenbahnlinien ergibt bei der Annahme einmaligen Auf- und Abladens $5-10$ Cts. per Ster und per Kilometer. Je länger die Transportlinie, desto günstiger gestaltet sich der Transportpreis per Kilometer. Unter allen Umständen und alle Verhältnisse des Sihlwaldes ins Auge fassend, darf man sagen, dass der Holztransport mit Waldeisenbahn in ergiebigerer und billigerer Art bewerkstelligt werden kann, als derjenige mit Strasse oder Schlittbahn. 


\section{Die Riesen.}

Der für das Holztransportsystem des Sihlwaldes aufgestellte Grundsatz der Benützung des stärksten Gefälles bedingt die Verwendung der Riese. Das im Schwarzwald gebräuchliche Seilen der Stämme ist zufolge der Gestaltung des Sihlwaldterrains nur ausnahmsweise durchführbar, indem steile Hangpartien mit Terrassen von geringerem Gefälle wechseln. Es wurde bereits betont, dass in früheren Zeiten die Erdriese den Holztransport da zu vermitteln hatte, wo die Schlittbahn denselben nicht zu bewältigen vermochte. Mit Beginn der Wirtschaftsperiode 1875-1900 und nachdem die Erfahrungen mit dem strassenbau wenig günstige Resultate zutage gefördert hatten, trat die Holzriese für den Stammholz- wie für den Brennholztransport in den Vordergrund sie bildet hente neben den Waldeisenbahnen das unentbehrlichste Hülfsmittel des Holztransportsystems.

Bevor der Forstbetrieb des Sihlwaldes dazu gelangte, für den Transport in der Richtung des grössten Gefälles die Riese zur Verwendung zu ziehen, musste er sich Klarheit über das anzuwendende System verschaffen. Der Holzriese stellte sich die Drahtseilviese gegenüber. Welche von beiden ist die den Sihlwaldverhältnissen entsprechende?

a) Die Drahtseilriese.

Die Druhtseilviese, wie sie im schweizerischen Hochgebirge und in den Vorbergen seit längerer Zeit bis auf heute zur Anwendung gelangt, int eines der leistungstähigsten Transportmittel. Dasselbe ist geeignet, grössere oder kleinere Holzmassen von den am schwersten zugänglichen und höchst gelegenen Punkten unter Benïtzung des Luftraumes talwärts oder sogar mehrere Schluchten und Täler durchquerend, auf eine tiefer gelegene Stelle zu schaffen. Die zu transportierende Last ist dabei in eine Form zu bringen, welche das Anhängen und das unbehinderte Fortgleiten derselben mit dem über das Drahtseil fortrollenden Wagen ermöglicht. Der Anfangspunkt muss die Eigenschaft einer zentralen Aufiahme-telle für das dem Transport zugewiesene Material besitzen und ähnlich wie die Endstelle geeignet sein, die für die Anspannung und die Bremsung 
des Seiles nötige Installation zu ermöglichen. Dem entsprechend eignet sich die Drahtseilriese wesentlich für den Stammtransport; schon weniger für den Transport von grösseren Reisigmassen und noch weniger für das in Scheitholz aufgearbeitete Brennmaterial. Die Drahtseilriese hat den unbedingten Vorteil, dass das Holz durch den Transport keinen Schaden leidet und dass die Witterung keinerlei Einfluss ausübt. Mit diesen Vorzügen geht aber parallel der Nachteil, dass für die Aufnahme des zu transportierenden Materials nur die oberste, d. h. die Anfangsstelle benutzbar ist. Weiter abwärts liegende, von der Riese durchzogene Orte, sind ausserhalb des Benutzungsrayons. Für einen Wirtschaftsbetrieb, der ähnlich wie derjenige im Sihlwald die Abteilungsbildung von der Berghöhe bis zur Talsohle reichen låsst und dadurch in der Lage ist, Material in verschiedenen Höhenlagen fortschaffen zu müssen, eignet sich die Drahtseilriese nicht. Sie ist da am Platze, wo der zu exploitierende Wald auf dem Höhenplateau, der Berghang ausserhalb des Benutzungsrayons liegt. Die Ausgestaltung, die der Drahtseilriese zum $/ /$ wecke eines leistungsfähigen Betriebes nach und nach gegeben wurde, macht ihre Deplazierung an einen andern Waldort zu einer kostspieligen Manipulation und lässt ihre Anwendung nur in solchen Fällen empfehlenswert erscheinen, wo sie mit einfachsten Mitteln installiert werden kann (vide Figur pag. 167).

b) Die Holzriese.

Die Holzriese musste aus den angegebenen Gründen für die Verhältnisse des Sihlwaldes als das zweckentsprechendere Transportmittel der Drahtseilriese vorangestellt werden. Sie gelangte nach zwei Richtungen hin zur Entwicklung; einmal als stabile Riese füı. den Transport von Stamm- und Scheitholz und sodann als transportable Riese, ausschliesslich für den Brenuholztransport herechnet. Eine dritte, neben dem Stammholz- und Scheitholztransport auch für das IVellenmaterial dienliche Art der Riese, die crst in jüngster Zeit konstruiert wurde, ist eine Verbindung der festen Riese mit Drahtseilschlittbahn.

Die Holzriese ist noch in höherem Grade als die Drahtseilriese vom Neigungswinkel des Terrains abhängig. Ohne ein angemessenes Gefälle ist sie nicht verwendbar. Vielfach angestellte Untersuchungen und Versuche haben ergeben, dass der obere Dritteil 


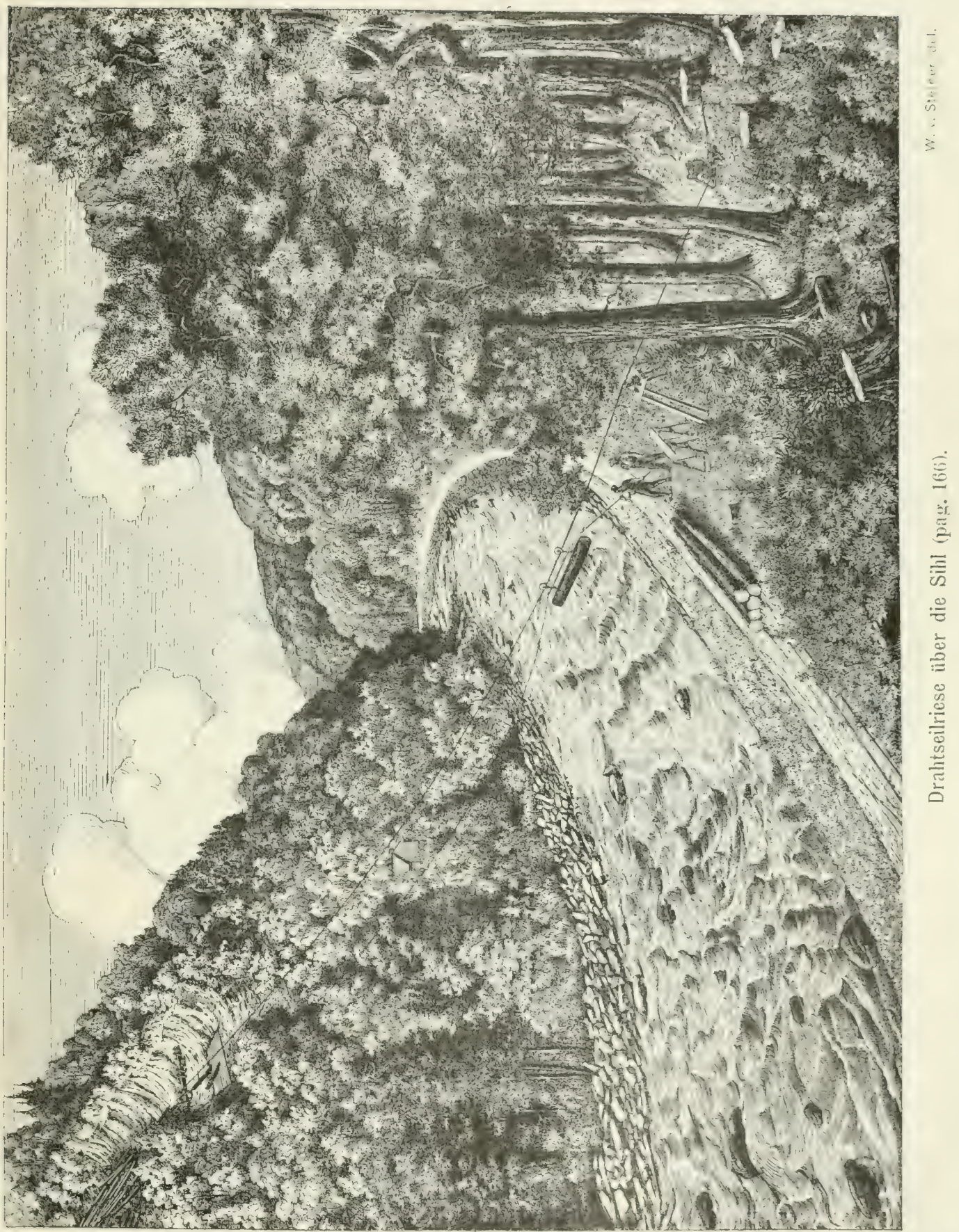


einer Holzriese zum mindesten 15 Grad Gefälle aufzuweisen hat, wenn die ïbrigen zwei Dritteile mit weniger als 15 Grad Neigung noch durchlaufen werden sollen. Die für eine Holzriesenanlage mögliche Länge ist von diesen Faktoren abhängig. Zu grosses Gefälle wirkt selbstverständlich nachteilig auf die zu transportierenden Holzmassen, was sich insbesondere beim Transport von Laubholzstämmen bemerkbar macht. Die Neigunøswinkel des Sihlwaldterrains sind für die Anlage langer Riesen ungünstig infolge

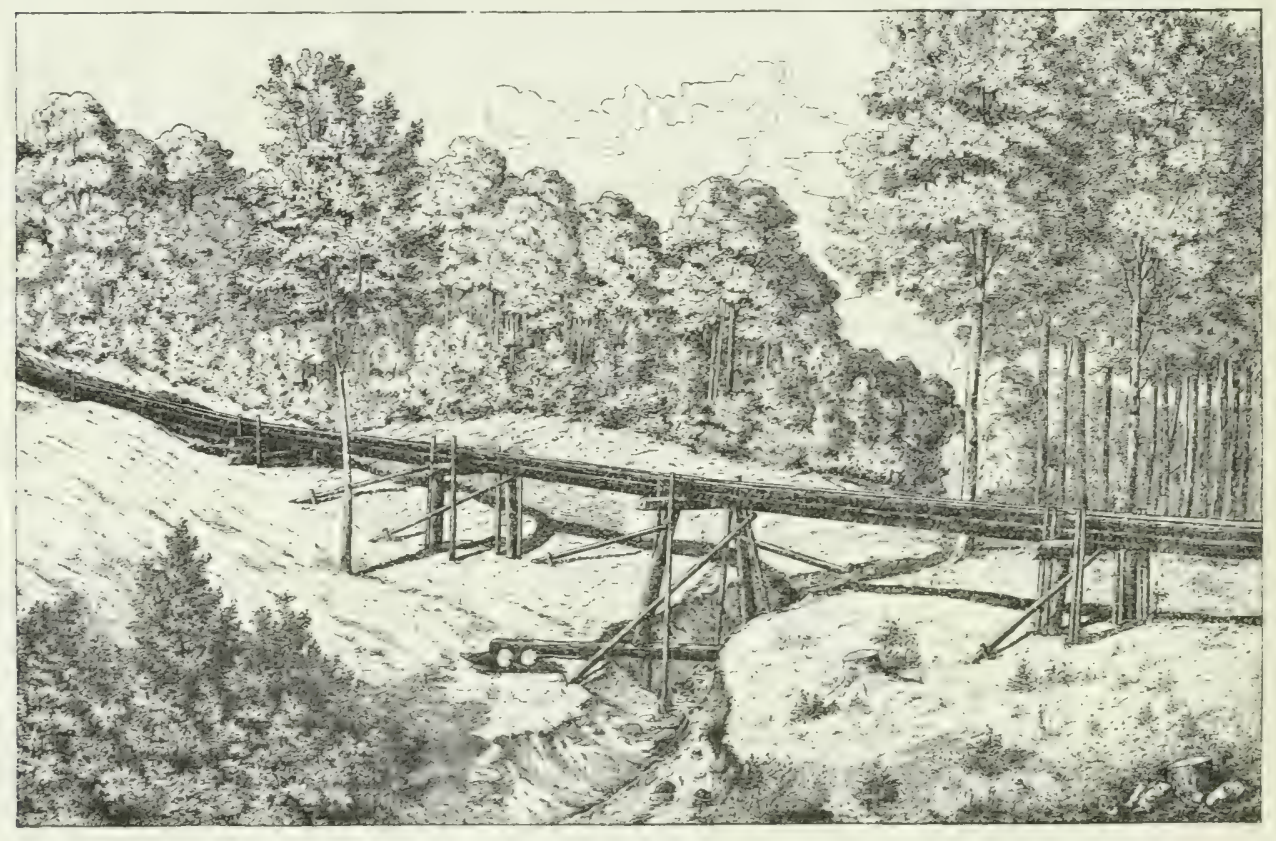

Mittelstück einer Stammliolzriese.

$\therefore$ S. . . . .

der mehrfach erwähnten Terrassenbildungen mit Maximum 5 Grad Neigung, sodass Riesen von $300 \mathrm{~m}$ Länge maximale Leistungen sind und längere Anlagen, welche vom betriebstechnischen Standpunkte aus sehr (mpfehlenswert gewesen wären, unterhleiben müssen.

Die stabile oder die permanente Riese wurde im Sihlwalde anfänglich in der allgemein üblichen Art aus $0,12-0,25 \mathrm{~m}$ dicken Stangen von 5-8 m Länge angefertigt, mit einer Kanalweite von 0,70-1.20 m. Zu den Jochen wurde ebenfalls Rundholz angemessener Stärke mit den nötigen Verstrebungsstangen rerwendet. 
Der Auswurf wurde aus starken Buchenbohlen, verstärkt durch Eisenbeschläge, konstruiert. Keine der in dieser Art konstruierten Riesen konnte in fortlaufend gerader Linie erstellt werden; an jeder waren im Anschluss an das Terrain gekrümmte Strecken

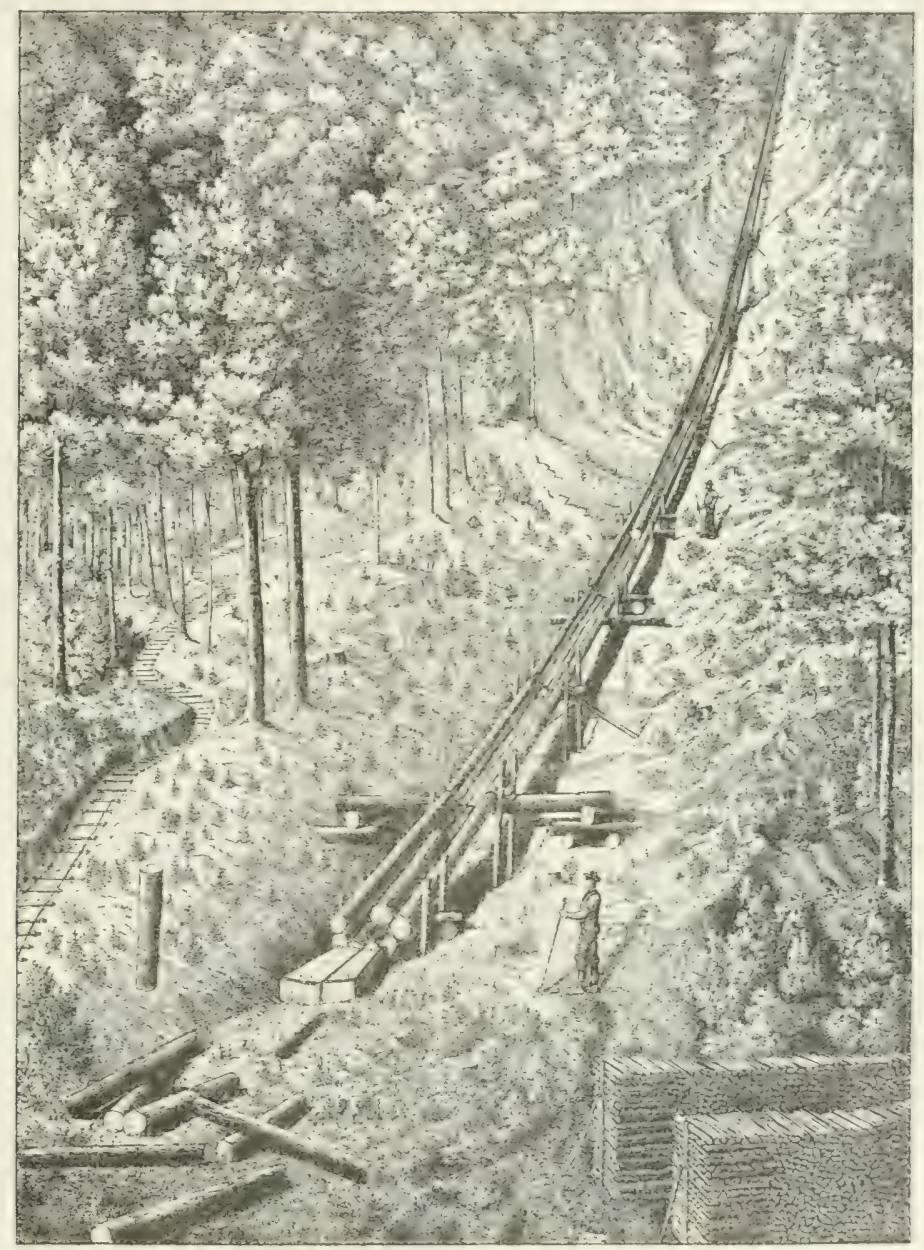

Unterer Teil einer Stammholzriese.

anzubringen. Der Erstellungspreis dieser Riesen belief sich durchschnittlich, ohne Einrechnung des Holzes, auf Fr. 2.- per Meter: mit Anrechnung des Holzes auf Fr. 4.50. Die Daner derselben war im Maximum eine siebenjährige. Die Leistungsfähigkeit muss 
als eine sehr hohe bezeichnet werden, sowohl für das Stammholz, wie für das Brennmaterial. Die Transportspesen für die mit den Riesen zurïckgelegten Vertikaldistanzen bestanden nur in den Einwurfskosten und in der Amortisation des Betriebsmittels. Der Einwurf der Holzmassen kann an verschiedenen Orten der Gesantstrecke der Riese bewerkstelligt werden. Der Nachteil, der dieser Konstruktion der Riese anhaftet. liegt in der grossen Masse des zum Bau notwendigen Holzmaterials und in den relativ hohen Kosten, denen die Verwendung der schweren Stangenhölzer von $15-25 \mathrm{~cm}$ beim Bau ruft. Aus diesem Grunde, und weil dieses Stangenmaterial anderweitig bessere Terwertung finden kann, wurde dieses Konstruktionssystem verlassen. An Stelle der schweren Stangen wurden parallel abgekantete Schwartenstücke (Abfälle vom Sägewerk) von 3-4 cm Dicke und $6 \mathrm{~m}$ Länge für den Bau des Kanals zur Verwendung gezogen und dieselben in kantig geschnittenen Sätteln in solider und dauerhafter Art befestigt. Allerdings bewirkte die Anfertigung dieser Sättel eine Erhöhung der Kosten. es darf aber angenommen werden, dass ihre Verwendung auch bei einer Deplazierung des Geleises möglich ist. Die wohlfeilere Erstellung des Kanals der Riese durch Schwartenstücke anstatt durch Stangenhölzer und die dadurch bewirkte solidere Konstruktion machen das neue System umso empfehlenswerter, als auch die Reparaturen weniger kostspielig ausfallen, indem die Auswechslung der einzelnen Stücke leichter durchführbar ist (vide Figur A. pag. 174).

Die transportable Holzriese setzt sich zusammen aus einer Anzahl von tragbaren Einzelstücken von 5-6 m Länge. Jedes Einzelstück besteht whs zwi aneinandergefügten $25-35 \mathrm{~cm}$ langen und $3,5 \mathrm{~cm}$ dicken Brettern, welche durch Befestigung auf vier stumpfwinklig ausgeschnittenen Sätteln einen festen Leitungskanal bilden. Ist an irgend einer Stelle des Waldes, welche das nötige Gefälle für die Anlage einer Riese besitzt, ein Brennholztransport zu vermitteln. so werden so viele einzelne Teilstücke auf passageren .Jochen dachziegelartig zusammengefügt, als die zu durchlaufende Strecke erfordert. Am untern Ende wird ähnlich wie bei der stabilen Riese der Auswurf angehracht, unter demjenigen Neigungswinkel, der die Bildung eines ausgiebigen Auswurf hanfens ermöglicht (vide pap. 172).

Die Leistungsfähigkeit dieser transportablen Riesen ist ungemein gross und erleichtert insbesondere sehr die Ausbringung des auf vicle Abteilungen sich erstreckenden Durchforstmesmate- 
rials. Die Kosten des einzelnen T'eilstückes belaufen sich untel' Einrechnung des Holzwertes auf Fr. 10.-- oder Fr. 2. - per Meter. Die Verwendungsdauer derselben wird erhöht durch die Aussohlung

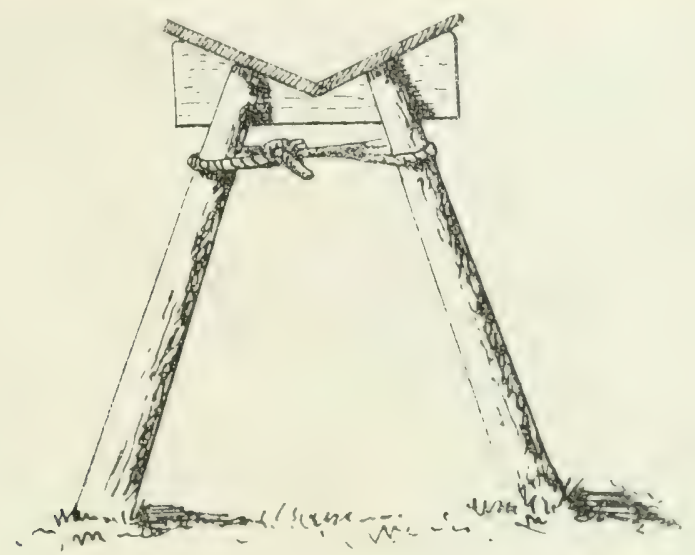

Querschnitt der transportablen Riese.

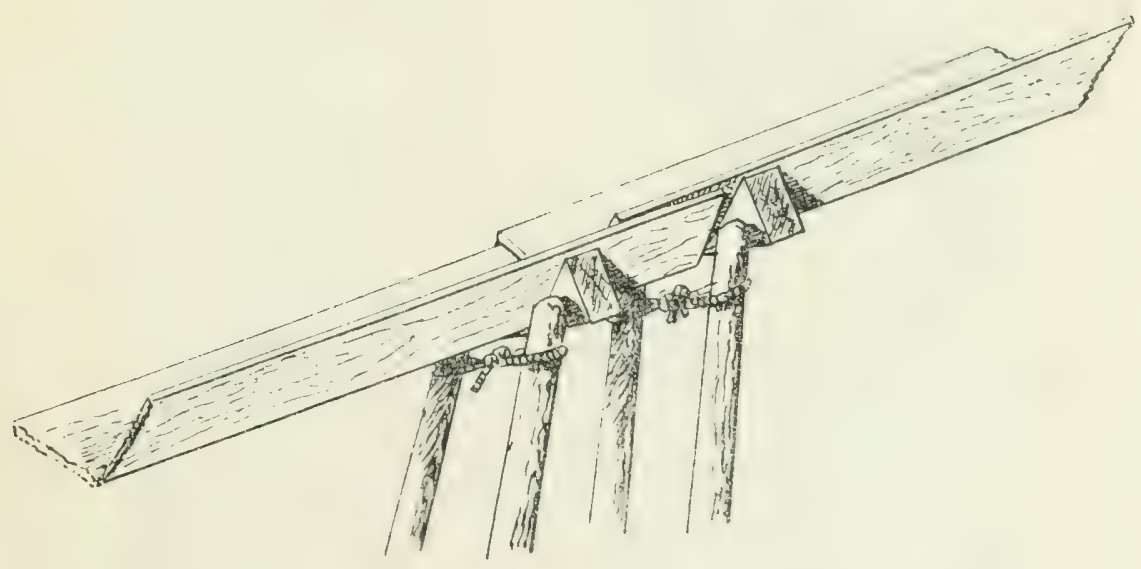

Die Zusaminenfügung der Joche der transportablen Riese.

der untern Innenseite des Kanals mit dümnen Buchenbrettern. Die Erstellung wie der Abbruch und das Deplazement dieser Riesen wird von den Holzhauern mit grosser Virtuosität und Leichtigkeit 
durchgeführt. Per laufenden Meter berechnet sich das Aufstellen auf nur Fr. - 20. Der Einwurf des Holzes kann auch hier an rerschiedenen hiefür geeigneten Terrainstellen erfolgen. Die Verwendbarkeit der «Rutschen erstreckt sich auf 3-5. Jahre.

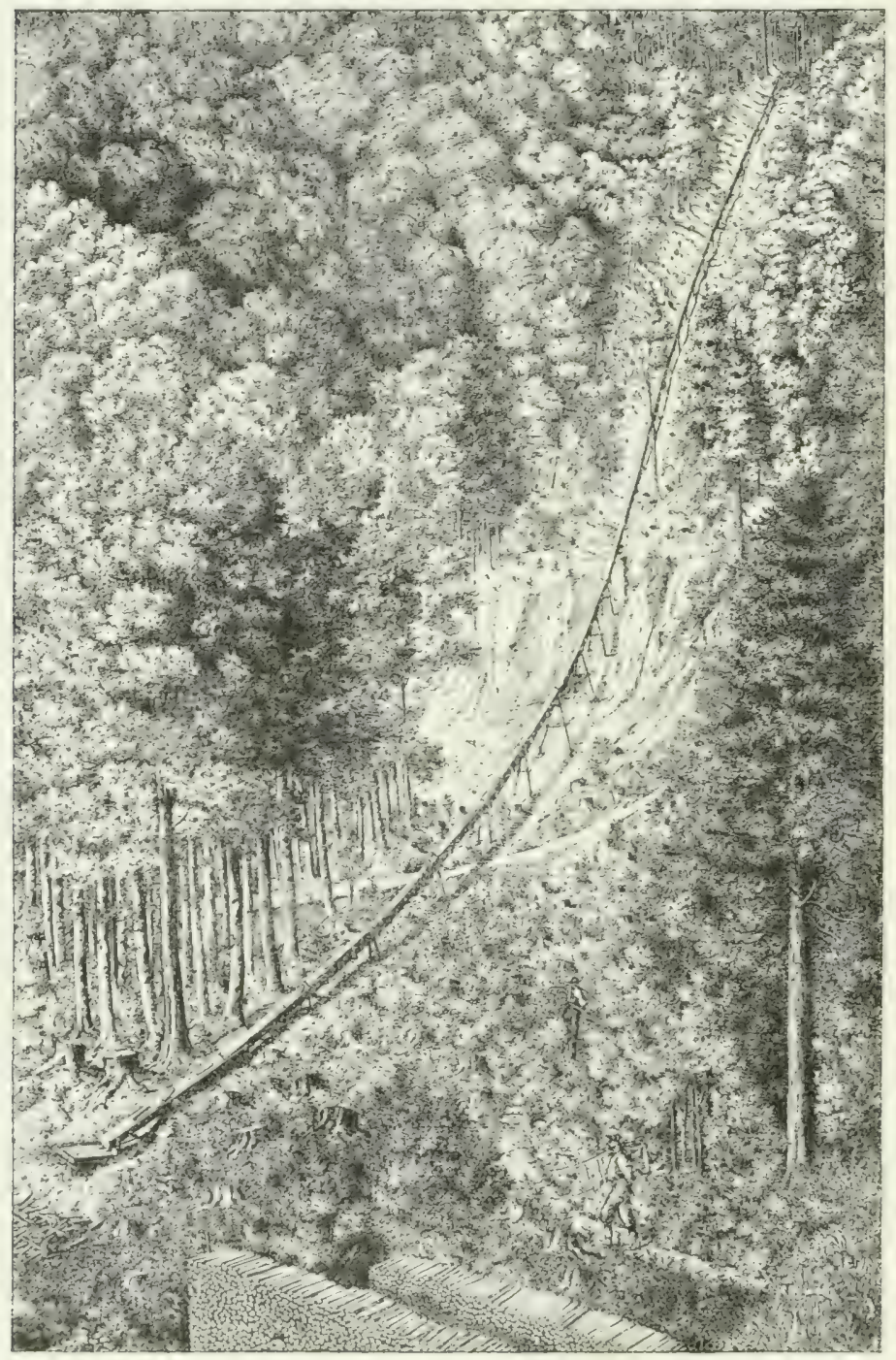

Passagere Brennholzriese. 
c) Die Seilbahn.

Die beiden erörterten Holzriesensysteme haben bei aller Vorzüglichkeit die Schattenseite, dass sie nicht geeignet sind, den Massentransport des Wellenmaterials zu vernitteln. Sowohl für die grossen Reisigwellen von $85 \mathrm{~cm}$ Länge und $1 \mathrm{~m}$ Umfang, wie für die kleinen Reisigbüschel von 50 cm Länge und s)(l (mI Tmfang, beide mit Draht gebunden, versagen die Riesen ihren Dienst. Bei der vollständigen Aufarbeitung des Materials und dem grossen Unfang der Durchforstungsarbeiten ist aber das sich ergebende Wellenquantum ein so bedeutendes, dass eine billige und rechtzeitige Ausbringung desselben im höchsten Interesse der Wirtschaft liegt. Soweit die Rollbahnen den Transport zu vermitteln vermögen, kann dieser Anforderung entsprochen werden; wo dagegen der Transport durch Riese seinen Anfang nimmt, musste vordem zu einer kostspieligeren 'Transportart, sei es mit Schlitten oder Karren geschritten werden. Langjährige Bestrebungen und Versuche, diesem Uebelstande abzuhelfen, führten endlich dazu, ein Transportsystem ausfindig zu machen, welches sich an dasjenige der stabilen Holzriese anschliesst, dieselbe hiefür verwendbar macht und nach jeder Richtung hin befriedigende Leistungen aufzuweisen vermag.

Das System beruht auf der Anwendung des Prinzips der Drahtseilbahn, unter Benützung der Holzriese zur Leitung des Fahrmaterials. Statt der seitlichen Ausweichung der an dem Drahtseil sich auf- und niederbewegenden Wagen (Schlitten), tindet eine solche in vertikaler Richtung statt. Die Holzriese wird zur Leitung der Wagen dienlich gemacht, indem über die oberen Jochenden zu beiden Seiten des Kanals Rundhölzer von $10-12 \mathrm{~cm}$ Dicke als Leitungsstangen aufgelegt und befestigt werden. Das auf diesen sich fortbewegende Fahrmaterial, schlittenartige, solid konstruierte Holzgestelle mit Querkufen, hat in letzteren Einschnitte, die dem Querschnitt der Leitungshölzer entsprechen, sodass der Schlitten genötigt ist, denselben zu folgen. Ein über zwei Rollen führendes Drahtseil verbindet den beladenen und den leeren Schlitten. Wenn sich nun der beladene Schlitten zufolge der Wirkung der Schwerkraft abwärts bewegt, so zieht er gleichzeitig den leeren Schlitten aufwärts, und zwar mit der durch die Bremsvorrichtung. welche mit den Rollen in Verbindung steht, zu regulierenden Geschwindigkeit. Nähern sich die beiden Schlitten der Bahnmitte. so verläisst der leere Schlitten das Geleise (Fig. A), indem er auf die über dem- 
selben angebrachten Leitungsstangen übergeht und sich auch anf denselben bis zum Balancepunkt aufwärts bewegt. Der beladene Schlitten passiert inzwischen die Bahnmitte. Wie der leere Schlitten am Seil weiter rorwärts gezogen wird. drückt er durch sein Gewicht das balancierende obere Geleise auf das untere und auf diesem vollendet er dann seine Bahn aufwärts, bis der beladene Schlitten an der Endstation Halt macht und damit den leeren Schlitten

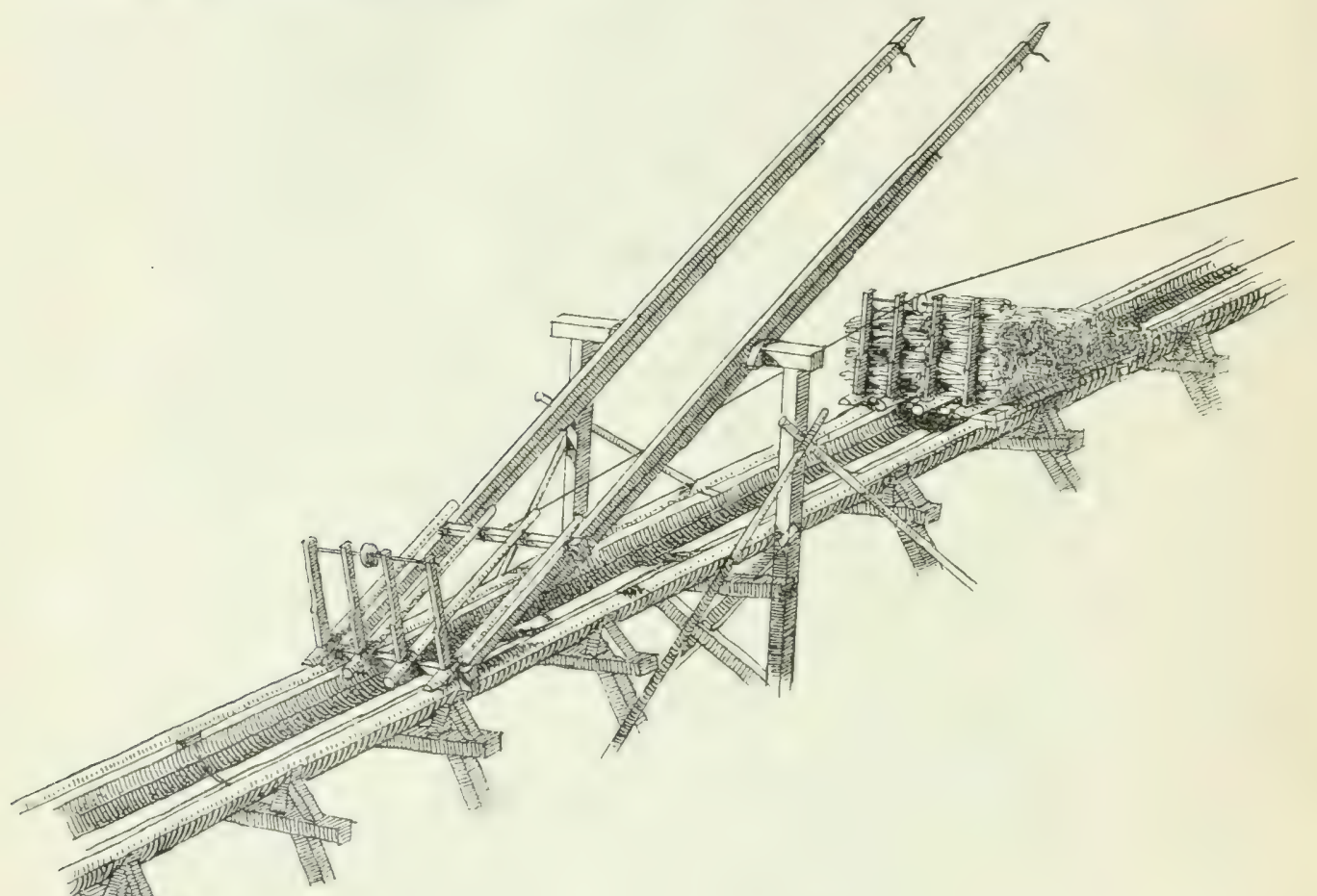

Figur A.

Genfalls zum Stillstand bringt (vide Tafel XVI). I hie balancierenden Leitungsstangen sind indessen zufolge ihres Lebergewichtes auf der untern Seite in die ursprüngliche Lage zurückgegangen. Der volle Schlitten wird unten entladen, der obere neu beladen und der Transport kann wieder seinen Fortgang nehmen.

Die bisher mit diesem neu und noch nirgends anderswo eingefiuhrten Transportsystem gemachten Frfahrungen gestatten, liassellhe als ein leistungsfähiges zu bezeichnen. Der Wellentransport vollzieht sich mit demselben ohne. Schädigung des Materials in raschester 


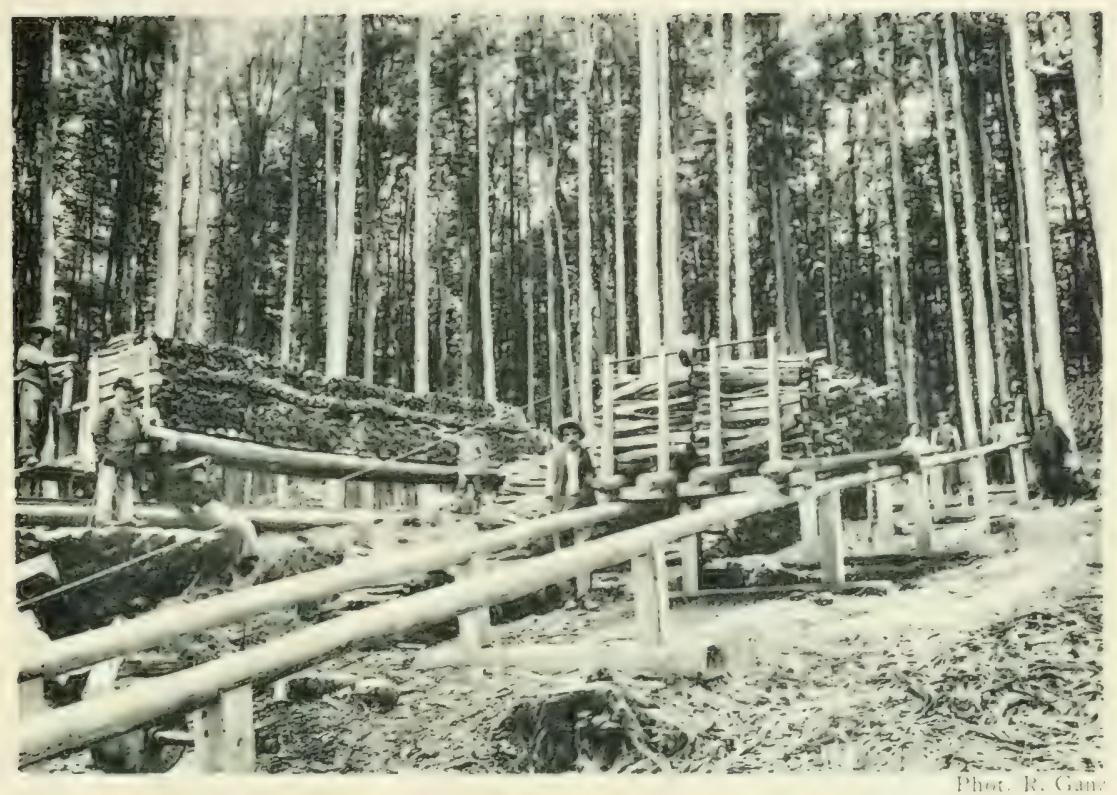

Wellentransport mit Walibahn und Drahtseilbahn.

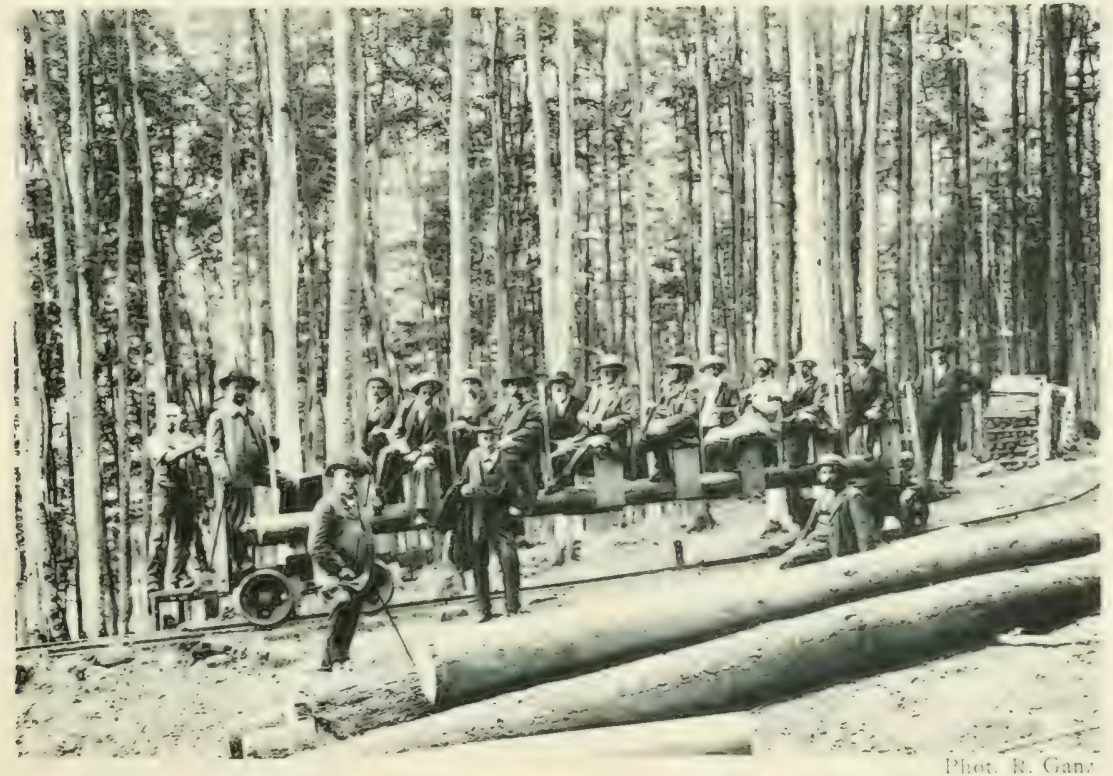

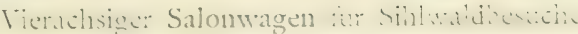




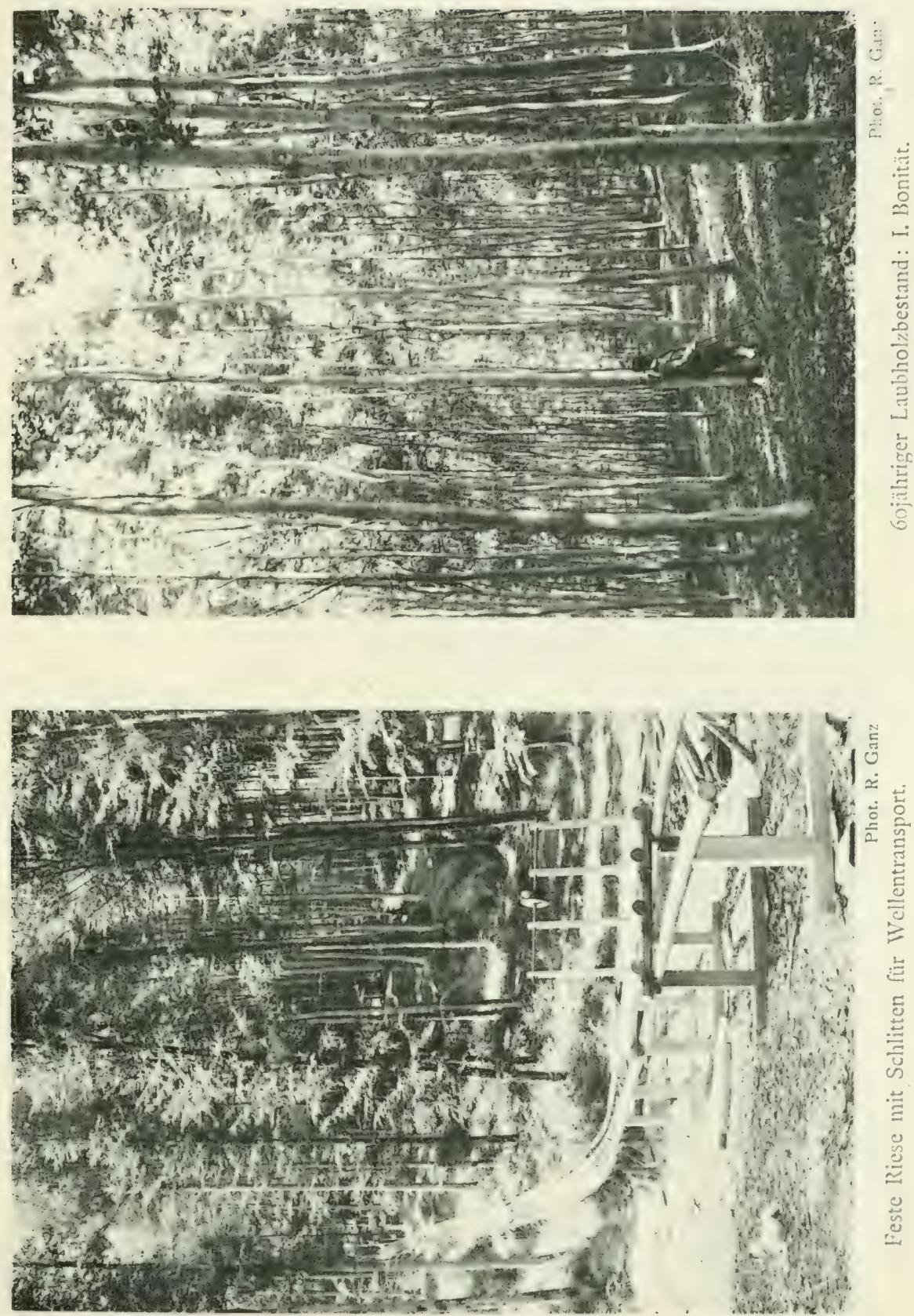

Weise. Die Erstellungskosten sind relativ gering, unter allen Umständen kleiner als bei der Drahtseilriese. wie auch die Transportkosten selbst. Die Holzriese wird dabei in keiner Weise beschädigt und ihrer Zweckerfüllung jeweilen nur während der bauer des Wellentransportes entzogen. Tehrigens lässt sich die Seilhahn auch für den Stammholztransport verwenden: wohl mit forteil heim Transport wertvoller Stammholzsortimente, welche man vor den Beschädigungen sichern will, die beim Transport durch Holzriese nicht ausgeschlossen sind.

\section{Uebrige Hïlfsmittel für den Holztransport.}

Eine für jede Witterung, Jahreszeit und Bodenverhältnisse eingerichtete Holzausbringung bedarf solbstverständlich noch weiterer Hülfsmittel als der Waldeisenbahnen und Riesen. Sie wird sich des Wagentransportes bedienen, wo vorhandene Strassen denselben

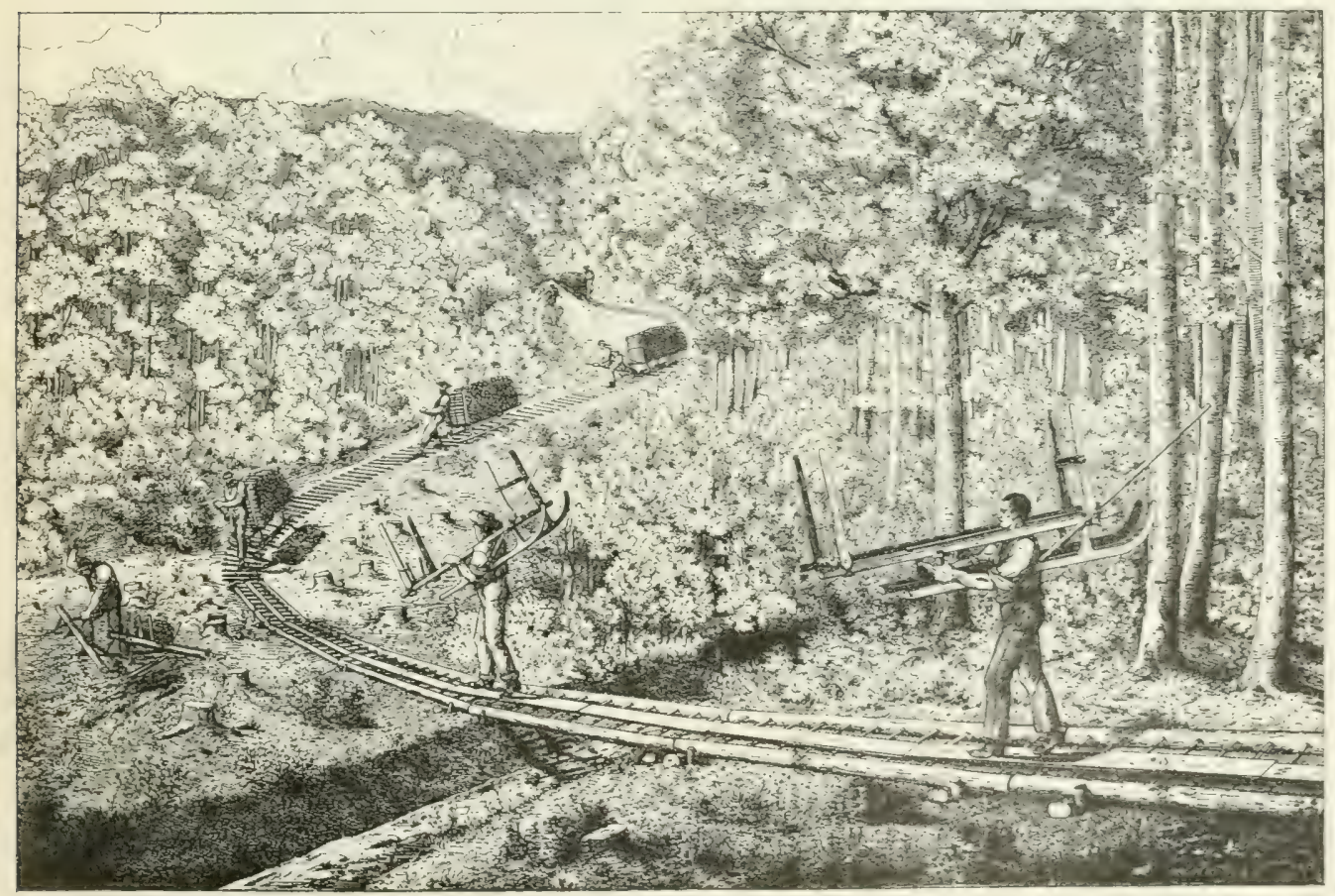

Prügelweg-Schlittbahn in Verbindung mit Leiter-Jochen.

W. v. Steint. - 
empfehlenswert erscheinen lassen; sie wird die Schneebahn benützen. wenn eine solche von der Jahreszeit geboten wird. Wagen und Schlitten sind deshalb auch für den Sihlwaldbetrieb unent-

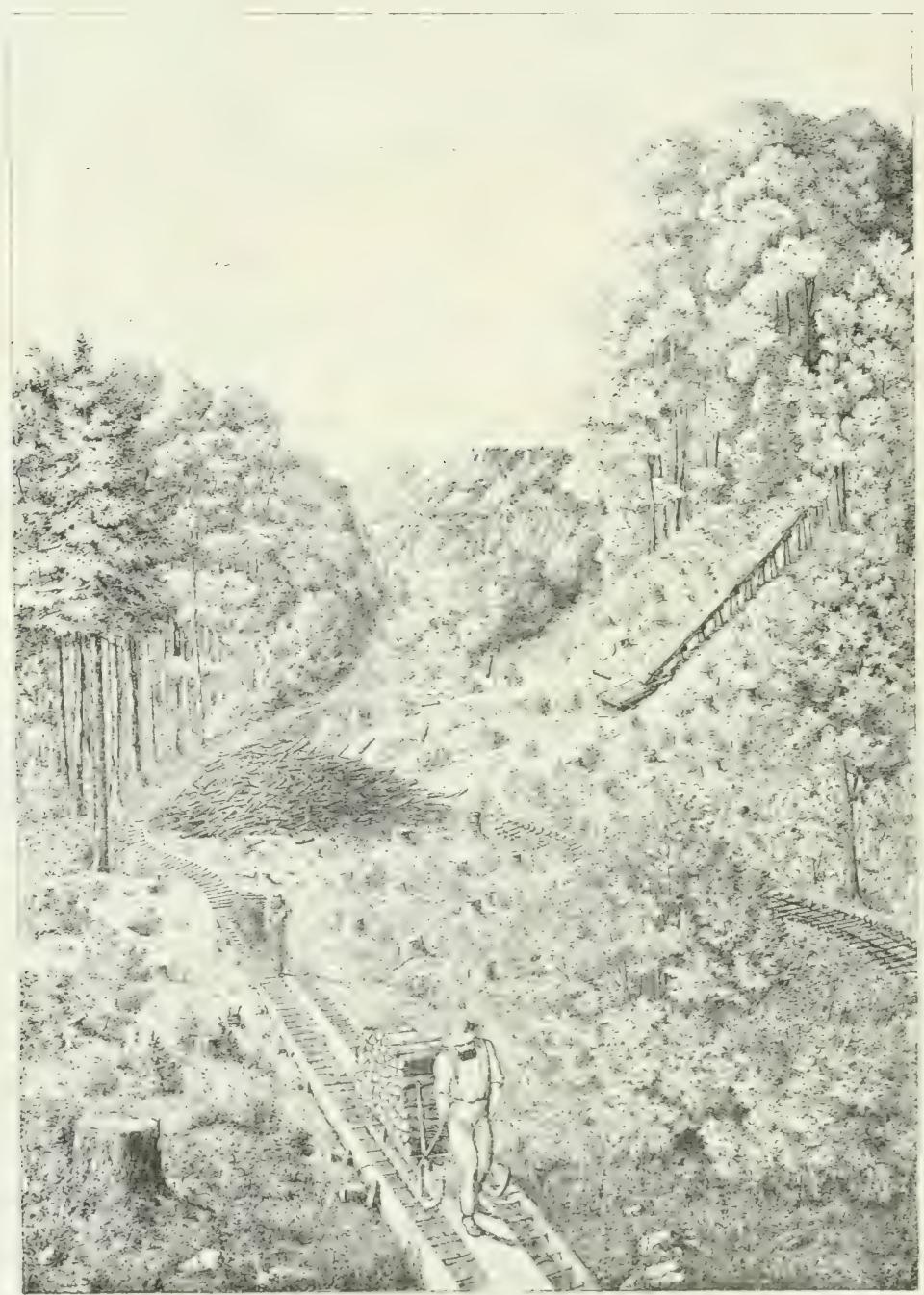

Auswurf der Brennholzriese und Sommer-Schlittweg-Transport.

behrliche Huilfsmittel. Die im Sihlwald zur Verwendung gelangenden Wryen und ihre Ladeart entsprechen den hiefür allgemein üblichen Typen, sodass eine nähere Beschreibung derselben nicht 
notwendig sein dürfte. Der seit Jahrhunderten im Sihlwald gebräuchliche Handschlitten ist dem gebirgigen ('harakter des Terrains angepasst; er hat ein Gewicht von $50 \mathrm{~kg}$, sodass der Arbeiter imstande ist, denselben auf den Schultern bergwärts zu tragen. Eine Unterlagkette ermöglicht dem Schlitter die Bremsung bei steiler Bahn; eine zwei Meter lange an der rechtseitigen Kufe befestigte Stange dient zum Lenken des Schlittens, der ausschliesslich zum Brennholztransport verwendet wird. Seit der Einführung des Bahnbetriebes wird er wesentlich zum Rücken an die Linie verwendet. Bei schneefreiem Boden wird seine Verwendung durch Unterlegen von Astwerk ermöglicht. Bachübergänge, kleinere Einschnitte überhaupt, werden durch das Mittel fliegender Brücken in der Form etwa acht Meter langer und ein Meter breiter, starker Leitern passierbar gemacht (vide Fig. pag. 175 und 176). Neben dem Handschlitten wird für das Rücken des Brennholzes noch der Handkarren verwendet. Derselbe unterscheidet sich von den sogenannten Schiebkarren durch kleinere Dimensionen und geringeres Gewicht $=16 \mathrm{~kg}$, sodass er vom Arbeiter ohne starke Belästigung bergwärts getragen werden kamn. Für das Rücken des Stammholzes ist im Sihlwald der sogenannte Bockschilitten gebräuchlich. Gegenüber dem früher verwendeten Lotbaum ist dieses Transportmittel für die Schonung der natürlichen Verjüngung für alle Jahreszeiten, wie auch vom Standpunkte der Leistungsfähigkeit aus betrachtet, empfehlenswert. Die sogenannten «unpfleglichen Rückermethoden» sind im Sihlwaldbetrieb längst ausgeschieden. 


\section{VII. \\ Die Holzernte.}

\section{A. Allgemeine Betrachtungen.}

Auch bei dem der Kategorie der Urproduktion angehörenden Gewerbe der Forstwirtschaft tritt die Erzeugung möglichst hoher Erntewerte in die vorderste Reihe der an den Gewerbebetrieb gestellten Anforderungen. Allerdings sind der Forstwirtschaft ausserdem meist noch andere Zweckbestimmungen zugewiesen. Einfluss auf die Gestaltung des örtlichen Klimas, Sicherung der Bodenoberfläche, Regulierung der hydrographischen Verhältnisse und nicht zum wenigsten die Mitwirkung auf den ('harakter des Landschaftsbildes in ästhetischer Beziehung - all das wird von der Waldwirtschaft in bald geringerem, bald grösserem Umfange verlangt. Bei einer Waldung, welche wie die Stadtwaldung von Zürich eine tausendjährige Geschichte hat, welche vermöge ihrer Lage und Gestaltung einerseits den landschaftlichen Reiz erhöht, anderseits unzweifelhaft auch auf die klimatischen und hydrographischen Verhältnisse der Gegend regulierend einwirkt, spielen diese den Forstbetrieb neben seinem Erwerbszweck begleitenden Aufgaben eine nicht unwesentliche Rolle. Sie lassen sich aber nicht im Ernteertrag ausdrücken, sie sind nicht messbar; messbar ist nur der aus der Holzernte erzielbare Reinertrag. Diesen so hoch als möglich zu gestalten, unter gleichzeitiger Berücksichtigung der übrigen Faktoren, ist neben den wirtschaftlichen Massnahmen im allgemeinen vorab auch abhängig von der Art der Durchführung der Holzernte.

Die Verschiedenartigkeit des Waldbesitzes nach seiner Grösse und Lage, nach dem Charakter der Waldbesitzer: ob Fiskus, Gemeinde, Privatpersonen, schliesst von vorneherein die Aufstellung eines einheitlichen, gleichartigen Ernte-Modus aus; insbesondere 
mit Bezug auf die Art der Verwertung der Ernte oder der Waldprodukte. Dagegen darf und muss konstatiert werden. dass doch für eine rationelle Durchführung der Holzernte eine Reihe allgemein wirtschaftlicher und nicht bloss rein forstlicher Gesichtspunkte massgebend sind. Wenn in früherer Zeit und an vielen Orten noch jetzt das forstliche Gewerbe als ein gesondertes, von den übrigen Gebieten der Volkswirtschaft scharf ausgeschiedenes aufgefis st wird, so macht sich heute in überwiegendem Masse die Erkenntnis geltend, dass die Forstwirtschaft sich nicht ausserhalb der in Handel und Verkehr im allgemeinen Beachtung findenden Richtlinien bewegen darf. Das Angebot muss sich mehr denn früher der Nachfrage und den durch diese gestellten Anforderungen anjassen. Die forstpolizeilichen Rücksichten sind für sie nicht ausschlaggebend, sie akzeptiert dasjenige Angebot, das ihr nicht bloss dem Preise nach, sondern auch mit Bezug auf anderweitig in Betracht fallende Faktoren das zusagendste ist.

Die Verwertung der Waldprodukte ist im grossen und ganzen abhängig von der Art und Weise, wie sie auf den Markt gebracht werden. Diese steht in engstem Zusammenhang mit dem Umfang des Marktgebietes, das für ihre Aufnahme geschaffen werden kann. Die Verbesserung der Verkehrsverhältnisse hat auch für das forstliche Gewerbe ungeahnte Veränderungen herbeigeführt, sie hat dasselbe in der V erwertung seiner Produkte vom eng begrenzten, nächstliegenden Marktgebiete unabhängiger. sie hat das Angebot konkurrenzfähiger gemacht, dabei allerdings auch den Schattenseiten der Konkurrenz Tür und Tor geöffnet.

Die Entwicklung des Transportwesens und Hand in Hand damit die Fortschritte in der Holzverarbeitungstechnik haben die Möglichkeit geschaffen, die Waldprodukte. gestützt auf vorangegangene Transformation in konsumfähigen Zustand auf ein von der Produktionsstelle weit entferntes, für den Absatz günstigeres Marktgebiet zu werfen. Die Transportdistanz und die damit in Zusammenhang stehenden Spesen spielen hiebei angesichts der durch den Verarbeitungsprozess herbeigeführten Gewichts- und Volumen-Verminderung eine weniger in Betracht fallende Rolle. Kann für die anlässlich der Terarbeitung sich ergehenden Abfälle cin nächstliegentes Marktgebiet, bezw. eine direkte Abnehmerschaft gefunden werden, und beschränkt sich die Umwandlung der Rohprodukte und deren Versand nur auf diejenigen Teile, für die das entfernte Narktgebiet eine günstigere Abnehmerschaft bietet - dann entspricht der Ver- 
wertungsmodus den Anforderungen eines kommerziellen Betriebes. Diesen Charakter hat wohl die heutige Forstwirtschaft anzunehmen. wenn sie im wahren Sinne des Wortes eine Wirtschaft des höchsten Reinertrages sein will und gleichwertig anderen Betrieben dastehen soll. Von dieser Auffassung ausgehend sucht der städtische Forstbetrieb seine Holzernte anzubahnen, um sich zum intensiven zu gestalten. Wie in der Bestandespflege, so will er auch in der Bestandesernte individualisieren und nicht generalisieren.

Die Holzernte ist nach dem Vorangestellten nicht der einfache wirtschaftliche Prozess, als welcher er vielfach noch betrachtet und durchgeführt wird. Sie zerfällt in verschiedene Einzelaufgaben, die unter sich im engsten Zusammenhang stehen. Wir unterscheiden:

1. die Holzaufarbeitung im Wald,

2. die der Verwertung vorangehende weitere Zurichtung und Verarbeitung,

3. die eigentliche Verwertung,

4. die Bemessung des quantitativen Ertrags der Holzernte.

Bevor auf die Detailbetrachtung dieser vier Phasen der Holzernte eingetreten wird, dürfte es angezeigt sein, noch auf zwei liomente hinzuweisen, welche als charakteristische Erscheinungen der heutigen Wirtschaftspolitik im allgemeinen auch im forstlichen Gebiet ihre Beachtung gefunden haben.

Die früher allgemein herrschende Ansicht, es seien öffentliche Personen, wie der Staat, die Gemeinden oder die Korporationen, nicht geeignet, an dem produzierten Rohmaterial eingehende Veränderungen zum Zwecke der besseren Verwertung vorzunehmen, hat einer anderen Auffassung Platz gemacht. Man ist nicht mehr der einseitigen Ansicht, dass nur das private Kapital und die private industrielle Ansnützung desselben lohnenden Betriehsertrag zu schaffen imstande ist. Die Erfahrung zeigt, dass Betriebsunternehmungen, geschaffen oder gestützt durch öffentliche Personen, nicht weniger prosperieren als Privatbetriebe, sobald erstere von Persünlichkeiten geleitet werden, die mit Bezug auf Intelligenz und Geschäftstüchtigkeit den gestellten Anfordermngen Genüge zu leisten vermögen, wenn ihnen die nötige Aktionsfreiheit gewährt ist, und die erforderlichen Betriebsmittel zur Verfügung gestellt sind.

Neben dieser neuen wirtschaftlichen Strömung tritt die Forderung vermehrter Arbeit immer dringender an das forstliche Gewerbe heran. Das grosse Produktionsgebiet, welches demselben zur Verfügung gestellt ist, bietet bisher für die menschliche Tätig- 
keit nur eine karge Verwendung. Die sich überall bemerkbar machende Ausdehnung des der Waldwirtschaft zugewiesenen Areals ist dazu angetan, diese Schattenseite zu einem fühlbaren Uebelstand im staatlichen Leben herauszugestalten, sofern die Forstbetriebe nicht Abhiilfe schaffen.

In der städtischen Forstverwaltung haben diese beiden Momente seit Dezennien eine den lokalen Verhältnissen entsprechende $\mathrm{Be}$ achtung gefunden und zwar nicht zum Nachteil des WaldernteErgebnisses.

\section{B. Die Holzverarbeitung im Walde.}

Die Fällung und Aufarbeitung des Holzmaterials in seinen verschiedenen Altersstufen vom 10. bis zum 100. Jahr ist nicht dazu angetan. dem Maschinenbetrieb eine Rolle zuzuweisen. Lemzufolge vollziehen sich diese Arbeiten wie schon frïher so auch heute noch durch persönliche Arbeitsleistungen, teils im Akkord. teils im Regiebetrieb; im Sihlwald ist letzterer vorherrschend. Der Umstand, dass hier ein ständiges Arbeiterpersonal zur Verfügung steht und dass ron seiten des Terarbeitungshetriebes die verschipilenartigsten und wechselndsten Anforderungen an den Sortimentshedarf gestellt werden, verlangt vollste Dispositionsfreiheit in der Arbeitszuweisung.

Die Tag- und Akivordlöhne haben im Verlaufe der zwei letzten Dezennien im Anschluss an die allgemeine Lohnsteigerung eine bedeutende Erhöhung erfahren, was aus nachstehenden Zahlen hervorgeht:

$1880 \quad 1900$

Fr. Fr.

$\begin{array}{rrrr}\text { Akkordlohn per Festmeter Bau- und Nutzholz } & 1.00 & 1.20 \\ & \text { Ster Einmeter Brennholz } & 1.50 & 1.80 \\ & \text { Ster Halbmeterholz } & - & 2.40 \\ 》 \quad 100 \text { Stück grosse Wellen } & 8.00 & 12.00 \\ & & & 5.00\end{array}$

Taglolen der Waldarbeiter

$3.00-3.40 \quad 3.60-4.20$

Der Akkordarbeiter hat sein eigenes Geschirr zu verwenden; für die Regiearbeit im allgemeinen, nicht nur für die Holzhanerei. liefert das Materialdepot der Forstverwaltung das nötige Geschirr. 
Für das gesamte Arbeiterpersonal hesteht seit 1876 eine Krankenund eine Unfallversicherung.

Die Sortimentsausscheidung, soweit sie dem Holzhauereibetrieb zufällt, zielt wesentlich daraufhin, die Nutzholzausbeute möglichst auszudehnen, beim Nadelholz sowohl wie bei den verschiedenen Laubholzarten, beim Durchforstungsbetrieb wie bei den Hauptnutzungen. Sie beginnt schon bei den Reinigungen der Jungwüchse mit der Gewinnung von Reisigmaterial fiir Besenfabrikation, bei den Aufästungen der Weisstannen für Deckreisig und setzt sich in den Laub- und Nadelholzbeständen der verschiedenen Altersstufen durch Entnahme des für diverse Verwendungszwecke verlangten Materials fort, speziell mit Bezug auf die für die vorhandenen Imprägnierungsinstallationen verwendbaren Sortimente. Allgemein wird hiebei darauf gehalten, dieses Material dem Verarbeitungsbetrieb als Ganzes zu liefern, damit er die intensive Ausnützung aller einzelnen Teile und auch der Abfälle, je nach dem Bedarfsfall, vornehmen kann. Die zur Verarbeitung in die Säge gelangenden Stammhölzer irgend einer Art werden im allgemeinen in die Längen von 5 oder 6 Meter gebracht.

Das Brennmaterial wird ausgeschieden in Scheiter von 1 Meter Länge bei über $15 \mathrm{~cm}$ Durchmesser und beim Laubholz in Halbmeter-Scheiter für das Material von $10-15 \mathrm{~cm}$ Durchmesser. Das Prügelsortiment wird nur beim Nadelholz ausgeschieden. Beim Laubholz ist seit Jahrhunderten des leichtern Austrocknens halber das Spalten der Prügel, vor Einführung des Metermasses in zwei Fuss, nunmehr $50 \mathrm{~cm}$ lange Scheiter, üblich. Das Aufschichten des Scheiterholzes erfolgt in Klaftern von 3 Ster, $2 \mathrm{~m}$ lang, 1,5 $\mathrm{m}$ hoch; diejenige des kleinen Materials in Beigen von etwa $1 \mathrm{~m}$ Höhe. Ein Zumass ist ausgeschlossen. Das Reisigmaterial wird in zwei Formen aufgearbeitet; in die kleinere, die sogenannten Bürdeli, gelangt das schwächere Jurchfor'stungsmaterial. soweit es sich nicht zu Nutzholzzwecken verwenden lässt, und das schwächere Reisig des Astholzes älterer Bäume. In die grössere Form, in die Wellen, gelangt das ausgeschneiselte Material bis zur Stärke von $10 \mathrm{~cm}$. sümtliche Wellen werden auf dem Wellbock mit Draht gebunden. I)amit nur Draht von ausreichender Stärke zur Verwendung gelangt. hat der Holzhauer denselben von der Forstverwaltung gegen Vergütung der Anschaffungskosten zu beziehen.

Bei dem als Nutzholz unaufgearbeitet dem Walde entnommenen Stammholzmaterial aller Sortimente findet das Ausmass mit der 
Rinde statt, analog dem Vorgehen bei den Zuwachs- und Massenermittlungen der Bestände zu taxatorischen Zwecken.

Zufolge der während 25 Jahren gemachten Eiffahrungen liegt alle Veranlassung vor, einer systematisch und korrekt durchgeführten Aufarbeitung und Aufschichtung des Bremmaterials vollste Aufmerksamkeit zuzuwenden. wemn Missverhältnisse zwischen Etatsfestsetzung und Etatsnutzung vermieden werden wollen. Bei der städtischen Forstverwaltung, wo der Etat Derbholz und Reisig umschliesst, ist dies in doppeltem Masse der Fall. Dementsprechend wird der Ermittlung der Reduktionsfaktoren für die I'eherfiihrung des Raummasses in feste Masse bezw. der Ster und der Wellen in Festmeter, wie der Benutzung genau ermittelter Faktoren besonderes Gewicht beigelegt.

Die beim Abtrieb und der Aufarbeitung haubarer Probeflächen gewonnenen Resultate sind geeignet, die Berechtigung dieser Forderung und die Tragweite unregelmässiger Aufarbeitung zahlenmässig zu belegen. Die vorliegenden Zahlen beziehen sich auf eine 105jährige Probefläche von 1/2 Hektar Grösse.

1. Messungsergebnis des stehenden Holzes, festgestellt durch die forstliche Zentralstation unmittelbar vor dem Schlag a) mit Probestämmen . . . . . . . . . . . 330,75 b) mit Faktor $\mathrm{r}$. . . . . . . . . . . . . 361,00

2. Sektionsweise Messung des liegenden Derbholzes, Gewichtsermittlung des Reisigholzes .

3. Ergebnisse der Aufarbeitung und Ermittlung der festen Masse unter Beilegung verschiedener Reduktionsfaktoren, Scheitholz mit und ohne Zumass.

a) Berechnung mit Zumass und landesüblichem Reduktionsfaktor

$$
\begin{array}{ccccc}
0,70 & \mathrm{~m}^{3} & \text { per Ster } & \text { und } \\
3,0 & \mathrm{~m}^{3} & \text { per } & 100 & \text { Wellen } \\
& & \mathrm{m}^{3} & \mathrm{~m}^{3}
\end{array}
$$

Stammholz

Scheitholz 354 Ster mit $10 \mathrm{~cm}$ Zumass à $0,70=247,80$

Waldscheitli 9 Ster mit Zumass . . à $0,70=6,30$

Grosse Wellen 812 Stück . . . . à $3,00=24,36$

Kleine Wellen 2105 Stück ․ . à $0,50=10,53$

Summa 296.84

b) Aufschichtung ohne Zumass, Berechnung nach den xylometrisch festgestellten Reduktionsfaktoren: 


$$
\begin{array}{llll}
0,6977 & \mathrm{~m}^{3}=0,7 \mathrm{~m}^{3} & \text { per Ster } \\
3,61 \mathrm{~m}^{3} & \text { per } 100 \text { Wellen } \\
0,45 & \mathrm{~m}^{3} & \text { per } 100 & \text { Bürdeli } \\
& & \mathrm{m}^{3} & \mathrm{~m}^{3}
\end{array}
$$

Stammholz . . . . . . . 7,85

Scheitholz 389 Ster . . . à $0,70=272,30$

Traldscheitli o Ster . . . . . a $0, \pi 0=6, \ldots 0$

Grosse Wellen 812 Stück . . a à $3,61=29,31$

Kleine Wellen 2105 Stück . . a à $0,45=9,19$

Summa 325,25

Per Hektar bezogen, stellen sich diese verschiedenen Berechnungs- und Messungsverhältnisse wie folgt:

$\mathrm{m}^{3}$

1. Stehendes Holz nach Probestämmen berechnet . . 661,50

2. Stehendes Holz nach Faktor $\frac{V}{G}$ berechnet . . . . 722,00

3. Sektionsweise Messung des liegenden Holzes . . . 653,30

4. Aufarbeitungsergebnis mit Zuschuss und landesüblichem Reduktionsfaktor . . . . . . . . . . . . . 593,68

๖. Aufarbeitungsergebnis ohne Zumass und xylometrisch festgestellten Reduktionsfaktor . . . . . . . 650,50

Es geht daraus hervor, welch grossen Täuschungen man sich bei der pünktlichsten Etatsnutzung hingeben kann, wenn Aufarbeitung und Buchung des Schlagmaterials divergieren. In der Regel wird mehr geschlagen, als tatsächlich gebucht wird.

Von nicht minderem Interesse und von Bedeutung für das Gelderträgnis des Waldes ist die Art und Weise der Sortimentsausscheidung des Schlagmaterials. Betrachten wir zunächst die Verhältnisse beim Brennholz. Welche Dimensionen sollen bei dieser Ausscheidung massyebend sein. damit hei den Aufarbeitungskosten. die je nach dem Sortiment voneinander abweichen, die günstigste Verwertung des Materials erzielt werde? Hierüber angestellte Untersuchungen ergahen nachfolgendes Material zur Beantwortung dieser Frage.

1. Scheiterholz.

Es betragen:

Per ster Per $m^{3}$ t'otal p. $m^{3}$

Aufarbeitungskosten . . . . . . . . . . $1.80 \quad 2.57$

Transportkosten an Strasse oder Talbahn . . 1.50 2.14 4.71

Es rerwertet sich an der Lagerstelle angenommen der Ster ì Fr. 12.- 17. -

Nettoergebnis der Aufarbeitumg des Bremmaterials in Scheiterholz . 12.29 
2. Halbmeterscheiterli.

(Aufarbeitung des über $6 \mathrm{~cm}$ starken Brenmmaterials.)

Es betragen:

Per Ster Per $m^{3}$ Total p. m $^{3}$

Aufarbeitungskosten

fir. Fr. Fr.

Transportkosten an Strasse oder T'albahn

2. $40 \quad 3.43$

1. $60 \quad 2.30$

5. 7.9

Es verwertet sich der Ster it Fr. 11.-

15. 71

Nettoergebnis der Aufarbeitung in Halbmeterscheiterli.

9. 98

3. Wellen.

(Aufarbeitung des unter $6 \mathrm{em}$ starken Materials.)

Die Erstellungskosten betragen:

P. 100 Stek. P'er $\mathrm{m}^{3}$ T'totil P. m Fr. Fr.

Fr.

Abhauerlohn zwischen $0-3 \mathrm{Fr}=$

$1.50 \quad 0.42$

Aufarbeitungskosten .

12. - 3.3:-

Transportkosten an Talstrasse oder Bahu . . 7.50 2.08

5.82

Es verwerten sich an der Strasse 100 Wellen à Fr. 48.-

13. 28

Nettoergebnis der Aufarbeitung in Wellen.

7.46

4. Biirdeli.

(Aufarbeitung des schwachen Reisigmaterials.)

Die Erstellungskosten betragen:

P. 100 Stek, Per $m^{3}$ Total p. $m^{3}$ Abhanerlohn Fr. $0-1.50=\ldots .+.75 \quad$. . . . . . . . . 1.66

Aufarbeitungskosten . . . . . . . 5.- 11.10

Transportkosten an Stralsse . . . . . . . 1.50 3. 39 16.09

Es verwerten sich an der 'Talstrasse 100 Bürdeli ì Fr. 10.- . . . 22. 22

Nettoergebnis der Aufarbeitung in Bürdeti . . . . . . . . . 6.13

Aus diesen Zahlen geht zunächst hervor, dass die Aufarbeitung des Reisigmaterials in seiner Totalität für die Geldertragsverhältnisse von grösster Bedeutung ist. Lokale Neigungen mögen das ihrige dazu beitragen, dass die Abnehmerschaft des städtischen Wellenmaterials demselben ein besonderes, anderwärts vielleicht nicht vorhandenes Wohlwollen entgegenbringt. Doch dürfte die völlige Aufarbeitung dieses Materials auch bei ungünstigeren Absatzverhältnissen schon deshalb zu empfehlen sein, weil einzig dadurch die genaue Buchung der Erträge eines Waldes von der Bestandesgrïndung $a b$ bis zum durchgeführten Abtrieb möglich gemacht wird.

Die Differenz zwischen der Aufarbeitung in Halbmeterscheiterli (Prügelholz) oder in Wellen ist nicht sehr gross. Bei Annahme der in Rechnung gesetzten Verwertungspreise, die als solche dem gegenwärtigen Markt entsprechen, wird der Holzhauereibetrieb sein 
Augenmerk darauf zu richten haben, dass die Wellenaufarbeitung nicht allzu schweres Material zur Verwendung zieht. Umgekehrt kann allerdings der Fall eintreten, wo das Wellenmaterial gesuchter ist als dasjenige der Scheiter und dannzumal wird eine Bevorzugung der Wellen in der Aufarbeitung angezeigt sein. Aehnliche Schwankungen können stattfinden zwischen Nutzholz- und Brennholzmarkt; auch hier legen die Verhältnisse des Marktes den Forstrerwaltungen die Iufgabe nahe. ihre Sortimentwasscheidungen den Konjunkturen desselben anzupassen. Im allgemeinen sind die Schwankungen des Marktes, sowohl mit Bezug auf Qualität als auf Quantität seines Bedarfes grösser, als man gewöhnlich anzunehmen geneigt ist; sie können bald zum vermehrten Aushalt von Nutzholz, bald zur Begünstigung des Brennholzes hinweisen. Den heutigen Terhältnissen entsprechend, richtet die Holzaufarbeitung mit Bezug auf die einzelnen Holzarten, wie sie in den Bestandesmischungen der stïdtischen Taldungen vorkommen. ihr Augenmerk auf die nachstehenden Sortimentsausscheidungen, sowohl bei den Durchforstungen als bei den Hauptnutzungen.

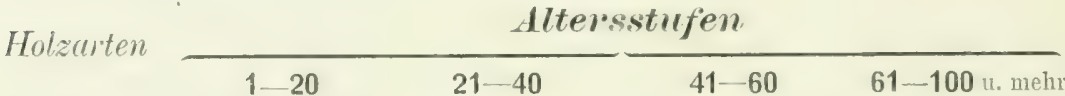

Fichte: Käfenstickel Zaumaterial 'T'elegraphenstg. Bauholz

Bohnenstangen I Leiterstangen Stangen f.elekt. Schnittwaren

Baumstecken Halblattenmat. Starkstromltg. Holzwollemater.

Zaunhälblinge Pfahlmaterial Gerüststangen Schindel-u.Rah-

Pfahlmaterial 'T'elegraphenstg. Holzwollemater. menmaterial

Anlagepflanzen Papierholz

Brennholzmaterial

Bremnholz Astmaterial für Zäune, roh u. geschält

Weisstanne: Obiges Obiges

Deckreisignaterial

Kiefer:

Brennmaterial

Lårche :

Brenmmaterial
Obiges Obiges

Papierholz

Brennmaterial

Telegraphen- Bauholz und stangen Schnittwaren

Schwellen

Brennmaterial

T'elegraphen- Schwellen

stangen Bauholz und

Schnittwaren

Eibe:

Schnitzereimaterial

Pfahlmaterial 


\begin{tabular}{|c|c|c|c|c|}
\hline \multirow{2}{*}{ Holzaiten } & \multicolumn{4}{|c|}{ Altersintufen } \\
\hline & $1-20$ & $21-40$ & $41-60$ & $61-100$ u. mehr \\
\hline Eiche: & \multicolumn{2}{|c|}{ Wenig vertreten } & \multicolumn{2}{|c|}{$\begin{array}{l}\text { Schwellenmaterial } \\
\text { Konstruktionshölzer } \\
\text { Schnittwaren }\end{array}$} \\
\hline
\end{tabular}

Buche: Kleines n. gross. Wellenmaterial Scheitholy Wagnereimater.

und Welleı Schwellen

Imprägnierte Bodenbelege

Hölzer Holzpflaster

Wagnerei- Riemen

material Imprägn. Artikel

Irehereiartikel Drehereiartikel

Rundstangen

Scheithoiz 11. Wellen

Esche: Stielmaterial Stiel-u.Stangen- Material f. Werkzeugstielfabrik. material für verschiedene Gewerbe
Kleine und grosse Wellen
Wagnereimaterial

Ahorn: Stielmaterial Stiel-u.Stangen- Drehereiartikel, spulen u. Spinmaterial deln f. B'woll- u. Seidenindustrie

Kleine und grosse Wellen Rundstangen

Brennmateria]

Hainbuche: Kleine und grosse Wellen Naturstielmaterial

Wagnereiartikel

Schnittw. f.Mraschinenbestandteile

Werkzeugstiele

Brennmaterial

Ulme: $\quad$ Kleine und grosse Wellen

Wagnereiartikel
Brennmaterial

Birke :

Besenreisig

Kleine und grosse Wellen

Drehereiartikel

Brennmaterial

Gärtnereiartikel

Kirschbaum: Kleine und grosse Wellen Brennmaterial Möbelschreinerei

Erle: $\quad$ Faschinen u.Flechtzaunmaterial

Brennmaterial

Drehereiartikel

Brennmaterial

Akazie:

Brennmaterial

W erkzeugstiele

Wagnereiartikel

Mit der Ausscheidung in vorstehende Kategorien hat die Holzhauerei ihre Aufgabe erfüllt und es reiht sich nun daran die Aufgabe der Verwertung der verschiedenen Sortimente. Ist fuir diese ein aufnahmsfähiges Marktgebiet mit ausreichender Nachfrage in unmittelbarer Nähe vorhanden. so wird der $\mathrm{WVeg}$ der öffentlichen 
Versteigerung gewählt. Dies ist der Fall mit den Produkten des oberhall '/ürich gelegenen Forstbezirkes Adlisberg, dem für bequeme Alfulı ein entwickeltes Strassennetz und für die erforderliche Nachfrage eine entsprechende Käuferschaft zur Verfügung steht. Sind daher, wie sich dies bei den Waldungen im Sihltal zeigt, diese Voraussetzungen nicht vorhanden, so wird der Weg der weiteren Verarbeitung betreten, um dadurch dem Waldprodukte für seinen Absatz ein grösseres Marktgebiet zu verschaffen. Infolge der mehr und mehr sich zeigenden Erscheinung, dass der Konsument von Waldprodukten es vorzieht, seine Bedarfsartikel in der für die direkte Verwendung notwendigen Form und zu der ihm dienenden, von der Steigerungsperiode oft weit entfernten Zeit, beziehen $\mathrm{zu}$ können, ist auch die erste Kategorie der Verwertungsart gerade in städtischen Umgebungen nicht mehr vollständig durchführbar. Eine Reihe von Hauptnutzungs- und Durchforstungsprodukten müssen vom Walde in Lagerräume geschafft werden, von wo aus sie dann nach der Konvenienz der Konsumenten geliefert werden können. Ein anderer Teil wird direkt dem Verarbeitungsbetrieb zugeführt.

Die Verhältnisse des Holzmarktes haben sich speziell mit Bezug auf das Brennholz in den letzten zehn Jahren in unerwartet grossem Umfange zu ungunsten des Systems der Verwertung durch das Mittel der öffentlichen Versteigerung verändert. So ist ganz besonders die Zahl der direkten Käufer von Brennmaterial anlässlich der Steigerungen in raschem Abnehmen begriffen, sodass auch für die so günstig gelegenen Waldungen oberhalb Zïrichs die Auflagerung und die Verarbeitung stetig wächst. Auch auf die Nutzholzsortimente dehnt sich diese Strömung aus, namentlich auf solche, die nicht für Spezialitäten dienen und vom Händler jederzeit in kleinern oder grössern Quantitäten von anderswo per Eisenbahn bezogen werden können. Dem Holzproduzenten steht nur das eine Mittel, konkurrenzfähig zu bleiben, zur Verfügung, er muss dem Konsumenten näher treten, ihm die nämlichen Vorteile bieten, wie der Zwischenhändler. Magazinierung des Materials an leicht zugånglicher Stelle oder Verarbeitung des Holzes zu direkter Verwendung sind die einzuschlagenden Wege. 


\section{Die der Verwertung vorangehende weitere Verarbeitung.}

\section{Zweck und Charakter.}

Bis zum Jahre 1864 wurden die Sihlwaldprodukte, die grösstenteils aus Brennmaterial, grossem und kleinem Scheiterholz und daneben zum kleineren Teile aus Nutzholzstämmen bestanden, auf dem Wege der wilden Flösserei durch den Sihlfluss in die Stadt Zürich als ihren einzigen Absatzort geliefert und dort in unverarbeiteter Form an die Bürger oder an einzelne Verwaltungszweige abgegeben. Der erhöhte Wert, den die Holzprodukte gegen die Mitte des vorigen Jahrhunderts erhielten, liess dieses V'rwertungssystem nachgerade nicht als ein passendes erscheinen. Man entschloss sich von seiten der städtischen Verwaltung, auf Anregung des damaligen Forstmeisters C. v. Orelli, das Brennholz im Sihlwald selbst aufzustapeln und dort anf mechanischem Wege zu zerkleinern und in passender Form den Bezügern zuzuführen. Für die Nutzholzsortimente wie für Sag- und Bauholz wurde ebenfalls die mechanische Verarbeitung in Aussicht genommen. So entstant das Sügereiwerk, die mechanische Dreherei, und die heute noch bestehende mechanische Spalterei, unter Benützung der Wasserkraft der Sihl als Motor. Bis zum Jahre 1875 funktionierten diese Installationen im Pachtbetrieb. Die Pächter waren zur Abnahme des dem Verarbeitungsbetrieb zugewiesenen Materials verpflichtet; der übrige. nicht zur Verarbeitung gelangende Teil wurde direkt im Walde verkauft, teils auf dem Submissions-, teils auf dem Steigerungswege. Mit Beginn der Periode 1875 und dem damit verbundenen Wechsel in der Betriebsleitung der städtischen Waldungen hörte der Pachtbetrieb auf und an dessen Stelle trat der Regiebetrieb, der nun sukzessive bis auf die heutige Zeit die Tendenz verfolgte, einem möglichst grossen Teil der Waldprodukte durch den Verarbeitungsbetrieb die tunlichste Wertsteigerung zu verschaffen.

In Ausführung dieses wirtschaftlichen Programmes wurde der Imprägnierungsbetrieb mit System Boncherie eingeführt. um dadurch einer Reihe von Holzsortimenten, deren Verwertung bisher, der abgeschiedenen Lage wegen, keine günstige war, bessern Absatz zu 
ermöglichen. und im Sägereibetrieb gegenüber dem Import fremrler Ware konkurrenzfähiger zu werden. Zum Zwecke einer angemessenen Verwertung der im Sihlwald sich besonders günstig entwickelnden Eschen und Ahorne wurde Anno 1878 die Werkzeugstielfabrikation mit Maschinenhetrieb eingeführt. sodamn die mechanische Erstellung von Rund- und Rouleaustangen daran angereiht. Für die bessere Verwertung des schwächern Nadelholz-Durchforstungsmaterials wurde eine besondere Abteilung zum Zwecke der Erstellung von Zaunmaterial mit Dämpferei eingerichtet. Es folgte dann die Holzwollefabrikation, zuerst mit einer, dann infolge zunehmenden Absatzes mit mehreren Maschinen. Die Einrichtung einer Holztrocknungsanstalt für die Sägerei- und Dreherei-Artikel bildet den Schluss der bei den vorhandenen Raumverhältnissen möglichen Installationen. Sämtliche Kosten mussten vom Betriebe selbst gedeckt werden, was in Form ein- oder mehrjähriger Amortisationen geschah.

Die ganze Entwicklung dieses Fabrikbetriebes, nicht nur diejenige des technischen, sondern auch die des noch wichtigeren merkantilen Teiles war Aufgabe der Forstrerwaltung. Die Bewältigung dieser Aufgabe ist abhängig von der Gewährung der hiefür notwendigen selbständigkeit der Betriebsleitung und diese wird derselhen von seiten der Oberbehörde in ununterbrochener und weitgehender Weise zuteil. Ohne die von der Leitung eines kommerziellen Betriebes absolut unzertrennbare Freiheit der Aktion lassen sich erspriessliche Resultate nicht mit demselben erzielen; freilich steigert sich damit anch die Verantwortlichkeit der Betriebsleitung und das Mass der an letztere zir stellenden Anforderungen.

\section{Die verschiedenen Abteilungen des Verarbeitungs- betriebes.}

$\mathrm{Zu}$ den einzelnen Verarbeitungsabteilungen übergehend, mag zuerst die mechanische Spalterei (vide Tafel XVIII und XLX) als die älteste und ursprüunglich hedeutendste in Betracht gezogen werden. Sie lat die Aufgahe. das rom Walde gelieferte Bremmaterial so zu verarbeiten. dass der Konsument dasselbe direkt für seinen Zweck beziehen und verwenden kann, für Heizungs- oder Küchenzwecke. Die Fräse zersägt das Brennholzscheit in Stücke von $20,25,33 \mathrm{~cm}$ Länge und die Spaltmaschine zerkleinert nun diese Stücke in der dem Sortiment entsprechenden Art und Teise. Das gespaltene Material 


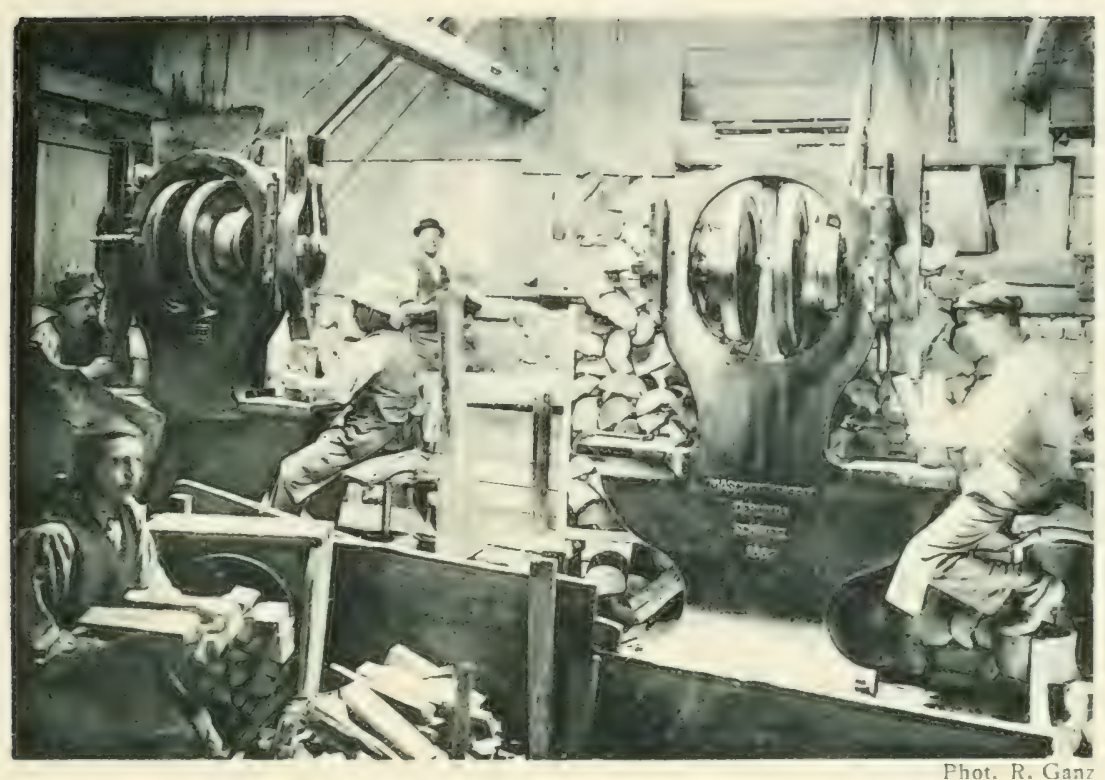

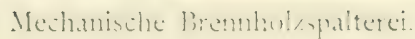

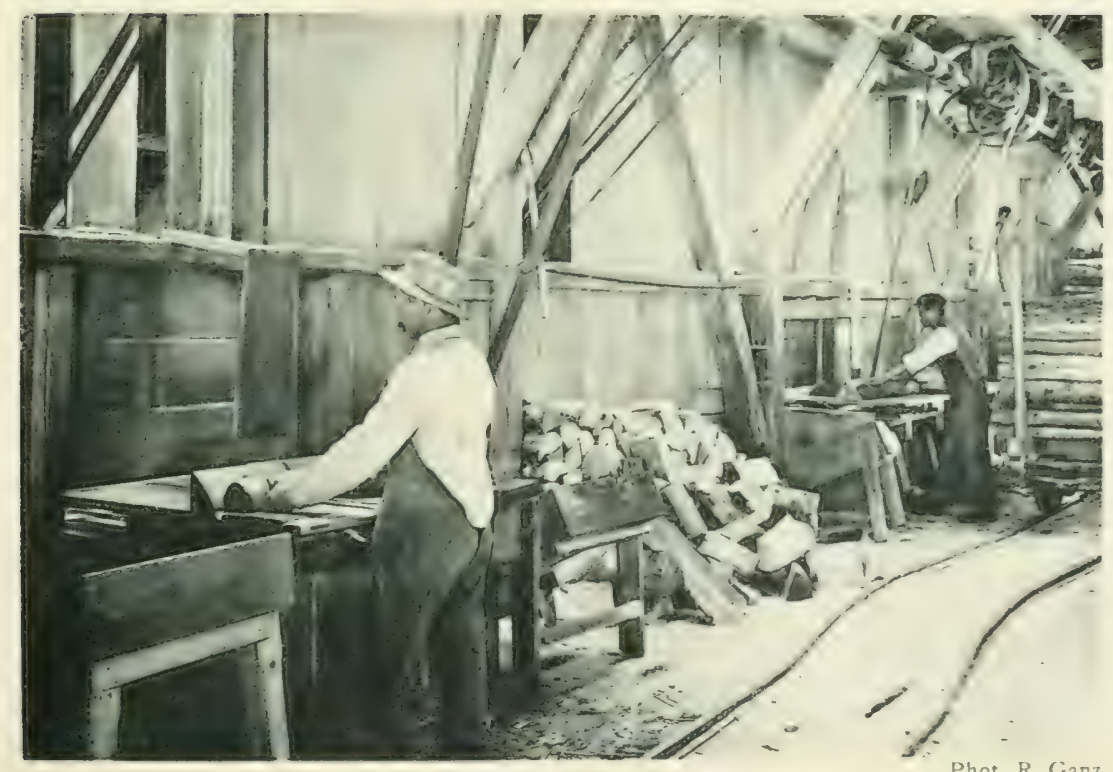

Frïsen des Brennholzes. 

wird in amtlich geeichte Reife von $50 \mathrm{~cm}$ Durchmesser derart fest verpackt, dass die "Reifwelle», ohne auseinanderzufallen, weitern Transport und mehrfaches Umladen gestattet und als Verkaufseinheit in den Handel gebracht wird. Bei der mittleren Sortimentsschnittlänge von 2.5 cin entsprechen 20 Reifwellen genan cinem Ster. Der Abnehmer ist daher, wie bei keinem andern Masse, leicht in die Lage versetzt, das ihm gelieferte Quantum kontrollieren zu können. Die Reifwelle wird dem Konsumenten entweder vom Sihlwaldgeschäft oder durch eines seiner Depots direkt ins Haus geliefert, dort ihres Inhaltes entleert und der Reif zurückgenommen. Die Leistungsfähigkeit einer Snaltmaschine beziffert sich auf 10 Ster per Tag und per Mann; eine Fräse mit ein Mann ist ausreichend, zwei Spaltmaschinen zu bedienen.

Die mechanische Spalterei ist geeignet, weitgehenden Anforderungen in schnellster und billigster Weise genügen zu können. Dabei enthebt sie die Verwaltung der Notwendigkeit, bei der Sortimentsausscheidung des Spaltmaterials verschiedene hategorien aufzustellen; die Ausscheidung nach Holzarten genügt; die Spaltmaschine schafft die Ausgleichung in der Qualität von selbst. Allerdings setzt der Betrieb der mechanischen Holzspalterei und das damit verbundene Verkanfsgeschätt das Vorhandensein entsprechender Lagerschuppen und Lagervorräte voraus. Dieser letztere Umstand ermöglicht dann aber für die Holzausbringungen aus dem Wald in die Lagerschuppen jeweilen die geeignete Zeitperiode auszuwählen: sie verlangt nicht, wie das System der Auktionen, bestimmte Jahreszeiten oder Monate. Unter allen Umständen schafft sie gegenüber dem Verkauf im Wald einen Unternehmergewinn, der in nachfolgenden Verhältniszahlen seinen allgemeinen Ausdruck findet:

Eilös beim Verkauf des verarbeiteten Quantums $=100 \%$

Beschaffingskosten des verarbeiteten Quantums

Holzwert loco Schlagstelle . . . . 5 54,0\%

Transportkosten vom Wald in die Schuppen 9,0

Fräsen und Spalten . . . . . . . . 4.,

Reiffüllung . . . . . . . . 3,0

Fracht bis zum Abgabeort und der Entleerung der Reifwelle inkl. Depotspesen 12,5 》 83 》

Es ergibt sich somit ein Unternehmergewinn von $17 \%$

Die Holzverwertung erhält somit durch den Verarbeitungsbetrieb eine Steigerung von $17 \%$ des Verkaufserlöses. 
Der Imprägnierungsbetrieb (vide Tafel XXII) gehört neben der mechan. Spalterei zu den ältesten Installationen des Verarbeitungshetriebes Sihlwald. Er wurde im Jahr 1875 eingeführt und hatte von Anfang an die Aufgabe, dem Sägereibetrieb dasjenige Naterial zu liefern, welches in imprägniertem Zustande als Schnittware verlangt wird. Anderseits boten die alljährlichen Submissionen für Stangenhölzer von seiten der Telegraphenverwaltung Veranlassung, das im Walde vorhandene Material durch Imprägnierung besser zu verwerten. Bekanntlich hat das Srstem der Imprägnierung nach Boucherie, Yerwendung von Kupfervitriollösung ( $\mathrm{Cu} \mathrm{SO} 4$ ) unter hydrostatischem Druck. den grossen Vorteil, dass Imprägnierungs-Installationen ohne grossen Kostenaufwand eingerichtet werden können. Es eignet sich deshalb gerade aus diesem Grunde für Forstbetriebe, die ihr Naterial durch die Imprägnierung zu besserer Verwertung bringen wollen. Das für die Boucherie-Imprägnierung erforderliche frisch geschlagene Material kann aus dem eigenen Forstbetrieb leichter zu jeder Zeit beschafft werden, als von einem andern Unternehmer. Seine Leistungsfähigkeit gegenüber den pneumatischen oder DampfdruckImprägnierungsverfahren ist allerdings eine geringere.

Die städtische Forstverwaltung hat neben dem permanenten Imprägnierungsbetrieb im sihlwald auch passagere Installationen in andern Forstbezirken etabliert, um in der Nähe befindliche Stangenhölzer ohne grosse Transportspesen imprägnieren zu können, so auf dem Albisplateau, 345 Meter über dem Sihltal, dann im Forsthezirk Adlisberg, 270 Meter über dem Spiegel des Zürichsees. An beiden Orten konnte der Imprägnierungsbetrieb, d. h. die erforderlichen Druckıöhe ron 11-16 Meter ohne Anwendung eines Motors durch einfache Wasserzuleitung aus einer in dieser Höhe gelegenen Quelle in das Druckbassin bewerkstelligt werden. Die Installations- und Betriebskosten sind dementsprechend niedrige geblieben. Im Sihlwald hat der Imprägnierungsbetrieb eine vielseitigere Aufgabe, weil er dort den verschiedenartigsten Anforderungen genügen muss und hiefür auch eine ausgedelntere Bezugsquelle besitzt als abgelegene kleinere Forstbezirke. Neben den Stangen für Starkstromleitungen von $12-18 \mathrm{~m}$ sind hier die Stammhölzer von Buchen, Fichten, Tannen, Föhren und Lärchen, sodann schwächere Durchforstungshölzer für mannigfachste Artikel des Verarbeitungsbetriebes zu imprägnieren. Die Anlage ist dementsprechend ausgedehnter und die Verwendung einer Pumpe als Motor zur Hebung der Imprägnierungsflüssigkeit in wechselnden 


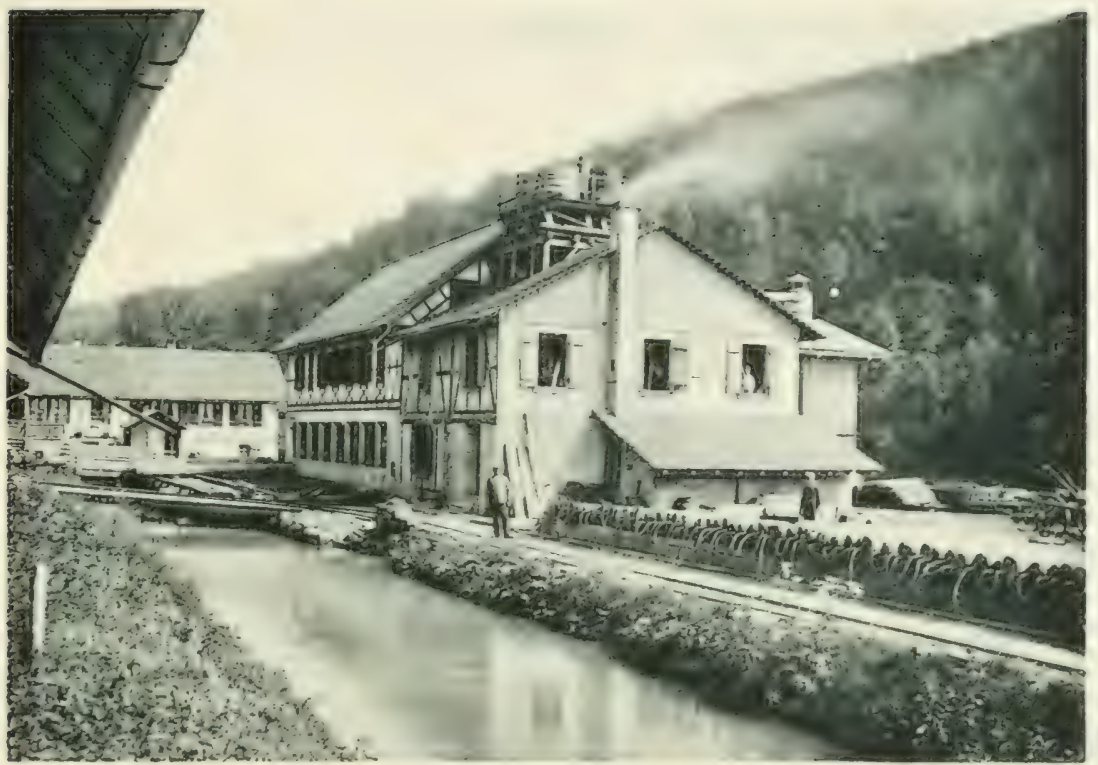

Imprägnierung Sihlwald.

Phot. R. Ganz

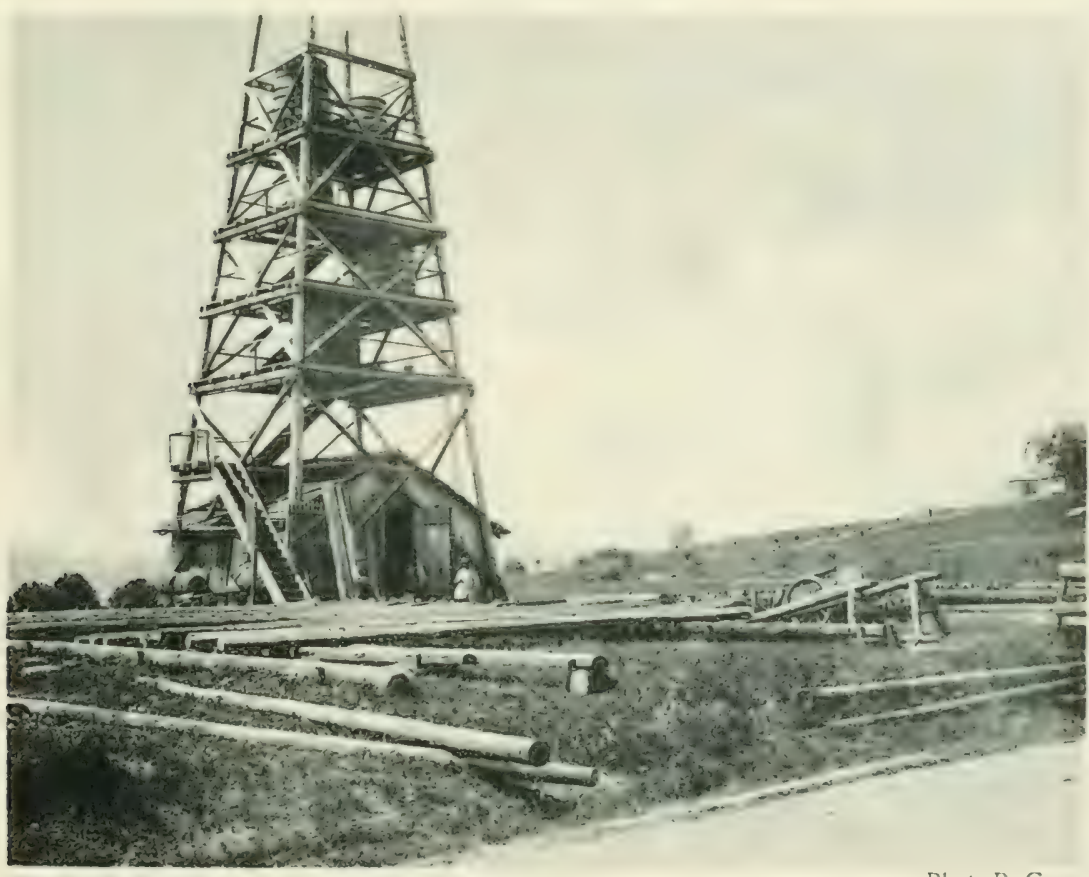

Imprägnierung Zürichberg. 

Quantitäten erforderlich. Die Installation im Sihlwald hat vor allem aus den Vorteil, dass die Abfälle, welche sich bei der Bearbeitung imprägnierter Hölzer ergeben, zum grössten Teil durch weitere Verarbeitung zur Verwendung gezogen werden können, speziell für Weinbaupfähle, Umzäunungsmaterial, Staketen ete.

Die Imprägnierung macht den Verarbeitungsbetrieb konkurrenzfähiger; sie gestaltet die Umwandlung der sonst nur für Schnittwarenartikel verwendbaren und von überall her auf den Markt gebrachten Hölzer in eine Ware, für welche weniger Angebot vorhanden ist, sodass bessere Preise für dieselbe erzielt werden können. Sodann lässt sie das schwächere Nadelholz-Durchforstungsmaterial aus den 15-30jährigen Beständen noch zu vorteilhafter Verwendung ziehen, ohne die Imprägnierung könnte dasselbe nur als Brennholz verwendet werden. Aus allen diesen Gründen ergibt sich für den Imprägnierungsbetrieb durchschnittlich ein befriedigender Unternehmergewinn, wobei allerdings die Schwankungen des Kupfermarktes von wesentlichem Einfluss sind. Die nachstehenden Verhältniszahlen mögen als Beleg hiefür dienen.

Erlös aus dem imprägnierten Rundholzmaterial. . . $=100 \%$

Beschaffingskosten des verarbeiteten Quantums

Holz loco Schlagstell $: 30 \%$

Transport zur Imprägnierung . . . . . . 5

Ĺupfervitriol . . . . . . . . .

Arbeitslöhne . . . . . . . . . . $14 \gg 73 »$

Es ergibt sich somit ein Unternehmergevinn von . . . $27 \%$

Die ausreichende Imprägnierung eines Festmeters Rundholz erfordert durchschnittlich $23 \mathrm{~kg}$ Kupfervitriol, sodass bei einem Schwanken der Preise zwischen 40 und 75 Fr. per q das Nettoergebnis ein sehr verschiedenartiges sein kann. Von grossem Einfluss auf die Rentabilität ist auch der Umstand, dass nur ganz gesundes Holz zur Imprägnierung herangezogen werde. Sonnenbrand, Rotfäulnis, Kernfäule und andere pathologische Erscheinungen rerummöglichen die absolute Durchtränkung ter hievon betroffenen stammteile. während nach gemachten Erfahrungen die Verletzung der Rinde, ja sogar die völlige Entrindung den Imprägnierungsprozess nicht beeinträchtigt, vorausgesetzt, dass die Bastschicht intakt bleibt. Auch eine noch zur späteren Winterszeit vorgenommene Holzfällung setzt der Imprägnierung keine Schwierigkeiten entgegen, sofern die Aufstapelung der Hölzer an schattiger Stelle stattfindet. 
Am ungünstigsten gestaltet sich der Imprägnierungsbetrieb zur Saftzeit. Mit Bezug auf die einzelnen Holzarten klassifizieren sie sich hinsichtlich ihrer Aufnahmsfähigkeit wie folgt: Fichte, Tanne. Buche, Kiefer, Lärche, wobei der grössere oder geringere Grad der Kernholzentwicklung ron wesentlichem Einfluss ist, da Kernholz sich nur unvollständig oder gar nicht imprägnieren lässt. Schwächeres Stangenmaterial von nicht mehr als $15 \mathrm{~cm}$ Durchmesser am dicken Ende wird nicht mehr in gleicher Art imprägniert. Dasselbe wird zu Zaunmaterial, wie sogenannte Hälblinge und Halbiatten verwendet oder in seinen schwächsten Dimensionen (vide Holzverwendungstabelle pag. 186) zu Käfen-. Bohnenstickeln und Baumpfählen ausgeschieden und zu sofortiger Verwendung hergerichtet. Die als Zaunmaterial zur Terwendung gelangenden Stangen werden in Sektionen zerlegt. deren Länge der jeweiligen Stärke für Hälblinge von $1-2 \mathrm{~m}$ zu entsprechen hat. Die Entrindung erfolgt Sommer und Winter nach vorgegangener Einlage in den Dampfkasten; mit der Zirkularsäge und der Drehbank wird die weitere Zurüstung bewerkstelligt. Die Imprägnierung geschieht sodann durch Einlagen in heisse Kupfervitriollange während $4-6$ Tagen. Die hiebei sich vollziehende Resor'ption vermag allerdings nicht eine vollständige Durchfiltrierung des Imprägnierungsstoffes herheizuführen. immerhin wird das Holz durch diesen Prozes: wesentlich dauerhafter gemacht, vorausgesetzt, dass eine voliständige Austrocknung des Materials vor seiner Verwendung stattfindet. Die nicht zu Hälblingsmaterial rerwendbaren Teile der einzelnen Baumstangen, wie die Gipfel oder die knorrigen untern Teile gelangen als Pfahlholz zur Verwertung. Die vorstehende Verwendungsart des aus deri jungen Nalelholzbeständen reichlich anfallenden Durchforstungsmaterials sichert ihm eine lohnende Verwertung, die sonst fehlen würde.

Imprägnierte Zaunhäiblinge. die aus schwachem Nadelholz-Durchforstungsmaterial hergestelltwerden, erzielen bei Annahme eines mittleren Sortiments von 1,30 m Länge folgenden Unternehmergewinn:

Evlös aus imprägnierten Zaunhälblingen . . . . $=100 \%$ Beschaffingskosten des verarbeiteten Quantums:

Holz loco schliag $2.5 \%$

Transport auf Werkplatz

Vollständige Ausarbeitung inklusive

Aufschichten zur Lagerung . . . . 48 » 78 »

Es ergibt sich somit ein Untemehmeryewinn von . . . $22 \%$ 
Der Sägereibetrieb (vide Tafel $X X$ ) des Sihlwaldes hat nicht die beschränkte Aufgabe, die in der Regel den Sägemühlen, da wo sie mit dem Waldbetrieb in Verbindung gebracht sind, zugewiesen wird. Dort soll er meistens das Rundholz in die gewohnten Schnittwarensortimente des Holzhandels umwandeln. Die maschinellen Einrichtungen haben dieser Aufgabe bestmöglichst zu entsprechen. Beim Sihlwaldbetrieb gestaltet sich die Aufgabe des Sägewerkes anders, indem die Schnittware meist zugleich noch einer weiteren Verarbeitung unterzogen wird, sodass sie entweder vollständig oder annähernd fertig dem Gebrauche ühergeben werden kann. Es besteht auch nicht eine Kontinuität in der Erstellung gleichartiger Ware, wodurch z. B. die Anwendung des Vollgatters sich als vorteilhaft erweisen würde; vielmelrr wechseln die Anforderungen mit jedem einzelnen dem Verarbeitungsbetriebe zukommenden Auftrage. Aus allen diesen Gründen funktioniert als Hauptmaschine des sägewerkes Sihlwald eine kontinuierlichte lırizontale Bandsäge mit beweglichem Wagren, System Maschinenfabrik ()erlikon. Diese Bandsäge hat den grossen Vorteil unbegrenzter und raschester Akkommodierung des Sägehlattes an den Charakter der Schnittware; sie gestattet an einem und demselben Stamme die Anwendung der verschiedenartigsten Schnittstärken, vom $3 \mathrm{~mm}$ Brettchen aufwärts bis zur dicksten Bohle, ohne dabei zu «verlaufen». Ihre schaltgeschwindigkeit ist grösser als die des Vollgatter's. Minimum $6 \mathrm{~m}$ per Minute und vermöge des dünnen Blattes und der relativ geringen Schränkung ist der Sägespäneabfall gegenüber den Gattersägen klein. Das System Oerlikon mit horizontallaufender Bandsäge hat gegenüber dem System Ransome mit vertikaler Bandsüge und seitlicher Befestigung des Stammes unbestreitbare Vorteile.

Für Bauholzschnittwaren diente früher die sich vor allem aus hiefür eignende Bauholzzirkularsäge; sie wurde indessen mangelBeschäftigung durch eine einfache Langholzfräse ersetzt. Dem Schnittwarenbetriebe steht für die kleineren, speziell gekrümmten Wagnereiartikel u. s. w. eine Perrinsche Bandsäge zur Verfügung. Eine Nut- und Hobelmaschine und zwei Zirkularsägen mit festem und drehbarem Tische, ebenfalls nach Perrinscher Konstruktion, ermöglichen die vollständige Fertigstellung der vom Yerarbeitungsbetrieb in Ausführung genommenen Bauartikel, sei es in imprägnierter oder nicht imprägnierter Form. Annähernd $70 \%$ derselben gehören der letztern Kategorie an, wie z. B. Schwellen, Holzpflaster, Bodenbelege in Form von Bohlen, Verschalungen, 
Treibbeete für die Gärtnerei, Pfosten, Latten und Staketen für Umzäunungen.

Die Leistungen dieser Abteilung des Verarbeitungsbetriebes und ihre Rückwirkung auf den Reinertrag des Forstbetriebes überhaupt lassen sich am sichersten aus nachstehenden Zusammenstellungen ableiten.

Herstellung von Dachlatten aus Rundholz.

Erlös aus dem verarbeiteten Material und den Ab-

fällen (Sägespäne, Schwarten) . . . . . . $100 \%$

Beschaffungsiosten:

Holzwert loco Schlagstelle . . . . . . . $57 \%$

Transport auf den Werkplatz . . . . . 9

Ausarbeitungskosten inkl. Amortisation . . . $16 \geqslant 82$ »

Es ergibt sich somit ein Unternehmergewinn von . . . $18 \%$

Herstellung von dïnnem Schnittmaterial $(8-10 \mathrm{~mm})$.

(Packbrettli für Papierfabrikation.)

Erlös aus dem verarbeiteten Material inkl. Abfälle $\quad 100 \%$ Beschaffungshosten:

Holzwert loco Schlagstelle . . . . . . $50 \%$

Transport auf den Werkplatz ... . . . . 9 »

Zerkleinerung d. die Maschine inkl. Amortisation 19 » 78 »

Es ergibt sich somit ein Unternehmergewinn von . . $22 \%$

Herstellung von dickeren Schnittwaren $(20-25 \mathrm{~mm})$.

Erlös aus dem verarbeiteten Material inkl. Abfälle $100 \%$ Beschaffingskosten:

Holzwert loco Schlagstelle . . . . . $61 \%$

Transport auf den Werkplatz . . . . . $10 »$

Zerkleinerung d. die Maschine inkl. Amortisation 16 » 87 » Es ergibt sich somit ein Unternehmergewinn von . . . $13 \%$

Mit dem Sägereibetrieb steht in engster Verbindung die Erstellung der Iolzrolle (vide T'afel XX), für welche zwei doppeltwirkende Haschinen der Haschinenfabrik Oerlikon nebst der isterreichischen zur Verfügung stehen. Ursprünglich wurden, analog dem Vorgehen in 


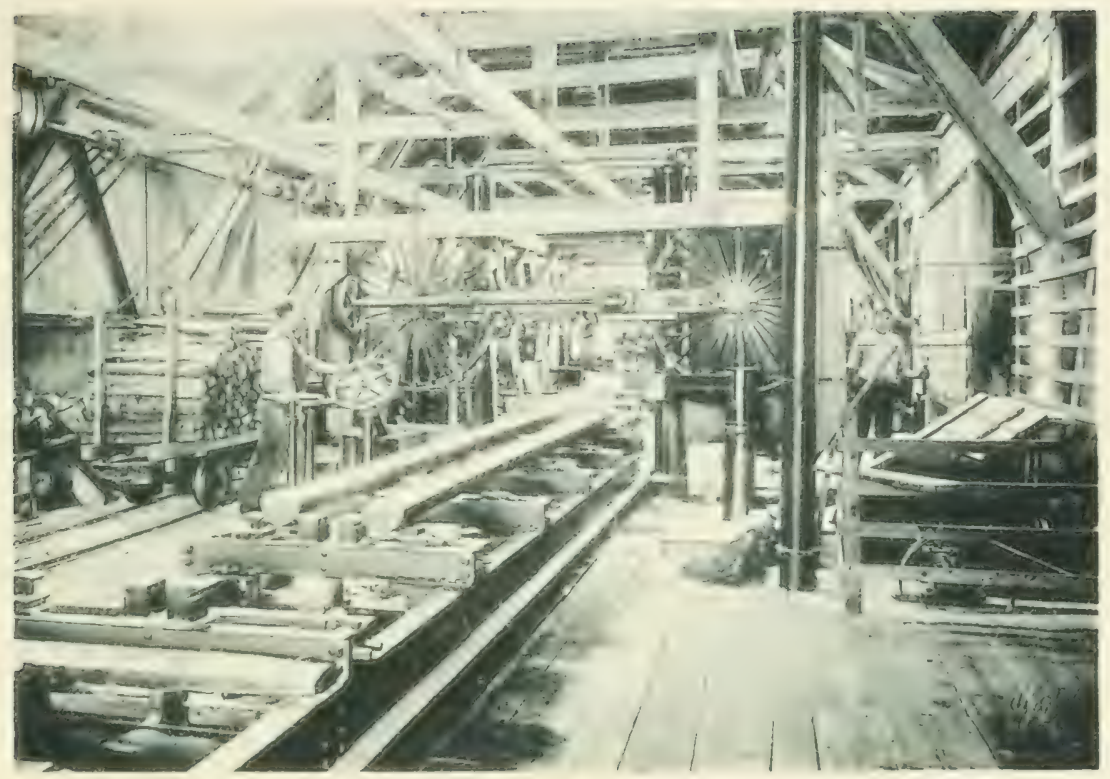

Horizontal-Bandsage fur Sulnittwaru

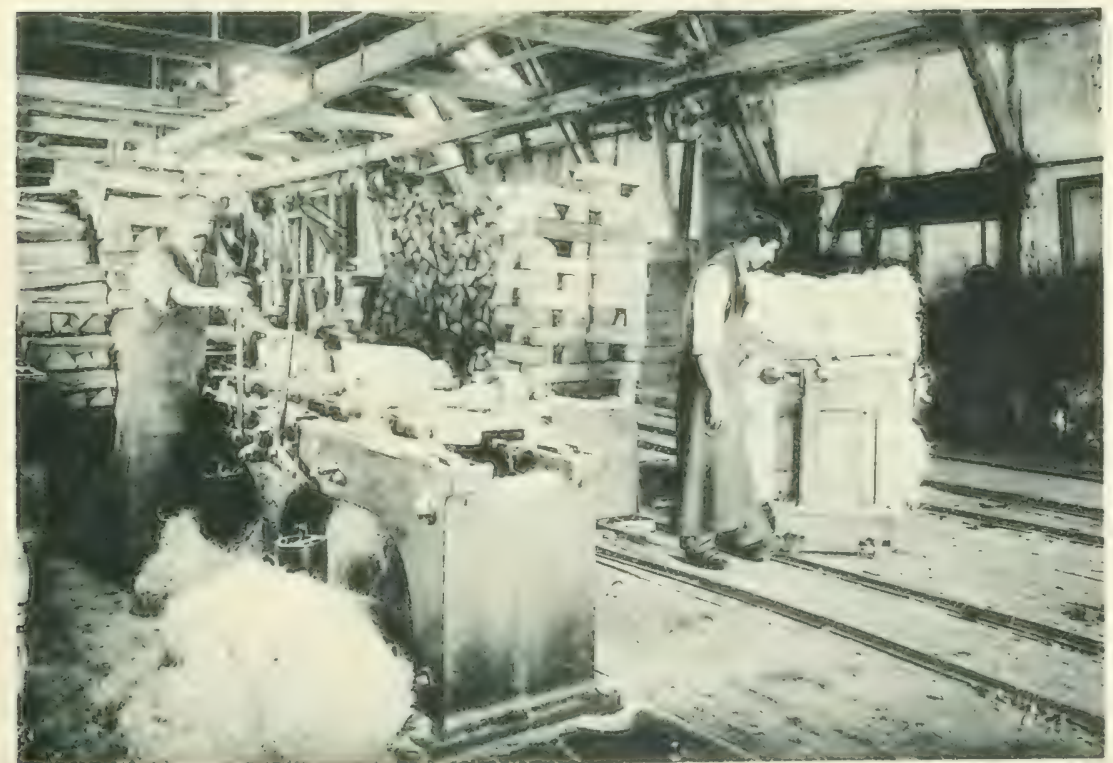

Holzwollemaschine. 

:ihnlichen Betrieben, ansschliesslich Nadelholzbrennholzscheiter verwendet. Es ergab sich indessen, dass die Leistungsfähigkeit der Maschinen bei der Verwendung des scheitholzsortiments nicht auf die wünschbare Höhe gebracht werden kann, weil der dreieckige (querschnitt des Scheites nicht die volle Schnittfläche der Hobelmesser in Anspruch nimmt. Verwendet man dagegen Holzstïcke von der Breite der Messer, so findet eine vollständige Ausnützung der Arbeit derselben statt. Dieser Umstand führte dazu, Rundhölzer geringerer Qualität in Bohlen von der Stärke der Messerbreite $(13 \mathrm{~cm})$ zu sägen, dieselben in Stücke von der Spannweite der Maschine $(50 \mathrm{~cm})$ zu zerlegen und diese sodann auf die Holzwollmaschine zu bringen. Das Resultat war ein durchaus günstiges, was aus folgenden Arbeitsergebnissen hervorgeht.

Erlös aus Holzwolle 98, $\%$ und Abfällen 1,6\% . $=100 \%$ Beschaffingskosten:

Holzwert im Walde

Transport zum Werkplatz

Entrindung der Stämme .

Trocknung des Holzes

Sägen des Holzes, Zerlegung in Stücke, Betriebsmaterial und Amortisation

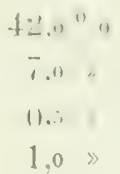

Holzwollmaschine, Bedienung, Betriebsmaterial und Amortisation

5.0

Packung und Fracht

15.1

$6,1 \gg 77 \gg$

Der sich ergebende Unternehmergevinn beträgt daher

$23 \%$

Das vorstehende Verfahren, das die Verwendung trockenen Materials in sich schliesst, ist selbstredend nur durchführbar, wenn die zur Verwendung gezogenen Bohlenstücke einen ausreichenden Trockenheitsgrad besitzen. Dieser lïsst sich nach gemachten Erfahrungen nicht durch einfachen Lufttrocknungsprozess erzielen. Es musste deshalb dem Betrieb die Erstellung einer Trocknungsanlage vorangehen. Diese ist vorhanden und bringt sogar frisch im Walde geschlagenes Holz innerhalb 60 Stunden auf den notwendigen Grad der 'Trockenheit.

Die Trocknungsanlage dient auch andern Abteilungen des Verarbeitungsbetriebes und enthebt denselben der Notwendigkeit, eine längere Lagerung der vorgearbeiteten Schnittwaren vorzunehmen. Die Nachfrage nach Holzwolle hat sich dank ihren treftlichen Eigen- 
schaften ungemein gesteigert: ihre Terwendbarkeit als Lagerungsund Packmaterial lässt noch ein weiteres Anwachsen derselben erwarten. Dabei zeigt es sich aber, dass an den Artikel selbst stets weitergehende Anforderungen sowohl mit Bezug auf Farbe als auf Homogenität gestellt werden und dass von einer blossen Verwenlung der Holzabfälle für die Lieferung marktfähiger Ware nicht mehr gesprochen werden darf. Die städtische Forstverwaltung berücksichtigt im Holzhauereibetriebe diese Verhältnisse in der Weise, dass sie das geringste Material dem Brennholzsortiment zuweist, die für die Holzwolleverarbeitung dienlichen Teile dagegen in den für den sägereibetrieb lienlichen Stammlängen ausscheidet. Die damit verbundene Entlastung des Nadelholzbrennholzquantums entspricht dem verminderten Bedarf an diesem Material.

Die Werkzengstielfabrikation (vide Tafel XIX) bildet eine weitere Abteilung des Verarbeitungshetriebes. Sie verdankt ihr Entstehen rlem verhältnismässig grossen Torrat des Sihlwaldes an denjenigen Holzarten. welche wie Esche. Ahorn. Buche, Hainbuche, Aliazie, ron diesem Verwendungszweck beansprucht werden, wie anderseits dem Umstande, dass die Vervollkommnung der Maschinen auch hier geeignet ist, die Handarbeit gänzlich oder wenigstens teilweise vorteilhaft zu ersetzen. Während in früheren Zeiten die Wagnerei und die Rechenmacherei imstande waren, das auf den Markt gelangende Rohmaterial vollständig für die Deckung ihres Bedarfes aufzunehmen, sind diese Gewerbe heute nicht mehr in der gleichen Lage. Die Landwirtschaft bedarf infolge des Ueberganges vom Getreide- zum Futterhau ein geringeres Geschirrinventar als früher: sodann hat die Eisenkonstruktion die voluminösen Holzgeräte vielfach aus dem Felde geschlagen, und endlich macht auch in diesem Gebiete der mit grossen Kapitalien arbeitende Fabrikbetrieb seine Einwirkungen auf das Kleingewerbe geltend. Nur da, wo noch die dem Holze oder einzelnen Holzarten speziell innewohnenden physikalischen Eigenschaften: das kleinere spezifische Gewicht. Elastizität. Biegsamkeit und Wärmeleitungstermögen für den Gehrauchszweck von besonderer Bedeutung sind, wird dem Holze eine stetige Marktfähigkeit erhalten bleiben. In die Kategorie dieser Artikel gehören nun vorab die Werkzeugstiele aller Art; sowohl diejenigen des landwirtschaftlichen mul forstlichen, als diejenigen des Bangewerbes und teilweise auch noch des mechanischen Gewerbes. Um möglichst viele Holzsortimente dieser Abnehmerschaft zuwenden zu können. wurde die Installation der hiefür notwendigen Maschinen vorgenom- 


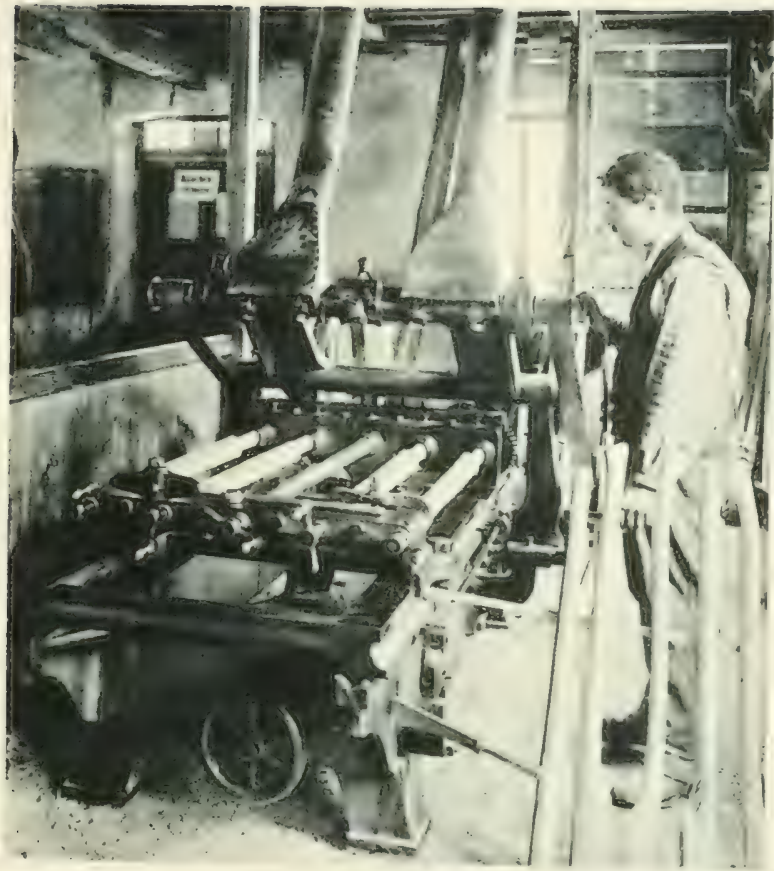

Verkzeuostielfabrikation.

Phot, K. Cimi

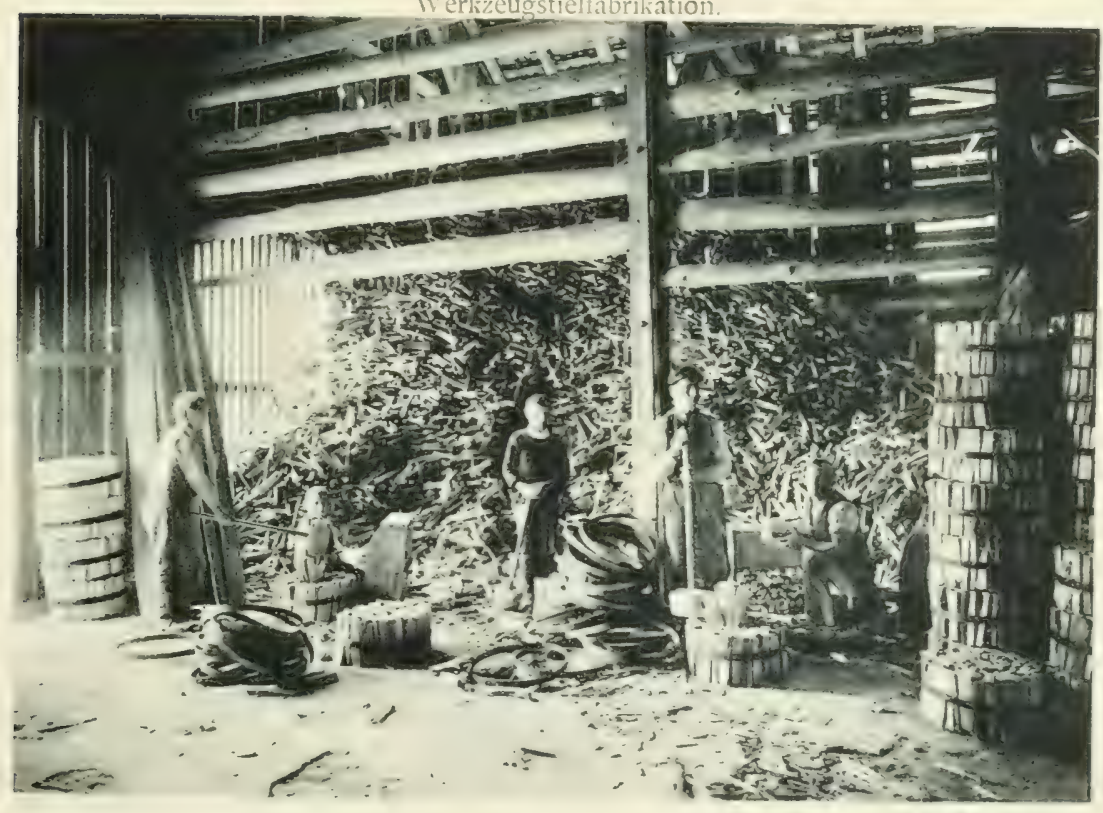

Prut. R. C....

Verpackung des kleingespaltenen Brennholzes in Reifi von 50 am Durchmesser. 

men. Eine Kopierbank bearbeitet nach eingelegtem eisernem Modell in je rier Stücken jedweden Werkzengstiel, nachrem die Holzstücke vorher durch die Bandsäge zugeschnitten sind. Eine Polierbank glättet die von der Kopierbank geformten Stiele. Für gerade Stiele dient die Rundstangen-Maschine (vide Tafel XXI); diese liefert in Nadelholz wie in Laubholz aus vierkantig zugeschnittenen Stäben beliebiger Länge sauber geglättete Rundhölzer von 10-6j) mm Durchmesser, welche für die mannigfachsten Verwendungszwecke dienen: Rouleau-, Fahnen- und Flaggenstangen, Rechen- und Gabelstiele, Schreinereiartikel, Rosen- und Blumenstäbe etc. Die sofortige Verwendbarkeit aller dieser Produkte wird durch die Benützung der Trocknerei-Einrichtungen (rmöglicht. Die Leistung dieses Betriebszweiges ergibt sich aus nachstehenden Zahlen.

\section{Pickelstiele (Eschenholz).}

Verwertung der Artikel und der Abfälle $100 \%$

Beschaffingskosten:

Holzwert im Walde . . . . . . . . $35 \%$

Transport nach dem Werkplatz . . . 6 »

Ausarbeitung . . . . . . . . . $27 » 68$ »

Es ergibt sich hieraus ein Unternehmergewinn von . . . $32 \%$

\section{Rundstäbe (Tannenholz).}

Verwertung der Artikel und der Abfälle . . . . $100 \%$

Beschaffingshosten:

Holzwert im Walde . . . . . . . $57 \%$

Transport nach dem Werkplatz . . . . 4 »

Ausarbeitung . . . . . . . . . . . . $10 » 71 »$

Es ergibt sich hieraus ein Unternehmergewinn von . . 29\%

Die Verwertungsmöglichkeit der Abfälle ist eine der wesentlichsten Beçingungen für die Rentabilität jedes Verarbeitungsbetriebes; dieselbe ist beim sihlwaldhetrieb vorhanten. Ile Al,fälle von imprägnierten und nichtimprägnierten Schnittwaren wie: Schwarten. Sägespäne und Rinden finden ihre weitere Verwertung. Erstere durch weitere Verarbeitung zu Rebpfählen, Zaunmaterial, Rundstangen, Gips- und Dachlatten und in letzter Instanz, wenn sie sich nicht für die vorgenannten Zwecke eignen, als klein gespaltenes Brennholz. Die Sägespäne werden von der Landwirtschaft 
als Streuematerial begehrt und die Rindenabfälle dienen teils als Feuerungsmaterial für die Trockenanstalt, teils werden sie als Heizmittel verkauft. Gut verwendbar sind vorab die Sägeabfälle der imprägnierten Rundhölzer, weil die äusseren Stammteile am besten vom Imprägnierungsstoff durchtränkt werden.

Eine Zusammenstellung der Betriebsergebnisse der einzelnen $\mathrm{Ab}$ teilungen des Verarbeitungsbetriebes weist nachfolgende Zahlen auf:

Unternohmergewimn

1. Verarbeitung in dicke Schnittwaren . . . . . . $13 \%$

2. Mechanische Brennholzspalterei . . . . . . . . 17 »

3. Verarbeitung von Nutzholz zu Latten . . . . . 18

4. $\gg \quad$ zu dünnen Schnittwaren . . . . . . 22

5. $\quad$ von Kleinstangenmaterial zu Hälblingen . 22

6. $\gg$ von Stammholz zu Holzwolle . . . . 23

7. Imprägnierung stärkeren Stangen- und Bauholzmaterials 27

8. Verarbeitung von Stammholz zu Rundstangen . . 29

$9 . \quad$ von Laubholznutzholz zu Werkzeugstielen 32

Es ergibt sich somit ein Durchschnittsunternehmergewimn von $22,5 \%$

Auf diesen verschiedenen Wegen und bei dieser allerdings noch nicht vollständig umschriebenen Zahl der Veräheitungsprodukte ist es dem Verarbeitungsbetrieb möglich, jede Holzgattung und jedes Sortiment in intensiver Weise auszuniitzen und ihm auf einem nähern oder entfernter liegenden Markt den vorteilhaftesten Absatz zu sichern. Gegenüber dem Modus der Versteigerung oder demjenigen der Submissice des Rohmaterials hat er jedenfalls den Vorzug, einer verminderten Konkurrenz zu begegnen. Auch hat die Erfahrung gezeigt, dass gerade in Zeiten, wo sich eine Stockung in Handel. Industrie md Gewerhe fühlhin macht. die Rückschliage im Verarbeitungsbetrieb weniger spürbar waren als auf dem Auktionsmarkt. Die Nachfrage erfolgt in kleineren Dosen, aber sie stellt sich immerhin ein.

Der am schwierigsten bestimmbare Punkt bleibt beim Verarbeitungsbetrieb die Auswahl der in denselben hineinzuziehenden Verarbeitungsartikel. Beim silhwalubetrieb ist weyleitend die Tendenz, der Umarbeitung den vorteilhaftesten Absatz des Jahresetats mit seinen verschiedenen Sortimenten zu erwirken, dabei nur solche Artikel zu erstellen, welche in der Konkurrenz mit analogen anderwärtigen Fabrikaten noch einen Nettoertrag liefern, bei welchem 


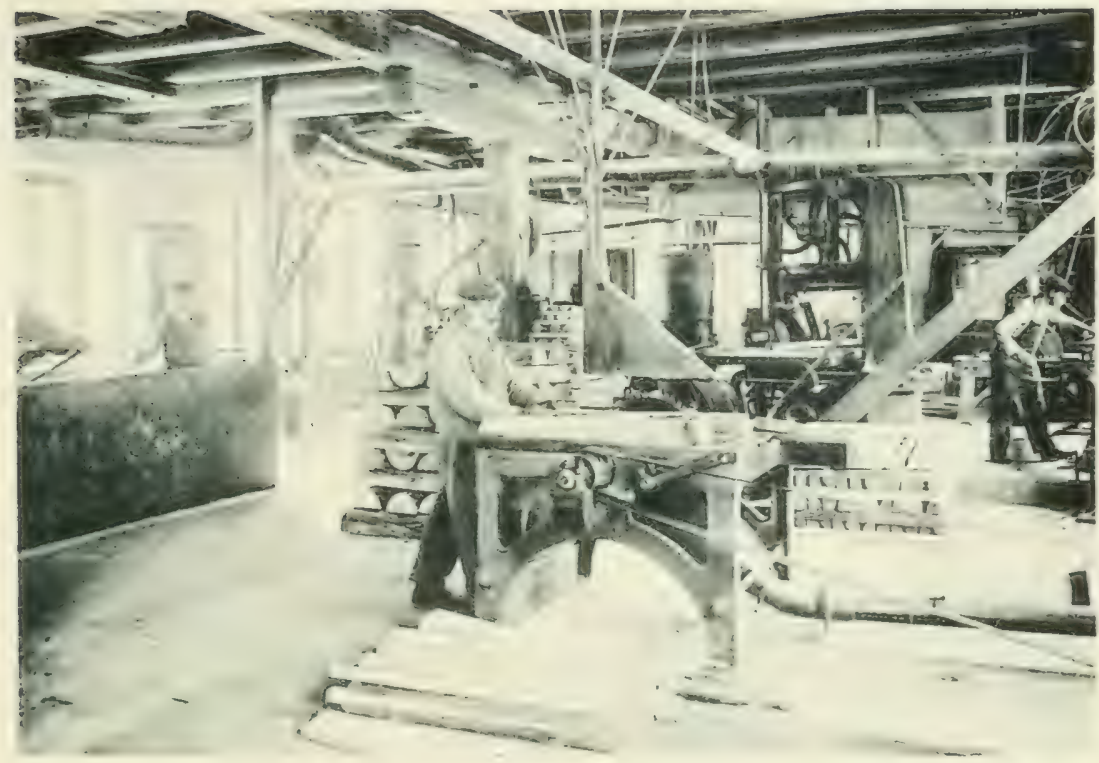

IVerazeugstiel-Ma-ihinenramm.

Phot. R. Ganz

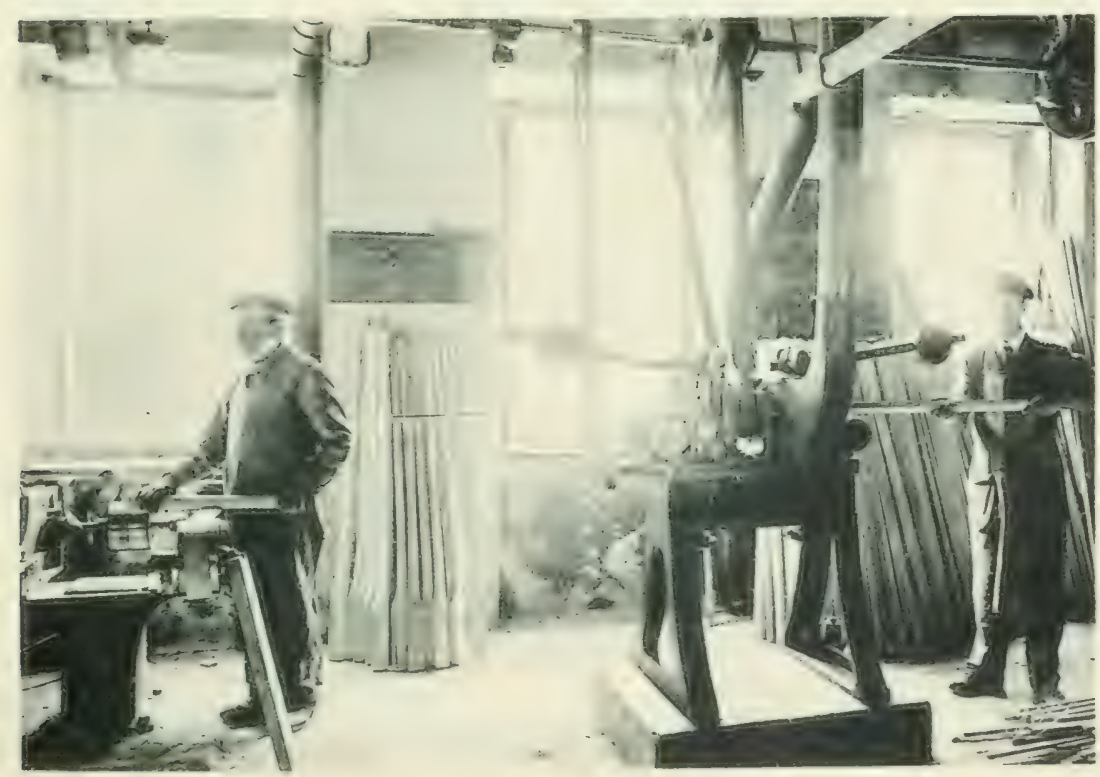

Poliermaschine.

Rundstabmascline.

Phot. R. Gan? 

ein höherer Verkaufswert des Rohmaterials resultiert: endlich die Fabrikate auf diejenige Zahl zu beschränken, die auf die Dauer nachhaltig in grösserem Umfange produziert werden können. Es soll durch den Verarbeitungsbetrieb die Nutzholzsortimentsverwertung auf Kosten der Verwertung des Holzes als Brennmaterial erhöht werden.

Der bisherige Entwicklungsgang hat trotz seinem günstigen Verlaufe diese Aufgabe noch nicht in wünschbarem Umfange zu lösen vermocht. Auch im Sihlwald ist die Frage der Buchenholzverwertung trotz allen Anstrengungen und vielen Erfolgen im kleinrn noch keinexwegs zum Abschluss gelangt. Sie tritt im Gegenteil angesichts des rapiden Rückganges des Buchenbrennholzkonsums erst recht zutage. umsomehr, als bei der bisherigen 90jährigen Umtriebszeit die für eine Reihe von Verarbeitungszweigen nötigen Stärken und Dimensionen nicht erzielbar sind. Die vielversprechenden Anfånge mit einem grössern Absatz von Buchenholz als Holzpflaster weisen leider keine Steigerung auf. Die momentan sich zeigende Tendenz, Buchenholz wiederum als Eisenhahmschwellemmaterial zu verwenden. eröffnet allerdings die Aussicht auf vermehrten Absatz des Buchenholzes, aber nach unsern Erfahrungen nicht auf einen günstigen. Die Parkettfabrikation, welche geeignet wäre, einem bedeutenden Buchennutzholzkonsum zu rufen, hat mit einer gewaltigen Konkurrenz, die über billiges Rohmaterial verfügt, zu rechnen. Die gewerbliche Verwendung der Buche hat infolge der Inanspruchnahme metallischen Rohmaterials statt des Holzes nachweisbar eine auffallend geringe Steigerung erhalten; sie bleibt unter allen Umständen fortwährend abhängig von der durch den Standort bedingten Qualität, so ganz besonders bei der Schuhleisten-, Holzschuh- und Küchengerätefabrikation. Die Möbelschreinerei, welche geeignet wåre, grosse Quantitäten Buchenholz aufzunehmen, zeigt auf europäischem Boden im Gegensatz zu den Verhältnissen in den Vereinigten Staaten Nordamerikas wenig Neigung und Geschick, Buchenholz für ihre Objekte zu verwenden. Für die Fabrikation der gebogenen Möbel liefern die Donauländer billigstes Material. Die Papierfabrikation hat sich sowohl bei der Erzeugung des mechanischen Holzstoffes, wie bei der Cellulose bis zur Stunde der Buchenholzverwendung wenig günstig erwiesen. Die technische Holzverkohlung, verbunden mit der Fabrikation von Essigsäure, Aceton, Methylalkohol und sonstigen Holzdestillaten liefert Nettoergebnisse, die geringer sind als die hiesigen Brennholzpreise, 
indem sich der Ster nicht höher als auf ca. 6 Fr. stellt. ${ }^{1}$ ) So hat denn die Forstwirtschaft ihre Hoffnungen, wie ihre Bestrebungen weiter dahin zu richten. dass die chemische und die mechanische Technologie Mittel und Wege eröffnen. die wert vollen Eigenschaften des Buchenholzes nutzbar zu machen und umgekehrt die nachteilige Seite desselben aufzuheben. Die technische Behandlung nicht nur des Buchenholzes, sondern unserer verschiedenen Nutzhölzer überhaupt, steht in Europa noch nicht auf dem Standpunkt der Entwicklung, der z. B. in Nordamerika erreicht ist. ${ }^{2}$ ) Durch die Anwendung leistungsfähiger Dämpferei-Einrichtnngen, durch Verbesserung der technischen Herstellung der einzelnen Objekte, überhaupt durch vermehrte Geltendmachung der schönen Textur einer Reihe bisher von der Forstkultur wie von den Gewerken geringschätzig behandelter Holzarten: wie Kirschbaum, Birke, Erle, Tulpenbaum u. a. m. liesse sich unzweifelhaft noch eine höhere Verwertung der Waldprodukte erzielen.

\section{Der Ertrag der Holzernte.}

\section{Allgemeines.}

Als im Jahre 1883 in der ersten Auflage der Schilderung der Betriehsverhältnisse unserer städtischen Waldungen auch über die Ertragsverhältnisse eìige $A$ ngaben gemacht wurden, stand für die hetreffenten Zusammenstellungen noch wenig städtisches Material zur Verfügung. Das heutige Verwertungssystem war damals erst in den Anfängen seiner Entwicklung begriffen und noch nicht in der Art organisiert, wie es nun seit einer Reihe von Jahren der Fall ist.

Bei der nunmehr festgehaltenen Organisation ist mit Ausnahme des nicht im Sihltal gelegenen Forstbezirkes Adlisberg der eigene Verarbeitungsbetrieb Abnehmer der sämtlichen Waldprodukte und

1) Technologie der Holzverkohlung und Fabrikation von Essigsäure, Aceton, Methylalkohol und sonstiger Holzdestillate von M. Klar. Julius Springer, Berlin. 1903.

2) Meyer-Zschokke, die Holzindustrie in Chicago in Beziehung auf Stil, Bearheitung, Werkzeug, Material und Arbeiterverhältnisse zur Zeit der Weltausstellung in Chicago. Berm. 1894. 
zwar nicht loco Schlag, sondern loco Talstrasse. Er nimmt von dieser Stelle aus die Ware in Empfang und liefert gewisse Sortimente wie z. B. Wellen und Waldabfälle direkt von dort an die Abnehmer mit dem ihm zur Verfügung stehenden Transportmaterial, unter Ansetzung fester Preise für die Frankolieferung. Für diejenigen Artikel, die auf vorangegangene Bestellung aus dem Ver- arbeitungsbetrieb hervorgehen, wird der Absatz entweder direkt vom Zentralbureau besorgt, oder gegen Einräumung einer bestimmten Provision durch die an verschiedenen Orten, so namentlich in Zürich etablierten Depots vermittelt. Das Depot Zürich hat den Charakter einer eigentlichen Filiale des Verarbeitungsbetriebes. Der Chef derselben ist Angestellter der Forstverwaltung. Es stehen ihm maschinelle Einrichtungen zur Verarbeitung des Brennholzes zur Verfügung, sodass er damit als Abnehmer des an den Versteigerungen am Zürichhere nicht rerkäuflichen Brenmmaterials, auch diesen If aldteilen die Vorteile des Verarbeitungsbetriebes zuwenden kann. Das Depot Zürich hat auch die Aufgabe, den sämtlichen Artikeln des Verarbeitungsbetriebes vermehrten Absatz zu verschaffen und ihre Zustellung an die Abnehmer auf dem Platze Zürich zu besorgen. Betriebseinnahmen und Betriehsatisguthen figurieren als gesonderte Abteilung im Gesamthaushalt des Sihlwald-Yerarbeitung-hetriebes. Die übrigen Depots sind vornehmlich Brennholzvermittler in den Tachbargemeinden des Sihltales und des linken Seent... Fie haben das Brennmaterial zu den von der Forstverwaltung festgesetzten Preisen dem Abnehmer zuzustellen und beziehen hiefür eine bestimmte Provision, nicht aber einen festen Gehalt, sie arbeiten auf eigene Rechnung und Gefahr, sodass die Forstverwaltung statt der grossen Zahl der Einzelabnehmer nur mit diesen Depothaltern als Zwischenhändler zu verkehren hat. Der Zentralverwaltung im Sihlwald, wie derjenigen der Depots in Zürich steht das nötige Immobilien- und Mobilieninventar zur Verfügung. Jede besitzt eine eigene Fuhrhalterei, diejenige im Sihlwald eigene Waggons für den Eisenbahnbetrieb ab Station der Sihltalbahn.

Das Zentralbureau bestimmt die Warenpreise gemäss den Fluktuationen des Holzmarktes und den Erstellungskosten und besorgt die Reklame für die Gewinnung und Erhaltung einer ausreichenden Abnehmerschaft. Vor Eintritt der heute sich zeigenden Stockung im Brennholzabsatz hatte es auch für die Beschaffung genügender Vorräte für den Gesamtbedarf, soweit er nicht durch die eigenen Waldprodukte gedeckt werden konnte, zu sorgen. 
Der auf dieser Grundlage aufgebaute Betrieb arbeitet demgemäss mit einem weniger einfachen Organismus als die meisten andern Forstverwaltungen. Er hat dafür den Nachweis zu liefern, dass den entsprechenden Mehrausgaben auch Mehreinnahmen gegenüberstehen, sodass das Nettoergebnis zum mindesten demjenigen anderer Verwaltungen gleichsteht oder dieselben womöglich übertrifft. Die nachstehenden Daten mögen das Material für die diesfällige Beurteilung bieten. Sie sind, um die Vergleichung mit andern Verwaltungen zu ermöglichen, auf die Einheit des Betriebsfaktors bezogen und soweit möglich prozentual ausgedrückt.

\section{Materialerträge.}

Der Wirtschaftsplan vom Jahre 1880 hatte einen Jahreshauptnutzungsetat von $5,7 \mathrm{~m}^{3}$ und einen ungefähren Durchforstungsetat von $2,3 \mathrm{~m}^{3}$, Summa $8,0 \mathrm{~m}^{3}$, Derbholz und Reisig zusammengefasst, festgesetzt. Abzüglich der unregelmässigen Schneebruchjahre beträgt die in den letzten zwei Dezennien bezogene Hauptnutzung $5,38 \mathrm{~m}^{3}$ und 2,73 $\mathrm{m}^{3}$ Zwischennutzung, zusammen $8,11 \mathrm{~m}^{3}$. Aus den Zuwachsberechnungen der gegenwärtigen Wirts haftsperiode ergibt sich ein wirklicher laufender Zuwachs von $6,1 \mathrm{~m}^{3}$ Hauptbestand und $3,1 \mathrm{~m}^{3}$ Nebenbestand, Summa $9,2 \mathrm{~m}^{3}$.

Dementsprechend hat sich der Betrieb in seinen Nutzungen innerhalh der Grenzen strengster Nachhaltigkeit und unter der Grenze der zulässigen Ausnützung des laufenden Zuwachses bewegt. Werden die sieben unregelnässigen Schneebruch-Aufarbeitungsjahre in die Berechnung des 20jär. sich eine durchschnittliche Hauptnutzung von $6,68 \mathrm{~m}^{3}$ und eine Zwischennutzung von 2,92 $\mathrm{m}^{3}=9,60 \mathrm{~m}^{3}$. Mit Bezug auf die Sortiments-Ausscheidungen ergeben sich für die gleiche Periode in Prozenten ausgedrückt nachfolgende Verhältniszahlen:

Hauptnutzung

Nadelholz Laubhol\%

Nutzholz . . $62 \% \quad 12 \%$

Brennholz . . $34 \gg 79$

Reisig. . . . 4 » 9

Derbholz . . $96 » 91$

Rivisie.

$4 \quad 4$

$\mathrm{Zwischennutzung}$

Nadelholz Laubhol\%

Nutzholz - 38,0\% 5,6\%

Bremnholz . 56,3 > 56,4

Reisig . . 5,7 * 38,0 »

Derbholz . . 94,3 》 62,0 》

lieisig. . ‥ 34."

Derbholz: Hauptnutzung $91,8 \%$; Zwischennutzung $72 \%$ Reisig: 
Es dürfte aus diesen Zahlen hervorgehen, dass die Laub-Nutzholzausbeute auch im Sihlwaldbetriet) eine relativ geringe ist angesichts der Qualität des vorhandenen Laubholzes und trotz den Erleichterungen des Verarbeitungsbetriebes. Dabei ist jedoch zu bemerken, dass in diesen 20 jährigen Daten auch die Schneebruchmassen inbegriffen sind, bei welchen die Nutzholzgewinnung von vorneherein eine abnormale war. Zieht man nur einzelne Abteilungen in Betracht, so ergeben sich je nach den Verhältnissen weit

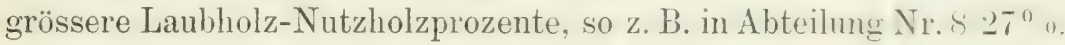
Bedeutend ist die Nutzholzausbeutung in den Nadelholzdurchforstungsbeständen, wo die Ziffer von $38 \%$ wohl hauptsächlich der durch den Verarbeitungsbetrieb ermöglichten Terwertung des Kleinmaterials zuzuschreiben ist. Der verhältnismässig niedrige Prozentansatz der Nutzholzausbeute in den Hauptnutzungen des Nadelholzes hängt damit zusammen, dass während einer Reihe von Jahren ein erheblicher Teil des für die Holzwollefabrikation bestimmten Nadelholzes dem Nadelholz-Nutzholzsortiment entnommen und sterweise in Brennholzform aufgearbeitet wurde. Bei den Laubholzdurchforstungen ist der ungewöhnlicł hohe Reisiganfall, $38 \%$, bemerkenswert; er ist das Ergebnis der schon mit dem 15. Jahre eingelegten Reinigungshiebe und Durchforstungen und der vollständigen Aufarbeitung der sich ergebenden Anfälle.

Das Verhältnis der Durchforstungs- zu den Hauptnutzungsbeträgen ist gegenüber den zum Vergleich heranziehbaren Zahlen anderer Verwaltungen ein sehr günstiges, obschon die Anfälle aus den Durchforstungen der über 70 Jahre alten Bestände bisher der Hauptnutzung zugewiesen worden sind. Es fallen im Durchschnitt der letzten 20 Jahre von der Gesamtnutzung $71 \%$ auf die Hauptnutzung und $29 \%$ auf die Zwischennutzung. Nimmt man den Durchschnitt der regelmässigen Durchforstungen der fünf letzten Jahre des II. Dezenniums, so ergeben sich 64,3\% Hauptnutzung und $35,7 \%$ Durchforstung.

\section{Gelderträge.}

Der Nettogeldertrag der städtischen Stiftungsgutswalilung: setzt sich zusammen aus den Gelderträgnissen des Waldes selbst und aus dem weitern Zuschlag des Nettogewinnes des Verarheitungshetriehes. Der letztere ist erst seit einem Dezennium für sich ausgeschieden. Dit Gesamterträgnisse der vier letzten Dezennien stellen sich wie folgt: 
per Jahr

1861-1870: Fr. 71,242.71

1871-1880: 》92,799.01 (höchste Holzpreise)

1881-1890: 》 $\quad$ 86,243.93

1891-1900: 》95,706.06 (höhere Arbeitslöhne und niedrigere Irolzpreise.)

In das Dezennium 1881-1890 fällt die Schneebruchperiode mit ihren ungünstigen Verwertungsverhältnissen (pag. 52). Sodamn ist zu bemerken, dass in den Betriebskosten der zwei letzten Dezennien die rollstänlige Amortisation der gesamten maschinellen Einrichtung des Verarbeitungsbetriebes mit Fr. 85,000.- - die Anschaffungskosten der Geleise für die Waldbahnen und endlich Fr. 25,000. - für die Neuvermessung und Kartierung der Waldungen inbegriffen sind.

Für die Klarstellung der Betriebsergebnisse bietet das zweite Dezennium 1891-1900 sicherere Anhaltspunkte als dasjenige von 1881-1890, umsomehr, als in demselben auch mit der gesonderten Rechnungsstellung für Waldbetrieb und Verarbeitungsbetrieb begonnen wurde. In dieser zehnjährigen Periode ergibt sich per Hektare produktive Waldfäche ein Nettoertray von $F$ r. 95. 70, von diesen fallen auf den Waldbetrieb Fr. 79.40 und auf den Verarbeitungsbetrieb Fr. 16.30. In Prozenten ausgedrückt liefert der Waldbetrieb $83 \%$ und der Verarbeitungsbetrieb $17 \%$ der Jahresrendite.

Fasst man die Bruttoeinnahmen ins Auge, wie sie sich aus der Verwertung per Festmeter eines Durchschnittsjahres ergeben, so resultieren folgende Zahlen als Bruttoerlöse:

Nutzungsquantum $9293 \mathrm{~m}^{3}$; Bruttoerlős Fr. 284,038. -

Ververtung der einzelnen Sortimente:

Nutzholz $1813 \mathrm{~m}^{3}$. . . ergeben $44 \%$ der Gesamteinnahmen Fr. 67. - per Festmeter.

Brennholz verarbeitet $4522 \mathrm{~m}^{3}$ ergeben $36 \%$ der Gesamteinnahmen Fr. 23.70 per Festmeter.

Brennholz unverarb. $857 \mathrm{~m}^{3}$ ergeben $5 \%$ der Gesamteimnahinen Fr. 18.60 per Festmeter.

Wellen $2101 \mathrm{~m}^{3}$ ergeben $15 \%$ der Gesamteinnahmen Fr. 18.90 per Festmeter.

Der Nettogeldertrag des Waldbetriebes beträgt $44 \%$ und derjenige des Verarbeitungsbetriebes 9,2\% des entsprechenden Bruttoertrages, woraus hervorgeht, dass das Betriebssystem nur mit einem grossen Kostenaufwand seine günstigen Resultate erzielen kann. 
Beim Waldbetrieb verteilen sich diese Kosten wie folgt:

per ha Fr:

Verwaltung, Bureau und Arbeiterversicherung .

17. 76

Holzhauerei . . . . . . . . . . 35.45

Transport . . . . . . . 30.31

Immobilienunterhalt . . . . . . . . . 3. 3:3

Weg- und Wasserbau . . . . . . . 5.39

Inventarunterhalt . . . . . . . . . . . 1.93

Kulturen, Säuberungen . . . . . . . 3.34

Allerlei . . . . . . . . . . 0.43

Total 98. 24

Hiebei ist zu bemerken, dass die hohen Quoten bei der Holzhauerei und beim Transport mit dem grossen Durchforstungsquantum, speziell Wellenmaterial in den jüngeren Beständen, im engsten Zusammenhange stehen.

Beim Verarbeitungsbetrieb verteilen sich die Betriebsspesen wie folgt:

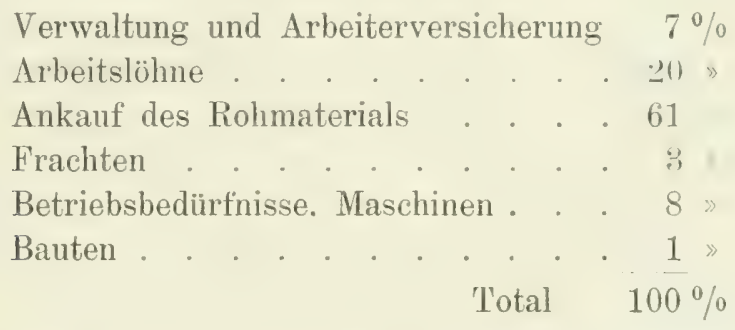

Wald- und Verarbeitungsbetrieb zusammengenommen beanspruchen gegenüber den sonst üblichen Forstbetriehen ein ungewöhnich grosses Arbeitsquantum, eine Erscheinung, die wohl nicht zu ungunsten des Betriebssystems gedeutet werden darf. Beim Waldbetriebe ergaben sich per Betriebsjahr 20,000 Arbeitstage, inklusive 1800 Pferdetage; beim Verarbeitungsbetrieb 11.440 Arheitstage. Rechnet man 300 Arbeitstage per Jahr, so resultiert für den erstern eine Arbeiterzahl von 66, bei letzterm von 38, zusammen: 104 Arbeiter oder per 100 ha 10 Arbeiter oder 3000 Arbeitstage. Diese starke Inanspruchnahme menschlicher Arbeitskräfte schliesst allerdings die Gefahr in sich, dass bei einer weitern Steigerung der Löhne, welche nicht gleichzeitig ron einer Preissteigermg der Arbeitsprolukte hegleitet sein würde, die Rentabilität des Betriebssystems zurückgehen 
müsste, ja unter Umständen sogar hinter derjenigen der gewöhnlichen Waldbetriebe zurückbleiben könnte. Wenn daher irgendwo die Nachführung einer genauen Statistik, als beste Wegleiterin für die Beurteilung einer Wirtschaft notwendig ist, so trifft das bei dem in Frage liegenden Wirtschaftssystem zu.

Hundeshagen ${ }^{1}$ )

hat 143.5 auf 1041 ha Wali 20:5) Arbeitstage

von Berg

Bernhardt

» $1850 \gg 100 \gg$ » 925

》 $1869 \gg 100$ »

675

do. bei der Haubergswirtschaft $\gg 100 \gg$ » 1390

Es darf wohl angenommen werden, dass seit dieser Zeit an den genannten Orten ebenfalls eine Steigerung der mit dem Forstbetriebe verbundenen Arbeitsleistungen stattgefunden hat, konform der in diesen Ländern erfolgten Preissteigerungen des Holzes.

Der Mangel einer einheitlichen Statistik erschwert die so wünschbare Vergleichung der Ergebnisse der verschiedenen Forstbetriebe, ganz abgesehen davon, dass die der Oeffentlichkeit übergebenen Publikationen der einzelnen Länder entweder bloss summarischer Natur sind; oder sich nur auf grössere Forstbezirke beziehen. Immerhin mag auch die Zusammenstellung ungleichartiger Verhältnisse etwelche Anhaltspunkte bieten für die Beurteilung der so sehr von andern Betrieben abweichenden Daten der Stadtwaldungen von Zürich.

$\begin{array}{ccc}\begin{array}{c}\text { Brutto- } \\ \text { einuahmen }\end{array} & \begin{array}{c}\text { Betriebs- } \\ \text { ausgaben }\end{array} & \text { Reinertrag } \\ \text { Fr. } & \text { Fr. } & \text { Fr. } \\ \text {. } 44.79 & 18.33 & 26.46 \\ .92 .26 & 39.60 & 52.66 \\ .67 .06 & 32.46 & 34.60 \\ .127 .27 & 61.14 & 66.13 \\ \text { z) } 197.42 & 67.40 & \left.130.02^{2}\right) \\ .145 .40 & 37.40 & 108 .- \\ .307 .82 & 212.12 & 95.70 \\ .155 .65 & 42.53 & 113.12\end{array}$

1) Handbuch der Forstwissenschaft von Dr. Tuisko Lorey, zweite Lieferung pag. 89, Die Aufgaben der Forstwirtsehaft, bearbeitet ron Dr. R. Weber in München.

*) Sowohl bei den Winterthurer als bei den Zofinger Stadtwaldungen macht sich das überwiegende Vorherrschen der Nadelholzbestände bemerkbar. 


\section{YIII. \\ Zukünftiger Etat.}

\section{A. Grundsätzliche Auffassung der Etatsbildung.}

\section{Allgemeines.}

Die Durchführung eines intensiven, nachhaltigen Forstbetriebes hat als erste Voraussetzung die genaue Feststellung des jährlichen Etats, ausgedehnt nicht nur auf die Hauptnutzung, sondern auch auf die Zwischennutzungen. Beide stehen zu einander in einem unzertrennbaren Verhältnisse, das im Gesamtgeldertrag des Waldes zum Ausdruck gelangt. Der Forstbetrieb hat allerdings bei der Etatsermittlung grundsätzlich nur auf die Gleichartigh rit bezw. die kontinuierliche Steigerung der Materialerträge hinzuarbeiten. denn die anfallenden Gelderträge sind bis zu einem gewissen Grade von den Konjunkturen des Tages abhängig. Die scharfe Ausscheidung der bei der Etats-Aufstellung sich ergebenden sortimentsmassen bietet aber die nötigen Anlıaltspunkte, um auch die Gelderträge in der für die Aufstellung der Staats-, Kommunal- und Privathaushaltsbudgets notwendigen Art und Weise möglichst zutreffend zu entwerfen. Es ist auch zu beachten, dass die Durchforstungserträge zufolge den üherall zur Geltung gelangenden Wirtschaftsgrundsätzen gegenüber dem Hauptnutzungsertrag in stetem Zunehmen begriffen sind; an vielen Orten erreichen sie beinahe die Hälfte derselben. Aus allen diesen Gründen kann die einseitige Feststellung des Hauptnutzungsetats verbunden mit einer bloss prozentualen Veranschlagung der Zwischemntzungs- oder Durchforntungserträge nicht mehr als ausreichend bezeichnet werden.

Von nicht minderer Bedeutung für eine streng nachhaltige Wirtschaft ist sowohl rom Standpunkt der Massen- als der Geld- 
ertragsregulierung aus betrachtet die Heranziehung aller Sortimentsanfälle, nicht nur des Derbholzes, sondern auch des Reisigs bei der Bestimmung der jährlichen Nutzung. Sie ist besonders dann, wenn man einen speziellen Durchforstungsetat für angezeigt erachtet. eine unabweisbare Notwendigkeit; ebenso unerlässlich ist sie aber auch vom Standpunkte einer zuverlässigen Massenkontrolle und einer Vergleichung der Zuwachs- mit den Ertragsansätzen.

Die vorliegende Ertragsregulierung fusst auf der Berücksichtigung der beiden Anforderungen. Sie konstruiert einen die Hauptund Nebenbestandsnutzung umfassenden Gesamtetat. Sie berechnet denselben auf Grund der vorgenommenen Zuwachsermittlungen und unter Benützung des Materials. das in zwanzigjähriger Wirtschaftsführung bei genauer Buchung von Haupt- und Zwiscliennutzungen. Derbholz und Reisig, gesammelt werden konnte.

Der Umfang der jährlichen Gesamtnutzung eines Waldbetriebes entspricht bei vorhandenem Normalzustand dem jährlich laufenden Zuwachs der betreffenden Waldung: derselbe repräsentiert in diesem Fall die maximale Massennutzung. Der Tormalzustand hesteht. wenn das der gewählten Untriebszeit entsprechende Altersklassenverhältnis vorhanden ist und wenn auf den, den einzelnen Altersklassen zugehörenden Bestandesflächen der grösstmögliche Zuwachs erreicht wird. Sind diese Anforderungen nicht erfüllt, so ergeben sich für den Etat Abweichungen von der Nutzung des laufenden jährlichen Zuwachses, deren Lmfang im direkten Verhältnis steht zu der Differenz zwischen den normalen und den wirklichen Faktoren. Hauptund Nebenbestandsnutzung weichen von einander ab, sodass eine getrennte Würdigung jeder derselben zu erfolgen hat.

\section{Der Etat des Hauptbestandes.}

Das normale Altersklassenverhältnis steht in innigstem $\mathrm{Zu}-$ sammenhang mit dem normalen laufenden 'Zuwachs und dem normalen Vorrat. Der in einer Betriebsklasse erfolgende laufende $\mathrm{Zu}$ wachs ist nur dann nicht der normale oder wie wir ihn heissen, der maximale, wenn die Altersabstufung nicht eine gleichartige ist, mit andern Worten, wenn nicht sämtliche Schlatgflächen voin ersten bis zum Schlussjalı des Untriebes. orler sämtliche Periodenflächen gleich gross sind, sodass sie deshalb nicht den der Zuwachsreihe entsprechenden laufenden Zuwachs liefern können. 
Je nachdem kann hiebei der maximale laufende Zuwachs entweder überschritten oder umgekehrt nicht erreicht werden. Ist ein Ueberschuss von Periodentlächen in den Jahren des höchsten laufenden Zuwachses vorhanden, so wird der in der Betriebsklasse mögliche Maximalgesantzuwachs überschritten. Ist das umgekehrte Verhältnis zu konstatieren, sind die jüngsten oder aber die ältesten Bestandesalter mit ihrem geringeren laufenden Zuwachs vorherrschend vertreten, so bleibt der wirkliche laufende Gesamtzuwachs hinter dem maximalen zurück. In beiden Fällen gelangt dieses Verhältnis in Form des normalen und des wirklichen Vorrates zum Ausdruck.

Bei nur dem summarischen Betrage nach vorhandenem Normalvorrat, wo also die normalen Altersstufen fehlen, werden diese und damit auch der Normalzustand sich allmählich von selbst herstellen. sobald man kein grösseres Quantum als das dem wirklichen jährlichen Zuwachs entsprechende im ältesten Holze fortnutzt. Ist ein Mangel an normalem Vorrate vorhanden, so kann derselbe nur dadurch beseitigt werden, dass ein Teil des laufenden Zuwachses nicht genutzt, sondern zur Anhäufung am Vorrate verwendet wird; übersteigt umgekehrt der wirkliche Vorrat den normalen, so kann dieser Vorratsüberschuss in kürzeren oder längeren Perioden nächst dem laufenden jährlichen '/uwachs zur Nutzung herangezogen werden.

Der Etatsermittlung der Hauptnutzung hat daher vor allem aus voranzugehen die Feststellung des bei der vorhandenen Altersklassengliederung sich ergebenten Verhältnisses des maximalen Gesamtzuwachses zum wirklich erfolgenden, und dasjenige des Maximal- oder Normalvorrates zum wirklichen Vorrat. Je genauer beide Faktoren ermittelt werden können, desto richtiger kann die Feststellung des Etats erfolgen.

Der laufende Gesamtzuwachs ist eine Summe von Produkten, deren jedes einzelne gebildet wird aus dem laufenden Zuwachs eines jeden Jahres der L'mtriebszeit und der demselben zufallenden Fläche. Die Zahl der Produkte entspricht demgemäss der Zahl der Jahre der Umtriebszeit, sodass sich nachfolgende allgemeine Formel ergibt: $\mathrm{MZ}=\mathrm{lz}_{1} \cdot \mathrm{f}_{1}+\mathrm{lz}_{2} \cdot \mathrm{f}_{2}+\ldots \ldots+\mathrm{lz}_{\mathrm{u}} \cdot \mathrm{f}_{\mathrm{u}}$.

Beim maximalen Zwwachs ist $\mathrm{f}_{1}=\mathrm{f}_{2}=\ldots \ldots \mathrm{f}_{\mathrm{u}}=\frac{\mathrm{F}}{\mathrm{U}}$, sodass die allgemeine Formel übergeht in die rereinfachte Formel

$$
\mathrm{M} Z=\left(1 z_{1}+1 z_{\ldots}-\ldots \ldots z_{z}\right)^{\mathrm{l}} \mathrm{L}^{\mathrm{C}}
$$


Beim wirklichen Zuwachs werden die jedem einzelnen Jahre zufallenden Flächen ungleich gross sein, sodass sich die Formel verändern muss und sich nachfolgend gestalten wird:

$$
\mathrm{WZ}=\mathrm{lz}_{1} \cdot \mathrm{f}_{1}+\mathrm{lz}_{2} \cdot \mathrm{f}_{2}+\ldots+\mathrm{lz}_{11} \cdot \mathrm{f}_{11} \cdot
$$

Das Endresultat bleibt dasselbe, und die Berechnung wird dadurch vereinfacht, wenn je eine Anzahl von einzelnen Jahren in Perioden zusammengefasst wird, die je nach den Verhältnissen zehn, zwanzig oder mehr Jahre betragen können. Wird nun der in der Mitte dieser Perioden anfallende laufende Zuwachs mit der wirklichen Periodenfläche multipliziert, so ist die gleiche Reihe in kürzerer Weise erstellt. Wenn wir die Periodendauer mit n, die Periodenzahl mit $m$, die Periodenflächen mit $f_{1}, f_{2} \ldots f_{m}$ bezeichnen, so ist:

$$
W Z=z_{1 n-\frac{n}{2}} \cdot f_{1}+l_{2 n-\frac{n}{2}} f_{2}+\ldots .+z_{m n-\frac{n}{2}} \cdot f_{m} .
$$

In analoger Weise wie der Maximalzuwachs kann der maximale oder normale Vorrat ermittelt werden; wir haben nur in der Formel: $\mathrm{MZ}=\left(\mathrm{lz}_{1}+\mathrm{lz}_{2} \ldots \ldots . \mathrm{lz}_{12}\right) \frac{\mathrm{F}}{\mathrm{U}}$ statt des laufenden Zuwachses die Bestandesmasse eines jeden Jahres der Umtriebszeit: $V_{1}, V_{2}, V_{3}$ $\ldots . . V_{11}$ einzusetzen und erhalten dann für den Normalvorrat nachfolgende Formel:

$$
\text { IIV }=\left(V_{1}-V_{2}+V_{3} \ldots \ldots+V_{u}\right) \frac{\mathrm{E}}{\mathrm{U}}
$$

Sowohl die Formel für die Feststellung des maximalen laufenden Zuwachses, als diejenige des maximalen Vorrates kann selbstverständlich nur dann zur Anwendung gelangen, wenn durch lokale Ertragstafeln die nötigen Faktoren geliefert sind.

Der wirkliche Vorrat kann ebenfalls nach der oben aufgestellten Formel unter Zuhülfenahme der Ertragstafeln berechnet werden. Man wird aber vorziehen, denselben wenigstens für die obern Glieder durch direkte Massenaufnahmen zu ermitteln, um dadurch ein den konkreten Verhältnissen möglichst entsprechendes Waldbild zum Zwecke der Etatsfestsetzung zu erhalten: bei der vorliegenden Ertragsregulierung ist dies tatsächlich für alle über 70 Jahre alten Bestände geschehen. Die okulare Einschätzung wurde als unzureichend befunden und die Kluppierung aller dieser Bestände vorgenommen. Die Massenberechnung erfolgte an Hand der Formel $\frac{Y}{G}$, deren Faktoren für den Sihlwald mit Hülfe der vorhandenen Probeflächen der forstlicien Zentralanstalt genau ermittelt waren. 
Sind die Zuwachs- und Vorratsverhältnisse bekannt, und ist die Umtriebszeit gegeben, so kam zur Feststellung des Ftats geschritten werden. Wie weiter oben dargetan wurde, ist derselbe gleich dem wirklichen laufenden maximalen \%uwachs, sofern der Wald, sowohl mit Bezug auf Altersabstufung als auf Vorrat, normal ist. Fehlt es an einem dieser Faktoren, so ist die Etatsbildung derart vorzunehmen, dass innerhalb eines bestimmten Ausgleichungszeitraumes mit der regelmässigen Altersabstufung der maximale laufende 'Zuwachs und mit beiden vereinigt die Gleichheit von wirklichem Vorrat und Maximalvorrat vorhanden ist. Die notmale Altersabstufung kann frühestens unter Inanspruchnahme einer ganzen Umtriebszeit erzielt werden. Sie ist abhängig von der jeweilen zum Abhieb gebrachten Fläche, welche so lange grösser oder kleiner als der Quotient aus $\underset{\bar{U}}{\mathrm{~F}}$ sein wird. bis der auf derselben angewachsene Vorrat genau der zugehörenden Altersstufe entspricht.

Der wirkliche Vorrat, bestehe er in einem Ueberschuss oder in einem Fehlbetrag, lässt sich ja allerdings in kürzerer \%eit in den normalen überführen, sodass, wenn es sich bloss um die Lösung dieser Aufgaben handeln wïrde, A kleiner als $\mathrm{U}$ angenommen werden könnte. Mit dem Vorhandensein des normalen Vorrates ist dagegen der normale Waldzustand noch nicht erreicht. Die normale Altersabstufung, nicht im Sinne einer strengen ätlichen Aneinanderreihung der einzelnen Altersstufen, sondern allgemein derart, dass eine gleichmässige Flächenausstattung aller Altersstufen überhaupt vorhanden sei. ist das anzustrebende, aber nur allmählich erreichbare Wirtschaftsziel.

Es ist daher angezeigt, $\mathrm{A}=\mathrm{U}$ zu setzen und den Etat aus nachstehender Formel abzuleiten:

$$
\mathrm{E}=\mathrm{WZ}+\frac{\mathrm{WV}-\mathrm{NI}}{\mathrm{U}}
$$

\section{Der Etat des Nebenbestandes.}

Es ist schon bei den Betrachtungen über die Bestandespflege hervorgehoben worden, dass die Durchforstungen nach zwei Richtungen hin ins Auge zu fassen sind, einmal als waldbauliche Massregel und sodann als integrierender Bestandteil des Gesamtertrages, als Vornutzung. Dem entsprechend muss auch bei der Etatsregulierung derselben dieser doppelte (harakter bericksichtigt werden. Seinem Wesen nach - es wurde dies bei Darlegungen 
über die Zuwachsverhältnisse des Nebenbestandes zu begründen versucht (pag. 151) hat derselbe seine Masse von einer Durchforstung. zur andern erst zu bilden und aufzuspeichern, um dann bei der kommenden Durchforstung wieder zu verschwinden. Um somit einen Etat des Nebenbestandes konstruieren zu können, ist es notwendig, den Betrag des laufenden Zuwachses, der vom Hauptbestand jeweilen sich ausscheidenden Masse festzustellen. Ist der Normalzustand einer Betriebsklasse vorhanden und zwar sowohl mit Bezug auf die Altersklassen- als auf die Zuwachsverhältnisse, so ist ähnlich wie leim Haupthestand der Etat des Nebenbestandes im laufenden Zuwachs ausgedrückt; er bleibt unter der Voraussetzung gleicher Wirtschaftsgrundsätze während einer ganzen Umtriebszeit der gleiche. Ist das normale Altersklassenverhältnis nicht vorhanden, so machen sich teilweise veränderte Anforderungen geltend als bei der Festsetzung der Hauptbestandesnutzung. Ein Ueberwiegen der 30-50jährigen Bestände kann dann beim Vorhandensein normaler Vorratsverhältnisse im Haupthestand eine Steigerung des Zwischennutzungs- und damit eine Zunahme des Gesamtetats zur Folge haben. Der Ueberschuss an Durchforstungsmasse über die normale Grösse könnte auch dazu verwendet werden, vorübergehend den Hauptnutzungsetat zu reduzieren, sorlass dadurch eine Reserve geschaffen wäre, welche entweder die Erhöhung der Umtriebszeit ermöglicht, oder in gelegenem Zeitpunkt zur Verwendung gezogen werden kann. Es würde also in diesem Falle ein Vikarisieren zwischen Haupt- und Nebenbestandesetat imnerhalb der Grösse des normalen Gesamtetats stattfinden. Anders gestalten sich dagegen die Verlältnisse des Zwischennutzungsetats, wenn die jüngern 15-30jährigen, oder die ältern 70-100jährigen Altersklassen überwiegen und dannzumal ein Fehlbetrag an Durchforstungsmasse gegenüber ier berechneten normalen Grösse vorhanden ist. In diesem Falle muss der Gesamtetat notwendigerweise geringer. werden als der normale. Hier darf nun aber ein Vikarisieren des Haupthestandesetats für den fehlenden Betrag an Durchforstungsmasse nicht eintreten; der Fehlbetrag am Durchforstungsetat darf nicht durch eine vermehrte Nutzung am Hauptbestamd kompensiert werden. Aus diesen Erwägungen geht wohl zur Genüge hervor, dass die Festsetzung des Nehenbestandecetats sich in engster IVeise an die konkreten Verhältnisse des Wirtschaftsbetriebes anzuschliessen hat und dass ihr vor allem aus die genaue Ermittlung der Zuwachsverhältnisse des Nebenbestandes voranzugehen hat. 


\section{Der Gesamt-Etat.}

Der Gesamtetat eines Waldbetriebes als Ausdruck seiner Gesamtleistung kann nach den vorstehenden Darlegungen nichts anderes sein als die Zusammenfissumg des Hinpthestandesetats mit dem des Nebenbestandesetats. Er entspricht der Summe der Abtriebsschläge und der Durchforstungen; beides sind bekannte, aus genauester Ermittlung der Vorrats- und Zuwachsverhältnisse abgeleitete Grössen. Ihre genaue Erhebung sichert die Erhaltung eines bereits vorhandenen oder aber erst anzustrebenden Normalzustandes. Wenn über diesen Punkt eine Veimmgsdiflerenz nicht stattfinden kann, so gestalten sich die Verhältnisse anders, wenn die Frage aufgeworfen wird: wie lässt sich die Erhebung dieses Gesamtetats mit Bezug auf die Innehaltung der ermittelten Teilquoten im Wirtschaftshetrieb kontrollieren: Sind die Garantien dafür vorhanden. dass bei der so naheliegenden, iìrer Einfachheit halber bestechenden, einzig auf die Gesamtanfälle von Hauptnutzung und Durchforstung eingeschränkten Materialkontrolle der für dic angesetzte Umtriebszeit nötige Vorrat an Holz der ältesten Klasse erhalten bleibt, bezw. wenn er noch nicht vorhanden sein sollte, erreicht werden wird? Wie kann dabei anderseits die Möglichkeit geschaffen werden, im Interesse der Hebung des Qualitätszuwachses in den älteren Bestandesklassen oder der rechtzeitigen Nutzung ron Holzarten mit früherem Hiebsreife-Alter die Bestandeslichtungen örtlich und zeitlich weiter auszudehnen, als es grundsätzlich auf dem Durchforstungswege angezeigt wäre? Ist in einem solchen Falle, der ganz im Interesse der Wirtschaftsführung liegen, ja durch dieselhe eigentlich geboten sein kann, ein sich ergebendes Plus am Durchforstungsanfall der jüngeren Bestände einzusparen, oder hat eine Reduktion der Hauptbestandesnutzung stattzufinden: Diese und noch andere Fragen müssen in Betracht gezogen werden bei der Art der Festsetzung des Gesamtetats und der mit dieser in unzertrennbarem Zusammenhange stehenden Etatskontrolle. In bisherigen Wirtschaftssystem hat man, und es geschieht dies noch an vielen Orten. um diesen Fragen aus dem Wege zu gehen und Schmälerungen des Vorratskapitals zu vermeiden, zu dem willkürlichen Wittel gegriffen. die Durchforstungsanfälle und Vorhiebe der letzten -nj|ïhrigen Periode ganz einfach der Hauptnutzung zuzuschlagen und das eigentliche Schlagquantum um so viel zu kürzen. Es liegt aber in diesem Vorgehen eine unzweifelhafte Inkorrektheit, denn der auf den Haubar- 
keits-Durchschnittsertrag basierte Etat war rom Massengehalt des bis zu Ende der Umtriebszeit durchforsteten Bestandes abgeleitet. Bei dem in vorliegender Wirtschaftsregulierung befolgten System der Etatsfeststellıng wird für den Hauptbestandesetat elrenfalls nur der laufende Zuwachs an dem bis zur Erntezeit durchforsteten Bestande in Rechnung gezogen und gleichzeitig der Anfall vom Zuwachs des Nebenbestandes, d. h. der Durchforstung, als ein mit dem Hauptbestand nicht vermengbarer zweiter Nutzungsteil ausgeschieden. Uebersteigt der in den älteren Bestandesklassen erhobene Anteil den Betrag des in denselben am Nebenbestand sich ergebenden Zuwachses, hat sich die Durchforstung zu einem Vorhieb ausgestaltet, so ist der Hauptbestandesetat nur um diesen Betrag und nicht um den aus dem Gesamtbetrag der diesen Klassen entnommenen Massen zu kürzen.

Bei den Betrachtungen über den Etat des Nebenbestandes wurde dargetan, dass je nach dem Ueberwiegen der jüngeren, mittleren oder älteren Bestandesklassen sich ein Ueberschuss oder ein Nanko gegenüber dem normalen Durchforstungsetat ergeben könne. Im ersteren Falle dürfe derselbe entweder als Zuschlag zum normalen Nebenbestandesetat ohne Einsciränkung des Hauptbestandesetats oder als Abzug an letzterem, sei es zur Bildung einer Reserve oder zur Mehrung des Vorrates behufs Erhöhung der Umtriebszeit verwendet werden. Ein Aufspeichern der Nebenbestandes-Etatshiebe durch Einschränkung der Durchforstungen stünde im Widerspruch mit den durch die Bestandespflege gestellten Anforderungen: derselbe würde eine Becinträchtigung des laufenden Gesamtzuwachses bedeuten. Fasst min demgemäss ins Auge, dass es jedweder Betriebstührung. speziell beim System der natïrlichen Terjüngung und bei der Erstrebung eines grösseren Sortimentszuwachses in den älteren Bestandesklassen, schwer fallen. ja geradezu unmöglich sein wird, Durchforstung und Vorhiebsnutzung scharf auseinander zu halten, so dürfte die Zusammenfassung von Hauptbestand- und Nebenbestandesetat der älteren Klassen, mit anderen Worten die Verschmelzung des Hauptnutzungsertrages mit dem berechneten Durchforstungsertrag derselben und daneben die getrennte, separater Kontrolle unterliegende Nutzung des in den jüngeren Klissen sich ergehenden Nebenbestandes-7uwachses die unantastbare Grundlage einer soliden Etatshestinmung und Etatskontrolle bilden. Die für die jüngeren Altersklassen einzig in Betracht fallenden Rücksichten auf eine zutreffende Bestandespflege, wie die anderseits bei 
den älteren Klassen gemeinsam zutage tretenden Forderungen der Erzielung des höchsten Ernteertrages und der hiefür nötigen waldbaulichen Massnahmen, sind bei diesem System gewahrt; seine Durchführung sichert die Nachhaltigkeit und gibt der Bestandespflege hüben und drüben freien Spielraum. Die Altersgrenze, welche für die beiden Abschnitte als Scheidelinie anzunehmen ist, dürfte in den Zeitpunkt fallen, wo der grösste laufende Massenzuwachs erreicht oder bereits überschritten, die samenfähigkeit eingetreten ist und wo der Aushieb der Holzarten mit früherem Hiebsalter begonnen werden muss. In den zürcherischen Stadtwaldungen kanm das 70. Altersjahr hiefür angenommen werden.

\section{B. Die Anwendung der vorstehenden Grundsätze auf die konkreten Waldverhältnisse.}

\section{Die Ausscheidung in Betriebsklassen und Abteilungen.}

Die Uebertragung der allgemeinen Grundsätze der Ertragsregulierung auf die konkreten Verhältnisse der in Betracht fallenden Wirtschafts- Winheit führt zunächst zur Feststellung der Zahl und Art der Betriebslilasen, welche der künftigen Wirtschaftsführung als Basis zu dienen haben. In ihnen liegt die Möglichkeit, der Verschiedenartigkeit der Verhältnisse, wie sie sich in jeder grösseren Wirtschaftseinheit ergeben, Rechnung zu tragen; sie gestatten lie Individualisierung des starren Ganzen, indem sie nur dasjenige zu gleichartiger Behandlung zusammenziehen, was sich nach den Stumdorts- und den Bestandesverhältnissen, wie mit Bezug auf die Bewirtschaftung zu gleichartiger Behandlung eignet.

Der Wirtschaftsplan vom Jahre 1880 hatte in Anlehnung an diesen Grundsatz und in Würdigung der damaligen Verhältnisse drei Betriebsklassen ausgeschieden: den Sihlwall als tranzes gennmmen, Oberer und Unterer Sihlwald nebst den Albishölzern, sodann den auf dem linken Sihlufer liegenden Forst und endlich den auf den Höhen des Zürichbergs gelegenen Waldbezirk Adlisberg. Diese 
Ausscheidung hat wohl zu einseitig nur den Standortsunterschieden und nicht auch der Verschiedenartigkeit der Wirtschaftsverhältnisse Rechnung getragen. Schon im Jahre 1895 wurden deshalb bei der damals vorgenommenen Zwischenrevision die Albishölzer von der sihlwaldbetriebsklasse abgetrennt und in eine besondere Betriebsklasse ausgeschieden, der die zwei vorher zur Wildgartenstiftung gehörenden Komplexe Winzelen und Albisplateau zugewiesen wurden. Der seit Jahrhunderten in zwei Hiebsfolgen getrennte, aber als eine Betriebsklasse mit einheitlicher Umtriebszeit behandelte Wirtschaftsbezirk verblieb in dieser Klassifikation. Heute milissen die Würdigung der durch die Schneebruchkatastrophe 188.5 im Oberen Sihlwald herheigeführten Anormalität der Altersklassen und Vorratsverhältnisse, wie anderseits die für Erhöhung der Umtriebszeit im Untern Sihlwald sprechenden Momente dazu führen, eine Ausscheidung in zтrei Betriebsklassen vorzunehmen; denn nur dadurch wird es möglich werden, jeden einzelnen dieser Teile seinem Charakter entsprechend zu behandeln.

Der künftigen Wirtschaftsführung und zunächst dieser Ertragsregulierung werden somit nachstehende Betriebsklassen zugrunde gelegt:

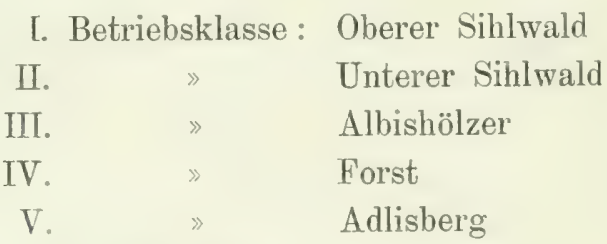

Für jede dieser Betriebsklassen sind Umtriebszeit und Etat besonders festzustellen; ihre Grösse ist ausreichend, um sowohl den Haupt- wie den Zwischennutzungen die für einen rationellen Wirtschaftsbetrieb nötige Ausdehnung zu sichern.

Die für die Betriebsführung erforderliche weitere Ausscheidung der Betriebsklassen in Abteilungen gibt zu keinen Aenderungen gegenüber der bisherigen Anlass, es würde eine solche auch nicht im Interesse der Wirtschaftskontrolle liegen. Das wertvolle forststatistische Material, welches in der genauen Buchung der bisher in jeder Abteilung erfolgten Haupt- und Zwischennutzungen vorhanden ist, müsste an Wert verlieren, sobald eine Aenderung in der Abteilungsbildung vorgenommen würde: die konsequente Fortführung lesselhen würde durch diese Veränderung der Abteilungen unterbrochen. An und für sich entspricht die im Jahre 1880 vor- 
genommene Ausscheidung der Ahteilungen den von w Wirt-chaftsführung zu stellenden Inforderungen in hefriedigemlex 11 eise. sowohl nach der Grösse als der Abgrenzung, wie auch mit Bezug auf die natürliche Verjüngung; sie gestattet derselben denjenigen freien Spielraum, der verlangt werden muss, wenn die Bestandeslichtung den Lichtungszuwachs am alten Bestand wie am Jungwuchs in dem erstrebten Umfange fördern soll.

Wenn somit bei der Abteilungsbildung keinerlei Aenderungen für nötig erachtet werden, so gestalteten sich dagegen die Verhältnisse bei den Unterabteilungen in entgegengesetzter Art; die im Jahr 1880 vorgenommene Gliederung ler Abteilungen in Interabteilungen wurde mit Ausnahme der Schneebruchpartien fallen gelassen. Während der zwei Dezemien der abgelaufenen Wirtschaftsperiode hatte es sich genugsam erzeigt. dass die detaillierte Glierlerung in Unterabteilungen der Wirtschaftsführung hindernd im Wege steht. Die davon erwarteten Vorteile werden durch die damit verbundenen Nachteile nicht aufgewogen. Die Hiebskontrolle wit die Blichung werden durch zu viele Unterabteilungen mit einem Ballaste beladen. der entbehrlich wird, sobald die fiir die Altersklassen- und Vorratstabelle nötigen Bestandeserhebungen mit angemessener Genauigkeit ausgeführt sind.

\section{Die Umtriebszeit.}

Soweit die Geschichte der Sihltalwaldungen Aufschliisse zu goben vermag. zeigt sich, dass der Forstbetrieb sich imnerhalb einer 90 bis 100jährigen Umtriebszeit bewegt hat: diese Dauer entsprach dem vorherrschenden Bedïrfnis nach Brennmaterial. Dank den gïnstigen Standortsverlältnissen genuigte sie aber auch für die Nachzucht wertvoller Nadelhölzer, die ja, wie auf pag. 64 nachgewiesen ist, bis 1690 dominierten und erst von da ab gegenüber den Laubhölzern zurücktraten. Dieser historische Nachweis war anlässlich des Wirtschaftsplanes 1880 neben der Berücksichtigung der bei der Festsetzung der Umtriebszeit allgemein geltenden forstlichen Grundsätze der Ausschlag gebende. Er führte zur Beibehaltung der 90jährigen Umtriebszeit in der ganzen Wirtschaftseinheit. Die Erhöhung derselben wurde auf eine folgende Periode hinausgeschohen. Die - i.herbruchkatastrophe führte dann aber zu einer derartigen Reduktion der Vorrats- und Zuwachsverhältnisse des Obern Sihlwalcles, dass 
im Interesse baldigster Miederherstellung des grösstmöglichen Zuwathses für diese Betriebsklasse eher eine 80jährige Umtriebszeit angezeigt war. Inzwischen sind weitere Momente hinzugetreten, welche die früher so einfache Ableitung der Umtriebszeit aus der historischen Angewöhnung einerseits und aus dem physischen Haubarkeitsalter anderseits durchkreuzen. Das wie überall, so auch in den städtischen Waldungen eingebürgerte Prinzip der Erziehung gemischter Bestände bietet der Wahl der Umtriebszeit an und für sich grössere Schwierigkeiten, als dies bei reinen Beständen der Fall ist. Dieselben vermehren sich noch, wenn die bisher in der Mischung dominierende Holzart auf dem Holzmarkt einer ganz reränderten Nachfrage begegnet. Und dies trifft nun in hohem Masse zu bei der Buche, welche als die Haupt-Bestandesbildnerin der städtischen Waldungen bezeichnet werden muss. Die bisher gewählte Umtriebszeit von 90 Jahren fällt ja allerdings noch heute mit der Periode des höchsten Durchschnittszuwachses dieser Holzernte zusammen: auch die neuen Tafeln weisen denselben ähnlich wie die früheren auf das 86. Jahr hin. Aber der Absatz der 90jährigen Buche ist heute viel schwieriger als früher, weil die Brennholznachfrage zufolge der rapiden Zunahme des Gas- und Kohlenkonsums auf dem Platze Zürich in stetigem Rückgang begriffen und die Nutzholzverwendung der Buche in der Altersperiode von 90 Jahren, trotz den Erleichterungen, welche der städtische Terarbeitungsbetrieb hiefür bietet, äusserst beschränkt ist. Eine Aenderung der Bestandesmischung kann wohl beim Abtrieb der haubaren Bestände und bis zu einem gewissen Grade auch bei den Durchforstungen in den jüngeren Bestünden vorgenommen werden. Für die nächsten 40 Jahre wird sich jedoch der Charakter des Schlagmateriales der älteren Sihlwaldbestände anders nicht gestalten lassen, als durch die Erhöhung der Umtriebszcit, womit damn ein vermehrtes Nutzholzquantum erhältlich sein dürfte.

Die Zuwachsverhältnisse der Sihlwaldbuche sind, wie weiter oben dargetan wurde, im Alter von über 90 Jahren noch so günstig, dass eine Erhöhung der Umtriebszeit auf 110-120 Jahre nicht von einer wesentlichen 1 bmahme des Massenzuwachses begleitet sein wird; wohl aber ist dabei eine erhebliche Steigerung des Sortimentszuwachses in Aussicht zu nehmen. Von diesem Gesichtspunkte amsgehend wäre somit die Wahl der 110-120jährigen Umtriebszeit für die beiden Sihlwald-Betriebsklassen olne weiteres angezeigt: aber es muss dabei auch der fuir diese erhöhte Umtriebszeit nötige 
Holzvorrat ins Auge gefasst werden. Er ist zurzeit nicht vorhanden, namentlich nicht im Oberen Sihlwald; die am jährlichen Etat vorzunehmende Einsparung wäre zu empfindlich. Das angestrebte Ziel kann somit nur auf dem Wege eines sukzessiven Ueberganges erreicht werden. Zudem sind die Torhältnisse in jeder einzelnen Betriebsklasse jeweilen im besondern zu würdigen.

In der ersten Betriebsklasse Oberer Sihlwald ist auch bei einer $90 j a ̈ h r i g e n ~ U m t r i e b s z e i t ~ n o c h ~ e i n ~ V o r r a t s d e f i z i t ~ v o n ~ 21,508 ~ \mathrm{~m}^{3}$ vorhanden. Die aus der Einsparung desselben sich ergebende Reduktion des jährlichen Etats darf durch eine Erhöhung der Untriebszeit nicht mehr vergrössert werden. Aus diesem Grunde ist für diese Betriebsklasse die 90jährige Umtriebszeit beizuhehalten. Ander's gestalten sich die Verhältnisse bei der zweiten Betriebsklasse Unterer Sihlwald, wo die Altersklassen und Vorratsverhältnisse weit günstiger sind. Bei einer Erhöhung der Umtriebszeit auf 110 Jahre ergibt sich nur ein Vorratsmanko von 16,912 $\mathrm{m}^{3}$, dessen Einsparung im Verlaufe einer ganzen Imtriebszeit eine wesentlich Beeinträchtigung des Etats nicht zur Folge hat, Für die Betriel)klassen drei und vier, Albishölzer und Forst, wäre angesichts des Vorherrschens der Nadelhölzer eine Erhöhung der bisherigen 90jührigen Untriebszeit angezeigt. In Berücksichtigung des ungleichartigen Bestandescharakters, der sich in beiden Betriebsklassen zufolge ilrrer Zusammensetzung aus ganz ver'schiedenartigen Bestandteilen s. Itend macht. erscheint uns die baldige Erzielung einer normalen Altersabstufung und damit verbundener normaler Alters- und Zuwachsverhältnisse als nächstliegende Aufgabe. Dies umsomehr, als auch der Absatz der bei 90 Jahren erzielten Nutzholzsortimente dank der Hülft des Verarbeitungsbetriebes ein gesicherter und durchaus günstiger ist.

Dieses letztere Moment trifft für die fünfte Betriebsklasse, für den Forstbezirk Adlisberg, nicht zu. Das Hiebsmaterial gelangt hier auf öffentlicher Steigerung zum Verkauf, wobei sich der Wert stärkerer Sortimente sofort bemerkbar macht. Zudem treten hier die Laubhölzer nicht in dem vorherrschenden Unfange als Bestandesbildner auf, wie in den Sihltalwaldungen. Weisstanne und Fichte zeigen auch in höherem Alter noch besonders günstige Zuwachsverhältnisse. Aus allen diesen Grünlen ist eine Erhöhung der Umtriebszeit von 90 auf 100 Jahre angezeigt. Der hieraus entstehende Vorratsmanko von $6020 \mathrm{~m}^{3}$ ist nicht derart, dass eine Einsparung einer fühlbaren Reduktion des Etats rufen wird. 
Die Umtriebszeiten der fünf Betriebsklassen stellen sich demgemäss wie folgt:

$\begin{array}{llr}\text { I. Betriebsklasse: } & \text { Oberer Sihlwald } & 90 \text { Jahre } \\ \text { II. } & \text { Unterer Sihlwoald } & 110 \\ \text { III. } & \text { Albishölzer } & 90 \\ \text { IV. } & \text { Forst } & 90 \\ \text { V. } & \text { Adlisberg } & 100 \gg\end{array}$

Sie bedeuten in ihrer Gesamtheit eine Annäherung an die Starkholzwirtschaft, die nur bei einer angemessenen Höhe der Umtriebszeit durchführbar ist. Auch ohme spezielle Berechnung des Weiserprozentes dürfen sie zugleich als die finanziell günstigsten bezeichnet werden. Nicht minder ist zu betonen, dass auch die Verschiedenartigkeit der Bestandesmischung bei den gewählten Ansätzen allerwärts durch Ausnützung des grösstmöglichsten Zuwachses ihre Berücksichtigung findet.

\title{
3. Die Berechnung des Etats nach der beigefügten Ertragstafel.
}

\author{
a) $\mathrm{H}$ a uptbestand.
}

Gemäs: den Grundsätzen, welche für die Etatsbildung des Hauptbestandes aufgestellt wurden, ist die Konstruktion des Etats für jede der fünf Betriebsklassen einzeln vorzunehmen. Sie vollzieht sich durch Einsetzung der betreffenden Faktoren in die allgemeine Formel: $\mathrm{E}=W W+\frac{W T-N T}{\mathrm{C}}$. wobs: ler Ausgleichungszeitraum entsprechend del für jede Betriebsklasse gewählten Umtrielszeit anzunehmen ist. Es ergeben sich demnach folgende Zahlen:

\begin{tabular}{|c|c|c|c|c|c|c|c|}
\hline \multirow{2}{*}{ Betriebsklasse } & \multirow{2}{*}{$\mathrm{U}$} & \multirow{2}{*}{ WIZ } & \multicolumn{3}{|c|}{ Torratsverhältnisse } & \multirow{2}{*}{$\begin{array}{c}\text { Etat } \\
\mathrm{m}^{3}\end{array}$} & \multirow{2}{*}{ Bemerkungen } \\
\hline & & & Wr & NV & Differenz & & \\
\hline Oberer Sihlwald & 90 & 1,838 & 62,270 & 83,778 & $-21,508$ & 1,600 & Schneebruchdefizit \\
\hline Unterer Sihlwald & 110 & 1,812 & 87,230 & 104,142 & $-16,912$ & 1,660 & Erhöhung von U \\
\hline Albishölzer & 90 & 1,248 & 42,520 & 42,328 & $+\quad 192$ & 1,250 & $\begin{array}{l}\text { voll } 90 \text { aut } 110 \\
\text { Jahre }\end{array}$ \\
\hline Forst & 90 & 732 & 28,660 & 29,438 & $-\quad 778$ & 720 & \\
\hline Adlisberg & 100 & 589 & 23,310 & 29,330 & $-6,020$ & 530 & Erhöhung von U \\
\hline Total: & & 6,219 & 243,990 & 289,016 & $\begin{array}{r}-45,218 \\
+\quad 192\end{array}$ & 5,760 & Jahre \\
\hline
\end{tabular}


Der im Jahre 1893 bei annähernd gleichem Arealbestand auf Grundlage des Haubarkeitsurehschnittsuwachses und bei der einheitlichen Umtriebszeit von 90 Jahren ermittelte Etat betrug 5900 Festmeter. In der geringen Differenz der beiden auf so verschiedenartige $W$ eise berechneten Etat: diurfte wohl dic wünschbare Garantie für die richtige Bemessung der fïr eine nächstliegende Periode angesetzten Nutzung zu finden sein. Eine Vergleichung mit dem Etat vom Jahre 1880 ist deshalb nicht statthaft, weil der Arealbestand geringer war. Gegenüber dem dazumaligen Etat von 5740 Festmeter ist demgemäss der heutige relativ kleiner.

\section{b) Neben bestand.}

Die Kurve des laufenden Zuwachses beim Nebenbestande des Sihlwaldes zeigt uns die jährliche Zuwachsanhäufung bis zum 100 . Jahr. sie ermöglicht uns deshalh die Gesamtheit der Nebenhestandesnutzungen dadurch zu ermitteln, dass wir die jeder Altersstufe zugehörende Bestandesflïche mit dem ihr entsprechenden Zuwachs multiplizieren. Da die Altersklassenabstufung keine normale ist, so sind die anfallenden Erträge nicht gleich denjenigen, die sich bei normalem Altersklassenverhältnis ergeben: sie sind, wie aus nebenstehender Tabelle hervorgeht. einesteils infolge der Einwirkungen der Schneebruchkatastrophe und sodann wegen Veränderung der Betriehsklassen bzw. Verschiebung derselben meist kleiner als die normalen.

\begin{tabular}{|c|c|c|c|c|c|c|c|c|c|}
\hline \multirow{2}{*}{ Betriebsklasse } & \multicolumn{3}{|c|}{$1-70$ jährig } & \multicolumn{3}{|c|}{ 71-Ujährig } & \multicolumn{3}{|c|}{$i-c_{j}$ jihri: } \\
\hline & normal & wirklich & Differenz & normal & mirklich & Differenz & normal & wirklich & | Differenz \\
\hline Oberer Sihlwald & 793 & 617 & -176 & 332 & 293 & $|-\quad 39|$ & 1,125 & 910 & -215 \\
\hline Unterer sihlwald & 634 & $5+1$ & $\ldots \quad 43$ & 460 & 377 & -83 & 1.044 & $41 ऽ$ & -17 \\
\hline Albishölzer & 453 & 593 & +140 & 190 & 61 & $|-129|$ & 643 & 654 & +11 \\
\hline Forst & 282 & 313 & +31 & 117 & 84 & -33 & 399 & 397 & - \\
\hline Adlisberg & 226 & 209 & -17 & 125 & 68 & -57 & 351 & 277 & -74 \\
\hline
\end{tabular}

Diese Nutzungsansätze treffen nun allerdings nur zu für die laufende 10jährige Periode, für jede weitere sind sie neu zu bestimmen; sie werden sich speziell für die nächstfolgende, wegen des Vorrückens der 15-30jährigen Bestände im obern Wald in die grösste Zuwachsstufe, um ein wesentliches erhöhen.

Die vorstehenden Zahlen zeigen, dass in der ersten und zweiten Betriebsklasse, aus den gleichen Ursachen. die zu cinem Fehllsetrag des wirklichen Vorrates im Hauptbestand Veranlassung geben, auch 
beim Nebenbestand ein solcher vorhanden ist, sodass ein Vikarisieren des Nebenbestandes zu gunsten der Vorratsanhäufung im Hauptbestand nicht eintreten kann. Bei den übrigen Betriebsklassen sind die Differenzen zwischen normalem und wirklichem Betrag so gering, dass sie nach keiner Seite hin in Betracht fallen.

$$
\text { c) Gesamtetat. }
$$

Nach den für die Aufstellung des Gesamtetats entwickelten Grundsätzen sind die für den Etat des Hauptbestandes, wie für den Etat des Nebenbestandes ermittelten Werte in der Weise in Rechnung zu bringen, dass dem jeweiligen Hauptnutzungsetat noch derjenige des Nebenbestandes von 70-U Jahren beigefügt wird. Der sich ergebende Betrag bildet mit demjenigen der Nebenbestandesoder Zwischennutzungen vom 1.-70. Jahr den Gesamtetat. Unter Abrundung auf die Zehnerzahlen gestaltet sich der Gesamtetat für die Periode 1900-1910 wie folgt:

\begin{tabular}{|c|c|c|c|c|c|}
\hline \multirow{2}{*}{ Betriebsklasse } & \multicolumn{3}{|c|}{ Hauptnutzung } & \multirow{2}{*}{$\frac{\text { Zwischennutzung }}{\begin{array}{c}\text { Durchforstung } \\
\mathrm{m}^{3}\end{array}}$} & \multirow{2}{*}{$\begin{array}{c}\text { Total } \\
m^{3}\end{array}$} \\
\hline & $\begin{array}{l}\text { Schlag } \\
\mathrm{m}^{3}\end{array}$ & $\begin{array}{c}\text { Vorhieb } \\
\mathrm{m}^{3}\end{array}$ & $\begin{array}{c}\text { Total } \\
\mathrm{m}^{3}\end{array}$ & & \\
\hline Oberer Sihlwald & 1,600 & 290 & 1,890 & 610 & 2,500 \\
\hline Unterer Sihlwald & 1,660 & 370 & 2,030 & 540 & 2,570 \\
\hline Albishölzer . & 1,250 & 60 & 1,310 & 590 & 1,900 \\
\hline Forst . & 720 & 80 & 800 & 310 & 1,110 \\
\hline Adlisberg & 530 & 70 & 600 & 200 & 800 \\
\hline Summa & 5,760 & 870 & 6,630 & 2,250 & 8,880 \\
\hline per Hektar & 5,65 & 0,85 & 6,5 & 2,2 & 8,7 \\
\hline
\end{tabular}

Diese Werte haben der Wirtschaftsführung für die Einlegung der Hiebe, wie für die Nachführung der Kontrolle zu dienen. Ihre genaue Berücksichtigung ist um so angezeigter, weil eine parallel gehende Flächenkontrolle bei dem adoptierten Etatssystem nicht statthaft ist. Die zehnjährigen Zwischenrerisionen werden jeweilen Gelegenheit hieten. die vorliegende Ertragsregulierung da zu modifizieren, wo sich Veränderungen als notwendig erweisen. Die Altersklassentabelle und die für Wirtschaftsführting im allgemeinen aufgestellten Wirtschaftsgrundsätze bieten dem Wirtschafter die Anhaltspunkte für die örtliche Einlegung und Durchführung der Haupt- und Zwischennutzungsschläge. Ein spezieller Haumgsplan ist enthehrlich. 
IX.

Flächen-Verzeichnis. 
In der Kategorie "Unbestockte Fläche» sind angeführt: Wies- und Streueland, und als «Ertraglose Fläche» werden hezeichnet: Strassen und Wege, Hofråume, Gebäude, Gewässer und Felspartien.

\begin{tabular}{|c|c|c|c|c|c|c|c|c|c|c|c|}
\hline \multirow{3}{*}{$\begin{array}{l}\text { Bezeichnung } \\
\text { Betriebsklasse }\end{array}$} & \multirow{3}{*}{ 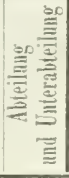 } & \multirow{2}{*}{\multicolumn{2}{|c|}{ Wraldboden }} & \multirow{2}{*}{\multicolumn{2}{|c|}{$\begin{array}{l}\text { Unbesiockte } \\
\text { Fläche }\end{array}$}} & \multirow{2}{*}{\multicolumn{2}{|c|}{$\begin{array}{c}\text { Ertraglose } \\
\text { Fläche }\end{array}$}} & \multicolumn{4}{|c|}{ Flächengrösse } \\
\hline & & & & & & & & \multicolumn{2}{|c|}{ Interabteilung } & \multicolumn{2}{|c|}{ Abteilang } \\
\hline & & ha & $m^{2}$ & ha & $m^{2}$ & ha & $m^{2}$ & $h a$ & $m^{2}$ & ha & $\mathrm{m}^{2}$ \\
\hline \multirow[t]{19}{*}{ Oberer Sihlwald } & 1 & 24 & 2686 & - & 290 & - & 4370 & - & - & 24 & 7346 \\
\hline & 2 & 24 & 8411 & - & 7631 & - & 3978 & - & - & 26 & 20 \\
\hline & 3 & 30 & 9596 & - & 5930 & - & 4049 & - & - & 31 & 9575 \\
\hline & $4 a$ & 12 & 8028 & - & 2000 & - & 2039 & 13 & 2067 & - & - \\
\hline & b & 21 & 8129 & - & 8830 & - & 3525 & $2: 3$ & 484 & - & - \\
\hline & 1. & 18 & 6052 & - & 2060 & - & 940 & 18 & 9052 & - & - \\
\hline & & 53 & 2209 & 1 & 2890 & - & 6504 & - & - & 55 & 1603 \\
\hline & $5 \mathrm{a}$ & 6 & 1012 & - & - & - & 2552 & 6 & 3564 & - & - \\
\hline & $b$ & 14 & 3820 & - & - & - & 887 & 14 & 4707 & $-\ldots$ & - \\
\hline & c & 42 & 3924 & 1 & 129 & - & 7419 & 44 & 1472 & - & - \\
\hline & & 62 & 8756 & 1 & 129 & 1 & 858 & - & - & 64 & 9743 \\
\hline & $6 a$ & 61 & 1600 & - & 1090 & - & 1700 & 6 & 3790 & - & - \\
\hline & $\mathrm{b}$ & 16 & 9904 & - & 2000 & - & 4395 & 17 & 6299 & - & - \\
\hline & c & 20 & 2500 & - & 3076 & - & 9642 & 21 & 5218 & - & - \\
\hline & & 43 & 3404 & - & 6166 & 1 & 5737 & - & - & 45 & 5307 \\
\hline & $7 a$ & 25 & 6180 & - & 1575 & 1 & 430 & 26 & 8185 & - & 一 \\
\hline & b & $13 \mid$ & 1824 & - & - & - & 1990 & 13 & 3814 & - & - \\
\hline & & 38 & 8004 & - & 1575 & 1 & 2420 & - & - & 40 & 1999 \\
\hline & 8 & 39 & 3750 & - & - & - & 8810 & - & - & 40 & 2560 \\
\hline $\begin{array}{l}\text { Tolal } \\
\text { Oberer Sihlwald }\end{array}$ & & 317 & 6816 & 4 & 4611 & 6 & 6726 & $\ldots$ & - & 328 & 8153 \\
\hline
\end{tabular}




\begin{tabular}{|c|c|c|c|c|c|c|c|c|c|c|c|}
\hline Bezeichnunn & 咅 & Walde & boden & Unbes: & stockıa & & aglose & & Pliichls & nerörs & \\
\hline & 焉焉 & & & & & & ache & limeral & threilung & thitej & ilung \\
\hline Betriebsklasse & 㪯 & ha & $m^{2}$ & ha & $m^{2}$ & hat & $11^{2}$ & hat & $m^{2}$ & ha & $m m^{2}$ \\
\hline Unterer Sihlwald & 9 & 39 & 4360 & -1 & - & & 276 & - & & 40 & 4636 \\
\hline & 10 & 30 & | $\quad 329$ & & 2870 & & $\mid 5489$ & - & - & $35 !$ & 8688 \\
\hline & 11 & 46 & $\mid 8356$ & $-!$ & $: 88.5$ & 1 & 1726 & - & - & 48 & 467 \\
\hline & 12 & 40 & $\mid 9629$ & -1 & 20.56 & - & 5,518 & - & 一 & +1 & 7203 \\
\hline & $1: 3$ & 41 & | 9138 & -1 & $: 3084$ & 1 & 889 & - & - & $4: 3$ & |:3111 \\
\hline & 14 & 41 & $|5: 260|$ & $-i$ & 443 & & 3800 & $-\cdots$ & - & 41 & 1960: \\
\hline & 15 & 27 & 8020 & 31 & 4965 & - & 7145 & - & - & 32 & 130 \\
\hline & $16 \mathrm{a}$ & 43 & 18556 & 11 & 405 & $: 3$ & :3118 & & 2079 & $x^{2}$ & 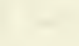 \\
\hline & h & 2 & $\mid 2: 340$ & -1 & - & - & - & 2 & 2340 & $-:$ & : - \\
\hline & & 46 & 896 & 1 & 405 & 3 & 3118 & - & - & 50 & 4419 \\
\hline $\begin{array}{c}\text { Total } \\
\text { Unterer Sihlwald }\end{array}$ & & $\$ 14$ & 6088 & 7 & 4208 & 11 & 7961 & - & - & 333 & 8257 \\
\hline Albishölzer . & 17 & 36 & 6137 & - & 7746 & 1 & 4855 & - & - & $\therefore 8$ & 8238 \\
\hline & 18 & 42 & 797 & 3 & 3415 & 2 & 4860 & - & - & 47 & 9072 \\
\hline & 19 & 35 & 3202 & 8 & 1446 & 1 & 4004 & - & - & 44 & 8652 \\
\hline Albisplateau & 20 & 30 & 4880 & 3 & 7773 & 1 & 6003 & - & - & 35 & 8656 \\
\hline & 21 & 17 & 7000 & - & 4176 & - & 9541 & - & - & 19 & 717 \\
\hline Winzelen & 22 & 17 & 4029 & - & - & - & 3340 & - & - & 17 & 7369 \\
\hline Tolal Albishölzer & & 179 & 6045 & 16 & 4556 & 8 & 2103 & - & - & 204 & 2704 \\
\hline Forst & 1 & 25 & 8871 & 11 & 7529 & 1 & $\mid 8775$ & - & - & 29 & 15175 \\
\hline & 2 & 33 & | 8120 & $\ddot{31}$ & 5020 & 2 & $2430 \mid$ & -1 & $1-$ & 39 & 15570 \\
\hline & 3 & 24 & 5813 & 41 & 7196 & - & 6830 & - & - & 29 & 9839 \\
\hline & 4 & 15 & 6379 & 21 & 7990 & - & 1679 & -1 & - & 18 & 6048 \\
\hline & 5 & 2 & | 7450 & -1 & 7416 & - & 1776 & -1 & - & 3 & | 6642 \\
\hline & 6 & 9 & | 3902 & 2 & 554 & - & 471 & - & - & 11 & 4927 \\
\hline Total Forst & & 112 & 535 & 15 & 5705 & 5 & 1961 & - & - & 132 & 8201 \\
\hline
\end{tabular}




\begin{tabular}{|c|c|c|c|c|c|c|c|c|c|c|c|}
\hline \multirow{3}{*}{$\begin{array}{l}\text { Bezeichnung } \\
\text { Betriebsklasse }\end{array}$} & \multirow{3}{*}{ 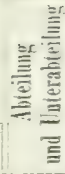 } & \multirow{2}{*}{\multicolumn{2}{|c|}{ Waldboden }} & \multirow{2}{*}{\multicolumn{2}{|c|}{$\begin{array}{c}\text { Unbestockte } \\
\text { Fläche }\end{array}$}} & \multirow{2}{*}{\multicolumn{2}{|c|}{$\begin{array}{l}\text { Ertraglose } \\
\text { Fläche }\end{array}$}} & \multicolumn{4}{|c|}{ Flächengrösse } \\
\hline & & & & & & & & \multicolumn{2}{|c|}{ Unterabteilng } & \multicolumn{2}{|c|}{ Abteilung } \\
\hline & & ha & $m^{2}$ & ha & $\mathrm{m}^{2}$ & ha & $m^{2}$ & ha & $\mathrm{m}^{2}$ & ha & $m^{2}$ \\
\hline \multirow[t]{7}{*}{ Adlisberg . } & 1 & 16 & 1002 & - & - & - & - & - & - & 16 & 1002 \\
\hline & 2 & 16 & 8127 & - & - & - & 200 & - & - & 16 & 8327 \\
\hline & 3 & 11 & 4314 & - & - & - & 1016 & - & - & 11 & 5330 \\
\hline & 4 & 15 & 7996 & - & - & - & - & - & - & 15 & 7996 \\
\hline & 5 & 21 & 2870 & - & - & - & 2144 & - & - & 21 & 5014 \\
\hline & 6 & 17 & 3243 & 1 & 70 & - & - & - & - & 18 & 3313 \\
\hline & 7 & - & - & 7 & 9264 & - & 402 & - & - & 7 & 9666 \\
\hline Total Adlisberg & & 98 & 7552 & 8 & 9334 & - & 3762 & - & - & 108 & 648 \\
\hline
\end{tabular}

\section{Rekapitulation:}

\begin{tabular}{|c|c|c|c|c|c|c|c|c|c|c|}
\hline \multirow{3}{*}{$\begin{array}{l}\text { Bezeichnung } \\
\text { Betriebsklasse }\end{array}$} & \multirow{2}{*}{\multicolumn{2}{|c|}{ Waldboden }} & \multirow{2}{*}{\multicolumn{2}{|c|}{$\begin{array}{c}\text { Unbestockte } \\
\text { Fläche }\end{array}$}} & \multirow{2}{*}{\multicolumn{2}{|c|}{$\begin{array}{c}\text { Ertraglose } \\
\text { Fläche }\end{array}$}} & \multicolumn{4}{|c|}{ Flächengrösse } \\
\hline & & & & & & & \multicolumn{2}{|c|}{ Tnterabteilnng } & \multicolumn{2}{|c|}{ Abteilusg } \\
\hline & ha & $m^{2}$ & ha & $\mathrm{m}^{2}$ & ha & $\mathrm{m}^{2}$ & ha & $m^{2}$ & ha & $\mathrm{m}^{2}$ \\
\hline 1. Oberer Sihlwald & 317 & 6816 & 4 & 4611 & 6 & 6726 & - & - & 328 & 8153 \\
\hline II. Unterer Sihlwald & 314 & 6088 & 7 & 4208 & 11 & 7961 & 一 & - & 333 & 8257 \\
\hline III. Aluishölzer . . & 179 & 6045 & 16 & 4556 & 8 & 2103 & - & - & 204 & 2704 \\
\hline IV. Forst . & 112 & 535 & 15 & 5705 & 5 & 1961 & - & - & 132 & 8201 \\
\hline V. Adlisberg . . & 98 & 7552 & 8 & 9334 & - & 3762 & - & - & 108 & 648 \\
\hline $\begin{array}{l}\text { Total der Stiftungs- } \\
\text { gutswaldungen }\end{array}$ & 1022 & 7036 & 52 & 8414 & 32 & 2513 & - & - & 1107 & 7963 \\
\hline
\end{tabular}


X.

Altersklassentabelle. 


\begin{tabular}{|c|c|c|c|c|c|c|c|c|c|c|c|}
\hline \multirow[t]{2}{*}{ Betriebsklasse } & \multirow{2}{*}{ 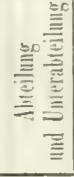 } & \multicolumn{2}{|c|}{$\begin{array}{l}\text { 1. Klasse } \\
\text { 1-10jährig }\end{array}$} & \multicolumn{2}{|c|}{$\begin{array}{l}\text { 2. Klasse } \\
\text { 11-20jährig }\end{array}$} & \multicolumn{2}{|c|}{$\begin{array}{c}\text { 3. Klasse } \\
\text { 21-30jährig }\end{array}$} & \multicolumn{2}{|c|}{$\begin{array}{c}\text { 4. Klasse } \\
\text { 31-40jährig }\end{array}$} & \multicolumn{2}{|c|}{$\begin{array}{c}\text { 5. Klasse } \\
\text { 41-50jährig }\end{array}$} \\
\hline & & hal & fin & ha & $\mathrm{fm}$ & hal & $\mathrm{fm}$ & ha & fim & ba & $\mathrm{fm}$ \\
\hline \multirow[t]{15}{*}{ Oberer Sihlwald } & 1 & - & - & - & - & - & - & 24,27 & 3950 & - & - \\
\hline & 2 & 6,10 & 100 & 18,74 & 1100 & - & - & - & - & - & - \\
\hline & 3 & 18,51 & 280 & 5,00 & 300 & - & - & - & - & - & - \\
\hline & $4 \mathrm{a}$ & - & - & - & - & - & - & - & 一 & - & - \\
\hline & b & - & - & 21,81 & 1280 & - & - & - & - & - & - \\
\hline & c & - & - & - & - & - & - & - & - & - & - \\
\hline & วa & - & -- & - & - & - & - & - & - & - & - \\
\hline & $\mathrm{b}$ & - & - & 14,38 & 850 & $\ldots$ & - & - & - & - & - \\
\hline & c. & - & - & - & - & - & - & - & - & - & - \\
\hline & $6 \mathrm{a}$ & - & - & - & - & - & - & - & - & - & - \\
\hline & $\mathrm{b}$ & - & - & 16,99 & 1000 & - & - & - & - & - & - \\
\hline & c & - & - & - & - & - & - & - & - & - & - \\
\hline & $7 \mathrm{a}$ & - & 一 & - & - & - & - & 25,62 & 4860 & - & - \\
\hline & b & - & - & - & - & - & - & - & - & - & - \\
\hline & 8 & 3,00 & 100 & 27,93 & 1660 & 8,45 & 910 & - & - & - & - \\
\hline Total Oberer Sihlwald & & 27,61 & 480 & 104,85 & 6190 & 8,45 & 910 & 49,89 & 8810 & - & - \\
\hline \multirow[t]{9}{*}{ Unterer Sihlwald. } & 9 & 33,74 & 600 & 5,70 & 340 & 一 & - & - & - & - & - \\
\hline & 10 & 19,10 & 200 & $6,4: 3$ & 250 & - & -- & - & - & - & - \\
\hline & 11 & - & - & 19,00 & 1120 & 27,83 & 3000 & - & - & - & - \\
\hline & 12 & - & - & - & - & - & - & 3,69 & 620 & 37,27 & 8700 \\
\hline & 1:; & - & - & - & - & - & - & - & - & - & - \\
\hline & 14 & - & - & - & - & - & - & - & - & - & - \\
\hline & 15 & - & - & - & - & - & - & - & - & - & - \\
\hline & $16 \mathrm{a}$ & - & - & - & - & - & - & - & - & - & - \\
\hline & $\mathrm{b}$ & - & - & - & - & - & - & - & - & - & - \\
\hline Total Unterer Sihlwald & & 52,84 & 800 & 31,13 & 1710 & 27,83 & 3000 & 3,69 & 620 & 37,27 & 8700 \\
\hline \multirow[t]{6}{*}{ Albishölzer } & $\mid 17$ & 4,00 & 60 & - & - & - & - & - & - & - & - \\
\hline & 18 & 1,92 & - & - & - & 6,54 & 780 & 3,06 & 500 & 7,92 & 1880 \\
\hline & 19 & - & - & 9,05 & 270 & 2,49 & 300 & 3,00 & 700 & - & - \\
\hline & 20 & - & - & 9,30 & 300 & - & - & - & - & 1,94 & 460 \\
\hline & 21 & 4,00 & 50 & 5,70 & 150 & - & - & 4,00 & 800 & 4,00 & 1000 \\
\hline & 22 & 4,00 & 50 & 13,40 & 400 & - & - & - & - & - & - \\
\hline Total Albishölzer & & 13,92 & 160 & 37,45 & 1120 & 9,03 & 1080 & 10,06 & 2000 & 13,86 & 3340 \\
\hline
\end{tabular}




\begin{tabular}{|c|c|c|c|c|c|c|c|c|c|c|c|c|c|}
\hline \multicolumn{2}{|c|}{$\begin{array}{l}\text { 6. Klasse } \\
\text { i1-10ujührig }\end{array}$} & \multicolumn{2}{|c|}{$\begin{array}{l}\text { 7. Klasse } \\
\text { (i1-7ojiihrie }\end{array}$} & \multicolumn{2}{|c|}{$\begin{array}{l}\text { 8. Klasse } \\
\text { 71-v1jühriy }\end{array}$} & \multicolumn{2}{|c|}{$\begin{array}{l}\text { 9. Klasse } \\
\text { 1-!njoilutis }\end{array}$} & \multicolumn{2}{|c|}{$\begin{array}{l}\text { 10. Klasse } \\
\text { (1- 11!!itint }\end{array}$} & \multicolumn{2}{|c|}{ 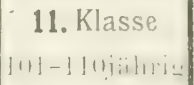 } & \multicolumn{2}{|c|}{ 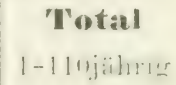 } \\
\hline hir & $\mathrm{fm}$ & ha & fm & ha & fin & ha & $\mathrm{fm}$ & hat & fin & ha & fim & litit & $1 \pm 1$ \\
\hline- & - & - & - & - & - & - & - & - & - & - & - & 24,27 & 3950 \\
\hline- & - & - & - & - & - & - & - & - & - & - & - & 24,84 & 1200 \\
\hline- & - & - & - & - & - & - & - & - & - & 7,45 & 4850 & 30,96 & 5430 \\
\hline- & - & - & - & - & - & - & - & 12.80 & 4900 & - & - & 12,80 & 4900 \\
\hline - & - & - & - & - & - & - & - & - & - & - & - & 21.81 & 1280 \\
\hline - & - & - & $\therefore$ & - & - & - & - & 18,61 & 5940 & - & - & 18,61 & 5940 \\
\hline- & - & - & - & 6,10 & 2500 & - & - & - & -. & - & - & 6,10 & 2500 \\
\hline- & - & - & - & - & - & - & - & - & - & - & - & 14,38 & 850 \\
\hline- & - & 10,90 & 4140 & 31,49 & 12300 & - & - & - & - & - & - & 42,39 & 16440 \\
\hline 6,10 & 1950 & - & - & - & - & - & - & - & - & - & - & 6,10 & 1950 \\
\hline- & - & -- & - & - & - & - & - & - & - & - & - & 16,99 & 1000 \\
\hline 20,25 & 6000 & - & - & - & - & - & - & - & - & - & - & 20,25 & 6000 \\
\hline- & -- & - & - & - & - & - & - & - & - & - & - & 25,62 & 4860 \\
\hline 一 & - & 13,18 & 3300 & - & - & - & - & - & - & - & - & 13,18 & 3300 \\
\hline - & - & - & - & - & - & - & - & - & - & - & - & 39,38 & 2670 \\
\hline 260.35 & 7950 & א.1.1. & 7.140 & : & $1.1 \times 1011$ & & $\ldots$ & $: 1111$ & 10810 & 7.45 & 15.01 & :117, (i) & 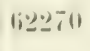 \\
\hline- & - & - & - & - & - & - & - & - & - & - & - & 39,44 & 940 \\
\hline- & - & - & - & - & - & 4,50 & 600 & - & - & - & - & 30,03 & 1050 \\
\hline . & - & -- & - & - & - & - & - & - & - & - & - & 46,83 & +120 \\
\hline . & - & - & - & - & 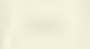 & . & 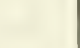 & - & & - & - & 40.96 & $9: 320$ \\
\hline 15,00 & 4700 & 22,31 & 8100 & 4,60 & 2260 & - & - & - & - & - & - & 41,91 & 15060 \\
\hline- & - & 6,31 & 2800 & 28,79 & 14500 & 6,44 & 3500 & - & - & - & 一 & $\$ 1,54$ & 20800 \\
\hline- & - & - & - & - & - & 8,34 & 4640 & 19,46 & 10100 & - & - & 27,80 & 14740 \\
\hline - & - & - & - & - & - & - & - & 14,33 & 7100 & 29,53 & 18800 & 43,86 & 20900 \\
\hline - & - & 2,23 & 300 & - & - & - & - & - & - & -- & - & 2,23 & 300 \\
\hline 1500 & 1700 & $30.8 \%$ & 1120110 & $3: 3.89$ & lizitill & איגב. & 8.10 & :39.7! & 172010 & 29.3 & 1:3\1111 & $\forall i t .101\}$ & (1):310 \\
\hline- & - & 32,61 & 12200 & - & - & - & - & - & - & - & - & 36,61 & 12.260 \\
\hline 13,64 & 4300 & 8,00 & 3200 & 1,00 & 490 & - & - & - & - & - & - & 42,08 & 11150 \\
\hline 12,69 & 4300 & 6,29 & 2330 & - & - & 1,80 & 1200 & - & - & - & - & 35,32 & 9100 \\
\hline 6,65 & 1650 & - & - & 3,00 & 1050 & 5,00 & 2000 & 4,60 & 2100 & - & - & 30,49 & 7560 \\
\hline - & - & - & - & - & - & - & - & - & - & - & - & 17,70 & 2000 \\
\hline & - & - & - & - & - & - & - & - & - & - & - & 17,40 & 450 \\
\hline 32.98 & $10 \div 50$ & 46,90 & 17730 & 4.00 & 1.510 & $1 i .80$ & 320111 & 4.610 & 21011 & & & 179.601 & 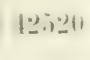 \\
\hline
\end{tabular}




\begin{tabular}{|c|c|c|c|c|c|c|c|c|c|c|c|}
\hline \multirow[t]{2}{*}{ Betriebsklasse } & \multirow{2}{*}{ 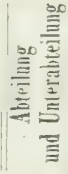 } & \multicolumn{2}{|c|}{$\begin{array}{l}\text { 1. Klasse } \\
\text { 1-10jährig }\end{array}$} & \multicolumn{2}{|c|}{$\begin{array}{l}\text { 2. Klasse } \\
\text { 11-20jïhrig }\end{array}$} & \multicolumn{2}{|c|}{$\begin{array}{l}\text { 3. Klasse } \\
21-30 j \text { jihrig }\end{array}$} & \multicolumn{2}{|c|}{$\begin{array}{l}\text { 4. Klasse } \\
\text { 31-4()jührigr }\end{array}$} & \multicolumn{2}{|c|}{$\begin{array}{c}\text { 5. Klasse } \\
41-50 j a ̈ b r i g\end{array}$} \\
\hline & & ha & $\mathrm{fm}$ & ha & $\mathrm{fm}$ & ha & $\mathrm{fm}$ & ha & $\mathrm{fm}$ & hat & fm \\
\hline . . . & 1 & 1,00 & 10 & 1,50 & 90 & 2,80 & 300 & 16,19 & 2720 & - & $\cdots$ \\
\hline & 2 & 4,82 & 70 & 2,90 & 170 & 6,22 & 660 & 3,00 & 500 & - & - \\
\hline & 3 & - & - & 6,03 & 350 & - & - & 5,90 & 1060 & - & - \\
\hline & 4 & 1,60 & 20 & 4,00 & 240 & - & - & 8,24 & 4900 & - & - \\
\hline & 5 & - & - & - & - & 2,74 & 300 & - & - & - & - \\
\hline & 6 & - & - & - & - & 3,91 & 420 & - & - & - & - \\
\hline Total Forsi & & 7,42 & 100 & 14,43 & 850 & 15,67 & 1680 & 39.,33 & 9180 & - & - \\
\hline \multirow[t]{6}{*}{ Adlisberg . } & 1 & - & - & - & - & - & - & - & - & 5,64 & 1350 \\
\hline & 2 & 6,81 & 100 & 7,00 & 400 & - & - & - & - & - & - \\
\hline & 3 & - & - & - & - & 11,43 & 1170 & - & - & - & - \\
\hline & 4 & 2,00 & 30 & - & - & 0,80 & 60 & - & - & - & - \\
\hline & 5 & 5,90 & 80 & 5,51 & 320 & 5,14 & 500 & 4,74 & 950 & 一 & - \\
\hline & 6 & - & - & - & - & - & - & 16,15 & 2720 & 1,17 & 250 \\
\hline Total Adlisberg & & 14,71 & 210 & 12,51 & 720 & 17.37 & 1730 & 20.89 & 3670 & 6,81 & 1600 \\
\hline
\end{tabular}

Rekapi-

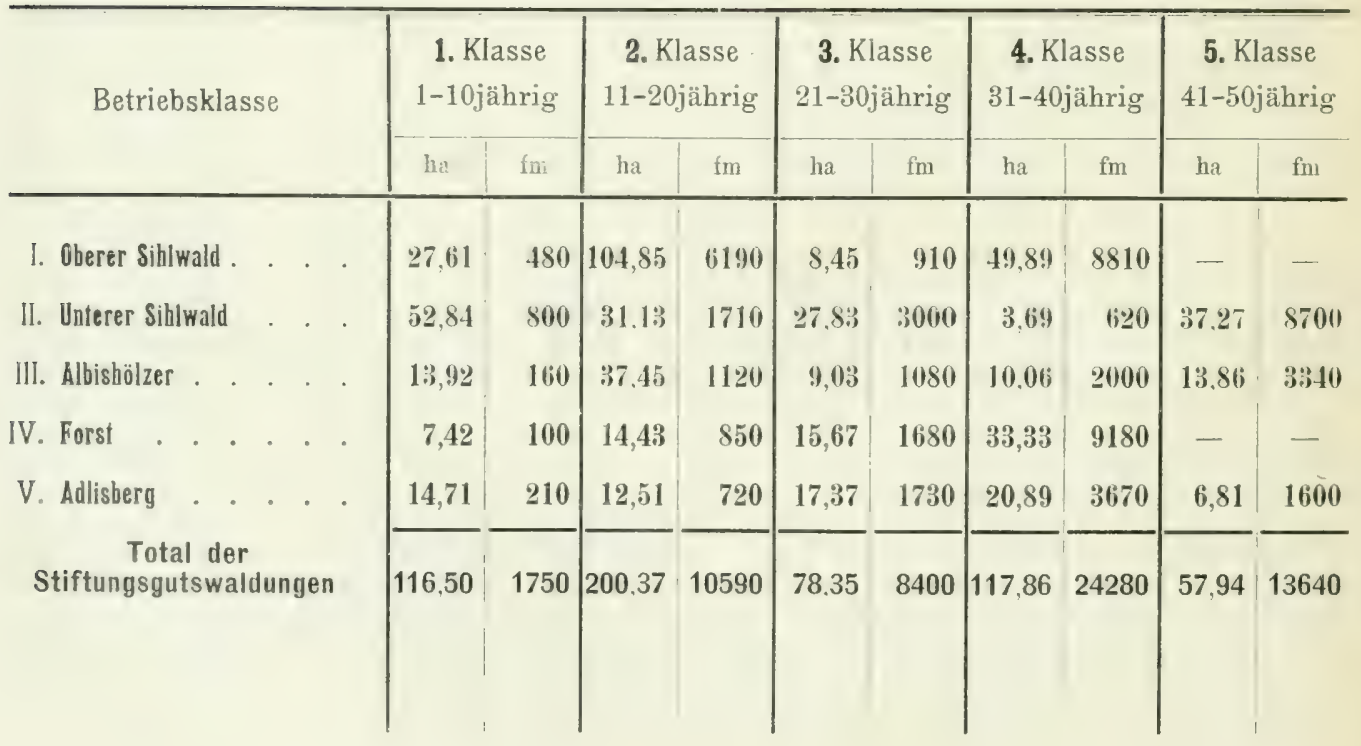




\begin{tabular}{|c|c|c|c|c|c|c|c|c|c|c|c|c|c|}
\hline \multicolumn{2}{|c|}{$\begin{array}{c}\text { 6. Klasse } \\
\text { 51-60jährig }\end{array}$} & \multicolumn{2}{|c|}{$\begin{array}{c}\text { 7. Klasse } \\
\text { 61-70jährig }\end{array}$} & \multicolumn{2}{|c|}{$\begin{array}{c}\text { 8. Klasse } \\
\text { 71-80jährig }\end{array}$} & \multicolumn{2}{|c|}{$\begin{array}{c}\text { 9. Klasse } \\
81 \text {-90jährig }\end{array}$} & \multicolumn{2}{|c|}{$\begin{array}{c}\text { 10. Klasse } \\
91-100 \text { jührig }\end{array}$} & \multicolumn{2}{|c|}{$\begin{array}{c}\text { 11. Klasse } \\
\text { 101-110jährig }\end{array}$} & \multicolumn{2}{|c|}{$\begin{array}{c}\text { Total } \\
\text { 1-110jährig }\end{array}$} \\
\hline ha & $\mathrm{fm}$ & ha & fm & lai & $\mathrm{fm}$ & ha & tim & Ina & fin & hat & fm & ha & fim \\
\hline- & - & - & - & 4,40 & 2140 & - & - & - & - & - & - & 25,89 & 5260 \\
\hline 7,10 & 2280 & - & - & 6,77 & 3330 & 3,00 & 1750 & - & - & - & - & 33,81 & 8760 \\
\hline- & - & 11,65 & 4600 & 1,00 & 450 & - & - & - & - & - & - & 24,58 & 6460 \\
\hline- & - & - & - & - & - & 1,80 & 1000 & - & - & - & - & 15,64 & 6160 \\
\hline$\therefore$ & - & - & - & - & - & - & - & - & - & - & - & 2,74 & 300 \\
\hline 5,48 & 1300 & - & - & - & - & - & - & - & - & - & - & 9,39 & 1720 \\
\hline 12,58 & 3580 & 11,65 & 4600 & 12,17 & 5920 & 4,80 & 2750 & - & - & - & - & 112,05 & 28660 \\
\hline- & - & 10,46 & 5140 & - & - & - & - & - & - & - & - & 16,10 & 6490 \\
\hline- & - & - & - & - & - & - & - & 3,00 & 2000 & - & - & 16,81 & 2500 \\
\hline- & - & - & - & - & - & - & - & - & - & - & - & 11,43 & 1170 \\
\hline- & - & - & - & - & - & 13,00 & 8240 & - & - & - & - & 15,80 & 8330 \\
\hline- & - & - & - & - & - & - & - & - & - & - & - & 21,29 & 1850 \\
\hline- & - & - & - & - & - & - & - & - & - & - & - & 17,32 & 2970 \\
\hline- & - & 10,46 & 5140 & - & - & 13,00 & 8240 & 3,00 & 2000 & - & - & 98,75 & 23310 \\
\hline
\end{tabular}

\section{tulation:}

\begin{tabular}{|c|c|c|c|c|c|c|c|c|c|c|c|c|c|}
\hline \multicolumn{2}{|c|}{$\begin{array}{c}\text { 6. Klasse } \\
51-60 \text { jährig }\end{array}$} & \multicolumn{2}{|c|}{$\begin{array}{l}\text { 7. Klasse } \\
\text { 61-70jührig }\end{array}$} & \multicolumn{2}{|c|}{$\begin{array}{l}\text { 8. Klasse } \\
\text { 71-80jührig }\end{array}$} & \multicolumn{2}{|c|}{$\begin{array}{l}\text { 9. Klasse } \\
\times 1-90 j a ̈ \text { arig }\end{array}$} & \multicolumn{2}{|c|}{$\begin{array}{l}\text { 10. Klasse } \\
91-100 \text { jälnrig }\end{array}$} & \multicolumn{2}{|c|}{$\begin{array}{c}\text { 11. Klasse } \\
101-110 \text { jïhrig }\end{array}$} & \multicolumn{2}{|c|}{$\begin{array}{c}\text { Total } \\
1-110 j a ̈ h r i g\end{array}$} \\
\hline hat & $f m$ & ha & $\mathrm{fm}$ & ha & $\mathrm{fm}$ & ha & $f m$ & ha & $\mathrm{fm}$ & ha & $\mathrm{fm}$ & hit & $\mathrm{fm}$ \\
\hline 26,35 & 7950 & 24,08 & 7410 & 37.59 & 14800 & - & - & $: 31,41$ & $10 \times 40$ & 7.45 & 1550 & 317,68 & 62.271 \\
\hline 15,00 & 4700 & 30,85 & 11200 & 3:3.3!) & Ilizlio & 19.2א & 8740 & $3: 7.7 !$ & 17200 & 29.53 & $1: 3 \times 00$ & $: 314.60$ & s7:3010 \\
\hline 32,98 & 10250 & 46.90 & 17730 & 4.00 & 1540 & 6,80 & 3200 & 4.611 & 2100 & - & - & 179.60 & 42500 \\
\hline 12,58 & 3580 & 11,65 & 4600 & 12,17 & 5920 & 4,80 & 2750 & - & - & - & - & 112,05 & 28660 \\
\hline- & - & 10,46 & 5140 & - & - & 13,00 & 8240 & 3,00 & 2000 & - & - & 98,75 & 23310 \\
\hline 86,91 & 26480 & 123,94 & 46110 & 87,15 & 39020 & 43,88 & 22930 & 72.80 & 32140 & 36.98 & 18650 & 1022.68 & 243990 \\
\hline
\end{tabular}



XI.

\section{Ertragstafel}

für die Buche im Sihlwald ill. Bonitätı

Hauptbestand.

1903. 


\begin{tabular}{|c|c|c|c|c|c|c|c|c|c|c|}
\hline \multirow{2}{*}{$\begin{array}{c}\text { Bestandes- } \\
\text { alier }\end{array}$} & \multicolumn{4}{|c|}{ Bestandesverhälinisse } & \multicolumn{3}{|c|}{ Laufender Zuwachs } & \multicolumn{3}{|c|}{ Durchschnittszuwachs } \\
\hline & zahl & $\begin{array}{l}\text { Stamm- } \\
\text { grund- } \\
\text { fläche }\end{array}$ & $\left|\begin{array}{c}\text { Bestan- } \\
\text { des- } \\
\text { hobe }\end{array}\right|$ & $\begin{array}{l}\text { Molz. } \\
\text { masse }\end{array}$ & $\begin{array}{l}\text { Stamm- } \\
\text { grund- } \\
\text { Häche }\end{array}$ & $\left|\begin{array}{c}\text { Bestan- } \\
\text { des- } \\
\text { höhe }\end{array}\right|$ & $\begin{array}{l}\text { Holz- } \\
\text { masse }\end{array}$ & $\begin{array}{l}\text { Stamm- } \\
\text { grund- } \\
\text { flache }\end{array}$ & $\left|\begin{array}{c}\text { Bestan- } \\
\text { des- } \\
\text { höhe }\end{array}\right|$ & $\begin{array}{l}\text { Holz- } \\
\text { masse }\end{array}$ \\
\hline Jahre & Stïck & $m^{2}$ & $\mathrm{nl}$ & $m^{3}$ & $n x^{2}$ & 111 & $\mathrm{~m}^{3}$ & $m^{2}$ & m & $\mathrm{m}^{3}$ \\
\hline 1 & & & & & & & & & & \\
\hline 2 & & & & & & & & & & \\
\hline 3 & & & & & & & & & & \\
\hline 4 & & & & & & & & & & \\
\hline 5 & & & & 15 & & & 4,20 & & & 3,00 \\
\hline 6 & & & & 18 & & & 4,22 & & & 3,15 \\
\hline 7 & & & & 22 & & & 4,24 & & & 3,28 \\
\hline 8 & & & & 26 & & & 4,27 & & & 3,40 \\
\hline 9 & & & & 31 & & & 4,31 & & & 3,50 \\
\hline 10 & & & & 36 & & & 4,35 & & & 3,60 \\
\hline 11 & & & & 40 & & & 4,39 & & & 3,70 \\
\hline 12 & & & & 44 & & & 4,43 & & & 3,78 \\
\hline 13 & & & & 48 & & & 4,47 & & & 3,84 \\
\hline 14 & . & & & $5: 3$ & & & 4,51 & & r & 3,89 \\
\hline 15 & & & & 59 & & & 4,55 & & & 3,94 \\
\hline 16 & & & & 63 & & & 4,60 & & & 3,99 \\
\hline 17 & & & & 68 & & & 4,65 & & & 4,05 \\
\hline 18 & & & & 73 & & & 4,71 & & & 4,09 \\
\hline 19 & & & & 78 & & & 4,78 & & & 4,12 \\
\hline 20 & & & & 83 & & & 4,85 & & & 4,15 \\
\hline 21 & & & & 88 & & & 4,93 & & & 4,19 \\
\hline 22 & & & & 93 & & & 5,01 & & & 4,22 \\
\hline 23 & & & & 98 & & & 5,10 & & & 4,26 \\
\hline 24 & & & & 103 & & & 5,20 & & & 4,29 \\
\hline 25 & & 12,9 & 8,75 & 108 & 0,500 & 0,480 & 5,30 & 0,516 & 0,350 & 4,32 \\
\hline 26 & & 13,3 & 9,25 & 113 & 0,492 & 0,471 & 5,40 & 0,515 & 0,354 & 4,36 \\
\hline 27 & & 13,8 & 9,73 & 118 & 0,484 & 0,463 & 5,50 & 0,514 & 0,358 & 4,40 \\
\hline 28 & & 14.3 & 10,20 & 124 & 0,476 & 0,456 & 5,61 & 0,513 & 0,362 & 4,44 \\
\hline 29 & & 14,8 & 10,65 & 130 & 0,468 & 0,448 & 5,73 & 0,512 & 0,365 & 4,48 \\
\hline 301 & +1110 & 15.3 & 11,05 & 136 & 0,460 & 0,440 & 5,85 & 0,510 & 0,368 & 4,52 \\
\hline 31 & 3820 & 15.7 & 11,50 & 142 & 0,451 & 0,433 & 5,97 & 0,508 & 0,370 & 4,57 \\
\hline 32 & $: 3530$ & 16,1 & 11,94 & 148 & 0,442 & 0,427 & 6,09 & 0,506 & 0,371 & 4,62 \\
\hline$: 33$ & 3250 & 16,6 & 12,33 & 154 & 0,433 & 0,421 & 6,21 & 0,504 & 0,372 & 4,67 \\
\hline 34 & 3050 & 17,0 & 12,71 & 160 & 0,424 & 0,415 & 6,33 & 0,502 & 0,373 & 4,72 \\
\hline 35 & 2900 & 17,5 & 13,10 & 167 & 0,415 & 0,410 & 6,45 & 0,500 & 0,3743 & 4,77 \\
\hline
\end{tabular}




\begin{tabular}{|c|c|c|c|c|c|c|c|c|c|c|}
\hline \multirow{2}{*}{$\begin{array}{c}\text { Bestandes- } \\
\text { alter }\end{array}$} & \multicolumn{4}{|c|}{ Bestandesverhältnisse } & \multicolumn{3}{|c|}{ Laufender Zuwachs } & \multicolumn{3}{|c|}{ Durchschnittszuwachs } \\
\hline & Stamm- & $\begin{array}{l}\text { Stamme- } \\
\text { grund- } \\
\text { flicher. }\end{array}$ & $\begin{array}{l}\text { Besstan- } \\
\text { des- } \\
\text { höhe }\end{array}$ & $\begin{array}{l}\text { Holz- } \\
\text { masse }\end{array}$ & $\begin{array}{l}\text { Stamm- } \\
\text { yrmut- } \\
\text { iliache }\end{array}$ & 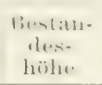 & $\begin{array}{l}\text { II olz- } \\
\text { In:arse }\end{array}$ & $\begin{array}{l}\text { Stanum. } \\
\text { yrumel- } \\
\text { lliche }\end{array}$ & $\begin{array}{l}\text { Bertat. } \\
\text { ders: } \\
\text { hiohe. }\end{array}$ & $\begin{array}{l}\text { Holy- } \\
\text { masse }\end{array}$ \\
\hline Jahre & Stück & $\mathrm{m}^{2}$ & $\mathrm{~m}$ & $m^{3}$ & $\mathrm{~m}^{2}$ & m & $m^{3}$ & $m^{2}$ & $\mathrm{~m}$ & $m^{3}$ \\
\hline 36 & 2760 & 17,9 & 13,51 & 173 & 0,409 & 0,406 & 6,56 & 0,498 & 0,3751 & 4,82 \\
\hline 37 & 2600 & 18,3 & 13,90 & 180 & 0,403 & 0,402 & 6,66 & 0,495 & 0,3759 & 4,87 \\
\hline 38 & 2470 & 18,7 & 14,31 & 187 & 0,397 & 0,398 & 6,76 & 0,492 & 0,3767 & 4,92 \\
\hline 39 & 2350 & 19,1 & 14,71 & 194 & 0,391 & 0,394 & 6,95 & 0,490 & 0,3772 & 4,97 \\
\hline 40 & 2240 & 19,5 & 15,10 & 201 & 0,385 & 0,390 & 7,10 & 0,487 & 0,3775 & 5,02 \\
\hline 41 & 2100 & 19,9 & 15,50 & 208 & 0,382 & 0,386 & 7,24 & 0,484 & 0,3776 & 5,07 \\
\hline 42 & 1965 & 20,3 & 15,90 & 215 & 0,379 & 0,382 & 7,35 & 0,481 & 0,3777 & 5,13 \\
\hline 43 & 1840 & 20,7 & 16,28 & 222 & 0,376 & 0,378 & 7,48 & 0,479 & 0,3778 & 5,19 \\
\hline 44 & 1730 & 21,0 & 16,66 & 230 & 0,373 & 0,374 & 7,59 & 0,477 & 0,3779 & 5,24 \\
\hline 45 & 1660 & 21,4 & 17,01 & 238 & 0,370 & 0,370 & 7,70 & 0,475 & 0,3780 & 5,29 \\
\hline 46 & 1575 & 21,8 & 17,37 & 246 & 0,367 & 0,366 & 7,84 & 0,473 & 0,3776 & 5,35 \\
\hline 47 & 1505 & 22,1 & 17,73 & 254 & 0,364 & 0,362 & 7,95 & 0,471 & 0,3770 & 5,40 \\
\hline 48 & 1435 & 22,5 & 18,05 & 262 & 0,361 & 0,358 & 8,05 & 0,469 & 0,3762 & 5,46 \\
\hline 49 & 1370 & 22,8 & 18,35 & 270 & 0,358 & 0,354 & 8,15 & 0,467 & 0,3756 & 5,51 \\
\hline 50 & 1320 & 23,2 & 18,70 & 278 & 0,355 & 0,350 & 8,25 & 0,464 & 0,3748 & 5,56 \\
\hline 51 & 1275 & 23,5 & 19,02 & 286 & 0,352 & 0,346 & 8,33 & 0,462 & 0,374 & 5,61 \\
\hline 52 & 1240 & 23,9 & 19,37 & 294 & 0,349 & 0,342 & 8,38 & 0,460 & 0,373 & 5,66 \\
\hline 53 & 1210 & 24,3 & 19,70 & 302 & 0,346 & 0,338 & 8,42 & 0,458 & 0,372 & 5,71 \\
\hline 54 & 1180 & 24,6 & 20,05 & 310 & 0,343 & 0,334 & 8,46 & 0,456 & 0,371 & 5,76 \\
\hline 55 & 1150 & 25,0 & 20,40 & 320 & 0,340 & 0,330 & 8,50 & 0,454 & 0,370 & 5,81 \\
\hline 56 & 1110 & 25,4 & 20,72 & 328 & 0,337 & 0,326 & 8,53 & 0,452 & 0,369 & 5,86 \\
\hline 57 & 1080 & 25,7 & 21,05 & 337 & 0,334 & $0,32 \cdot 2$ & 8,56 & 0,450 & 0,368 & 5,91 \\
\hline 58 & 1050 & 26,0 & 21,40 & 346 & 0,331 & 0,318 & 8,59 & 0,448 & 0,368 & 5,96 \\
\hline 59 & 1025 & 26,4 & 21,70 & 354 & 0,328 & 0,314 & 8,62 & 0,446 & 0,367 & 6,01 \\
\hline 60 & 1000 & 26,7 & 22,00 & 363 & 0,325 & 0,310 & 8,65 & 0,445 & 0,366 & 6,05 \\
\hline 61 & 975 & 27,0 & 22,32 & 372 & 0,322 & 0,306 & 8,66 & 0,443 & 0,365 & 6,09 \\
\hline 62 & 950 & 27,4 & 22,62 & 381 & 0,319 & 0,302 & 8,67 & 0,441 & 0,364 & 6,13 \\
\hline 63 & 930 & 27,7 & 22,91 & 388 & 0,316 & 0,298 & 8,68 & 0,439 & 0,363 & 6,17 \\
\hline 64 & 910 & 28,0 & 23,21 & 397 & 0,313 & 0,294 & 8,69 & 0,437 & 0,362 & 6,21 \\
\hline 65 & 890 & 28,3 & 23,50 & 406 & 0,310 & 0,290 & 8,70 & 0,435 & 0,361 & 6,25 \\
\hline 66 & 870 & 28,6 & 23,80 & 415 & 0,307 & 0,286 & 8,68 & 0,433 & 0,360 & 6,29 \\
\hline 67 & 850 & 28,9 & 24,11 & 424 & 0,304 & 0,282 & 8,65 & 0,431 & 0,359 & 6,33 \\
\hline 68 & 830 & 29,2 & 24,40 & 432 & 0,301 & 0,278 & 8,62 & 0,429 & 0,358 & 6,37 \\
\hline 69 & 812 & 29,5 & 24,70 & 441 & 0,298 & 0,274 & 8,59 & 0,427 & 0,357 & 6,40 \\
\hline 70 & 795 & 29,8 & 25,00 & 450 & 0,295 & 0,270 & 8.55 & $0,4^{6} 25$ & 0.356 & 6,43 \\
\hline
\end{tabular}




\begin{tabular}{|c|c|c|c|c|c|c|c|c|c|c|}
\hline & & & JTIIIISS & & Laufe & & & Durch & & \\
\hline alter & $\begin{array}{l}\text { Stamm- } \\
\text { zahl }\end{array}$ & $\begin{array}{l}\text { Stamm- } \\
\text { grund- } \\
\text { fäche }\end{array}$ & $\begin{array}{c}\text { Bestan- } \\
\text { des- } \\
\text { höhe }\end{array}$ & $\begin{array}{l}\text { Holz- } \\
\text { masse }\end{array}$ & $\begin{array}{l}\text { Stamm- } \\
\text { srund- } \\
\text { fläche }\end{array}$ & $\left|\begin{array}{c}\text { Bestan- } \\
\text { des- } \\
\text { höhe }\end{array}\right|$ & $\begin{array}{l}\text { Holz- } \\
\text { masse }\end{array}$ & $\begin{array}{l}\text { Stamm- } \\
\text { grund- } \\
\text { flache }\end{array}$ & $\begin{array}{c}\text { Bestan- } \\
\text { des- } \\
\text { höhe }\end{array}$ & $\begin{array}{l}\text { Holz. } \\
\text { masse }\end{array}$ \\
\hline Jahre & Stiick & $m^{2}$ & $\mathrm{~m}$ & $m^{3}$ & $m^{2}$ & $m$ & & $m^{2}$ & $m$ & $\mathrm{~m}^{3}$ \\
\hline 71 & 777 & 30,0 & 25,29 & 458 & 0,292 & 0,266 & 8,50 & 0,423 & 0,355 & 6,46 \\
\hline 72 & 760 & 30,1 & 25,58 & 466 & 0,289 & 0,262 & 8.44 & 0,421 & 0,354 & 6,49 \\
\hline 73 & 743 & 30,6 & 25,83 & 475 & 0,286 & 0,258 & 8,36 & 0,419 & 0,353 & 6,52 \\
\hline 74 & 726 & 30,9 & 26.07 & 483 & 0,283 & 0,254 & 8,28 & 0,417 & 0.352 & 6.54 \\
\hline 75 & 710 & 31,2 & 26,30 & 492 & 0,280 & 0,250 & 8,20 & 0,415 & 0,350 & 6,56 \\
\hline 76 & 695 & $31, \overline{5}$ & 26,57 & 501 & 0.277 & 0,246 & 8,11 & 0,413 & 0.348 & 6,58 \\
\hline 77 & 680 & 31,8 & 26,84 & 509 & 0,274 & 0,242 & 8,02 & 0.411 & 0,346 & 6,60 \\
\hline 78 & 665 & 32,1 & 27,09 & 517 & 0,271 & 0,239 & 7,92 & 0,409 & & 6,62 \\
\hline 79 & 651 & 32,4 & 27,31 & 525 & 0,268 & 0,235 & 7,81 & & & 6,68 \\
\hline 80 & 640 & 32,6 & 27,50 & 532 & 0,265 & 0,232 & 7,70 & & & 6,64 \\
\hline 81 & 625 & 32,9 & 27,75 & 540 & 0,263 & 0,229 & 7,57 & 0,405 & 0,342 & 6,65 \\
\hline 82 & 612 & 33,1 & 27,99 & 548 & 0,261 & 0,226 & 7,42 & 0,403 & 0,340 & 6,66 \\
\hline 83 & 600 & 33,3 & 28,21 & 555 & 0,259 & 0,222 & 7,25 & 0,401 & 0,339 & 6,67 \\
\hline 84 & 589 & 33,6 & 28,46 & 562 & 0,257 & 0,219 & 7,12 & 0,399 & 0,338 & 6.68 \\
\hline 85 & 580 & 33,9 & 28,70 & 569 & 0,255 & 0,216 & 6,90 & 0,398 & 0,337 & 6,69 \\
\hline$\times 6$ & 568 & 34,2 & 28,91 & 576 & $0,25: 3$ & 0,213 & 6,66 & 0,396 & 0,336 & 6,69 \\
\hline 87 & 557 & 34,4 & 29,13 & 582 & 0,251 & 0,210 & 6,45 & 0,395 & 0,334 & 6,70 \\
\hline 88 & 546 & 34,7 & 29,33 & 589 & 0,249 & 0,206 & 6,20 & 0,393 & 0,333 & 6,69 \\
\hline 89 & 538 & 34,9 & 29,57 & 595 & 0,247 & 0,203 & 5,91 & 0,392 & 0,332 & 6,69 \\
\hline 90 & 530 & 35,2 & 29,80 & 601 & 0,245 & 0,200 & 5,65 & 0,391 & 0,331 & 6,68 \\
\hline 91 & 520 & 35,4 & 29,99 & 607 & 0,243 & 0,197 & 5,30 & 0,389 & 0,329 & 6,67 \\
\hline 92 & 511 & 35,7 & 30,19 & 613 & 0,241 & $0,19 \pm$ & 4,95 & 0,387 & 0,328 & 6,65 \\
\hline 98 & 503 & 35,9 & 30,40 & 617 & 0,239 & 0,190 & 4,56 & 0,385 & 0,327 & 6,63 \\
\hline 94 & 496 & 36,2 & 30,59 & 621 & 0,237 & 0,187 & 4,22 & 0,384 & 0,325 & 6,61 \\
\hline 95 & 490 & 36,4 & 30,80 & 625 & 0,235 & 0,184 & 3,90 & 0,383 & 0,324 & 6,58 \\
\hline 96 & 482 & 36,7 & 31,00 & 629 & 0,233 & 0,181 & 3,64 & 0,381 & 0,322 & 6,55 \\
\hline 97 & 474 & 36,9 & 31,19 & 632 & 0,231 & 0,178 & 3,37 & 0,379 & 0,321 & 6,52 \\
\hline 98 & 467 & 37,2 & 31,37 & 635 & 0,229 & 0,175 & 3,14 & 0,378 & 0,319 & 6,48 \\
\hline 99 & 461 & 37,4 & 31,54 & 638 & 0,227 & 0,172 & 2,91 & 0,377 & 0,318 & 6,44 \\
\hline 100 & 455 & 37,6 & 31,70 & 640 & 0,225 & 0,170 & 2,70 & 0,376 & 0,317 & 6,40 \\
\hline 101 & 448 & 37,8 & 31,88 & 642 & 0,223 & 0,167 & 2,52 & 0,374 & 0,315 & 6,35 \\
\hline 102 & 442 & 38,0 & 32,03 & 644 & 0,221 & 0,164 & 2,35 & 0,372 & 0,314 & 6,30 \\
\hline 103 & 436 & 38,2 & 32,20 & 646 & 0,219 & 0,161 & 2,17 & 0,370 & 0,312 & 6,25 \\
\hline 104 & 430 & 38,5 & 32,36 & 648 & 0,217 & 0,159 & 2,03 & 0,369 & 0,311 & 6,20 \\
\hline 10 is & +25 & 38,7 & 32,50 & 650 & 0,215 & 0,156 & 1,90 & 0,368 & 0,309 & 6,14 \\
\hline
\end{tabular}


X11.

\section{Zuwachstafel des Nebenbestandes.}

Durchforstung und Vorhieb. 


\begin{tabular}{|c|c|c|c|c|c|c|c|}
\hline Jahr & $\begin{array}{c}\text { Zuwachs } \\
m^{3}\end{array}$ & Jahr & $\begin{array}{c}\text { Zuwachs } \\
\mathrm{m}^{3}\end{array}$ & Jahr & $\begin{array}{c}\text { Zuwachs } \\
\mathrm{m}^{3}\end{array}$ & Jahr & $\begin{array}{c}\text { Znwachs } \\
\mathrm{m}^{3}\end{array}$ \\
\hline 1 & & 26 & 2,74 & 51 & 4,80 & 76 & 5,12 \\
\hline 2 & & 27 & 2,83 & 52 & 4,85 & 77 & 5,04 \\
\hline 3 & & 28 & 2,92 & 53 & 4,90 & 78 & 4,96 \\
\hline 4 & & 29 & 3,01 & 54 & 4,95 & 79 & 4,88 \\
\hline 5 & & 30 & 3,10 & 55 & 5,00 & 80 & 4,80 \\
\hline 6 & & 31 & 3,21 & 56 & 5.05 & 81 & 4,70 \\
\hline 7 & & 32 & 3,32 & 57 & 5,10 & 82 & 4,60 \\
\hline 8 & & 33 & 3,43 & 58 & 5,15 & 83 & 4,50 \\
\hline 9 & & 34 & 3,54 & 59 & 5,20 & 84 & 4,40 \\
\hline 10 & & 35 & 3,65 & 60 & 5,25 & 85 & 4,30 \\
\hline 11 & & 36 & 3,72 & 61 & 5,29 & & \\
\hline 12 & & 37 & 3,79 & 62 & 5,33 & & \\
\hline 13 & & 38 & 3,86 & 63 & 5,37 & & \\
\hline 14 & & 39 & 3,93 & 64 & 5,41 & & \\
\hline 15 & 1.50 & 40 & 4,00 & 65 & 5,45 & & \\
\hline 16 & 1.60 & 41 & 4,08 & 66 & 5,47 & & \\
\hline 17 & 1,70 & 42 & 4,16 & 67 & 5,49 & & \\
\hline 18 & 1,80 & 43 & 4,24 & 68 & $5, \check{5} 0$ & & \\
\hline 19 & 1,90 & 44 & 4,32 & 69 & 5,49 & & \\
\hline 20 & 2,00 & 45 & 4,40 & 70 & 5,48 & & \\
\hline 21 & 2,13 & 46 & 4,47 & 71 & 5,43 & & \\
\hline 22 & 2,26 & 47 & 4,54 & 72 & 5,38 & & \\
\hline 23 & 2,39 & 48 & 4,61 & 73 & 5,32 & & \\
\hline 24 & 2,52 & 49 & 4,68 & 74 & 5,26 & & \\
\hline 25 & 2,65 & 50 & 4,75 & 75 & 5,20 & & \\
\hline
\end{tabular}




Room 103

SD

214

$28 \mathrm{M} 4$

1903

BioMed
Meister, Ulrich

Die Stadtwaldungen von

Zürich 2., erw. Aufl.
PLEASE DO NOT REMOVE

CARDS OR SLIPS FROM THIS POCKET

UNIVERSITY OF TORONTO LIBRARY 
